UNIVERSIDAD NACIONAL DE LA PLATA

FACULTAD DE PERIODISMO Y COMUNICACIÓN SOCIAL

Trabajo de grado tesis realizado para optar al título de Doctor en Comunicación

Título

Medios de comunicación escolar, educación y ciudadanía. Una mirada desde las mediaciones

AUTOR: CEBALLOS SEPÚLVEDA, Juan Carlos

DIRECTORA: MARIN OCHOA, Beatriz Elena

Doctora Universidad Autónoma de Barcelona.

Directora GICU, Universidad Pontificia Bolivariana

CO-DIRECTORA: MORABES, Paula

Directora COMEDI, Universidad Nacional de La Plata

JUNIO DE 2015

La Plata, Argentina 


\section{Dedicatoria}

A mis padres Roberto y Rosa por su compañía amorosa, permanente y transformadora en el proceso de elaboración de esta tesis.

A mis hermanos y sobrinos por su solidaridad, paciencia y comprensión. 


\section{Agradecimientos}

Al final comprendo que una tesis doctoral es un camino de vida que me llevó a conocer personas, lugares y experiencias que enriquecieron este trabajo que llega a su fin y confía en marcar pautas para continuar otras búsquedas. Este viaje, aunque solitario, no hubiera sido posible sin la compañía de aquellas personas que en su momento marcaron rumbos y alentaron a seguir adelante durante estos años.

A la Doctora Beatriz Elena Marín Ochoa quien se constituyó en el faro orientador de este trabajo, por su tiempo y dedicación en las asesorías y lecturas de los avances de la tesis, por las recomendaciones, los retos, el aliento en los momentos en que las fuerzas desfallecieron y por todas las enseñanzas aportadas. Infinitas gracias por todo.

A Paula Morabes quien, a partir de un café en una tarde de otoño en La Plata, se constituyó en el punto de conexión de la tesis con la cultura argentina. Gracias por llevarme a las lecturas y los autores que le dieron otras miradas y perspectivas a un tema que apenas iniciaba y que de a pocos fue tomando cuerpo. Gracias Paula por la amistad, por la compañía y por las lecturas en "clave argentina" de esta tesis.

Un agradecimiento especial para las I.E. que abrieron sus puertas para hacer el trabajo investigativo; también a los maestros, comunicadores y sobre todo estudiantes, quienes aportaron lo fundamental para esta tesis: sus ideas, sus conocimientos, sus reflexiones, sus experiencias de vida y su tiempo en el periodo dedicado al trabajo de campo. Con ellos se construyó esta tesis y sin ellos hubiera sido imposible. 
A mis amigos de Prensa Escuela: Clara Tamayo y José Mario Cano, en primera instancia, con quienes se empezaron a fraguar las inquietudes de lo que sería el tema de esta tesis y con quienes el diálogo se sigue alimentado.

A las directivas de la facultad de Comunicación Social-Periodismo de la UPB, en primera instancia a Margarita Llano y luego a Juan Fernando Muñoz por impulsar y respaldar este proceso de formación doctoral, lo mismo que a la Universidad Pontificia Bolivariana por el apoyo para llevar a cabo este doctorado.

A mis estudiantes (y ahora colegas) Andrés Velásquez y Juliana Paniagua, con quienes tuve la oportunidad de crecer, vivir, descubrir y disfrutar de la cultura argentina. Gratitud también con los compañeros latinoamericanos con quienes compartí en esta experiencia de vida, por sus observaciones, sus críticas y sus comentarios.

Con gratitud muy especial a Alicia y Marcelo Miño, a la tía Pocha y a la abuela en La Plata, por hacerme sentir como integrante de su querida familia argentina.

A mis amigos de siempre, porque en ese ir y venir, a pesar de las distancias geográficas y temporales siguen ahí... siempre. ¡Gracias por su amistad! 


\section{Citas bibliográficas correspondientes a las publicaciones parciales del trabajo}

"Más que instrumentos, la memoria colectiva de la escuela"

Artículo publicado en: Revista Trampas de la Comunicación No. 73 noviembre-diciembre 2012, Facultad de Periodismo y Comunicación Social, Universidad Nacional de La Plata, La PlataBuenos Aires, Argentina. ISSN: 1668-5547. Disponible en:

http://www.revistatrampas.com.ar/2011/03/mas-que-instrumentos-la-memoria.html

"Medios escolares narran el mundo que rodea la escuela"

Ponencia publicada en: Memorias de la XIII Jornadas \& I Congreso Internacional del Maestro Investigador. Cultura escolar, apropiación tecnológica y democracia. UPB, Medellín, Colombia. Marzo 2013. ISBN: 978-958-764-081-6. Disponible en:

http://eav.upb.edu.co/JMI/memorias/13jcmi.zip

"El valor político de la palabra para transformar la sociedad"

Artículo publicado en: Revista Comunicación, $\mathrm{N}^{\circ} 30$ enero-diciembre 2013. Facultad de Comunicación Social-Periodismo, UPB, Medellín, Colombia. ISSN: 2390-0075. Disponible en:

https://revistas.upb.edu.co/index.php/comunicacion/article/view/2945/2584 
"La producción de contenidos en medios escolares, un asunto complejo"

Ponencia publicada en: Memorias del II Congreso Mundial de Comunicación Iberoamericana: los desafíos de la internacionalización. ISBN: 978-989-8600-29-5. Universidad de Minho, Braga, Portugal. Abril, 2014. Disponible en:

http://www.lasics.uminho.pt/ojs/index.php/cecs_ebooks/article/view/1972/1895

"Los medios escolares como espacios de (des) apropiación de la 'palabra"”

Ponencia publicada en: Memorias del II Congreso Mundial de Comunicación Iberoamericana: los desafíos de la internacionalización. ISBN: 978-989-8600-29-5 (Ponencia publicada en coautoría con la Doctora Beatriz Elena Marín Ochoa).Universidad de Minho, Braga, Portugal. Abril, 2014. Disponible en:

http://www.lasics.uminho.pt/ojs/index.php/cecs ebooks/article/view/1967/1890.

Simposio Ciencias Sociales: "Diálogo con los medios de comunicación producidos en la escuela"

Ponencia publicada en: Memorias de la XIV Jornadas \& II Congreso Internacional del Maestro Investigador. Investigar en educación y educar en investigación. Avances y perspectivas. UPB, Medellín, Colombia. Marzo, 2015. Disponible en:

http://eav.upb.edu.co/JMI/Maestro14/MEMJMI14/panelInv/MemCompilJMI2015.pdf 


\section{Título}

Medios de comunicación escolar, educación y ciudadanía. Una mirada desde las mediaciones.

\section{Resumen}

La tesis propone analizar los procesos de producción de medios de comunicación en instituciones educativas desde una perspectiva de las Mediaciones, para indicar la relevancia que pueden tener estos proyectos en la escuela, como espacios alternos para formar a los estudiantes como ciudadanos activos.

En su desarrollo, la tesis expone varias tensiones que emergen en este tipo de experiencias: la primera, relacionada con la visión instrumental de la comunicación, cuando la misma se reduce al medio, se privilegia el instrumento, su función difusionista y divulgativa, creando así un binomio instrumental/difusionista. La segunda está relacionada con la influencia que tienen los adultos (maestros y directivos) en todo el proceso de producción de los medios, en la que se manifiesta una incidencia fuerte de la educación tradicional que permea a este tipo de experiencias: un maestro que impone temas, orienta los contenidos y unos estudiantes que publican como "premio" por su trabajo elaborado en clase y están interesados en una calificación académica o ser reconocido por los otros.

Ante este panorama se genera una reflexión, una tercera tensión, y es propiciar otro escenario en perspectiva de Mediaciones comunicacionales que privilegia la relación comunicación/cultura, asociada a la educación problematizadora, que permita a los estudiantes hacer lectura de sus contextos sociales y apropiarse de la palabra para expresar sus mundos, como una manera de 
comprometerse en la transformación de las comunidades locales en donde viven y ejercer una ciudadanía activa.

De ahí que sea necesario insistir que este tipo de proyectos debe estar centrado en los estudiantes y su cultura experiencial. Por eso, desde la perspectiva de las Mediaciones, ellos se convierten en productores de sentidos y así cuando publican sus informes tienen la posibilidad de ejercer el derecho a la comunicación, como una posibilidad de iniciarse en el ejercicio de la ciudadanía.

Palabras clave: Comunicación, educación, cultura, mediaciones, medios escolares, ciudadanía. 


\section{Índice de contenido}

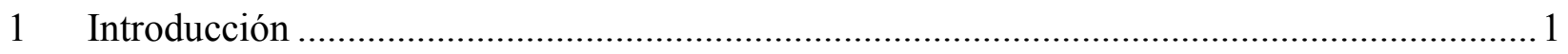

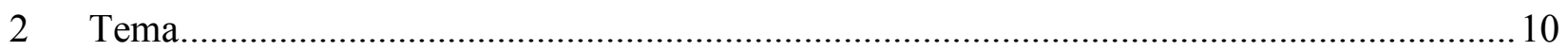

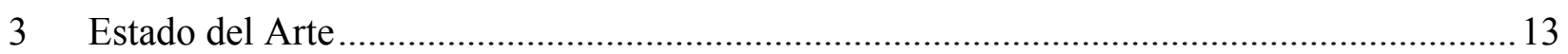

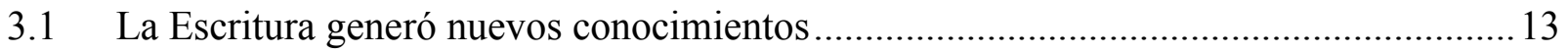

3.2 La imprenta, una revolución cultural................................................................. 15

3.3 La imprenta llega a la escuela ....................................................................... 18

3.4 La prensa entra a la escuela (El modelo prensa escuela) ..........................................23

3.5 Prensa escuela en Colombia .......................................................................... 25

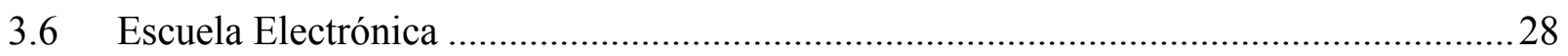

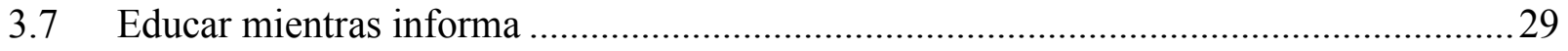

3.8 La escuela y la comunicación en Colombia. Una mirada instrumental ........................31

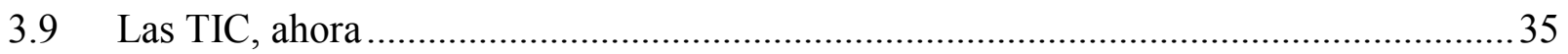

3.10 Confusión de la Escuela frente a los medios de comunicación ...................................39

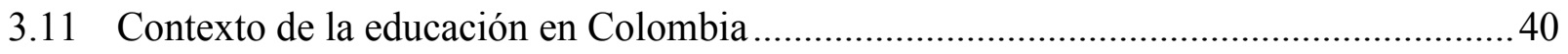

3.12 El contexto legal: La Constitución Nacional y algunas disposiciones en materia de

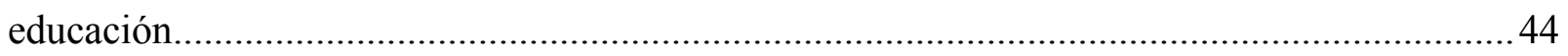

3.13 Algunos estudios sobre los medios escolares .........................................................50

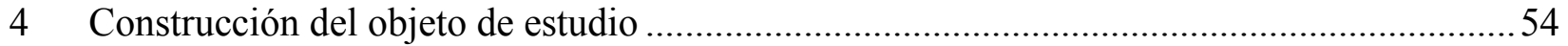

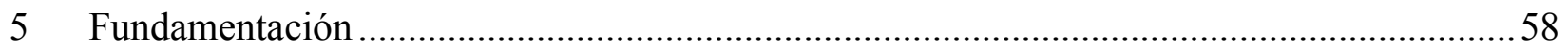

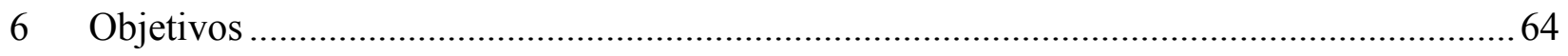

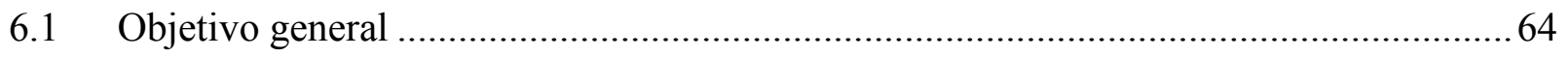


6.2 Específicos

$7 \quad$ Marco teórico 66

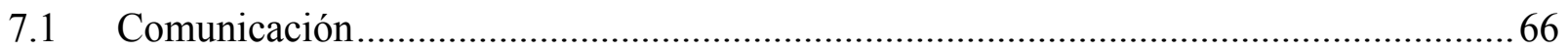

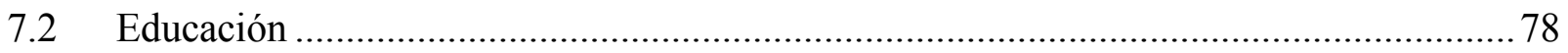

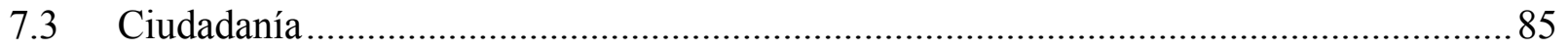

7.4 Los Caminos de la Comunicación/Educación ............................................................91

7.5 Comunicación y Ciudadanía: la Apropiación de la Palabra para Expresarse .................97

7.6 El valor de la comunicación y otras maneras de ejercer la ciudadanía ....................... 100

7.7 Buscando una definición de los medios de comunicación escolar.............................. 102

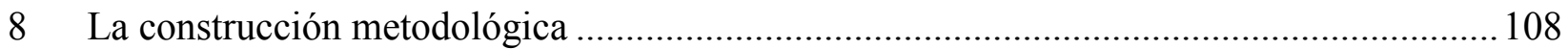

8.1 La selección de las instituciones educativas....................................................... 110

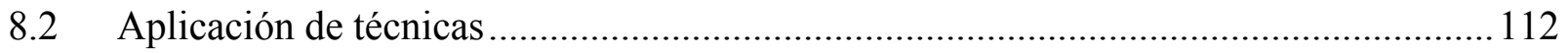

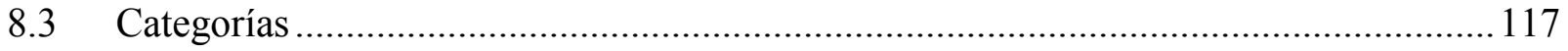

$9 \quad$ Rutas trazadas para el análisis y obtención de los resultados ......................................... 119

9.1 Etapa 1. Fase previa. Contextualización. ............................................................. 122

9.2 Etapa 2.Fase Emisión. Producción de contenidos ................................................. 125

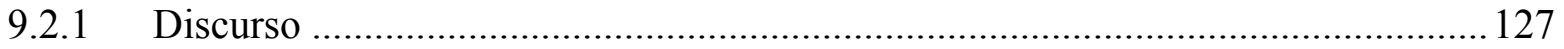

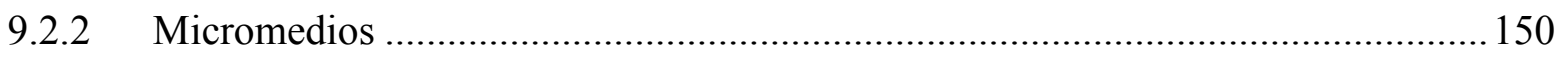

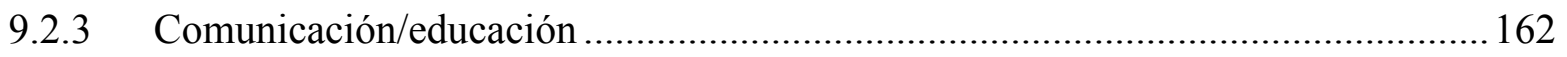

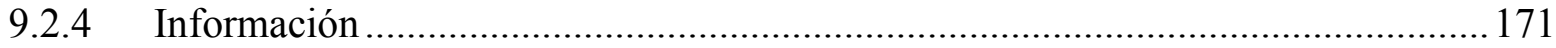

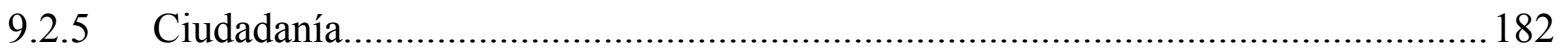

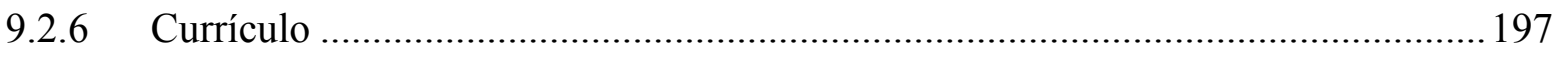

9.2.7 Categorías, reflexiones emergentes y cruce teórico .........................................208 


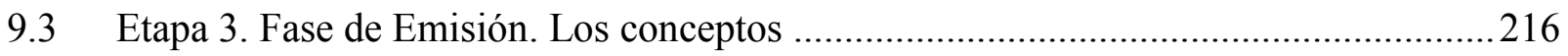

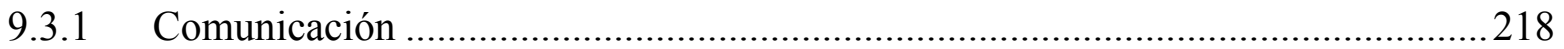

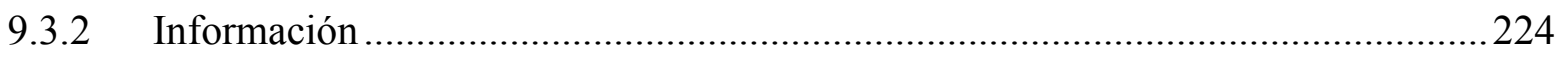

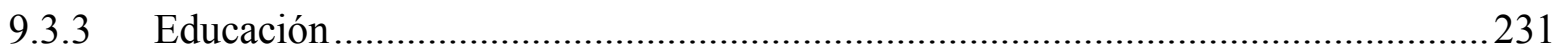

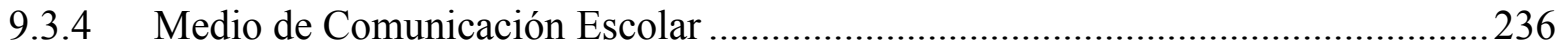

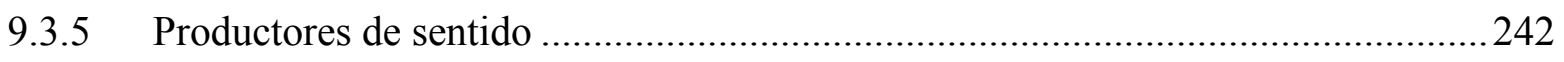

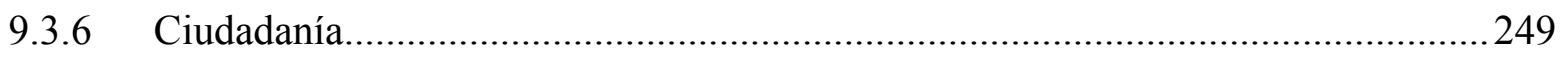

9.4 Etapa 4. Fase Mensajes. Análisis de contenido........................................................25

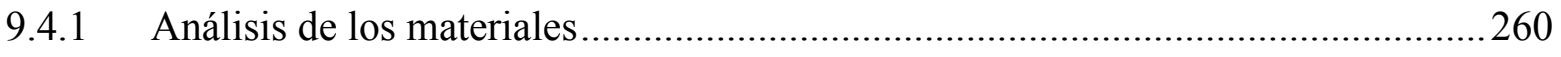

9.5 Etapa 5. Fase de recepción. Recepción de contenidos....................................................309

10 . Etapa 6. Reflexiones y conclusiones analíticas a las que llega este estudio.......................323

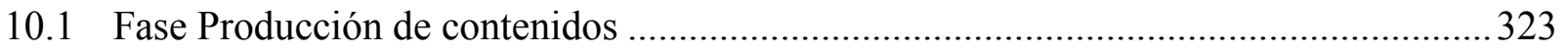

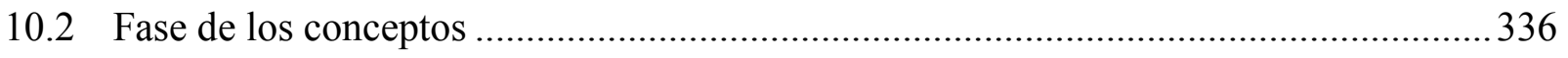

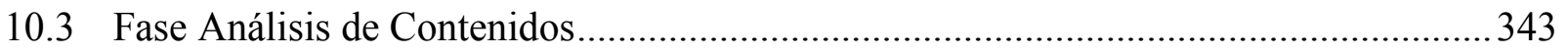

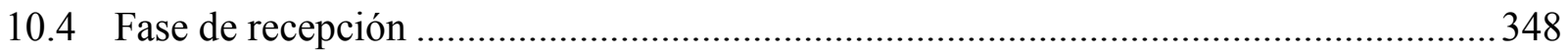

10.5 Por qué apostarle a las mediaciones en las experiencias de medios en la escuela.

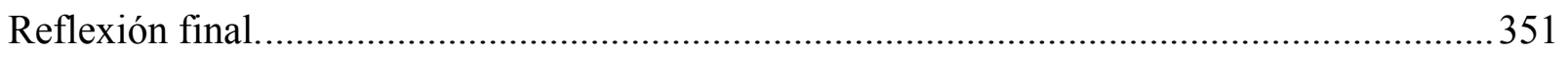

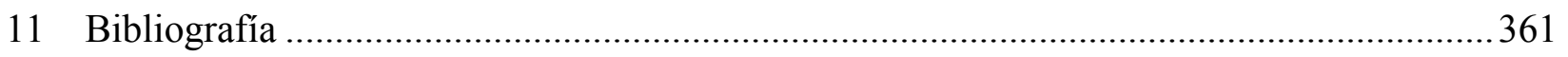




\section{Introducción}

El interés de esta tesis doctoral está centrado en la producción de medios de comunicación en instituciones educativas (I.E.), sin descartar el análisis de los productos y contenidos y la recepción de los mensajes por parte de la comunidad educativa. Lo anterior llevó a investigar las prácticas de producción de medios en las I.E. seleccionadas que sirvieron de muestra para este estudio y el sentido que tiene este tipo de proyectos comunicativos y educativos para estudiantes, maestros, padres de familia y directivas. Si bien existen diferencias, dadas las particularidades propias de cada institución que marcan diferencias, también aparecen algunos temas que son comunes en ellas y permiten develar los intereses, los enfoques temáticos y la participación de los actores (maestros y estudiantes). Lo anterior da pie para discutir sobre la identidad de estos proyectos, a los que denominan "escolares", cuando priman las iniciativas, las temáticas y las perspectivas de los educadores (adultos), sobre la de los estudiantes quienes asumen actitudes pasivas (Kaplún, 1998) y, en algunos casos, sin compromisos.

El ejercicio de producir y publicar medios de comunicación en las instituciones educativas, vale la pena discutirlo a la luz de la Comunicación, la Educación y de la relación Comunicación/Educación. En la actualidad, las experiencias de producción de medios de comunicación en la escuela, en su mayoría, se mueven bajo los paradigmas informativos, propios de los medios masivos, los cuales funcionan como los modelos a seguir y enfocados como preparación para el trabajo o como una tendencia para que los estudiantes ingresen a la universidad a seguir los estudios relacionados con la comunicación o el periodismo; esto puede generar algunos reduccionismos, porque las prácticas de comunicación en contextos educativos 
pueden provocar otros asuntos formativos como favorecer la expresión de las ideas de los estudiantes y generar procesos de diálogo entre el mundo de los niños y jóvenes y la institución educativa, por tanto, requiere de narrativas y otras maneras de relatar los textos (ya sea por la palabra escrita u oral, por la imagen, por el hipertexto) para poner en circulación sus ideas, sus reflexiones, sus conocimientos y sus contenidos propios que también pueden ser válidos y educativos, tanto al interior de las I.E., como para las comunidades locales de las que hacen parte. Lógicamente, esto puede generar rupturas con los modelos informativos tan arraigados en los proyectos de medios en la escuela.

Por eso, se hace necesaria una reflexión más profunda de la comunicación en la escuela, que trascienda los esquemas tradicionales que prevalecen en ella. De ahí que la apuesta de esta tesis, en materia de comunicación, fue por el concepto de las mediaciones propuesto por Martín Barbero (1997), porque genera rupturas y reivindica su carácter relacional, dialógico, participativo y cultural. Desde este punto de vista, la invitación a la escuela es a ver la comunicación más allá del objeto (el medio) y reconfigurar la participación de los estudiantes en la producción de medios, no como receptores pasivos, ni como destinatarios de mensajes, sino como productores de sentido y de significaciones de sus propios textos para ponerlos a circular en la comunidad educativa, tanto al interior, como al exterior de ella. ¿Y qué significa esto en el contexto educativo? Formar productores de contenidos que den cuenta de su cotidianidad, seres humanos con capacidad de relatar sus conocimientos, experiencias de vida y reflexiones para convertirlos en narraciones o relatos que circulen en la institución educativa y que, en el mejor de los casos, lleguen a las comunidades locales donde están ubicadas. 
Esta otra comunicación también requiere de otro enfoque de la educación, diferente a la tradicional, de ahí que la apuesta en educación sea la problematizadora (Freire, 1985) que propone la apropiación de la palabra para enunciar el propio mundo, para transformarlo. En esta perspectiva se reconoce la experiencia de vida del estudiante como un ser con capacidad de palabra y de nombrar lo que vive y lo que ve en su entorno, como una manera de hacer lectura de su contexto, ser consciente de los problemas sociales, las situaciones de injusticia que viven y, también, para dar cuenta de su riqueza social y cultural, con el fin de comprometerse en la construcción de un mundo más equitativo, justo y solidario.

Partiendo de un escenario real en el que las experiencias de producción de medios en la escuela se caracterizan por su verticalidad, imposición e institucionalidad, se hace necesario plantear otro escenario desde una comunicación/cultura y una educación problematizadora, no como único, sino como alternativo, que permita la construcción de procesos de comunicación más cercanos a la realidad del mundo de los estudiantes, que contribuya la formación de niños y jóvenes con capacidades de palabra para contar lo que sucede y comprometidos en la transformación del mundo que viven. Generar una reflexión desde la Comunicación/Educación/Cultura, que brinde otras posibilidades de producir medios de comunicación en la escuela es la apuesta de esta tesis.

La manera cómo se estructuró la tesis inicia con el Estado de Arte que parte con la creación de la palabra, la escritura y el alfabeto, como elementos esenciales del ser humano para comunicarse entre sí, establecer relaciones comerciales e ir condensando el conocimiento adquirido. La palabra como elemento esencial de la humanidad y que hoy sigue vigente gracias a otro invento maravilloso como fue la imprenta que favoreció la aparición del libro y la posibilidad de que 
miles de personas accedieran a conocimientos, obras literarias y pensamientos que antes solo estaban destinadas a unos pocos. Ya a inicios del siglo XX, un maestro francés Célestine Freinet introdujo en una pequeña escuela al sur de Francia y en sus aulas estos inventos culturales (palabra, alfabeto e imprenta): la pequeña imprenta Cinup fue el dispositivo que posibilitó que se iniciará una experiencia de Comunicación/Educación que luego se expandió por el país galo, a otros de Europa y algunos de África. En este mismo capítulo se hace referencia al surgimiento de las experiencias de Prensa Escuela tanto en Estados Unidos, como Europa y países latinoamericanos, para centrarse en Colombia y por último en Medellín.

También se ofrece un contexto general de la educación en Colombia y se exponen los fundamentos legales en materia educativa, para culminar con algunos estudios previos llevados a cabo en Colombia sobre proyectos de medios de comunicación en las I.E. que permiten tener un marco contextual y referencial acerca de este tipo de proyectos y experiencias en el ámbito colombiano, aspectos fundamentales para comprender el momento en que se encontraban los estudios y las reflexiones del tema al momento de trabajar la tesis.

En el aparte referido a la Construcción de objeto de estudio, se expone y comparte aquellos autores y teorías desde los que se cimienta la perspectiva de la comunicación/cultura con autores como Schmucler (1997), Martín Barbero (1998), Saintout (2006) que a partir de sus ideas y reflexiones exponen la necesidad de otra comunicación más allá del instrumento o de teorías establecidas. Al igual que este enfoque de la comunicación se hace necesario tener presente otros autores desde la educación que ofrezcan una mirada diferente a la educación tradicional y es ahí que Freire (1985) y los pedagogos críticos McLaren (1994) y Giroux (2008) ofrecen otra 
perspectiva más cercana al mundo de la vida de los estudiantes, a la apropiación de la palabra, aprender a reflexionar críticamente y a problematizar el contexto y las situaciones que viven los estudiantes. Así, conjugando estas perspectivas de comunicación y educación se hace necesario establecer otra perspectiva de la producción de medios de comunicación en las instituciones educativas, como indica Huergo (2001), en su dimensión comunicacional que articula prácticas y procesos culturales.

Del mismo modo, el aparte referido a la Fundamentación, se para en los autores que brindan una mirada de la comunicación desde las mediaciones y la cultura, problematizadora de la educación y ambas sirvan de base para constituir a los medios de comunicación en las I.E. en un eje del proceso educativo y formativo para los estudiantes. Y a su vez, permitan abrir la perspectiva a los estudiantes de hacer lectura crítica y reflexiva de los que viven en sus contextos educativos, sociales y familiares, de manera que este tipo de experiencias puedan asumirse también como espacios de formación ciudadana, en la medida que los estudiantes participan en proyectos colectivos, siguiendo a Ruíz (2007). Con estos elementos y perspectivas se propone que las experiencias de medios de comunicación sean vistas más allá de la mirada instrumental y se constituyan en espacios que incidan en las transformaciones de los modos de ser, sentir y pensar de los actores educativos, sobre todo, estudiantes y maestros.

Luego se exponen los objetivos (general y específicos) que orientaron las búsquedas y construcciones teóricas y metodológicas de esta tesis. Después se trabajó el Marco teórico que mereció una especial atención, porque en él se da cuenta de los conceptos de comunicación tanto tradicionales ligada a lo instrumental y lo divulgativo, para proponer desde ahí otras reflexiones 
más amplias y flexibles sobre el concepto ligadas a la cultura y al cambio de roles de los actores. Es una apuesta teórica construida desde autores latinoamericanos, en su mayoría, porque son quienes ayudan a tener una mejor comprensión de las discusiones, tensiones y realidades que se viven en nuestros contextos, en materia de comunicación. Para llegar a la discusión y definición teórica de los medios en la escuela, fue necesario primero volver a los conceptos en los que se para esta tesis: comunicación, educación y ciudadanía; luego se estableció el diálogo teórico entre comunicación/educación y comunicación/ciudadanía, atravesada esta última por la educación.

Con el Estado del arte, los objetivos y el Marco teórico organizados se procedió a construir la Metodología de la investigación. Teniendo en cuenta que cada I.E. tiene sus particularidades, que los actores (estudiantes y maestros) tendrían una valoración especial de sus propias ideas, reflexiones y conocimientos, se apostó por una metodología cualitativa para poder captar de manera rigurosa y precisa las realidades que se viven en las experiencias de producción de medios de comunicación en I.E. En este marco, se aplicaron las técnicas propias para acercarse a los actores y a leer las situaciones a las que el tesista se enfrentó en estos espacios. Así, las observaciones, entrevistas semi-estructuradas, entrevistas en profundidad y grupos focales sirvieron de instrumentos para obtener la información base para la interpretación de los resultados. También se hizo una lectura semántica de algunos productos (periódicos y videos), para confrontar y corroborar lo que expusieron los actores. Así mismo, se aplicaron encuestas a estudiantes y maestros, destinatarios de los contenidos que se publican, para hacer una lectura descriptiva de sus percepciones como receptores de los mensajes y lograr un panorama más completo del tema estudiado. En este capítulo también se comparte los criterios y procedimientos que sirvieron de base para seleccionar las I.E. que sirvieron de muestra para la 
investigación y la construcción de los instrumentos utilizados para la recopilación de la información. Por último, se comparten las categorías que sirvieron para el análisis de los datos obtenidos.

El desarrollo analítico de la tesis es su núcleo. El mismo se estructuró en 6 etapas, como se describe a continuación:

- Etapa 1. Contextualización. Fase previa. En la que se describe la I.E. y se da cuenta de la historia de los medios de comunicación en ellas.

- Etapa 2. Producción de contenidos. Fase de emisión. Es un aparte que merece especial atención, porque en la misma se centra el interés analítico y reflexivo de la tesis. Con base en los resultados obtenidos en las observaciones, entrevistas y grupos focales, y las categorías de análisis establecidas se da cuenta de las características propias, los intereses de quienes orientan el trabajo y los enfoques que se dan a los contenidos que se publican; de igual manera, se da cuenta de cómo participan los estudiantes en la producción de los medios. Aquí se refleja el papel de los actores, las intenciones y las tensiones que se generan en este tipo de proyectos.

- Etapa 3. Los conceptos. Fase de emisión. Este es otro momento especial de la tesis, porque a partir de las ideas propias de los estudiantes y maestros se reconstruyen los conceptos que orientan la tesis: comunicación, educación, ciudadanía, medios de comunicación escolar y ello permite comprender cuáles son los modelos y conceptos que orientan a los actores en su experiencia de producir medios de comunicación.

- Etapa 4. Análisis de contenido. Fase de mensajes. Una vez conocido lo que sucede en la fase de emisión, se entra a dialogar con los materiales: artículos de periódicos 
(editoriales, informes) y notas de televisión, en los que se evidencian los contenidos que llegan a sus destinatarios (integrantes de la comunidad educativa) y en los que se trata de develar a partir de un análisis semántico las tendencias temáticas y las intencionalidades que subyacen de este tipo de productos.

- Etapa 5. Recepción de contenidos. Fase de recepción. En ella se comparten algunos resultados de las encuestas que se aplicaron a los estudiantes y maestros de las I.E. que sirvieron de muestra para esta investigación. En ella se buscó identificar la pertinencia, el valor que otorgan y el significado que tienen los medios de comunicación y los contenidos que se ellos se publican para los estudiantes y maestros.

- Etapa 6. Conclusiones. Fase conclusiones. Recoge los aprendizajes, reflexiones, ideas y evaluaciones de las anteriores fases expuestas y expone al final los argumentos de por qué es necesario tener otras perspectivas desde la Comunicación/Educación/Cultura para producir medios de comunicación "escolares", que trasciendan la mirada instrumental, divulgativa y tradicional con la que se abordan este tipo de experiencias.

En definitiva este es el capítulo nuclear, en el que se exponen los elementos teóricos y conceptuales, la metodología y sus instrumentos; los materiales que fueron sometidos a la lectura analítica, las encuestas que fueron aplicadas a los estudiantes y maestros. Todo lo anterior en conjunto ofrece unos resultados concretos que permiten hacer una lectura más profunda sobre la producción de los medios de comunicación en I.E., por tanto, comprender las dinámicas, los intereses y las perspectivas con las que se llevan a cabo este tipo de proyectos, como también el papel que cumplen los maestros y estudiantes y, por último, tener una visión de las perspectivas 
que puedan tener las mismas bajo enfoques de Comunicación/Educación/Cultura que es uno de los propósitos centrales de esta tesis.

Con este preámbulo se llega a las conclusiones, expuesta como una lectura teórica y analítica de los hallazgos encontrados en las diferentes etapas expuestas en el capítulo anterior. Ello permite hacer un cierre de manera circular de la tesis, tomando como base los objetivos planteados para la investigación. A partir de este ejercicio se llega a la reflexión central de la tesis que tiene que ver con la posibilidad de pensar la producción de medios de comunicación en las I.E. en perspectivas de las Mediaciones comunicacionales, propuesta por Martín Barbero (1998) y las posibilidades que tienen este tipo de proyectos, pensados desde estas perspectiva teórica. Para ello se establece un comparativo entre el paradigma instrumental/divulgativo y el paradigma de las mediaciones del que emergen unas recomendaciones que sirvan de base para maestros, estudiantes e I.E. que estén dispuestas a darle un giro a sus experiencias de medios de comunicación, sobre todo, para que vayan más allá de lo institucional y le den el carácter escolar, esto es, que los medios sean los escenarios en los que se pone en circulación las palabras, las ideas, las reflexiones, las experiencias de vida y las propuestas de los estudiantes, y que sirvan a la vez como espacios educativos alternativos, para formar ciudadanos en clave de comunicación. 


\section{Tema}

Medios de comunicación escolar y educación: instrumentos de divulgación para fomentar la competitividad o espacios de producción de sentido para la formación de ciudadanos en una institución educativa pública y una institución educativa privada de Medellín (2009-2012) ${ }^{1}$.

Publicar un medio de comunicación en una Institución Educativa (I.E.), ya sea pública o privada hace parte de las prácticas comunicativas y educativas que en ellos se dan. En la mayoría de los casos centran el trabajo en promover el buen manejo del lenguaje y reforzar las competencias lingüísticas. La producción de los medios se da en espacios extra clase, cuyo trabajo es coordinado por un maestro y en que participan varios estudiantes (entre 10 y 15 en promedio) de varios cursos. La publicación promedio de estos medios es mensual (en el mejor de los casos) o bimestral; algunos, por falta de recursos económicos, lo hacen semestral e incluso de manera intermitente. La función básica es divulgar los eventos más importantes de la institución educativa y solo en pocos casos se publican temas relacionados con el acontecer del barrio o de la comunidad circundante de la escuela. Otros son el resultado de las tareas de clase y de los informes que son bien calificados por el profesor y por tanto publicados. En ellos prevalece el

\footnotetext{
${ }^{1}$ El periodo de tiempo seleccionado obedece a varias razones: uno, hacer un seguimiento de los materiales publicados en las dos instituciones seleccionadas, básicamente, periódicos y programas de televisión. Dos, en el momento de hacer el trabajo de campo (segundo semestre de 2012) la institución educativa privada llevaba diez años emitiendo mensualmente el programa de televisión e igual período de tiempo publicando el periódico del colegio, por su parte, la institución educativa pública llevaba cinco años desde su fundación- con este tipo de experiencias y debido a los escasos recursos económicos se experimentó con varios medios de comunicación: periódicos, blogs, hasta Facebook (como red social); tres, en Medellín las instituciones educativas han recibido capacitaciones sobre la creación o el mejoramiento de medios escolares (básicamente periódicos) desde proyectos liderados por las empresas periodísticas que tienen asiento en la ciudad: El Colombiano, con "Prensa Escuela" desde 1996; El Tiempo, con "Escuela Electrónica", entre 2002 y 2004; El Mundo con "Educar mientras se informa" desde 2011; además el proyecto de la Alcaldía denominado "Medellín Digital", que empezó en 2006 y en 2008 inició el programa Escuela Digitales. Estos proyectos liderados por los medios de comunicación y el gobierno municipal establecen un paradigma de trabajo con los medios de comunicación en las instituciones educativas y en los que han participado estudiantes y maestros. Las instituciones seleccionadas han hecho parte de las mismas.
} 
modelo tradicional de la educación, desde los que la comunicación es asumida bajo el enfoque instrumentalista y de transmisión de información.

Sin embargo, también existen unas experiencias que demuestran otra manera de trabajar con los medios de comunicación en las instituciones educativas. En algunos casos, llegan a ser el medio de la comunidad circundante, en los que se narra la vida cotidiana de personajes, lugares representativos, problemas que afectan a los habitantes y hechos destacados. Esta es la oportunidad para conectar a los estudiantes con sus contextos sociales, relacionarse con otras personas, comprender e interpretar las situaciones que se viven en sus barrios para ser publicados en el periódico, la revista o en el programa de televisión del colegio. Por eso, la experiencia de proponer un tema e investigarlo lleva a los estudiantes a hacerse responsables del acto de informar y a comprometerse a producir un texto comunicativo de calidad, es decir, que aporte al conocimiento de un tema y generar otras posibilidades temáticas (agenda) entre los destinatarios de la información: estudiantes, maestros, padres de familia y directivos que conforman la comunidad educativa. Cuando el medio de comunicación del colegio se asume como un espacio para la construcción del conocimiento, el encuentro de otras experiencias y la expresión de ideas, la responsabilidad de informar adquiere un carácter diferente, porque se constituye en un producto social nutrido de la experiencia de vida y de los propios conocimientos de los estudiantes.

En general estos proyectos carecen de fundamentos pedagógicos y comunicativos, tienen una mirada instrumentalista de la comunicación, asociada e influida por los modelos tradicionales de la educación que predominan en las instituciones educativas, dependen de la voluntad de un 
maestro u otro profesional, de ahí que se concentran en áreas como el Lenguaje y terminan como estrategias pedagógicas que sirven para corregir las falencias del lenguaje de los estudiantes. También carecen de un enfoque comunicacional más profundo que permita comprender los contextos sociales y culturales en los que está inscrita la institución educativa, por eso, desde estas dos perspectivas son proyectos reduccionistas. Esta tesis busca comprender los procesos de producción de los medios de comunicación en las instituciones educativas, que se adelantan como proyectos comunicativos/educativos y analizar qué posibilidades tienen de estructurarse bajo una perspectiva comunicacional desde las mediaciones, esto es, desde la cultura: no centrada en el medio, ni en la circulación de información, sino en la producción de significados y la construcción de sentidos por parte de sus integrantes: estudiantes y maestros. 


\section{Estado del Arte}

\subsection{La Escritura generó nuevos conocimientos}

Desde hace unos cuatro mil años el ser humano ha utilizado diversas formas de escritura. Los diagramas y las pictografías aparecen como los primeros indicios de lo que más tarde fue el alfabeto, como un sistema que favorecía la comunicación entre los hombres de diferentes culturas, ya fueran las sociedades primitivas del África, Los Mayas o las naciones asentadas en la región de la antigua Mesopotamia, en Egipto y la China. Entre los temas que aparecen registrados como antecedentes de la escritura figuran viajes, descubrimientos astronómicos y las relaciones comerciales. El hombre en su momento dejó constancia de la escritura en materiales como pergaminos, tallas en piedras y sellos, entre otros.

Según Goody (1992) la escritura se basó en signos gráficos que servían para realizar transacciones comerciales, por ejemplo, entre el productor rural y el mercader urbano (p. 204). Los primeros signos de la escritura eran gráficos y tuvieron fines mercantiles. Aparecieron en Creta, veinte siglos antes de Cristo y estaban acompañados con un primitivo sistema numérico decimal y en tallas de piedra-sello con dibujos ${ }^{2}$. Los sistemas de escritura evolucionaron a tal punto que en la parte baja de la Mesopotamia, los sumerios crearon la escritura cuneiforme ${ }^{3}$, que luego fue utilizada por los acadios para resolver una necesidad económica: organizar cuentas.

\footnotetext{
${ }^{2}$ Chadwick (citado en Goody, 1992) habla de las tablillas de la primitiva escritura cretense, conocida como lineal A. En ellas aparecían registros de cantidades de mercancías (agrícolas principalmente, pero también textiles) listados frente a nombres.

${ }^{3}$ El sistema cuneiforme, en forma de cuña, consistía en escribir sobre tablillas de arcilla húmeda, cuando se secaba la tablilla se guardaba o se enviaba al destinatario.
} 
Basado en los estudios del antropólogo francés Claude Schaeffer, Goody sostiene que el alfabeto fue inventado por los cananeos. Ellos descubrieron una variedad de materiales en los que aparecen una serie de relatos épicos y mitológicos escritos en un alfabeto consonante ${ }^{4}$ del dialecto cananeo y que data del siglo XIV a. de C. Llama la atención que fuera un alfabeto de 32 letras, escritos de izquierda a derecha, inspirado en un sistema pictórico proto-cananeo y en uno babilónico (p.222). Este sistema fue usado para la comunicación diplomática y comercial del Oriente próximo. Este sistema proto-cananeo fue el ancestro de la escritura fenicia, hebrea y aramea que tenía en un principio 27 letras y que luego se redujeron a 22. Más tarde los griegos adoptaron el alfabeto consonántico (de los fenicios) a los que agregaron cinco caracteres: las vocales. Este sistema se expandió luego por todo el Mediterráneo y llegó a Italia; influidos también por los fenicios se creó el alfabeto etrusco y los dialectos itálicos.

¿Qué implicaciones tiene este descubrimiento llamado escritura? Tiene sobre todo incidencias culturales: "permite la transmisión cultural (no genética) de generación en generación” (Goody, 1992, p. 237). Además, genera la preservación, entendida como la posibilidad de acumular cada vez más conocimientos. Es la preservación del pasado en el presente. Y sobre todo, la escritura provocó cambios sustanciales en la humanidad: "Porque no sólo creó una posibilidad, sino que la realización de esa posibilidad cambió el mundo del hombre, tanto en lo interior como en lo exterior, de forma extraordinaria” (Goody, 1992, p. 238). Y estos cambios están asociados a relaciones comerciales y económicas, como la identificación de mercancías, el registro de tipos y cantidades de bienes, cálculo de beneficios y pérdidas. Y también aportó "nuevos campos de

\footnotetext{
${ }^{4}$ Este alfabeto se desarrolló en un área de las tempranas civilizaciones egipcia y mesopotámica, en un pueblo conocido como Cananeo, habitantes Semíticos- hablantes de Siria y Palestina (Goody, 1992, p. 222).
} 
conocimiento y alentó nuevas formas de conocer (...) la información lingüística se organizó por medio de registros tangibles, lo que afectó la forma en que la inteligencia práctica del hombre, sus procesos cognitivos, funcionaban en el mundo" (p. 241).

Si la escritura y el alfabeto han evolucionado hasta nuestros días, hay que asumirlas en su dimensión histórica y cultural, sobre todo, para comprender la importancia que tienen en el desarrollo de la humanidad. En la actualidad a raíz del surgimiento de las tecnologías aparecen otras modalidades de escritura, ya no es solo el texto, sino que surgen imágenes, pictogramas y otros códigos que el ser humano se apropia para comunicarse. De ahí que los procesos de aprendizaje deben estar enfocados, más que un asunto técnico, en una motivación por prolongar el conocimiento y los nuevos descubrimientos a los que llega el hombre contemporáneo.

\subsection{La imprenta, una revolución cultural}

Pasaron 30 siglos para que se creara una verdadera revolución cultural que puso la escritura y el alfabeto al alcance de miles de personas: la imprenta. En un período de prosperidad de Alemania, vivido entre los siglos XIV y XV, Johann Gánsefleisch más conocido como Gutenberg creó una técnica de impresión utilizando tipos móviles. Hasta ese momento, existían avances en la fabricación de papel en países como Italia, Francia y en la propia Alemania y en buena medida ello favoreció este invento que se materializó con la impresión de la Biblia ${ }^{5}$. La importancia de la imprenta está en la aceleración de "la comunicación a varios niveles culturales" (Martin, 1992, p. 19-20), por ejemplo, con la impresión del libro sagrado se propagó el idioma alemán entre sus

\footnotetext{
${ }^{5}$ Como es conocido los primeros trabajos realizados por Gutenberg consistieron en la impresión de la Biblia, una de 42 líneas y otra de 36 líneas.
} 
habitantes como una lengua nacional. Más adelante aparecen libros de la literatura universal, como Don Quijote de la Mancha ${ }^{6}$, con el que el idioma español fue reconocido como una lengua con identidad propia.

La imprenta se expandió con gran rapidez por toda Europa, sobre todo en los centros de poder: Italia, Francia, Países Bajos, Polonia e Inglaterra. El primer medio "moderno" de comunicación generó una especie de red equiparable a lo sucedido años más tarde con la radio, la televisión y ahora la Internet y las redes sociales. La imprenta favoreció la publicación de cientos de miles de libros, periódicos y revistas en diferentes idiomas, regiones y países del mundo, con lo que la cultura de la escritura y el alfabeto se expandió por todo el planeta.

Este invento trajo consigo varias consecuencias, como lo señala Martin: regularizó la ortografía, favoreció la puntuación y, aunque parezca común en la actualidad, la división de los textos en párrafos (1992, p. 23). Empiezan a imprimirse libros y luego periódicos. Sobre el libro vale la pena resaltar que además de la creación de una página de título donde se plasmaba el nombre del autor, el tema y la dirección del editor, se dividió en "unidades" (capítulos) para facilitar la lectura. Esto creó otras maneras de lectura "rápidas e individuales" y, sobre todo, generó una élite letrada que constituyó una minoría frente a la cultura oral de la mayoría de la población (p. 24). Pero esa labor de lectura propició un nuevo aprendizaje en las culturas occidentales-como sucede con toda nueva tecnología-que implicaba entre otros aspectos, abrir el libro y pasar hoja por hoja; empezar a leer de izquierda a derecha y de arriba a abajo. Esas habilidades técnicas iban

\footnotetext{
${ }^{6}$ Don Quijote de la Mancha cumplió más de 400 años de ser publicado por primera vez. En la presentación de la edición del IV Centenario se indica que la primera impresión se realizó en 1604 y que se corrigió en 1605 para futuras impresiones. Los alcances de esta obra fueron tantos que en esa misma presentación se indica que en 1605 salieron 262 libros para México y un librero de Alcalá envío 60 bultos de mercancía con destino a Cartagena de Indias, Portobelo, Panamá y El Callao (2005, p. XI)
} 
acompañadas de un aprendizaje lento, como adquirir nuevos hábitos mentales para leer, familiarizarse con el idioma, seguir el argumento del relato, la comprensión de descripciones, además la confianza y la actitud para alcanzar otros conocimientos (p. 27). El libro se constituyó en el modelo del pensamiento ordenado por excelencia.

Luego del libro aparecieron los periódicos con el fin de cubrir la demanda de noticias políticas y financieras ${ }^{7}$. Fue Gran Bretaña la que impulsó el desarrollo de la prensa, a tal punto que en Londres se publicó el primer diario del mundo, Daily Courant (1702); y en 1785 se fundó The Times el más reconocido y grande de todos los periódicos británicos. Las cifras de impresión y el crecimiento con el pasar de los años son impresionantes: 10.000 en 1820; 40.000 en 1850 y más de 60.000 tras la guerra de Crimea. Por su parte Francia, a finales del siglo XVIII, tuvo una gran incidencia con la Declaración de los Derechos del Hombre que en el artículo XIX establecía una comunicación libre del pensamiento y la opinión como uno de los más preciados derechos. "Por lo tanto, cada ciudadano puede hablar, escribir o imprimir libremente excepto en los casos que la ley lo impida”, (Declaración de los Derechos del Hombre, citado por Martin, 1992).

El periódico constituyó una revolución de las comunicaciones que coincide con la Revolución Industrial, sobre todo en Gran Bretaña, y surgió como fuente de noticias rápidas y regulares en el momento que aparecieron el barco a vapor, la hélice, el telégrafo óptico y luego eléctrico, los cuales aceleraron la historia. Además de lo anterior se inició el proceso migratorio del campo a las ciudades y, por tanto, los nuevos habitantes de las ciudades, desarraigados y pobres, requerían

\footnotetext{
${ }^{7}$ Martin (1992) señala entre otros a Samuel Dilbaum, quien en 1597 publicaba una hoja mensual en Augsburgo (Augusta) importante ciudad comercial y política de Alemania; y otra ciudad reseñada fue Amberes (Bélgica), donde se publicó un boletín comercial con circulación quincenal. También resalta que fueron los alemanes y los holandeses quienes iniciaron un servicio regular de noticias, quienes publicaban panfletos con noticias cada quince días, a principios del siglo XVII (p. 37).
} 
"una voz organizadora" (Martin, 1992, p. 38), la cual encontraron en este medio de comunicación.

Así, la imprenta se constituyó en una revolución cultural y aceleró las comunicaciones en las diferentes sociedades. La escritura y el alfabeto empezaron a ser asuntos que requerían ser aprendidos para acceder a los libros y sus conocimientos, y años después a los periódicos como portadores de información y de opiniones. De igual forma, la imprenta posibilitó la divulgación de los alfabetos y los lenguajes.

En la segunda década del siglo XX, un maestro francés, inquieto y crítico con la educación tradicional de la época y buscando alternativas para generar otros procesos de enseñanza y aprendizaje, tomó una decisión histórica para la educación: introdujo en el aula de clase una imprenta. Y con esta decisión no solo llevó la tecnología a la escuela, sino toda una cultura creada por el hombre, primero con la escritura y el alfabeto, y luego con la imprenta; dos relevantes inventos que cambiaron la vida del hombre y establecieron importantes modificaciones en su forma de aprender y acercarse a los conocimientos acumulados a lo largo de la historia de la humanidad.

\subsection{La imprenta llega a la escuela}

En 1925, en un pueblo del sur de Francia, Bar -sur-Loup, en la Provenza-Alpes-Costa Azul, departamento de Alpes Marítimos, en el distrito de Grass, el maestro Célestine Freinet ${ }^{8}$ introdujo

\footnotetext{
${ }^{8}$ Este maestro era veterano de la Primera Guerra Mundial. En el campo de batalla fue víctima de una herida de bala que le perforó uno de los pulmones. Por esta razón recibió una pensión vitalicia, pero su deseo por ser maestro le impidió dejar las aulas. Sin embargo, la herida sufrida afectó su trabajo: no era capaz de hablar en voz alta y le era imposible mantener la atención de sus estudiantes. Esta fue otra de las razones que lo llevó a buscar alternativas para no dejar lo que era su razón de ser: enseñar.
} 
la imprenta en el aula de clase. Este hecho marcó cambios en una educación tradicional o escolástica como él la llamaba, fundamentada en lo memorístico, en la repetición, en el deletreo. En su búsqueda descubrió un instrumento sencillo: una imprenta Cinup. La misma sirvió de motor del proceso educativo en el aula de clase.

Su esposa Elise describió así ese momento:

Durante algunos días, nuestro innovador espera ansiosamente el paquete de la Cinup. Por fin llega. ¡La imprenta! ¡Los componedores! ¡Todos los instrumentos! ¡Es fácil imaginar la emoción de los niños! (...) Ordenan los caracteres en la caja y, en seguida, componen el primer texto. Por supuesto no es fácil. (...) Las letras resbalan, los componedores caen, pero con buena voluntad el molde entra finalmente bajo la prensa... Tinta, impresión... iy aparece la primera hoja impresa! (Freinet, 1983, p. $33)$.

Sin duda es un momento significativo que marca los inicios de los medios de comunicación escolares y un hito en la relación Comunicación/Educación. Freinet tenía una propuesta pedagógica que se fundamentaba en la expresión libre, la observación y la experimentación, por eso requería de "nuevos instrumentos de trabajo" que facilitaran esa labor, en este caso la imprenta. Con ello confiaba lograr una transformación de la pedagogía y empezó a aplicar una serie de técnicas. Una de ellas fue el "Diario escolar".

Éste era una publicación mensual que recopilaba los mejores textos escritos e impresos todos los días por los estudiantes. No eran los textos resultado de trabajos de clase, sino consecuencia de un proceso: el niño explica el tema y luego "escribe libremente aquello que necesita expresar, exteriorizar, comunicar a su entorno o a sus corresponsales. No escribe cualquier cosa" (Freinet, 1977, p. 20). La propuesta se resume en una frase: escribir para ser leídos. Esto implica una labor 
educativa en la que el niño debe tomar consciencia de que su texto va a ser publicado en el Diario escolar cuyas páginas leerían sus compañeros y otras personas, ya fueran del pueblo y de otras regiones, como los "corresponsales escolares". Así lo expresó: "el niño no escribe solamente aquello que le interesa a él; sino que escribe aquello que en sus pensamientos, en sus observaciones, sus sentimientos y sus actos puede atraer la atención de sus compañeros en primer término y de sus corresponsales después" (Freinet, 1977, p. 21).

En este trabajo de aula aplicó un "sistema democrático", para seleccionar los textos que serían publicados en el Diario escolar y que se entregaba al final del mes. Los mismos se escogían por votación y estos a su vez eran revisados y corregidos por los propios compañeros quienes tenían en cuenta la ortografía, la gramática y la sintaxis. Era un trabajo en equipo. Los contenidos de los textos no se basaban en los deseos o las imposiciones del adulto (en este caso el maestro) sino que partían de los "verdaderos intereses de los niños" (Freinet, 1977, p. 40). Los temas que publicaban en su momento los alumnos tenían que ver con "la vida del niño, sus reacciones frente al mundo, sus temores y sus triunfos" (Freinet, 1977, p.58).

Es a partir de la propia experiencia y las preguntas que surgen de los estudiantes frente a lo que ven, perciben y viven que estructuran y escriben sus relatos. El Diario escolar, a juicio de Freinet, tenía un valor histórico, porque los momentos memorables de la vida y de la experiencia escolar quedan fijados en las páginas, desafiando el paso de los años. Al respecto Kaplún sostiene: "La colección del periódico escolar se fue haciendo memoria colectiva del grupo, registro de su

\footnotetext{
${ }^{9}$ Esta figura consistió en generar una red de escuelas con las que intercambiaban los Diarios: los estudiantes de Bar-sur Loup iniciaron una correspondencia con los alumnos de una escuela ubicada en la costa norte de Francia. Así, entre ellos empezaron a conocer otras costumbres, otros trabajos, otros paisajes que describían en los diarios escolares.
} 
proceso de descubrimiento y de sus avances en la producción del conocimiento. De adquisición individual, el saber pasó a transformarse en construcción colectiva, en PRODUCTO SOCIAL, según lo designó Freinet” (1998, p. 205).

Con el paso de los años Freinet plasmó una serie de ventajas que se evidenciaron en el Diario escolar: los estudiantes aprendieron a asumir responsabilidades; la cooperación escolar, la producción del material exigía un trabajo colectivo; el fortalecimiento de relaciones con los padres en la medida que querían ver los trabajos de sus hijos y por último, se constituyó en una alternativa a la educación tradicional, sobre todo a los textos preparados por adultos. También resaltó que los niños aprendieron diferentes técnicas como hacer encuestas y reportajes, además de prepararse para hacer y recibir críticas de sus trabajos. Con base en lo anterior, vale la pena resaltar estas ideas que condensan su labor educativa:

Cuando escriban, vuestros alumnos pensarán en sus corresponsales; cuando haga cuestionarios de historia o de cálculo, pensarán en informar de los resultados obtenidos a sus corresponsales; cuando describan su pueblo o su región, ayudándose con mapas, no estarán realizando solamente una vulgar tarea escolar, sino que responderán a las demandas o a los deseos de sus compañeros (...) Nuestra enseñanza ya no centrará en la teoría intelectual escolástica, sino en el trabajo y la vida. Ahí reside precisamente la gran conquista pedagógica y humana de nuestras técnicas (Freinet, 1977, p. 141).

Lo logrado por Freinet a partir de su propuesta fue un movimiento de renovación pedagógica, en la que un periódico escolar se convirtió en el eje central y motor del proceso educativo (Huergo y Fernández, 2000, p. 58). La producción de medio de comunicación en un aula de clase cambió la dinámica de enseñanza- aprendizaje y convirtió a los niños en protagonistas y productores con un propósito claro: escribían para ser leídos (Kaplún, 1998, p. 207). Freinet (citado en Kaplún, 1998) 
sostiene: "el periódico ha cambiado totalmente el sentido y el alcance de la pedagogía de mi clase porque da al niño conciencia de su propio valer y lo transforma en actor, lo liga a su medio social, ensancha su vida". Se resalta que la propuesta del educador francés estaba focalizada en el alumno, su interés era ayudarlo a apropiarse de la palabra para que pudiera expresar su mundo, sus ideas y sus opiniones; para ello se valió de la imprenta, una tecnología, utilizada para divulgar el trabajo realizado por los estudiantes en el aula de clase; más que un elemento modernizador fue la oportunidad pedagógica para introducir en el aula de clase toda la memoria cultural de la humanidad (el alfabeto y la escritura) y los convirtió en productores de unos contenidos que compartían con las comunidades más cercanas y luego con otras ubicadas en diferentes regiones de Francia y del mundo.

En esos momentos, en los que los estudios de comunicación estaban en fase inicial ${ }^{10}$, Freinet marcó un hito en el trabajo con los medios de comunicación en la escuela. La imprenta fue un pretexto para apropiarse de la cultura de la escritura; privilegió la producción de contenidos por parte de los estudiantes, basado en la propia experiencia de vida: lo aprendido en la familia y en el entorno social que lo rodea ${ }^{11}$. Con su propuesta Freinet creó una red basada en el intercambio de periódicos que lo hacían mediante el correo; se escribía para ser leídos, es decir, había un compromiso por ofrecerle al destinatario del mensaje algo que necesitaba conocer o saber,

\footnotetext{
${ }^{10}$ Torrico señala que las teorías deben estar históricamente ubicadas en situaciones sociales concretas. Así, en la década comprendida entre 1920 y 1930 se vivían las consecuencias de la Primera Guerra Mundial. En cuanto a los períodos teóricos comunicacionales se empezaba a establecer el Difusionista (1927-1963) que respondía a la visión y necesidades de modelo capitalista impuesto por Estados Unidos y Gran Bretaña. Por su parte, en materia de comunicación, los abordajes principales eran de índole pragmática y socio-técnico y la concepción de la comunicación obedecía a factores motivacionales o inductores del cambio social y el desarrollo (2004, p. 126). Cabe anotar también que cuando Freinet introdujo la imprenta en clase, el periódico era uno de los medios de comunicación más difundidos, por su parte, en 1922 se dan las primeras emisiones de radio; en 1926 comienza el cine sonoro y para 1930 la televisión hace sus primeros ensayos. Los llamados medios masivos de comunicación ya empezaban a ser una realidad en el mundo.

${ }^{11}$ McLaren profundiza sobre este aspecto al que llama "Fondos de conocimiento".
} 
además se promovió la expresión libre, basada en las necesidades informativas de sus destinatarios. Así Freinet supo aprovechar la imprenta para desarrollar su propuesta pedagógica y estableció un paradigma educativo basado en los medios de comunicación, para apropiarse de la palabra y la expresión libre de las ideas.

\subsection{La prensa entra a la escuela (El modelo prensa escuela)}

Con el nombre de Prensa Escuela los grandes periódicos del mundo iniciaron unos programas para introducir la prensa en las instituciones educativas. Este se constituye en otro paradigma que se expandió con rapidez en diferentes instituciones educativas de Europa, América, Asia y África. Al principio llegó a la escuela a ofrecerse como material didáctico y como una gran biblioteca que aporta variedad de contenidos y unos lenguajes diferentes al libro y los textos académicos: noticias, entrevistas, crónicas, reportajes, imágenes fotográficas, además el diseño de sus páginas y la publicidad ofrecida, que en conjunto puede verse como una gran oferta informativa y educativa al servicio de los maestros y los alumnos.

La World Association Newspaper, WAN, y su programa Newspaper in Education, NIE, destacan que la primera experiencia de la prensa en la escuela data del año 1795, en Portland (Maine): The Eastern Herald, "published an item explaining the merits of using the newspaper to improve reading, teach geography, science and business practice (The full quotation at the end of this text)" (WAN, s.d). De igual forma, la NIE resalta que la primera experiencia de Prensa Escuela en el mundo moderno se dio con el New York Times y el Milwaukee Journal en la década del 30. Y luego, en los 60, se expandió por Europa en Finlandia y Suecia. Por su parte, en la década de los 70 la propuesta llegó a Noruega, Holanda y Alemania. La WAN reporta que a 2005 contaba 
con más de 60 programas en todo el mundo, incluyendo países de África, Suramérica, Europa y Asia.

En Iberoamérica Prensa Escuela empieza a ser más evidente en la década del 80, cuando se reportan experiencias de España y luego de América Latina. Es así como el periódico español La Voz de Galicia inicia en 1982 la publicación del suplemento "La Voz de la Escuela" que tenía entre sus objetivos que los programas educativos de los colegios tuvieran un "contacto con la realidad" y fomentaba el sentido crítico de los alumnos para ayudarlos a formarse como ciudadanos (Novacaixagalicia, 2011).

En el caso de América Latina se tienen referencias de experiencias en Argentina con el periódico La Capital de la ciudad de Rosario, Los Andes de Mendoza y Clarín; en Chile, el programa "Prensa Escuela" hacía parte de una propuesta de la Escuela de Periodismo de la Universidad Diego Portales desde 1988, y en Ecuador se conoce la experiencia con el periódico HOY desde 1982. Por su parte, en Colombia la experiencia se inició con el apoyo del Ministerio de Educación y la Organización de Estados, Iberoamericanos para la Educación, la Ciencia y la Cultura (OEI), en la que participaron 15 medios informativos impresos del país, desde el año de 1993.

Por su parte, la Sociedad Interamericana de Prensa, SIP, elaboró en 2002 el Manual "El Diario en la Educación" como una propuesta dirigida a los medios de comunicación asociados para ayudar a los periódicos 
... a orientar sus acciones a fin de poner en marcha un programa que ayuda a estabilizar o aumentar la circulación, presta un servicio práctico, respalda a los servicios educativos de las comunidades que atiende y, especialmente, eleva el nivel educativo de los escolares atrayendo a las aulas la realidad cotidiana para complementarla con la sabiduría de los libros de texto" (D’Elia, 2002, p. 5).

Con este programa, el principal propósito de los periódicos asociados a la SIP está asociado con el mercadeo: "estabilizar o aumentar la circulación”, porque cuando los periódicos llegan a las manos de los niños y los maestros empieza una relación de familiarización y conocimiento del periódico - fidelización-, y bajo este supuesto estos chicos serán los futuros lectores de los periódicos con los que trabajan en el aula de clase. En segundo lugar, sirve de respaldo a las instituciones educativas afiliadas a programas de Prensa Escuela, porque en casos de escuelas públicas ubicadas en los barrios o en poblados alejados de las grandes ciudades, el periódico se constituye en fuente de consulta e instrumento didáctico, dada la carencia de material bibliográfico (ahora dificultades para acceder a Internet) y de recursos para trabajar, por lo cual, es un material que ofrece información actualizada, fácil de manipular y de trabajar ${ }^{12}$. Y tercero, se da por sentado que eleva el nivel educativo de los estudiantes, porque los acerca a la realidad.

\subsection{Prensa escuela en Colombia}

El programa Prensa Escuela inició en Colombia el 25 de febrero de 1993 cuando se firmó un convenio entre la Asociación de Diarios Colombianos, Andiarios, el Ministerio de Educación Nacional y la Organización de Estados Iberoamericanos para la Educación, OEI. A esta iniciativa se unieron 15 diarios en el país que estuvo vigente hasta el año de 1998. Una vez terminado

\footnotetext{
${ }^{12}$ Es común que el periódico sea utilizado para recortar palabras para organizar oraciones o frases; las imágenes que ilustraran carteleras o en trabajos de clase; en otros casos utilizan el periódico para elaborar disfraces o vestidos que son exhibidos en fiestas institucionales.
} 
algunos periódicos continuaron con la propuesta fundamentada en hacer un uso pedagógico del periódico en el aula.

En agosto de 1994, el periódico El Colombiano ${ }^{13}$ empezó el programa de Prensa Escuela y plantearon entre sus objetivos:

- Proporcionar los elementos didácticos necesarios para poder alcanzar una visión científica del mundo, abierta a todas las realidades.

- Desarrollar el espíritu crítico y observador y la inquietud cultural que permitan aprender más allá de la Escuela.

- Facilitar y estimular la lectura de El Colombiano en el aula de clase para formar receptores y emisores activos y críticos, capaces de generar una cultura comunicativa (Marín, 1997, p. 9).

El Colombiano lleva 20 años con esta propuesta, basada en brindar capacitación a maestros, estudiantes y padres de familia en el uso pedagógico y didáctico de la prensa en el aula de clase y en la formación ciudadana. Al programa se sumó desde el año de 1996, la Universidad Pontificia Bolivariana, a través de la Facultad de Comunicación Social-Periodismo y con ella se estructuró el Taller de corresponsales escolares y que luego se denominó Taller de medios escolares, TAME y luego en el 2005 se unió la Facultad de Educación de la misma universidad. Ellas aportan los

\footnotetext{
${ }^{13}$ El periódico El Colombiano fue fundado en 1912. Es propiedad de las familias Gómez Martínez y Hernández Restrepo, es de tendencia Conservadora. Es el medio de comunicación más influyente en el departamento de Antioquia y en su capital Medellín.
} 
talleristas (estudiantes de sus carreras universitarias) que a su vez capacitan a los alumnos y profesores de los colegios que participan en Prensa Escuela ${ }^{14}$.

Para consolidar este programa se firmó un convenio inicial el 15 de abril de 1999 y luego se ratificó el trabajo en conjunto el 7 de mayo de 2009, en el marco del Seminario "Prensa y educación en equipo para formar ciudadanos", con un nuevo convenio en el que se evidencia su evolución académica y logística que es evidente en el objetivo principal:

Formar ciudadanos capaces de hacerse responsables de informar y de opinar, capaces de expresar claramente una idea o un sentimiento, personas autónomas y comprometidas con el desarrollo social; personas con competencias ciudadanas, comunicativas y laborales, que se propician desde dos componentes fundamentales: i) capacitación a maestros para utilizar la prensa como recurso didáctico; ii) asesoría y acompañamiento a los medios de información escolar (Universidad Pontificia Bolivariana y El Colombiano, 2009).

De esta forma se consolidó la propuesta del Taller de Medios Escolares, TAME, como un espacio para cualificar los medios de comunicación que existen en las instituciones educativas, sobre todo de la ciudad de Medellín. Además de lo anterior, Prensa Escuela El Colombiano ofrece aún formación a los maestros sobre el uso del periódico como recurso didáctico, la motivación de la lectura de la prensa por parte de maestros y estudiantes, y en el desarrollo de competencias comunicativas, ciudadanas y laborales.

El programa de Prensa Escuela sigue contando con el apoyo del periódico El Colombiano, la UPB con las facultades de Comunicación Social-Periodismo y Educación. La facultad de

\footnotetext{
${ }^{14}$ En la actualidad están inscritas 123 instituciones educativas, 73 públicas y 50 privadas en 35 municipios de Antioquia (el departamento cuenta con 125 municipios). En el TAME participan solo algunas dependiendo del número de talleristas aportados por ambas facultades.
} 
Educación de la Universidad de San Buenaventura se unió a esta propuesta a partir de 2012 y este año estableció alianzas con entidades públicas como el Plan de Lectura de Medellín, el Parque Explora, el Centro de Innovación del Maestro (MOVA), el Banco de la República y Proantioquia, esta última una fundación privada del sector empresarial que apoya, entre otros, programas educativos.

\subsection{Escuela Electrónica}

La oficina regional del periódico El Tiempo ${ }^{15}$ en Medellín tuvo el proyecto "Escuela Electrónica" que financió la Alcaldía de Medellín. Se llevó a cabo en el marco del programa "Internet para todos" que buscaba masificar este servicio entre los habitantes de la ciudad. Es recordado porque el alcalde Luis Pérez Gutiérrez ${ }^{16}$, intentó poner en venta 200 mil computadores, sobre todo en los estratos sociales más bajos ${ }^{17}$. Los colegios públicos participaron de esta propuesta, la mayoría de ellas fueron dotadas con salas de 20 computadores y conexión a Internet, además se hizo un programa de capacitación basada en la informática y la Internet. La misma se realizó entre septiembre de 2002 y culminó en 2004. En total participaron 210 instituciones educativas.

"Escuela Electrónica El Tiempo" enfocó su trabajo en dos áreas: acompañamiento en la producción de periódicos escolares impresos y digitales, orientados por periodistas y las tutorías en los colegios dirigidas por profesionales de la comunicación quienes acompañaron a profesores y estudiantes en la producción de sus medios de comunicación escolar, ya fueran impresos o

\footnotetext{
${ }^{15}$ El periódico El Tiempo es el medio de comunicación más influyente del país. Su sede es la ciudad de Bogotá y es considerado el primer periódico de circulación nacional, perteneció hasta hace pocos años a la familia Santos. La mayoría de las acciones de El Tiempo pertenecen en la actualidad a uno de los grupos empresariales más importantes de Colombia.

${ }^{16}$ Luis Pérez Gutiérrez fue alcalde de Medellín entre 2001 y 2003.

${ }^{17}$ En Colombia las clases bajas se ubican en los estratos 1 y 2 ; la clase media en estratos 3 y 4 , y la clase alta en 5 y 6.
} 
digitales. A manera de resultados, "Escuela Electrónica El Tiempo” brindó asesoría directa a 480 maestros, tres mil alumnos estuvieron vinculados en la elaboración de medios impresos y digitales, y se logró un acercamiento a las nuevas tecnologías por parte de docentes y estudiantes.

Sobre la producción de medios escolares se destaca que la experiencia “impulsó el espíritu investigativo a través de la reportería periodística y la exploración de Internet y software educativo y desarrollo de habilidades comunicativas en los jóvenes" (Escuela Electrónica El Tiempo, 2004). Además se resaltó la experimentación de otras formas de narrar desde los géneros periodísticos y el acercamiento al aprendizaje de la hipertextualidad, multimedia e interactividad.

\subsection{Educar mientras informa}

El diario El Mundo ${ }^{18}$ inició en el año 2012 un proyecto que compromete toda la labor periodística, desde sus contenidos hasta su distribución, denominado "Educar mientras se informa". Esta idea transformó el periódico en su totalidad y ahora es un proyecto que convirtió al medio en un instrumento de educación.

Entre los propósitos establecidos están:

\footnotetext{
${ }^{18}$ El periódico El Mundo se fundó el 20 de abril de 1979 por un grupo de empresarios y periodistas con tendencias liberales. En la actualidad pertenece a la familia Gaviria Correa, empresarios dedicados a la industria del banano, la ganadería y la minería. Familia política que tiene a su haber dos gobernadores de Antioquia (Guillermo Gaviria Correa, secuestrado y asesinado por las Farc); y Aníbal Gaviria Correa Gobernador de Antioquia (2003-2007) y en la actualidad Alcalde de Medellín.
} 
(...) uno, contribuir a la preparación académica y ciudadana del alumno en el aula de clase; dos, el periódico El Mundo puede aportar a las conversaciones colectivas de esta sociedad mediante estrategias que generen conversaciones; tres, el periódico El Mundo va a apostarle a la formación de los futuros periodistas de esta sociedad y de los futuros interlocutores de la vida pública de esta sociedad desde el aula de clase, apoyando la formación de medios de comunicación o en la maduración de medios de comunicación escolar (Tobón. Entrevista agosto 5 de 2011).

Al igual que sucede con Prensa Escuela de El Colombiano, "Educar mientras informa" también realiza una propuesta de medios escolares desde las lógicas de la casa editorial. Parte de la premisa de que el periódico va a ser aceptado como un factor determinante en la educación de los niños y los jóvenes, y que desde sus contenidos la comunidad académica empezará a participar en las discusiones públicas de la sociedad y además enfoca su trabajo en la formación de los futuros periodistas desde la experiencia de los medios escolares.

En marzo de 2011 El Mundo tuvo un relanzamiento en el que los lectores habituales vieron el cambio en el formato (pasaron del universal a un tabloide europeo), en la forma de presentar los contenidos además del texto, se incluye una pregunta problematizadora y una cifra que contextualice la información. El periódico llega a sus lectores habituales y a un número de instituciones educativas de Medellín y municipios circundantes. Ahora, para orientar el trabajo educativo a partir de los contenidos, se dispone de un equipo de promotores (comunicadores sociales y educadores) que acompañan a maestros y estudiantes en el proceso de incorporar el periódico en el aula de clase.

Y además de ello, otro componente de esta propuesta es el acompañamiento para la producción de medios escolares, en el caso que ya existan para que se mejoren y lo maduren, de ahí que Tobón proponga la siguiente reflexión: "Ojalá algún día esto impacte y que los gobiernos 
reconozcan el periódico escolar como un asunto medular de la escuela, no como un accidente o como un deseo del profesor” (Tobón. Entrevista, agosto 5 de 2011).

Esta experiencia naciente hace evidente los problemas y dificultades que conllevan este tipo de proyectos. Uno, se hace como actividad extracurricular, porque los maestros no son capaces de salirse del currículo y dos, el sistema educativo sigue interesado en llenar de contenidos a los alumnos, porque a las instituciones las evalúan por los resultados que obtengan con las pruebas que aplican los estudiantes y por ello les otorgan una certificación.

Como se ve, las empresas periodísticas de la ciudad no han sido ajenas al tema de Comunicación/Educación. Programas como "Prensa Escuela", "Educar mientras se informa" y "Escuela Electrónica El Tiempo" son una muestra de ello. Por ellas han pasado y se beneficiaron cientos de estudiantes y profesores, tanto de instituciones públicas como privadas.

\subsection{La escuela y la comunicación en Colombia. Una mirada instrumental}

La temática de la comunicación en la escuela, en el caso colombiano, tiene un enfoque instrumentalista: unos medios que posibilitan la trasmisión de unos contenidos académicos aplicados en diferentes procesos de alfabetización que se vivieron en el país, sobre todo a partir de la década del 50 del siglo XX. Esto generó un imaginario de lo que es la comunicación para la escuela. 
En general, los países de América Latina inician un proceso de incorporación de los llamados medios masivos, siendo la televisión ${ }^{19}$ uno de los principales. Así y ante problemas de analfabetismo creciente -en el caso colombiano- los medios de comunicación, sobre todo la radio y la televisión, comenzaron a jugar un papel importante en el sistema educativo de Colombia. En el caso de la radio y dado que llegaba a las grandes "masas" de la población, se le vio en ella la posibilidad de promover los valores conservadores y la reproducción de "prácticas culturales más tradicionales" (Álvarez, 2003, p. 71). Ante la penetración de la radio, la escuela asumió un papel de resistencia e intento acomodarla a sus propósitos educativos, Álvarez distingue dos: uno, introducirlo en la escuela para darle un uso didáctico y dos, asumir una función alfabetizadora: “se intentaría escolarizar la radio, utilizándola como medio para reproducir lo que se hacía en la escuela (alfabetización por radio, programas de concurso, campañas educativas y moralizadoras)" $(\text { p. } 73)^{20}$.

Debido a las transformaciones que empezó a vivir la sociedad colombiana a raíz de la "Violencia" (finalizando la década del 40 en el siglo pasado) y que produjo un desplazamiento de los pobladores a la ciudad, los medios de comunicación generaron una gran influencia en ellos. Es así como la escuela empezó a consolidar una formación tradicionalista, con la tarea de afrontar un analfabetismo creciente y al que pensaba "atacar" ofreciéndole a la población asuntos fundamentales: aprender a leer, escribir y manejar las operaciones básicas matemáticas. Y para

\footnotetext{
${ }^{19}$ En Colombia la televisión llegó en el año de 1954, bajo el gobierno dictatorial de Rojas Pinilla. La radio y la prensa ya tenían una influencia grande en una sociedad que como consecuencia de la llamada "Violencia" producida por la confrontación entre Liberales y Conservadores (los partidos tradicionales), trajo consigo grandes migraciones de campesinos a las ciudades capitales: Bogotá, Medellín y Cali, principalmente.

${ }^{20}$ Huergo señala que la radio se inscribe en la escuela bajo el modelo informacional, cumpliendo una labor instrumental, son vehículos por los cuales se trasmiten contenidos reemplazando la autoridad del maestro o del libro de texto (2000, p. 209). Ante esto propone una alternativa: la radio centrada en el receptor. Asumiendo a Freire sostiene que más importante que aprender a leer las palabras es aprender a leer el mundo, esto significa pronunciarlo, transformarlo (2000, p. 217).
} 
lograr esto introduce los medios en ella como divulgadores de información, instrumentos al servicio de un sistema educativo conservador

Sostiene Álvarez:

La radio, el cine y la televisión, cada uno en su momento, se quisieron poner al servicio de la enseñanza, para lo cual se hizo necesario generar una acción pedagógica sistemática. Se entendía por acción pedagógica sistemática el empleo de los medios en forma organizada, progresiva, coordinada y programada, de tal manera que se lograra la adquisición, total o parcial, de un conjunto de conocimientos, actitudes y experiencias, de alguna manera observables y evaluables (2003, p. 39).

El modelo de educación conductista orientaba este tipo de experiencias. Entre otros aspectos no se evidenciaba una reflexión pedagógica, porque prevalecía la necesidad de afrontar el déficit de aulas y maestros, y la falta de presupuesto para hacer frente a esa situación. En este marco entra también la llamada televisión educativa ${ }^{21}$. El escenario era el siguiente: un maestro (en estas primeras experiencias se invitó a los mejores docentes del momento) instruía a miles de personas en un horario programado- por lo general en horas de la mañana o de la tarde- asistían a la clase. El típico modelo tradicional y conductista de educación fue trasladado a la televisión. Cursos de diversa índole desde el español y las matemáticas, hasta cívica y religión pasaron por las pantallas de la televisión colombiana.

Hay que tener en cuenta los cambios que se suscitaron en su momento en la educación colombiana con el modelo de televisión educativa, porque como sostiene Álvarez estableció "una

\footnotetext{
${ }^{21}$ En Colombia, mediante el Decreto 1566 de 1960, se creó el Departamento de Televisión Educativa, con un planteamiento básico: la televisión podía ser un poderoso auxiliar de los métodos convencionales de educación, (subrayado propio) sobretodo, con la escuela básica. (Álvarez, 2003, p. 149). Este tipo de acciones obedece a lo que Huergo plantea como planificación educativa, bajo un enfoque desarrollista de la educación, el cual no se preocupó por la incorporación de innovaciones pedagógicas, "sino por la sustitución del lenguaje pedagógico por el lenguaje económico y tecnológico" (2004, p. 172).
} 
nueva mirada de lo pedagógico" con dos categorías: la instrucción programada y la planeación educativa, que llevó incluso a cuestionar el papel de la escuela y afirma que se planteó otra realidad bajo los siguientes aspectos:

Primero, que la educación era un proceso de enseñanza-aprendizaje, programable, predecible y controlable; segundo, que los medios de comunicación social podían educar según esa concepción; tercero, que había nuevos agentes educativos diferentes al maestro: los técnicos de instrucción programada o personas voluntarias de la comunidad; cuarto, las comunidades podían administrar su propia educación bajo la modalidad de autoeducación individual o colectiva. Todo esto suponía, además, que la escuela ya no era imprescindible (Álvarez, 2003, p.163).

El interés estaba en controlar el conocimiento de una población, se dejó de lado toda la reflexión pedagógica que era necesaria en ese momento. Desde esta perspectiva, los medios de comunicación cumplieron una función instrumental, que poco aportaron a la reflexión. Los efectos de estas estrategias que se aplicaron por varias décadas, los resume Álvarez:

El efecto que se produjo no fue entonces el de la sustitución de un sistema educativo por otro, como se sospechaba que iba a suceder, sino la incorporación de la lógica instruccionista al sistema escolar. Se echaron por la borda siglos de reflexión pedagógica y sin mayor cuidado se giró hacía un nuevo paradigma en el que la enseñanza, el maestro y su saber pedagógico, se reemplazaron por el logro de objetivos de aprendizaje identificados en la conducta e inducidos por estímulos motivacionales (2003, p. 174).

La televisión educativa llevó la escuela tradicional a la televisión, por eso prevaleció la clase magistral donde el maestro llegaba a mucha gente, pero como advierte Álvarez se dejaron de resolver problemas didácticos de la vieja escuela (p. 174). La historia y la experiencia de los medios de comunicación educativos en Colombia puede ser la misma de otros países de la región. 


\subsection{Las TIC, ahora}

Con la incursión de las llamadas Tecnologías de la Información y la Comunicación, TIC, a mediados de los 90, la discusión entre medios de comunicación y escuela vuelve a surgir, ahora más con la Internet, los computadores y los lenguajes hipertextuales que traen consigo y que entran en choque con la estructura lineal de la escuela y su cultura del libro. Martín Barbero había advertido la necesidad de que la escuela se insertará en los "ecosistemas comunicativos" considerados como "experiencia cultural, entorno informacional y espacio educacional difuso y descentrado" (1996-1997, p. 19). Sostiene Martín Barbero que lo que generan los medios de comunicación son "nuevas sensibilidades", esto es, "otros modos de percibir, de sentir y relacionarse con el tiempo y el espacio, nuevas maneras de reconocerse y de juntarse" (19961997, p. 19).

La escuela comienza por llevar equipos a las instituciones educativas y luego hace una labor “instructiva". Es así que la tecnología empieza a ser tema de agenda de los gobiernos y son mirados como oportunidades de desarrollo, progreso y competitividad en el mundo moderno y la escuela debe preparar a sus estudiantes para afrontar estos retos. Rodríguez (2004) precisa que las instituciones educativas canalizan los "conocimientos" de las tecnologías en los manejos de los programas básicos de Office, de correo electrónico y búsquedas en Internet. También indica que la producción está asociada a creación de programas de simulación, actividades en torno a las aulas virtuales, trabajos colaborativos, pero la participación de los estudiantes se centra en la producción de textos. Todo esto tiene un propósito: desarrollar habilidades con la tecnología dispuesta en la institución para prepararlos "a defenderse en un contexto globalizado"; ofrecer 
una visión más amplia del mundo al estudiante; convertirlos en metodologías que facilitan los procesos de enseñanza-aprendizaje, entre otros (p. 210).

El interés de los gobiernos (nacional, departamental y municipal en el caso de Colombia) es el de dotar a las instituciones educativas de computadores, conexiones y redes de banda ancha, para que los estudiantes accedan al conocimiento y puedan ser más competitivos. Sin embargo, la escuela sigue desarticulada frente a la incorporación de las tecnologías. Sostiene Kairuz Marquéz (2010) que uno de los principales obstáculos para la incorporación y uso de las TIC en las instituciones educativas es que no están integrados a los Proyectos Educativos Institucionales, PEI, "lo cual con frecuencia impide una orientación clara de las acciones emprendidas" (p. 40).

Las acciones del Gobierno colombiano para incorporar la tecnología en las instituciones educativas se centra en varias acciones: creación del portal educativo "Colombia Aprende", en el año $2004^{22}$; Ruta de apropiación de TIC para el desarrollo profesional docente; Redes y comunidades de aprendizaje; Modelos de innovación educativa; Centro de Innovación para la producción de contenidos; Proyectos colaborativos; Red de Bancos de objetos de aprendizaje. Y además de los anteriores, el proyecto bandera es "Computadores para educar", CPE, que tiene como lema "Menos niños fuera de la escuela”. Al respecto, Kairuz Márquez indica: “En 2005, las sedes beneficiadas con CPE disminuyeron la deserción en 4 puntos porcentuales" (p. 45). El balance de equipos entregados en los 10 años de funcionamiento de este programa es el siguiente:

\footnotetext{
${ }^{22}$ Se concibe el espacio como un lugar que posibilita el acceso al conocimiento a todos los colombianos, de interacción entre los diferentes actores del sector educativo y motor de desarrollo e innovaciones educativas. Este portal es liderado por el Ministerio de Educación Nacional (Kairuz Márquez, 2010, p. 41)
} 
205.244 equipos a 19.404 beneficiarias nuevas, entre sedes educativas, bibliotecas y casas de la cultura, todas oficiales (p. 48) ${ }^{23}$.

Por su parte, en Medellín, desde la alcaldía de Sergio Naranjo (1995-1997) se empezó a plantear la importancia de la inclusión tecnológica en el desarrollo de las actividades. Pero fue el alcalde Luis Pérez Gutiérrez (2001-2003) quien marcó el rumbo definitivo a este tipo de iniciativas y planteó en el Plan de Desarrollo de su gobierno la línea de Medellín Competitiva, en la que las TIC tuvieron un papel protagónico, porque se pretendía cambiar la vocación económica de la ciudad cimentada hasta entonces en el comercio y la industria. Planteó Pérez Gutiérrez:

Llevamos más de un siglo construyendo la ciudad sobre los pilares del desarrollo empresarial y los espejismos del cemento, sin que se haya hecho el mismo esfuerzo en construir las bases de una sólida cultura ciudadana [...] el plan de desarrollo Medellín competitiva se propone abrir las puertas hacia una nueva vocación económica para la ciudad, con el acento en la tecnología y los servicios modernos (Subrayado propio). No hay otra forma de sobrevivir en el competitivo mundo actual (citado en Tabares, 2009).

La concreción de esta propuesta se vio reflejada en los siguientes programas: Escuela del Maestro, Gobierno en línea, Masificación de Internet ${ }^{24}$, Universidad Electrónica Nocturna, Dotación de colegios $^{25}$, Contact Center, Escuela electrónica ${ }^{26}$, entre otros.

\footnotetext{
${ }^{23}$ De acuerdo con un documento Conpes de 2010, a ese año el Ministerio de Educación Nacional, a través del programa Uso de medios y nuevas tecnologías, se habían formado el 67\% (195.905) maestros de educación básica y media en competencias básicas de uso de tic; el $36 \%$ de los maestros recibió formación en la incorporación de medios y tecnologías en actividades de aula. Y además 9.282 docentes de educación superior se formaron en uso pedagógico de las Tic (Kairuz Márquez, 2010, p. 37).

${ }^{24}$ Con este programa se pretendía vender 200 mil computadores, sobre todo a la población de más bajos recursos; pero los mismos terminaron en manos de empresas y otras personas con más capacidad adquisitiva.

${ }^{25}$ Enfocado a las instituciones educativas oficiales. Se entregaron una o dos salas con 20 computadores cada uno, con conexión a Internet y navegación por banda ancha.

${ }^{26}$ Véase el aparte de Escuela Electrónica.
} 
Luego, en la administración del alcalde Sergio Fajardo Valderrama (2004-2007) se impulsaron otro tipo de programas, entre los que se destacó Medellín Digital, iniciado en 2006 y que buscaba aumentar el acceso a la tecnología y eliminar la brecha digital. Y este programa amplío las ofertas en la administración del alcalde Alonso Salazar (2008-2011) con Conectividad y acceso (Internet gratis, escuelas digitales, parques bibliotecas); Formación de docentes (Clic aprendo mejor, Intel educar, Academias Tic); Formación estudiantes (PC móviles, Clubes de informática) (Tabares, 2009, p.18). Y atado a esto figuran programas de capacitación de universidades con el fin de facilitar el uso y apropiación de las tecnologías con fines educativos.

Los resultados de estos programas y esfuerzos gubernamentales aún se desconocen. Al respecto, Rodríguez señala "en Colombia (...) no existe un balance censal ni un conocimiento sistemático de los desarrollos que existen en la escuela colombiana sobre el campo, hecho que incide en la formulación pertinente de políticas públicas y en la desarticulación en los procesos de formación sobre la incorporación, uso y apropiación de los medios y TIC en el mundo escolar" (2004, p.189).

Conocer los resultados sobre todo este tipo de acciones emprendidas por entidades gubernamentales y universidades será de gran ayuda, para comprender si con las llamadas TIC la escuela las incorporó más desde una perspectiva instrumental, transmisora de contenidos y ahora, bajo los paradigmas de la competitividad económica o, por el contrario, ha posibilitado una reflexión diferente de la comunicación. 


\subsection{Confusión de la Escuela frente a los medios de comunicación}

Rodríguez señala que la función de los medios en la escuela es instrumentalizadora: "su incorporación es meramente funcional de los medios de comunicación a los parámetros del mundo escolar" (2004, p. 188). Y en eso concuerda también con Huergo y Fernández quienes sostienen que bajo ese enfoque instrumentalizador los medios son utilizados como un "apoyo, como aporte o como refuerzo para la enseñanza" (2000, p. 63).

Son muchos los casos en que las instituciones educativas hacen grandes inversiones para dotar sus salones de clase con televisores y montar circuitos cerrados de televisión; otras obedecen a planes de masificación de Internet (sobre todo las oficiales) dotan diferentes salas con computadores y equipos portátiles destinados a profesores y algunos estudiantes. Esto puede caer en una tendencia modernizadora de la escuela, si no está "atada" a un propósito pedagógico y formativo, por eso, si la escuela no tiene claro el para qué de la tecnología en la institución seguirá confundida frente a los medios de comunicación.

Bajo esta mirada, pierde terreno debido a que su discurso y su manera de relacionarse con la realidad de los niños y jóvenes se encuentra desfasada frente a lo que propone la industria del entretenimiento. En general, mientras la escuela estructura su discurso y su pedagogía en la razón, en lo comprobable y en los resultados, los medios de comunicación se centran en el entretenimiento, en la emoción de la imagen sobre el argumento (Saintout, 2006, p.144) y la variedad de posibilidades narrativas que ofrece el lenguaje audiovisual. 
Entre los medios de comunicación y la escuela se genera entonces una tensión que hoy sigue vigente, en buena medida porque ésta ve en los medios de comunicación un rival y a la vez los reduce a simples instrumentos modernizadores que se instalan al interior de las instituciones educativas, para favorecer la labor de enseñanza. En esa perspectiva Huergo llama la atención:

Muchas de la experiencias de usos de los medios en educación se inscribieron, y se inscriben, en un modelo informacional que apunta a incrementar información dentro de una linealidad en la transmisión; en este caso, los medios utilizados cumplen una función meramente instrumental: son instrumentos por los cuales se transmiten determinados contenidos, reemplazando la autoridad del maestro o del libro de texto. (2004, p. 169).

Lejos está esa mirada de lo que proponía Freinet, quien sin perder su papel como educador entendió que la introducción de la imprenta en el aula debía propiciar cambios en la forma de enseñar y en el rol propio del maestro y del alumno. Lejos de los esquemas tradicionales de educación del momento, de sus métodos evaluativos, la imprenta jugó un papel importante en la formación de aquellos niños del sur de Francia: el educador los conectó con la realidad, les permitió escribir con libertad. Así, no es lo mismo introducir un medio de comunicación, por más sencillo o sofisticado que sea en el aula de clase con un propósito pedagógico, a instalar medios de comunicación como simples instrumentos, bajo el supuesto que facilitaran la tarea del docente.

\subsection{Contexto de la educación en Colombia}

En la década del 50 los problemas de la educación en Colombia estaban relacionados con el analfabetismo que llegaba al $44 \%$ y baja cobertura de primaria que solo alcanzaba el $46.3 \%$ de los niños entre los siete y once años. De igual manera, se presentaba bajos niveles de cobertura en secundaria y estudios superiores. En las décadas posteriores $(60,70$ y 80$)$, los respectivos 
gobiernos propusieron programas para bajar esos índices de analfabetismo y aumentar la cobertura, como también tratar de mejorar la infraestructura física de las instituciones educativas y la promoción de planes y políticas que favorecieran la equidad y el acceso a la educación de cientos de colombianos ${ }^{27}$.

En la década del 90, en el marco de la nueva Constitución Política Nacional (1991) se promulgó la Ley General de Educación (115) en el año de 1994 que reguló la prestación de los servicios educativos en el país, generó la discusión de la educación como un derecho y estableció los gobiernos escolares y los Planes Educativos Institucionales (PEI), que garantizan la autonomía de cada institución educativa.

Sin embargo, es a finales del siglo XX e inicios del siglo XXI cuando la educación en Colombia empieza a ser influenciada por las políticas y planes emanados por el Banco Mundial. Atehortúa (2012) señala que a partir del año 2000, Colombia asume las directrices del Banco Mundial a partir de las propuestas de "reorganización institucional y optimización de la capacidad instalada". Como resultado de lo anterior se lanzaron el "Plan Estratégico" del Ministerio de Educación y el "Plan de reorganización del sector educativo" (PRESE), los cuales fueron coadyuvados por el Ministerio de Hacienda y el Departamento Nacional de Planeación en el año 2000 (p. 3).

Durante los ocho años del gobierno de Álvaro Uribe Vélez (2002- 2010) la educación fue un tema importante incluido en sus Planes de Desarrollo. Sin embargo, la educación estaba definida

${ }^{27}$ Estos antecedentes pueden ser profundizados en los estudios adelantados por Iregui, A; Melo, L. y Ramos, J. (2006). La educación en Colombia: análisis en el marco normativo y de los indicadores sectoriales. Revista de Economía del Rosario. 9 (2), $175-238$. 
como un "factor esencial del desarrollo humano, social y económico y un instrumento fundamental para la construcción de equidad social (...). Al lado de la cobertura, la calidad y la pertinencia, apareció una nueva que era, en realidad, la más antigua de todas: la eficiencia (Atehortúa, 2012, p. 5). A partir de entonces, la educación adquiere una visión "instrumentalista" que siguió vigente en el Plan de Desarrollo del presidente Santos (2010-2014).

Atehortúa señala que desde el primer gobierno de Uribe (2002) la educación se define como factor de desarrollo humano, social y económico, además de un instrumento para la construcción de la equidad social. Esto conlleva a construir unas variables permanentes, que se señalan a continuación:
Educación $\longrightarrow$ Factor;
Educación $\longrightarrow$ instrumento;
Educación $=$ equidad, por tanto, reemplaza la relación Educación $=$ Derecho

Desde esta perspectiva, es una visión instrumentalista (p. 9) que difiere a los establecido en la Constitución Nacional en los artículos 44, 45 y 67 que establece a la Educación como un derecho fundamental para los niños y jóvenes que debe ser garantizado por el Estado. Indica Atehortúa que en el segundo periodo de Uribe (2006-2010) la educación continuó siendo utilitarista, en donde se le definió como "un instrumento para lograr la inclusión social". De ahí que las variables propuestas fueron:

Educación $\longrightarrow$ instrumento;

Educación = inclusión social. (p.9) 
Por su parte, en el primer gobierno del presidente Santos (2010-2014) se entendió a la educación como un instrumento poderoso para reducir la pobreza y un camino hacia la prosperidad, como se ve en las siguientes variables:

$$
\begin{aligned}
& \text { Educación } \longrightarrow \text { instrumento; } \\
& \text { Educación }=\text { Reducción de la pobreza. } \\
& \text { Educación }=\text { Prosperidad } .
\end{aligned}
$$

Frente a estas concepciones de la educación, el autor concluye que "en cada uno de los Planes el papel estratégico de la educación se ubicó en el incremento de las capacidades y destrezas personales, léase competencias, para el empleo y la productividad" (p. 10). Plantea que la formación no debe reducirse a una capacitación para el trabajo, por el contrario, la función principal debe estar en formar hombres y mujeres con sentido humano; comprometidos con una ética y por el cuidado de las decisiones que afecten a la sociedad en general (p. 13).

Por su parte, Mejía y Montoya (2011) señalan que a partir de las políticas establecidas en los gobiernos citados, se establecen mecanismos para mejorar la calidad en la educación, entre los que se destacan: definición de estándares de calidad, evaluaciones de resultados (pruebas censales) y evaluación de desempeño de directivos y maestros, con miras a aplicar planes de mejoramiento (p. 36-37). Todo lo anterior trae consigo consecuencias, como lo señalan los autores: el maestro hace parte de una empresa y la escuela es una empresa educativa con dinámica de eficiencia, lo que trae consigo transformaciones operativas y de sentido del acto de enseñar; ya los estudiantes son "clientes" a quienes se debe escuchar, atender y "darles con eficiencia lo que ellos demandan" (p. 162). Y sobre los procesos de certificación de la calidad a 
las que están sometidas ahora las instituciones educativas públicas, los autores concluyen que si bien "contribuyen a la organización y una mejor gerencia de la institución, por otro lado invisibilizan el aspecto pedagógico, eje central y razón ser de la escuela” (p. 168). Con lo anterior se muestra que Colombia asumió las directrices y políticas establecidas por el Banco Mundial que inciden en la concepción de la educación y en el acto de educar a las futuras generaciones de colombianos.

\subsection{El contexto legal: La Constitución Nacional y algunas disposiciones en materia de educación}

La Constitución Política Nacional de República de Colombia fue proclamada el 4 de julio de 1991. En ella se establece como principio fundamental que "Colombia es un Estado social de derecho" (Constitución Política, Art. 1). De igual manera, se establece como Derecho fundamental: "Se garantiza a toda persona la libertad de expresar y difundir su pensamiento y opiniones, la de informar y recibir información veraz e imparcial, y la de fundar medios masivos de comunicación. Estos son libres y tienen responsabilidad social. Se garantiza el derecho a la rectificación en condiciones de equidad. No habrá censura" (Constitución Política, Art. 20). Además, que en las instituciones educativas se "fomentarán prácticas democráticas para el aprendizaje de los principios y valores de la participación ciudadana" (Constitución Política, Art. 41). 
Una vez proclamada la Constitución Política Nacional el Congreso de la República promulgó la Ley 115 de 1994, más conocida como Ley General de Educación ${ }^{28}$, con la que se buscó que las instituciones fueran más autónomas, que tuvieran su propio Proyecto Educativo Institucional (PEI), que se constituyera un Gobierno escolar, entre otros. De ahí que el Artículo $1^{\circ}$ define la educación de la siguiente forma: "La educación es un proceso de formación permanente, personal, cultural y social que se fundamenta en una concepción integral de la persona humana, de su dignidad, de sus derechos y de sus deberes" (Colombia. Congreso de la República). En la perspectiva del trabajo con los medios de comunicación se resaltan algunos artículos en los que se puede fundamentar este tipo de proyectos, por ejemplo, en el Artículo 13 se plantea que el objetivo común en todos los niveles (de formación), es el desarrollo integral de todos los educandos, mediante acciones encaminadas a "fomentar en la institución educativa, prácticas democráticas para el aprendizaje de los principios y valores de la participación y organización ciudadana y estimular la autonomía y la responsabilidad"(Colombia. Congreso de la República) y en el Artículo 92 que se refiere a la "Formación del educando" señala lo siguiente:

Los establecimientos educativos incorporarán en el Proyecto Educativo Institucional acciones pedagógicas para favorecer el desarrollo equilibrado y armónico de las habilidades de los educandos, en especial las capacidades para la toma de decisiones, la adquisición de criterios, el trabajo en equipo, la administración eficiente del tiempo, la asunción de responsabilidades, la solución de conflictos y problemas y las habilidades para la comunicación, la negociación y la participación. (Colombia. Congreso de la República).

\footnotetext{
${ }^{28}$ Varios países ya habían emprendido reformas en materia de educación como el caso de Estados Unidos (1983-86), Francia (1989), Japón (1987-89), Inglaterra y Gales (1988), España (1986-1991). De igual manera, países de la región como Argentina, Chile, México y Venezuela también adelantaron reformas de tipo administrativo, curricular y pedagógico que se podrían considerar reformas educativas. (Colombia: al filo de la oportunidad, 1998, p. 120).
} 
Y además plantea la posibilidad de que la institución cuente con un medio de comunicación. El Artículo 141 dice: "Los establecimientos educativos que ofrezcan el servicio por niveles y grados, contarán con una biblioteca, infraestructura para el desarrollo de actividades artísticas y deportivas y un órgano de difusión de carácter académico" (Colombia. Congreso de la República $)^{29}$. Por su parte, la llamada "Misión de sabios" sugiere trabajar múltiples capacidades de expresión que no sea solo la escrita y la oral que es la que prevalece en la Escuela:

(...) desarrollar en los alumnos un variado repertorio de lenguajes y códigos (textuales, lógicos, icónicos, informáticos, televisivos, etc.) derivados del desarrollo de la ciencia, la tecnología y el mestizaje cultural, todos los cuales se requieren para operar exitosamente en la cultura actual y dominar las nuevas tecnologías (Presidencia de la República- Colciencias, 1998, p. 181).

Además de la Constitución, la Ley General de Educación y las recomendaciones de los “Sabios”, el Estado colombiano estableció los estándares y las competencias como los pilares para "medir" los resultados de la educación en el país. Por competencia el Ministerio de Educación entiende:

La noción de competencia, históricamente referida al contexto laboral, ha enriquecido su significado en el mundo de la educación en donde es entendida como saber hacer en situaciones concretas que requieren la aplicación creativa, flexible y responsable de conocimientos, habilidades y actitudes (Colombia. Ministerio de Educación, 2006, p. 12.

Como lo plantea el concepto, esto es tomado del mundo laboral y trasladado a la escuela, aunque el Ministerio señala que esta concepción busca romper con los modelos tradicionales de la educación memorística y permitir que los alumnos comprendan el conocimiento adquirido y lo

\footnotetext{
${ }^{29}$ Rodríguez plantea una crítica frente a la Ley General de Educación en el sentido que la misma no alude a los medios en los fines, en los objetivos de las modalidades y niveles, ni en los temas transversales. Y señala: Solo los artículos 43,44 y 45 del capítulo 3, "Educación informal", hacen alusiones a los medios: como fuentes de conocimiento libre y espontáneamente adquirido" (2004, p. 198).
} 
utilicen de manera efectiva dentro y fuera de la institución educativa. De esta manera, para el Ministerio los Estándares por Competencia lo que buscan es garantizar la calidad de la educación en todo el sistema educativo.

De igual forma, proyectos como en el caso de Prensa Escuela o en las instituciones educativas que cuentan con un medio de comunicación, tienen aceptación institucional si están enmarcados en estos propósitos. En este tipo de proyectos surgen como pilares de los mismos el desarrollo de competencias del Lenguaje y de la Comunicación, y en algunos las competencias ciudadanas, porque dentro de ellas encajan este tipo de proyectos.

Por su parte, el Ministerio de Educación estableció que los estándares y competencias del lenguaje deben apuntar

(...) hacia el desarrollo y el dominio de las capacidades expresivas y comprensivas de los estudiantes -tanto en lo verbal como en lo no verbalque les permitan, desde la acción lingüística sólida y argumentada, interactuar activamente con la sociedad y participar en la transformación del mundo (Colombia. Ministerio de Educación Nacional, 2006, p.21)

Sobre la formación en el Lenguaje:

plantea el reto de propiciar el desarrollo de las competencias que requieren las y los estudiantes para participar con éxito en las situaciones comunicativas que le ofrecen a diario la institución educativa, la región, el país y el mundo, teniendo presente que ser competente en lenguaje supone tanto el manejo de unos saberes referidos al sistema lingüístico, la producción y la comprensión textual, los contextos y la intencionalidad de los interlocutores, los universos emocionales de quienes se comunican, la cultura propia y las construidas por otros seres humanos, y los recursos ideológicos de que hace uso toda elaboración de discurso, como la adopción de una postura ética frente al discurso, los contextos y los individuos (Colombia. Ministerio de Educación Nacional, 2006, p. 23). 
Y de igual forma es importante tener en cuenta lo que se establece como los Lineamientos Curriculares $^{30}$ de manera especial Lengua Castellana y Constitución Política y Democracia ${ }^{31}$, más ligadas al objeto de estudio. Sobre la primera vale la pena resaltar que asumen el Lenguaje y la Comunicación bajo un enfoque cultural, asumen una posición crítica frente a la orientación instrumental con que se trabajan estos conceptos en la escuela que llevan a perder la dimensión socio-cultural y ética de la lengua y las habilidades comunicativas. Por eso, en este texto se plantea centrar la atención en los procesos de significación, esto es,

....a través del lenguaje que se configura el universo simbólico y cultural de cada sujeto. (...) Esta idea va un poco más allá de comprender el lenguaje únicamente como comunicación, es decir, como mensajes que se configuran a través de un canal entre un receptor y un emisor (Colombia. Ministerio de Educación. 1998, p. 47).

Agrega además que el lenguaje tiene como función principal la significación y plantea que la misma tiene que ver con los caminos que transcurre el ser humano para "llenar de significado y sentido a los signos, es decir, diferentes procesos de construcción de sentidos y significados” (Colombia. Ministerio de Educación. 1998, p. 47). La escuela se ocupa de la enseñanza de la lengua y el lenguaje como un sistema de reglas gramaticales y sintácticas, pero alejadas de las vivencias y conocimientos que posee el niño y el joven, lo que la hace más difícil aún de apropiarla. De igual forma, se propone que la lengua debe ser asumida como "patrimonio

\footnotetext{
30، Los lineamientos buscan fomentar el estudio de la fundamentación pedagógica de las disciplinas, el intercambio de experiencias en el contexto de los Proyectos Educativos Institucionales. Los mejores lineamientos serán aquellos que propicien la creatividad, el trabajo solidario en los microcentros o grupos de estudio, el incremento de la autonomía y fomenten en la escuela la investigación, la innovación y la mejor formación de los colombianos. (Constitución Política y Democracia. Lineamientos curriculares, 1998, p. 12).

${ }^{31}$ Sobre los Lineamientos curriculares, Rodríguez también establece sus diferencias: "solo se encontraron aspectos contextuales de la importancia con el áreas o el uso como ayudas audiovisuales, tal como se puede observar en Lengua Castellana, Ciencias Sociales, Idiomas Extranjeros o Matemáticas. Solo en Artes se considera un campo de formación, denominado 'Educación en audiovisuales', y se hacen referencias explícitas de orientación conceptual, metodológica y de logros para el cine, la televisión y la multimedia" (2004, p. 199).
} 
cultural", que vas más allá de las reglas gramaticales (Colombia. Ministerio de Educación. Lengua Castellana, 1998, p. 48).

La reflexión en estos lineamientos sobre la escritura apunta más allá de unas reglas lingüísticas, entienden que el escribir se constituye en un proceso "que a la vez es social e individual en el que se configura un mundo y se ponen en juego saberes, competencias, intereses, y que la vez está determinado por un contextos socio-cultural y pragmático que determina el acto de escribir: escribir es producir mundo" (Colombia. Ministerio de Educación. Lengua Castellana, 1998, p. 49). Así vale la pena resaltar que las experiencias de los medios escolares pueden adquirir una dimensión diferente del lenguaje y de la escritura que posibilite la "escritura del mundo" propio de los estudiantes que participan en estos proyectos, esto es, sus conocimientos, sus reflexiones, su manera particular de ver la sociedad que habitan, para compartirla con otros, las personas que recibirán sus productos comunicativos.

También existen los Lineamientos curriculares de Constitución Política y Democracia orientados a la formación ciudadana. El documento plantea la redefinición del concepto de ciudadano como quien no se limita a la acción de votar, sino que es un sujeto activo en búsqueda de objetivos colectivos (Colombia. Ministerio de Educación. Lineamientos curriculares Constitución Política y Democracia, 1998, p. 38). También señalan que la escuela debe convertirse en un laboratorio de cultura democrática, porque es el espacio donde se viven una serie de conflictos de manera cotidiana, los cuales pueden ser resueltos de manera civilizada (Colombia. Ministerio de Educación. Lineamientos Curriculares, Constitución Política y Democracia, 1998, p. 43). Por su parte, establece que para el desarrollo de competencias democráticas es necesario trabajar las 
habilidades dialógicas y comunicativas, las cuales en un ámbito académico posibilita que los estudiantes desarrollen actitudes de apertura hacia los otros, sus diversas opiniones y posiciones, y promueve de manera muy puntual que en los ámbitos escolares se debe estimular la organización de emisoras o periódicos escolares, entre otros (Colombia. Ministerio de Educación. Lineamientos curriculares. Constitución Política y Democracia, 1998, p. 53). Estas son, entre otras, las normativas constitucionales y legales que inciden en proyectos como los medios escolares que se desarrollan en las instituciones educativas públicas y privadas.

\subsection{Algunos estudios sobre los medios escolares}

En Bogotá se adelantaron algunos estudios sobre los medios de comunicación escolar. Es así como la investigación "Medios y tecnologías de la información y la comunicación: una caracterización de las prácticas en instituciones escolares de Bogotá ${ }^{32}$ demuestra que la producción de medios escolares no es una práctica generalizada, pero resalta lo siguiente:

La producción en prensa es significativa, pues el $64 \%$ del total de las instituciones encuestadas reporta que edita algún producto impreso. El mayor producto impreso en las instituciones es el periódico, con un promedio del $70.5 \%$ frente al $24 \%$ de revistas y el $5.5 \%$ de otros medios impresos. (...) la mayor frecuencia de las publicaciones es semestral, seguida de publicaciones anuales (Rodríguez, 2004, p. 201).

Además indica que el $56 \%$ de las instituciones tiene emisora escolar y el $9 \%$ presentó producciones de programas de televisión. En materia de infraestructura un 34\% tienen algún equipo de impresión masiva, un $26 \%$ contaban con una consola de edición de audio, un $8 \%$

\footnotetext{
${ }^{32}$ Este fue un estudio realizado por el Programa de Fortalecimiento de la Capacidad Científica en la Educación Básica y Media RED- y el Instituto de Estudios en Comunicación y Cultura -IECO- de la Universidad Nacional de Colombia (no indican fecha de realización del estudio). Al mismo convocaron 954 instituciones educativas (públicas y privadas) y respondieron 419 . A las mismas se enviaron formularios que devolvieron por diferentes medios (fax, correo electrónico, página web).
} 
circuito cerrado de televisión, $14 \%$ equipos de edición de video y un $88 \%$ grabadoras de audio y un 53\% grabadoras de video (2004, p. 202). Este estudio concluye lo siguiente: "La producción debería centrarse en mostrar la realidad escolar por parte de los mismos actores escolares y en generar espacios de participación de la escuela con los entornos locales” (2004, p. 216).

Otra investigaciones adelantadas fueron "Modalidades comunicativas en la formación ciudadana escolar” (2000-2001) y “Comunicación, educación y ciudadanía: discursos de actores escolares” (2002-2003), ambas en la ciudad de Bogotá ${ }^{33}$. A manera de conclusión se plantea:

Con respecto a la producción, los medios de comunicación escolar más comunes en los colegios son el periódico y la emisora. Casi todas las instituciones con las cuales trabajamos cuentan con uno de ellos o con los dos. Sin embargo, estos medios aparecen como el proyecto de unas pocas personas o de un área en particular (la de español), por ejemplo, y no parecen tener real incidencia en la cotidianidad de la cultura escolar (Valderrama, 2007, p. 83)

Así se evidencia que los medios de comunicación escolar más que proyectos institucionales, se queda como una iniciativa o una delegación personal en un profesor y lo más llamativo es la poca incidencia que tiene en la comunidad educativa y en lo que Huergo y Fernández denominan como “cultura escolar" ${ }^{34}$.Y en los casos de los periódicos escolares, la investigación señala que la responsabilidad de producción de los mismos está en pocas manos: algunos profesores y estudiantes de grados intermedios, que tienen como función recoger en los cursos artículos o pequeños trabajos para ser publicados (Valderrama, 2007, p. 84).

\footnotetext{
${ }^{33}$ Estas investigaciones se inscriben en el programa Comunicación-Educación del Instituto de Estudios Sociales Contemporáneos (IESCO-UC), financiadas por la Universidad Central y Colciencias.

${ }^{34}$ Cultura escolar es una forma de producción, trasmisión y reproducción que tiende a la organización racional de la vida social cotidiana. La cultura escolar trasforma desde dentro la cotidianidad social imprimiendo en ella formas de distribución, disciplinamiento y control de prácticas, saberes y representaciones aún más allá de los ámbitos identificados como la 'institución escolar' ( 2000, p. 268)
} 
Retomando a Rodríguez, las investigaciones realizadas sobre los medios de comunicación escolares muestran:

- En el marco de una escuela que asume una función civilizatoria y trasmisora de conocimientos, los medios de comunicación escolar tienen sentido si asumen una función de esparcimiento y de trasmisión de información, lo que demuestra que la comunicación es vista desde la instrumentalización $(2004, \text { p. } 211)^{35}$.

- Ahora si la escuela es configurada como un espacio de mediación cultural, que posibilite el diálogo entre lo local y global, que genere vínculos con el contexto social del que hace parte la comunidad educativa, en este marco, los medios de comunicación escolar pueden trabajar bajo los supuestos de modelos pedagógicos críticos, que posibiliten ese diálogo intercultural entre el contexto social y la escuela (2004, p. 212).

- Sin embargo, uno de los grandes problemas que tienen los medios de comunicación escolar está en que carecen de un "proyecto comunicativo-educativo", no hay una reflexión sobre el saber pedagógico y comunicativo que surge de estas experiencias, por eso no pasan de ser prácticas puntuales y no se configuran como un espacio de conocimiento articulado a los saberes y conocimientos que circulan en la escuela.

- Otro aspecto que resalta es la carencia de una dinámica investigativa en los medios de comunicación escolar, porque no posibilita la construcción de procesos de investigación en y desde la cultura escolar, se hace más desde la perspectiva de los medios y no se involucra en el estudio de esas realidades (2004, p. 213).

- Desde la pedagogía crítica es posible ver la escuela como mediadora cultural que permite la construcción de conocimiento a partir de la realidad social. Esta es una gran posibilidad

\footnotetext{
${ }^{35}$ En este sentido retoman lo planteado por Huergo sobre el enfoque instrumental de la comunicación. Los medios en la escuela son utilizados como apoyo o soporte para la enseñanza (2000, p. 63), pero no se trabaja desde lo cultural y la producción de sentidos y significados.
} 
que tienen los medios de comunicación escolar, porque a partir de la producción de ellos se posibilita la circulación de "contenidos culturales locales" (2004, p. 214).

- Y como grandes conclusiones Rodríguez plantea: la primera, la perspectiva informacional que predomina en los medios de comunicación y TIC escolares, no existe "una producción mediática significativa en las instituciones escolares" y la producción está ajustada a "modelos pedagógicos tradicionales"(2004, p. 214); la segunda, "la producción debe centrarse en mostrar la realidad escolar por parte de los mismos actores escolares y generar espacios de participación de la escuela con los entornos locales” (2004, p. 216).

La escuela no trasciende todavía esta mirada, hace falta introducir otras reflexiones y experiencias que demuestren la importancia de hacer de estos medios, espacios de producción de significados que conecten a la escuela con la realidad del contexto social, de manera que quienes participen en estos proyectos se apropien del lenguaje para "expresar el mundo" que viven y sean leídos por su comunidad educativa y por el contexto social en el que está involucrada la misma. 


\section{Construcción del objeto de estudio}

Sostiene Schmucler que el concepto de comunicar, entendido como transferir algo a otro, trasmitir algo a otro, es algo reciente y está relacionado con la incursión de los medios masivos a la sociedad, sucedido en las primeras décadas del siglo XX. Pero en un sentido ontológico, comunicar es un término que se conoce hace algo más de 1000 años y que significa "poner en común”, vivir algo con el otro: “es una manera de existir en el mundo” (1997, p. 199).

Por su parte, Jesús Martín Barbero, desde una perspectiva cultural, propone dejar de lado a los medios y las tecnologías como el centro del debate en comunicación, para enfocarse en las mediaciones, esto es, asumir desde la cultura a la comunicación como un espacio de producción de significaciones y no solo circulación de información, lo cual cambia incluso la perspectiva del esquema tradicional de la comunicación (Martín Barbero, 1998, p. 289). Desde las mediaciones se plantea que aquel a quien se denomina receptor pasivo, asume el papel de emisor, es decir, productor de sus propios mensajes (Martín Barbero, 1998, p. 291) los cuales circulan por otros medios diferentes a los masivos, más ahora con el desarrollo de otros dispositivos y tecnologías. Siguiendo con Martín Barbero, la mirada de la comunicación como producción de sentido deconstruye la idea misma de "emisor" y "receptor", al revelarlos como productos estancos e insuficientes para pensar el proceso de la comunicación en la cultura.

Ahora, la escuela asume la comunicación desde el instrumento, es decir, el medio y su carácter informacional, los medios son canales para trasmitir contenidos (Huergo, 2001, p. 65). Desde una perspectiva funcionalista supone que lo comunicativo trae implícito lo educativo y como 
resultado la negación de procesos de investigación en y desde la cultura escolar, aunque se acerca a la realidad contextual lo hace desde el medio, no desde la escuela (Rodríguez, 2004, p. 213). Y de otro lado, mientras la escuela se sostuvo en una matriz de conocimiento ligada a la escritura con la lógica del argumento y la razón, los medios se basan en la emoción sobre la razón y la imagen sobre el argumento con una lógica que rompe lo secuencial (Saintout, 2006, p.144).

En este contexto, las instituciones educativas realizan la producción de medios de comunicación, básicamente periódicos y otros como emisoras escolares, programas de televisión, en los últimos años toman auge las páginas web, los blogs y las redes sociales digitales, entre las que se destaca Facebook ${ }^{36}$. Estas prácticas de producción de medios están ligadas a conceptos de educación y a modelos pedagógicos, en especial los tradicionales caracterizados por ser memorísticos y repetitivos, a los que se suman las competencias ${ }^{37}$ que se imponen desde el sector empresarial en el sistema educativo. Es así que en instituciones educativas donde prevalezca un enfoque tradicional de la educación, el medio de comunicación tendrá una tendencia instrumental difusionista y su función básica será la divulgación de opiniones de las directivas y trabajos e informes productos de tareas escolares.

En contrapropuesta a lo anterior, existen otros modelos educativos más flexibles e integradores con el contexto social. La educación problematizadora expuesta por Freire en la Pedagogía del Oprimido y la Pedagogía Crítica propuesta por Giroux y McLaren, que hacen posible generar

\footnotetext{
${ }^{36}$ Es común entre los estudiantes tener una cuenta de Facebook y también las instituciones educativas que abren estos espacios como una posibilidad de relacionarse con padres de familia, estudiantes, maestros y en general con el "mundo". Con estos dispositivos la producción de mensajes se hace desde la lógica de la socialización, más que de la producción de mensajes que incidan en la sociedad.

${ }^{37}$ En el caso de Colombia, el concepto de competencias es asumido desde los modelos laborales, relacionado con el "saber hacer".
} 
reflexión crítica, problematizar el contexto social, apropiarse de la palabra y partir de la experiencia de vida y los "fondos de conocimiento" del estudiante, como bases para que el medio escolar sea resultado de una construcción colectiva, un producto social (Kaplún, 1998, p. 205) y los estudiantes se asuman como productores de significaciones desde la perspectiva cultural que propone Martín Barbero y que retoma Morabes (2001, p. 215).

Por eso, se hace necesario ver el medio de comunicación en su dimensión comunicativa, es decir, espacios donde se articulen prácticas y procesos culturales (Huergo, 2001, p. 31). Así, los periódicos, emisoras escolares, magazines de tv, blogs, Facebook, entre otros, adquieren otra dimensión comunicativa, educativa y cultural si estos medios se nutren del "mundo" de los estudiantes y se constituyen en escenarios para apropiarse de la palabra ${ }^{38}$, como una manera alternativa de aprender y formarse (educación) y expresarse (comunicación).

Hay que atreverse de nuevo a lo que hizo Freinet de introducir una imprenta en el aula y hacer de la producción del "Diario escolar" el eje del proceso educativo de sus estudiantes, bajo unos principios fundamentales: libre expresión, investigación y escribir para ser leídos (Freinet, 1977, p. 20), que en su momento rompió con los modelos tradicionales de educación. Por eso, se hace necesario reflexionar sobre las condiciones que se requieren para que los medios escolares (llámese periódicos, "blogs", "wikis", emisoras escolares, Facebook) se constituyan en los ejes

\footnotetext{
${ }^{38}$ Es importante tener en cuenta el planteamiento que hace Schmucler sobre la pérdida del valor de la palabra en el mundo informacional, "el imperio de la información lleva al imperio de la información intrascendente", sostiene (1997, p.197). Y 1lama la atención en el sentido que las palabras pierdan peso, las palabras no significan y como consecuencia de ello dejan de ser significativas y conllevan a una pérdida de la memoria de la significación de las palabras (1997, p. 197) De ahí que los proyectos de medios escolares y la escuela asuman esto como uno de los retos: recuperar el valor de la palabra y educar a los chicos en la responsabilidad de la palabra, como herramienta que permite construir la memoria de la humanidad y transformar la sociedad, como propone Freire (1985, p. 101).
} 
del proceso educativo bajo esa perspectiva comunicación/cultura, esto es, producción de significados. 


\section{Fundamentación}

La discusión con los proyectos de medios de comunicación en las instituciones educativas está en los alcances comunicativos y educativos que tienen este tipo de proyectos entre estudiantes, maestros, directivas y padres de familia, y en los sectores donde están asentadas. Los estudios adelantados hasta el momento dan cuenta de que son medios de comunicación que se ocupan de la divulgación de los eventos institucionales y de la selección de trabajos o tareas que los maestros ponen a los estudiantes.

Estas experiencias muestran una serie de falencias estructurales: se da más desde la práctica obedecen a unos paradigmas informativos propios de los medios de comunicación de masa- que desde una reflexión más profunda sobre la comunicación que vaya más allá del esquema tradicional de emisor-mensaje-receptor y la visión instrumental, y abarque otros aspectos relacionados con la cultura, para que ayude a comprender la relación que existe entre escuela y el contexto social, por un lado, y por otro, que a acercarse y entender las experiencias de vida (Pérez, 1998) y los "fondos de conocimiento" (McLaren, 1994) que los estudiantes tienen y llevan a la escuela.

También, es necesario que la escuela piense este tipo de experiencias de los medios de comunicación desde la educación, dado que gran parte de instituciones educativas siguen los paradigmas de una educación tradicional: por un lado, se llenan de contenidos, caso las editoriales escritas por los rectores y los ensayos de los estudiantes que sirven de contenidos que pueden ser objeto de evaluación en algunas clases. Así, los medios de comunicación cumplen la 
misma labor del libro: un repositorio de contenidos para ser evaluado y memorizados, pero no alcanzan a ser de interés para los estudiantes. Por eso es necesario pensar este tipo de proyectos de medios de comunicación desde otros paradigmas de la educación que promueva la pregunta problematizadora, genere debates y posibilite la interpretación de las realidades sociales.

Mirar los proyectos de medios de comunicación como posibles ejes del proceso educativo, espacios de producción de significados y de formación ciudadana es el propósito de esta tesis y requiere acoger teorías que contribuyan a plantear otras reflexiones y perspectivas para la producción de los mismos. En primera instancia, es necesario asumir los aportes teóricos de una comunicación más allá del medio (el instrumento) o el esquema básico de la comunicación; en segundo lugar, teóricos de la educación, con enfoques problematizadores y críticos que aporten con sus análisis diferentes maneras de concebir la educación a la tradicional y competitiva, por aquella que compromete a la educación y a la escuela con la formación de estudiantes reflexivos, como ciudadanos críticos y comprometidos con la construcción de la sociedad; siguiendo a Ruíz (2007) se trata de considerar la ciudadanía desde el ejercicio del rol político y la participación en proyectos colectivos para construir un orden social justo e incluyente, (p. 89-90),y en tercera instancia, un enfoque de Comunicación/Educación muy ligado a la cultura, a la producción de significados desde la escuela, a partir de la apropiación de los lenguajes de la comunicación por parte de los estudiantes y los maestros. Retomando lo anterior es posible ampliar la mirada de los propósitos de los medios de comunicación producidos en la escuela: más que instrumentos de divulgación pueden ser considerados espacios de construcción colectiva, producción de significados y de formación ciudadana. 
Así, el concepto de Comunicación se fundamenta en las mediaciones que propone Jesús Martín Barbero (1998), en la mirada ontológica y la comunicación como memoria propuesta por Schmucler en Memoria de la Comunicación (1997) y de igual forma, se toma como definición la de Saintout en Abrir la comunicación (2003), en la que propone la comunicación como una construcción social de sentidos, una puesta en común.

Por su parte, la educación será abordada bajos los preceptos de la educación problematizadora de Freire Pedagogía del Oprimido (1985) que tiene un carácter reflexivo y crítico, promueve la apropiación de la palabra, pronunciar el mundo (el propio) para transformarlo y además en la Pedagogía crítica de Giroux (2003, 2008) y McLaren (1994). De igual forma se toman aportes de autores como Ángel Pérez La cultura escolar en la sociedad neoliberal (1998) para analizar la educación y la escuela bajo enfoques competitivos al igual que Martínez Boom, La educación en América Latina: de politicas expansivas a estrategias competitivas (2003), porque realiza un acercamiento a las reformas educativas en la región, influenciadas por el FMI, Banco Mundial, la Cepal, entre otros orientadas a reconfigurar la escuela y la educación bajo el modelo de Escuela Competitiva. Otros autores que aportan a la temática: Saintout Jóvenes: el futuro llegó hace rato (2006).

Ahora, frente a la relación comunicación y educación, existen varias tendencias, pero para los efectos de esta investigación se asume aquella propuesta por Jorge Huergo de Comunicación/Educación en sus trabajos: Comunicación/Educación: Ámbitos, prácticas y perspectivas (2001); Hacia una genealogía de Comunicación/Educación. Rastreo de algunos anclajes político-culturales (2004); Cultura escolar, cultura mediática/intersecciones (en 
conjunto con Fernández) (2000) y Una guía de la Comunicación/educación, por las diagonales de la cultura y la política (2010). También se tiene en cuenta, como parte fundamental de la investigación, la obra de Freinet quién propuso hacer de los medios escolares los ejes del proceso educativo, a partir de: escribir para ser leídos y retomar la experiencia y el conocimiento del estudiante, que conllevó a una ruptura con los modelos tradicionales de educación en Francia $E l$ diario escolar (1977), Nacimiento de una pedagogía popular. Historia de una escuela moderna (1983). Otro de los autores que aporta a esta temática es Mario Kaplún Una pedagogía de la comunicación (1998) en el que plantea cambiar la concepción de los medios escolares de instrumentos a memoria de la institución, un producto social con proyección social. Y en esta misma temática se acogen las reflexiones de Paula Morabes Comunicación/Educación: trayectorias y representaciones en los docentes y sus propuestas escolares (2001); Jesús Martín Barbero Heredando el futuro. Pensar la educación desde la comunicación (1996-1997) y La educación desde la comunicación (2002); Carlos Valderrama, Discursos y dinámicas comunicativas escolares (2004).

Por su parte, el concepto de ciudadanía toma como referencia con los siguientes autores: Cullen, El malestar de la ciudadanía (2007). Otros autores que aportan al tema: Giroux, Teoría y resistencia en educación (2008); Valderrama, Ciudadanía y comunicación. Saberes, opiniones y haceres escolares (2007); Ruíz y Chaux La formación de competencias ciudadanas (2005); Ruíz, ¿Ciudadanía por defecto? Relatos de la civilidad en América Latina (2007).

También es necesario analizar el concepto de medios escolares y su evolución, ya no como el instrumento, sino desde las mediaciones para constituirse en ejes del proceso educativo. Los 
teóricos que aportan al respecto son: Valderrama, Ciudadanía y comunicación. Saberes, opiniones y haceres escolares(2007), quien reflexiona acerca de la incorporación de las tecnologías en la escuela no de manera mecánica, sino como "expresión del ser”, como una manera de expresión de su mundo (cultura); por su parte, Bacher, Tatuados por los medios (2009) sostiene que la incorporación de las tecnologías (medios) en la escuela tiene sentido, siempre y cuando esté acompañada de una propuesta pedagógica en tanto que se integre en una perspectiva social; y Rodríguez, Medios y tecnologías de la información y la comunicación: una caracterización de las prácticas en instituciones escolares de Bogotá (2004) en el que plantea que la producción debe centrarse en mostrar la realidad por parte de los actores escolares.

Estos planteos teóricos contribuyen a tener un enfoque diferente, tanto de la comunicación, la educación, la comunicación/educación, la ciudadanía y los medios escolares. Los mismos permiten centrar su foco en una mirada culturalista de la comunicación, porque no existe una preocupación por los medios y sus efectos, sino que se centra en las transformaciones, en los modos de ser, sentir, pensar en este caso de los actores educativos: maestros y estudiantes.

Esta tesis se inscribe en la línea de "Comunicación, Sociedad y Cultura", porque es donde se enmarca el estudio de las mediaciones desde el punto de vista comunicativo y lleva a establecer una relación y una reflexión con la educación desde una perspectiva problematizadora.

Desde el punto de vista metodológico, este trabajo centra su interés en la fase de producción, porque es en la que se deciden los temas, se determinan los enfoques, se delegan las funciones, se producen los contenidos y se pasa por el proceso de edición antes de ser publicados, (aunque tocará otros aspectos con los productos y la recepción). El propósito de acercarse a esta fase es 
comprender las intencionalidades, los enfoques y los intereses que tienen quienes participan en la producción de medios de comunicación en las instituciones educativas de la muestra seleccionada, básicamente maestros y estudiantes. Esto ayudará a entender las otras fases que también serán estudiadas para tener una mirada total del proceso y que lleve a establecer unas conclusiones o hallazgos significativos, que puedan ser útiles a quienes participan en este tipo de proyectos. 


\section{Objetivos}

\subsection{Objetivo general}

Analizar los procesos de producción de los medios de comunicación escolar desde la perspectiva de las Mediaciones comunicacionales de modo que posibilite una explicación sobre la relevancia que tienen estos proyectos en la escuela, la incidencia en la cultura escolar y las posibilidades de convertirse en espacios de formación ciudadana y de proyección social, tomando como base las experiencias de una institución educativa pública y una institución educativa privada de Medellín (2009-2012).

\subsection{Específicos}

- Indagar cómo y desde quiénes la escuela construye los procesos de producción de los medios de comunicación, que hacen circular informaciones y contenidos a estudiantes, maestros, directivos, padres de familia y comunidad aledaña a la IE.

- Examinar los modelos y conceptos de comunicación (medios de comunicación escolares), educación, información y ciudadanía que tienen los maestros y estudiantes que participan en los proyectos de medios de comunicación escolar.

- Revelar las tendencias y las intencionalidades de los temas publicados en los medios escolares en las instituciones y comunidades educativas desde el análisis de los contenidos de las publicaciones impresas y audiovisuales.

- Comprender la importancia que le otorga la comunidad educativa (estudiantes, maestros, directivos y padres de familia) a los medios de comunicación escolar que se producen en 
las instituciones educativas, teniendo en cuenta la pertinencia y la relevancia de los informes que se publican en ellos.

- Reflexionar las experiencias de los medios de comunicación escolar desde las mediaciones que propone la producción de significados y la relación entre escuela y contexto social, como alternativa frente a los proyectos actuales que privilegian el enfoque divulgativo/instrumental y la transmisión de información en la escuela. 


\section{Marco teórico}

Las experiencias de producción de medios de comunicación en las instituciones educativas requieren una estructura teórica basada en los siguientes conceptos, y en la relación y en los cruces que se dan entre ellos: Comunicación/Educación; Comunicación/Ciudadanía; Educación/Ciudadanía, tríada que posibilita leer el objeto desde una perspectiva diferente a la instrumental. Esta construcción parte de la revisión de los conceptos claves: comunicación, educación y ciudadanía, como se muestra a continuación.

\subsection{Comunicación}

Ideas Generales de un Concepto. La comunicación se entiende como un proceso de transmisión de información, desde un emisor a un receptor que utiliza un canal para tal propósito. La misma concuerda con la definición de la Real Academia de la Lengua (Rae): "Trato o correspondencia entre dos o más personas. Trasmisión de señales mediante un código común al emisor y al receptor" (2006); en el Diccionario Básico de Comunicación, Katz, Doria y Costa Lima (1980) la definen como "un proceso constituido por fuente, decodificador y transmisor, señales, receptor y codificador" (p. 102); en ella se privilegia el canal o medio, sobre la relación o participación de los actores sociales. Por su parte, Ander-Egg comparte esta definición: “Transmisión de signos, señales o símbolos de cualquier clase entre personas. Relación entre individuos encaminada a la transmisión de significados mediante el empleo del lenguaje, la mímica, los ademanes, las actitudes, etc.", e involucra una novedad en el rol que tiene el emisor y el receptor: "En esta interacción, ambas partes actúan como emisores y receptores de mensajes, utilizando un sistema simbólico mutuamente inteligible" (Ander-Egg, 1997, p. 34). A diferencia 
de la anterior definición, esta otorga otros elementos diferenciadores, como el que emisor y receptor cumplen el mismo rol, sin privilegiar al emisor como ocurre en el modelo difusionista e introduce otros conceptos como signos, símbolos y significados, aunque sigue asociando la comunicación a la transmisión.

Kaplún también aporta a la discusión y distingue tres tipos: al primero de ellos lo denomina comunicación "bancaria"39 que privilegia la transmisión de información: "un emisor que envía su mensaje a un receptor" (1998, p. 25); el segundo es la comunicación persuasiva, (Osgood, 1961, citado en Kaplún, 1998) la que es vista como una transmisión de señales, en la que una fuente emisora influye en el receptor. La novedad está en que al esquema tradicional agrega otro elemento: el feedback o retroalimentación. Para algunas personas, solo existe comunicación si este elemento está presente, sin embargo, Kaplún sostiene que la retroalimentación tiene una función esencial: verificar y controlar (p. 41). Por último plantea una "verdadera comunicación", como aquella en la que "dos o más seres o comunidades humanas intercambian y comparten experiencias, conocimientos, sentimientos" (p. 64).

Schmucler sostiene que la comunicación puede ser vista "desde arriba" y "desde abajo". Sobre la primera indica que está relacionada con el uso del término comunicación que data de hace más de 1000 años y que tiene como significado comulgar, es decir, "poner en común”, vivir algo con el otro; sobre el segundo (desde abajo) señala que tiene que ver con la idea más difundida: "la comunicación como el uso de determinados instrumentos para transmitir algo" (1997, p. 199). El autor indica que desde arriba, tiene un carácter humano, mientras que desde abajo reduce la

\footnotetext{
${ }^{39}$ Haciendo referencia al concepto de "educación bancaria" propuesta por Paulo Freire (1985, p. 72)
} 
mirada a un espacio instrumental y por eso plantea que si la comunicación es poner en común, entonces hay que poner en duda si lo que se define como comunicación ahora es comunicar o es otra cosa (p. 199).

Es necesario proponer otras miradas que trasciendan los modelos básicos y permitan analizar la relevancia que posee, sobre todo, si se aborda a partir de otros enfoques relacionados con la cultura. Como sostiene Schmucler, comunicar es comulgar, y agrega: "la comunicación es un hecho ético, es decir, político, no instrumental" (p. 150). En esta línea sigue Aparici (2006) quien indica que comunicar no implica manipular, modificar, alterar o cambiar las ideas de los otros, sino que es "un acto de concienciación. De toma de conciencia. De intercambio. De relaciones de iguales" (p. 40). Y con esto se retoma el carácter humano y de relaciones que tiene la comunicación, de construcción colectiva y de intercambio, más que de imposición y de manipulación.

\section{La Mirada desde la Cultura}

Es importante mirar la comunicación desde otros enfoques, que permitan abrir la discusión frente a un concepto que aún sigue reducido a un esquema básico. En ese sentido Martín Barbero plantea la necesidad de olvidarse del medio para ganar el objeto, es decir, pasar de los medios a las mediaciones (1998, p.257). Esto es, sostiene Martín Barbero, dejar de ser objeto para convertirse en sujeto y habla (destacado propio), que genera unas sensibilidades políticas nuevas, no instrumentalistas, abierta a la cotidianidad y a las múltiples solidaridades que operan en la 
sociedad $(1998, \text { p. } 258)^{40}$. Aclara que fue necesario perder el "objeto", como una teoría establecida y definida, para dar paso a otras disciplinas que enriquecieran la explicación del concepto (como el arte, la política, la antropología y la arquitectura), y desde ellas encontrar el camino al movimiento de lo social en comunicación, “a la comunicación en proceso" (p. 280). Señala que mirar la comunicación desde la cultura permite dejar los reduccionismos tecnológicos $(1998, \text { p. } 289)^{41}$ y apunta hacia un asunto clave en la discusión: la propone como un "proceso productor de significaciones y no de mera circulación de informaciones" y agrega también un cambio significativo en los roles: "el receptor no es un mero decodificador de lo que en el mensaje puso el emisor, sino un productor también" (1998, p.291). Esta es una alternativa para la escuela y, por ende, para sus medios de comunicación, en varios aspectos: uno, posibilita conectarse con el contexto social, establecer un diálogo entre la institución y las comunidades locales, de manera que pueda dar cuenta del mismo y en esa medida establecer relaciones más cercanas incidir en el mismo, a partir de la producción de contenidos; dos, más que generar información se deben producir contenidos pertinentes y relevantes tanto para la institución educativa, como para el contexto social, de tal manera que se generen procesos de diálogo, discusión y deliberación en ambientes democráticos; y tres, los estudiantes que participan en los grupos de producción de medios deben asumir la responsabilidad de ser productores de significados, no solo de tareas, datos e información para divulgar, de manera que puedan narrar

\footnotetext{
${ }^{40}$ En su obra de los Medios a las mediaciones. Comunicación, cultura y hegemonía, Martín Barbero analiza los dos paradigmas hegemónicos que han influido en América Latina: el modelo de Lasswell (psicológico-conductista) y el cientifista. El primero y que interesa en esta reflexión, genera un "comunicacionismo" que lleva a la instrumentalización de los medios de comunicación, privándolos de su espesor cultural y reduciéndolos a herramientas de acción hegemónica (1998, p. 281). Este es el modelo que prevalece en la escuela y sus medios de comunicación. Por eso, se requiere tener otro paradigma diferente, se hace necesario que la escuela también se deje permear del contexto social y que sus medios de comunicación den cuenta del mismo y relaten las historias que en él se dan.

${ }^{41}$ En el Oficio de Cartógrafo sostiene que pensar la comunicación desde la cultura es hacer frente al pensamiento instrumental que ha dominado a la comunicación desde su nacimiento, apoyado en la tecnología y asociado a la expansión de la información (2004, p. 211).
} 
su mundo, el mismo que circunda a la institución educativa y el mundo de la misma institución educativa; es posibilitar que entre estudiantes y maestros, estudiantes y directivas, se asuma la palabra para poner a circular sentidos y significaciones que generen espacios de reflexión y de intercambio de ideas.

Esta mirada desde la cultura también la comparte Schmucler, quien además propone establecer una relación comunicación/cultura, como una manera de fusionar dos elementos distintos de un mismo campo semántico, lo cual conduce a la posibilidad de "construir un espacio teórico nuevo, una nueva manera de entender y de estimular prácticas sociales, colectivas e individuales" (1997, p. 149). El sentido que se le otorga a partir de la cultura, parte de "ese mundo de símbolos que los seres humanos elaboran con sus actos materiales y espirituales" y desde los cuales "la comunicación tendrá sentido transferible a la vida cotidiana" (1997, p. 151). Si se tiene en cuenta lo anterior, cualquier ser humano puede contar su mundo, sus experiencias de vida, sus ideas y opiniones que construye a diario y, aún más, abrirse un lugar en la sociedad instalando la producción de sus significados alternativos y no hegemónicos, como espacio de lucha por los sentidos, en medio del mapa de las significaciones preferentes (Morabes y Rohtstein, 2012, p.9).

Por eso, la escuela con sus medios de comunicación debe permitir hablar de ese contexto social, de manera que los mismos puedan adquirir un reconocimiento diferente al interior de la escuela y también en las comunidades locales. Cuando el estudiante narra desde su propia realidad, adquiere más consciencia de ella y puede asumir la responsabilidad de actuar para mejorarla.

Y en esta línea Saintout también aporta a la reflexión, sobre la relación comunicación/cultura propuesta por Schmucler. Sostiene que la comunicación debe entenderse como una cuestión de 
sujetos y no de aparatos (2003, p. 82), con lo cual se reafirma esa condición propia del ser humano de producir significaciones y relatar sus experiencias de vida. Y afirma, de igual manera, que es un asunto de producción y no solo de reproducción desde la que es posible no solo ver el sujeto como reproductor, sino en su capacidad de creación (p. 82).

En esta línea de la comunicación relacionada con la cultura, Saintout propone una redefinición del concepto y lo asume como "construcción social de sentidos, puesta en común, tiene que ver con los modos de la socialidad, del estar juntos" (2003, p. 84), que está en consonancia con los planteamientos expuestos por los teóricos que proponen una mirada cultural de la comunicación. Desde esta perspectiva, el medio de comunicación debe ser un espacio de encuentro, de construcción colectiva de contenidos en los que se refleje la vida cotidiana de los estudiantes y de las comunidades que circundan la institución educativa. El medio de comunicación en la escuela debe ser un espacio que refleje y promueva la necesidad de "estar juntos".

Medios e Información en la Escuela. Todavía es necesario abrir la discusión sobre el tema de los medios y la información, porque tienen un peso muy fuerte en la sociedad y por consiguiente en las instituciones educativas. Los medios conservan un protagonismo en la discusión sobre la comunicación, más hoy por los desarrollos tecnológicos logrados en los últimos años, las incidencias que tienen en la sociedad y por los cambios de hábitos generados en el ser humano. De ahí que sea importante acercarse a algunas definiciones. Balle (1991) dice que un medio "es un equipo técnico que permite a los hombres comunicar la expresión del pensamiento, cualquiera que sea la forma o finalidad de expresión" (p. 50) y señala tres "familias de medios": autónomos, aquellos soportes donde publican los mensajes, sin necesidad de conexión a una red particular, 
como los libros, periódicos; la segunda son los medios de difusión, que abarcan grandes zonas de cubrimiento, entre los que se incluye la radio y la televisión; y la tercera son los medios de intercomunicación, definidos como cualquier medio de telecomunicación que permita una relación de diálogo entre dos personas o grupos, como los teléfonos (p. 50-51). Benito por su parte señala: "los medios de comunicación social- también llamados canales o mass media- son aquellas empresas, públicas o privadas, cuyo cometido es emitir información de actualidad desde soportes teóricos y físicos que la moderna tecnología ha hecho posible” (1991, p. 902), este autor agrega que los medios proporcionan a la sociedad un modelo del mundo y a su vez, una imagen y un conocimiento de lo que en él pasa, con lo que introduce una visión sobre el poder que tienen este tipo de dispositivos en la sociedad.

Desde la perspectiva de los estudios culturales los medios adquieren otra dimensión. Ya Williams se había referido a las comunicaciones como una forma de relación social y a los sistemas de comunicación como instituciones sociales (1992, p. 183); agrega que la tecnología es, en el sentido más amplio de la palabra, social (p. 185). Con ello hay que diferenciar: los canales y la tecnología, más que instrumentos utilizados para divulgar un contenido son espacios por donde circula la producción de significados y conocimientos producidos por actores alternativos que buscan abrirse espacio en un espectro dominado por los discursos hegemónicos. En este sentido, los medios y las tecnologías dejan de ser herramientas, instrumentos para comprenderlas como “dispositivos aglutinantes de significaciones sociales que las trascienden hasta extenderse en las más diversas esferas de la vida de los sujetos" (Morabes \& Rothstein, 2012, p.12), por eso, hay que asumir los medios y las tecnologías como "nuevas formas de reconocerse y juntarse, y nuevas formas de estar en el tiempo y en el espacio" (Martín Barbero, citado por Morabes \& 
Rothstein, 2012) o como sostiene Da Porta, las tecnologías y los medios de comunicación no hay que pensarlos como instrumentos para sino como prácticas complejas, como discursos abiertos y contradictorios (Da Porta, 2011, citado por Morabes \& Rothstein, 2012), en esta perspectiva, los medios adquieren otra dinámica y otro sentido: son espacios de construcción colectiva, por donde circulan significados y sentidos, elaborados por otros productores (estudiantes y maestros), que buscan generar un nuevo tipo de contenidos y ponerlos a circular entre los integrantes de la comunidad educativa y el contexto social-cultural que circunda a la escuela, con el fin de propiciar procesos de discusión y diálogo entre ellos, como una especie de agenda alternativa.

Sin embargo, la discusión en este caso está centrada más en la forma cómo se introduce en la escuela la comunicación y de manera específica los medios, porque ello incide también en el modo de estructurarlos y la función que les asignan. "No es extraño que nuestras escuelas sigan viendo en los medios únicamente una posibilidad de desaburrir la enseñanza, de amenizar unas jornadas presas de una inercia insoportable" (Martín Barbero, 2004, p. 334) y en otros casos existe un afán "modernizador" de la escuela y para ello instalan salas de computadores, televisores en las aulas, para generar sistemas cerrados de televisión, en algunos casos, como pretexto de servir como recurso didáctico y bajo el mismo parámetro se adquieren otro tipo de recursos tecnológicos, por ejemplo video beam, para proyectar las presentaciones de los maestros ${ }^{42}$. Cambia la "forma" de dar la clase, pero no los modelos pedagógicos.

\footnotetext{
${ }^{42}$ Huergo plantea que la escuela lleva los medios a la escuela bajo un enfoque instrumentalista, cuyo propósito es "utilizar a los medios como apoyo, como soporte o como refuerzo para la enseñanza" (2000, p. 63). Y en coincide con Valderrama quien señala que la introducción de los medios en la escuela obedece a la intención de hacer más "dinámicas" las clases o como soporte para transmitir los contenidos (2007, p. 81).
} 
En cuanto a los medios de comunicación escolar, Rodríguez señala que la creación de ellos obedece a varios factores: uno, que cumpla una labor de esparcimiento en los tiempos no curriculares; dos, que facilite la transmisión de contenidos relacionados con saberes escolares en espacios curriculares (2004, p. 211). El autor sostiene que la escuela no logra hacer una articulación adecuada de estos medios, porque existe una ausencia de "saber pedagógico", esto es "un saber reflexivo sobre la práctica, y una ausencia de saber sobre los medios" (p. 212), de ahí que lo que hacen con los medios en la escuela, no pasan de ser experiencias puntuales y de poca incidencia en la cultura escolar.

Es necesario entonces cambiar los enfoques que prevalecen en las instituciones educativas sobre ellos, para generar otro "saber de los medios", según la reflexión de Rodríguez. Además, en consonancia con la mirada de la comunicación desde las mediaciones y de la comunicación/cultura, Saintout propone abordar los medios no desde la exclusividad técnica, sino desde la densidad cultural y social: "Los medios no son sólo instrumentos neutros, no reflejan la realidad, sino que contribuyen junto a los demás actores a construirla como experiencia colectiva" (2003, p. 198). Y en sintonía con esta propuesta Huergo sostiene que ya es necesario dejar esa mirada instrumental y de transmisión de contenidos y asumir el carácter “comunicacional" de los medios: "cómo se articulan con prácticas y procesos culturales, que también resultan potencialmente educativos, y cómo funcionan como agencias de interpelación para los sujetos, frente a los cuales los sujetos reconocen (o no) y ante las cuales se forman o se educan” (2001, p. 31). Así se amplían las posibilidades de los medios de comunicación en la escuela. 
En primer lugar, al tomar la propuesta de Saintout, se adquiere la consciencia de aportar a la “construcción colectiva de la realidad”, no desde una posición neutra, en el caso de los medios escolares que producen sus contenidos a partir de las tareas y/o colaboraciones propuestas por los maestros, sino con el compromiso de relatar el mundo propio de los estudiantes y de esas realidades que hacen parte del contexto social en el que está inscrito la institución educativa. Realidades que tal vez confronten a la institución, a los maestros, a los mismos estudiantes, pero que los pueden enriquecer y aportar elementos para comprenderlas, a la vez de comprometerse a incidir en los posibles cambios en esos contextos sociales desde la labor educativa. Por su parte, tomando a Huergo, la escuela tiene la posibilidad de integrarse al contexto social, a la cultura propia del mismo y enriquecer sus visiones, desde la producción de medios de comunicación a partir de las experiencias de vida de los estudiantes y de los relatos de la vida cotidiana, propios de las comunidades locales, de manera que las dinámicas de producción de significados, de participación de los estudiantes como productores de sentidos y la recepción de los contenidos por los integrantes de las comunidades educativas dejen de ser una actividad de "mera transmisión de información".

Rodríguez afirma sobre las publicaciones en los medios escolares: "La producción debería centrarse en mostrar la realidad escolar por parte de los mismos actores escolares y en generar espacios de participación de la escuela con los entornos locales" (2004, p. 216) y llegar a una “resignificación” de este tipo de proyectos: “en torno de los cuales se puede aprender a construir un proyecto común, una forma consensual, dialógica de vivir juntos” (Valderrama, 2007, p. 192). Se plantea así otra manera de producir los medios de comunicación, en la medida que posibiliten la circulación de los saberes de la escuela, con los saberes de la vida cotidiana (Valderrama, 
2007, p. 190) y constituirse en puntos de encuentro de la comunidad educativa, una construcción colectiva, en un producto social (Kaplún, 1998, p. 205) que contiene la historia, los conocimientos y la experiencia de vida de los estudiantes, de los habitantes y de la propia escuela.

Información, una Discusión Pendiente. En la actualidad la información es un producto que circula por cientos de canales y en un contenedor de datos. Antes la información circulaba por ciertos canales o medios que estaba en manos de unos pocos, logrando de esa manera manipular y controlar lo que se decía, los momentos en que circulaba y con unas intencionalidades determinadas que favorecían a los dueños de los medios y a los poderes políticos bajo el modelo de pocos para muchos.

En una perspectiva diferente, Aparici (2006) presenta dos maneras de abordar la información: la primera se refiere al "proceso informacional" caracterizado por la transmisión de datos y la segunda se basa en el modelo de los medios de comunicación: "se caracterizan por producir y transmitir datos de todo tipo y cuyo objetivo principal es vender audiencias a diferentes empresas e instituciones públicas y privadas" (p. 40). Pero esto cambió en los últimos años con el auge de los dispositivos que están al alcance de muchas personas. Cada uno tiene la posibilidad de convertirse en un comunicador en potencia, por eso, los circuitos de información, la transmisión de datos e imágenes crecen inmensamente, con lo que se rompe el monopolio de la información que tenían antes los grupos empresariales y dueños de los medios, lo que lleva a que ahora surja otro modelo de muchos a muchos. 
Por su parte, Wolton (2006) establece una diferenciación entre información y comunicación, asocia a la primera como producir y transmitir mensajes "lo más libremente posible", y la segunda como un "proceso de apropiación" (p.16). Advierte que transmitir no es comunicar y para comunicar no basta con informar, entre otras cosas, porque el "receptor" moderno es cada vez más autónomo y crítico (p.16).

De igual manera, Schmucler sostiene que el imperio de la información lleva al imperio de las palabras intrascendentes, "en una época signada por la pérdida de la significación de la palabra" (1997, p. 197). Por eso, advierte Schmucler, sobre los peligros de asociar la información a la transmisión de datos y entrar en el circuito de ser conductores y difusores de información, puede llevar a un acto mecánico de recibir información y pasar información (p. 203-204) y el resultado de lo anterior es que la información se vuelva trivial, con el riesgo que las palabras pierden su sentido: "Si cualquier palabra da lo mismo, significa que nos declaramos irresponsables de nuestras palabras. Es el triunfo de la trivialidad. Las hacemos triviales para no responsabilizarnos” (1997, p. 204) y esto de por sí ya genera un reto para la escuela y sobre todo para los medios de comunicación que en ella se producen que tienen el deber de rescatar el sentido de la información como un servicio público y de la palabra como el elemento esencial del ser humano para expresar y narrar su mundo.

A la luz de estas reflexiones es importante que la escuela reflexione sobre el valor y sentido de la información como un derecho y un servicio público, porque desde ahí se le da otra dimensión diferente a la misma, adquiere mayor relevancia y compromiso con la comunidad educativa; y como consecuencia de ellos la escuela y los medios de comunicación pueden asumirla desde la 
perspectiva de producción de significados y sentidos, es decir, que pongan en circulación significados sociales. Y en el caso concreto de los medios de comunicación podrían denominarse escolares si los estudiantes tienen un empoderamiento de la palabra y desde ella asuman la construcción de información con los temas relacionados con sus propios intereses y sus experiencias de vida; de igual manera, le sirve para analizar sus contextos culturales y relatar sus mundos sociales. En esta perspectiva, los medios llamados escolares no serán un dispositivo más que contiene datos triviales que no logran conmover o a despertar interés en sus destinatarios, sino ese producto social que se construye de manera colectiva con la producción de contenidos significantes elaborados por estudiantes y maestros.

\subsection{Educación}

Llenar de contenidos o posibilitar la emergencia del ser. Una secuencia que representa la educación está en la película The Wall, dirigida por Alan Parker y cuya banda sonora es de Pink Floyd, en la que un grupo de niños sentados en sus pupitres van pasando sobre una banda mecánica y cuando caen salen convertidos en salchichas, representando una producción en serie. Es a su vez la representación de la educación tradicional, "basada en la transmisión de contenidos" (Kaplún, 1998, p. 22) o la "educación bancaria" en la que el educador lleva al educando a memorizar contenidos, desvinculados con la realidad y los contextos sociales, llenar unas "vasijas", los "depósitos" dispuestos por el educador, los cuales además de memorizar, deben repetir de manera mecánica (Freire, 1985, p. 72). Schmucler retoma esta idea del educador brasilero y sostiene que en la educación predomina la idea asociada con "llenar un hueco", lo cual se constituye en la instrumentalización con la transmisión del saber (1997, p. 201). La educación tradicional es la que ha predominado y aún tiene vigencia en la actualidad, porque su 
preocupación está en llenar de contenidos a los estudiantes, lo que lleva a despreocuparse por relacionar los mismos con las experiencias de vida de los alumnos, con sus problemas y con los de su contexto social, con lo que se establece un distanciamiento entre realidad y escuela, mundo de la vida y la escuela, preocupada solo por mostrar resultados tangibles y medibles.

Pérez señala que la finalidad de la escuela (y de la educación) es "fomentar y cuidar la emergencia del sujeto" (1998, p. 77) y en eso concuerda con Schmucler cuando indica que la educar, ante todo, “es posibilitar el ser" (1997, p. 201). Pero ese ser, no se educa para beneficio propio -como sugieren las algunas tendencias educativas individualistas actuales- por el contrario, "la educación verdadera es praxis, reflexión y acción del hombre sobre el mundo para transformarlo" (Freire citado en Barreiro, 1992, p. 7) y es el mismo Freire quien afirma que la educación se hace con el otro, "con la mediación del mundo" que se ofrece en sus diferentes dimensiones para ser visto, analizado, interpretado, un mundo que ofrece temas significativos, “en base a los cuales se constituirá el contenido pragmático de la educación” (1985, p. 108). Freire ofrece las bases para que educadores e institución educativa asuman la educación como un ejercicio que posibilite transformar la sociedad y transformar la vida de los estudiantes, para que en definitiva posibiliten la emergencia del ser.

Y una alternativa para alcanzar esa posibilidad del ser es la "educación problematizadora" que planteó Freire, como una contrapropuesta a la tradicional, porque tiene un carácter reflexivo, “implica un acto permanente de descubrimiento de la realidad" (Freire, 1985, p. 88). Estas son las ideas que dan pie a la llamada pedagogía crítica o educación crítica que tiene entre sus exponentes a Giroux y McLaren; esta pedagogía posibilita hacer un acercamiento crítico y entrar 
en contacto con la realidades y darles un sentido educativo, "aproximarnos a la realidad como un acto de conocimiento" afirma McLaren (1994, p. 47) y, agrega Giroux, lo siguiente:

Se preocupa de manera fundamental por la experiencia del estudiante; toma por punto de partida los problemas y necesidades de los propios estudiantes. Esto sugiere tanto confirmar como legitimar los conocimientos y experiencias gracias a los cuales los estudiantes dan sentido a su vida (Giroux, 2003, p. 250).

Esta idea apunta a algo fundamental para el desarrollo de los proyectos de medios de comunicación en la escuela: "debe suministrar las condiciones que dan a los estudiantes la oportunidad de hablar con sus propias voces para autenticar sus propias experiencias" (Giroux, 2008, p. 256). En esta perspectiva la educación posibilita: adquirir consciencia personal, reflexionar y comprender la realidad social, compartir las ideas personales y valorar las vivencias propias, en la perspectiva de comprometerse con una transformación social.

La educación problematizadora y la pedagogía crítica son claves a la hora de configurar proyectos de medios de comunicación escolar desde la perspectiva de las mediaciones y la comunicación/cultura, en las que los estudiantes se convierten en productores de significados relevantes para las comunidades educativas, porque los contenidos se basan en la propia "cultura experiencial", es decir, en los aprendizajes y conocimientos adquiridos por el estudiante en el medio familiar y social" ${ }^{43}$ " "la cultura del estudiante es el reflejo de la cultura social de su comunidad, mediatizada por su experiencia biográfica, estrechamente vinculada al contexto" (Pérez,1998, p. 199). Un medio de comunicación en la escuela que se nutra de este tipo de

\footnotetext{
${ }^{43}$ McLaren habla de los "fondos de conocimientos", referidos a las construcción de conocimientos que se hacen al interior de las familias y que los padres comparten con sus descendientes. Son enseñanzas y aprendizajes logrados por el interés y preguntas de los hijos, no de manera impuesta por los padres (1994, p.37).
} 
historias se transforma en un espacio colectivo y en el producto social que contiene la historia de una comunidad educativa y de un contexto cultural con identidad propia.

Qué tipo de escuela, para qué tipo de medio escolar. Es en las instituciones educativas donde se llevan a cabo las experiencias de los medios de comunicación escolar. Así, en las escuelas que tienen un modelo de educación tradicional, también se producen medios de comunicación ocupados en la transmisión de contenidos e informaciones institucionales. En estos espacios educativos, los medios son vistos como herramientas que posibilitan el mejoramiento de las llamadas "competencias" 44 del lenguaje y las "competencias" comunicativas, preocupadas por la adquisición de las normas lingüísticas ${ }^{45}$, más no de la apropiación del lenguaje desde una perspectiva cultural. Y esto es común que suceda en las llamadas "escuelas competitivas" que buscan conectar a la escuela con las demandas del mundo laboral (Martínez Boom, 2003, p.25).

Al respecto, Ball y Youdell (2007) muestran la manera el mundo empresarial es cada vez más influyente en la educación y concretamente en las escuelas públicas. Sostienen que la responsabilidad y la gestión de resultados son métodos que influyen en la orientación de trabajo en las instituciones educativas públicas y, por tanto, modifican "los valores y las prioridades de las actividades académicas y en las propias aulas” (p. 20). Es así como los maestros dejan de lado sus responsabilidades pedagógicas encaminadas a la formación de sus estudiantes, para ocuparse de asuntos administrativos, como el permanente diligenciamiento de formularios, reuniones de

${ }^{44}$ Competencia: El Ministerio de Educación de Colombia considera el concepto de Competencia bajo una perspectiva laboral, "saber hacer en situaciones concretas que requieren la aplicación creativa, flexible y responsable de conocimientos, habilidades y actitudes" (Colombia. Ministerio de Educación, 12).

${ }^{45}$ En el documento Lengua Castellana. Lineamientos curriculares del Ministerio de Educación de Colombia, se plantea una reflexión sobre la interpretación pedagógica instrumental que tuvo la concepción del lenguaje y la cual se centró en la teoría gramatical y en la lengua como centro de estudio, es decir, morfología, sintaxis y fonética (1998,p. 45). Igual sucedió con las habilidades comunicativas, que también tomaron una orientación instrumental, dejando de lado su aspecto cultural. 
evaluación, elaboración de informes, el control de los programas académicos y el mantenimiento de los registros. Todo esto lleva a desdibujar la razón de ser de la escuela pública. Sostienen los autores que se crea una "cultura del interés personal", ocupada del bienestar interno de la institución y sus miembros, trayendo consigo un olvido de las preocupaciones con respecto a cuestiones sociales y educativas más generales en la sociedad (P. 52). Y precisan que en este marco la educación se vuelve una especie de "mercancía" propiedad de unas personas concretas, que un bien público que beneficia a la sociedad en conjunto. Pasa de ser un derecho que debe garantizar el Estado, a convertirse en un producto de consumo que beneficia al ser individual, quien asume la responsabilidad de su educación y recoge los resultados de su educación (p. 53).

Es así que la escuela tradicional y la escuela competitiva establecen relaciones de tipo vertical. El maestro tiene un gran protagonismo y la educación está asociada a la transmisión de contenidos, la memorización y la repetición. Existe una preocupación por los "resultados" en las pruebas a las que son sometidas los estudiantes y que dan una especie de escalafón para que los identifican ante la sociedad como instituciones de calidad ${ }^{46}$.

Contrario a lo anterior, Valderrama sostiene que la escuela debe ser "un espacio de convergencia de diversos proyectos de formación del sujeto" (2007, p. 170), no solo de preparación para el mundo del trabajo, desligado de otros aspectos importantes como la ética y la política, la formación humana, social y cultural, que le permita a los estudiantes comprender e integrarse en

\footnotetext{
${ }^{46}$ En Colombia las instituciones educativas, tanto públicas como privadas, entraron en la moda de ser evaluados con el objetivo de obtener certificados de calidad bajo parámetros empresariales. Ya es común que los maestros ocupen el tiempo a los asuntos administrativos como llenar formularios, el mismo que antes utilizaban en atender a los estudiantes, preparar clases o evaluar. Al respecto Martín Barbero sostiene que la Escuela se convirtió en un espacio de "administración de saberes" y con ello las están desasocializando y abaratando, por ese afán de estandarizar la calidad y someterla a los sofisticados parámetros propios de la reingeniería de la administración y la competitividad de las empresas (2008, p. 67).
} 
su momento a la sociedad. Orientarse solo por la formación hacia el mundo del trabajo lo lleva a desvincularse de cualquier responsabilidad social, generar una insensibilidad por las injusticias y las inequidades que se manifiestan en la sociedad, con el peligro que se busque solo el beneficio propio, por encima del bien común, como lo indica Tenti (2008), al señalar que el objetivo de la escuela es influir en la formación de las subjetividades de la nuevas generaciones, con el fin que se preparen para integrarse a la sociedad en su conjunto (p. 16) ${ }^{47}$.

Por su parte, la pedagogía crítica defiende la escuela pública y la define como una "esfera pública democrática", caracterizada por ofrecer espacios donde los estudiantes aprenden conocimientos y habilidades ciudadanas que lleven a construir formas de vida comunitaria (Giroux, 2003, p.62), donde aprendan habilidades y conocimientos para vivir en una sociedad democrática viable y luchar por ella; que se comprometa a encarar los problemas que preocupan a los estudiantes en su vida cotidiana, que vinculen las situaciones personales con las sociales en proyectos pedagógicos, de manera que lleve a los estudiantes a convertirse en ciudadanos críticos y activos (p. 221). Este tipo de escuela no se ocupa de manera esencial por los contenidos, sino por la relación que establece el estudiante con su contexto social y su vinculación en propuestas que posibiliten la participación activa en sus comunidades locales.

De acuerdo con estas tipologías, en las instituciones educativas -sobre todo tradicionales y ahora marcadas por enfoques empresariales- los medios de comunicación son concebidos como instrumentos o una actividad muy puntual, que desarrolla un maestro sin un proyecto

\footnotetext{
${ }^{47}$ Ruíz y Chaux también aportan a la distinción de la escuela y establecen dos categorías para definirla: la aperturista y la no aperturista. La primera le apuesta a la formación de ciudadanos autónomos, tolerantes y solidarios, como parte de un proyecto político-pedagógico; la segunda, abandona intencionalmente la responsabilidad civilista de cohesión social que debe asumir toda institución educativa en un sistema democrático. (2005, p. 26).
} 
educativo/comunicativo específico y cuya función esencial es la divulgación de información que produce la institución. Una de las consecuencias que tiene este tipo de enfoques es la poca incidencia que tiene en la cultura escolar ${ }^{48}$.

De otro lado, cuando una institución educativa busca garantizar el derecho a la educación de sus estudiantes, decide entre otros aspectos abrir sus puertas al contexto social para tratar de influirlo y transformarlo. Y para ello requiere unos maestros dispuestos a escuchar las historias que llevan los estudiantes a sus aulas de clase, tratar de relacionarlas con los contenidos de sus cursos y buscar respuestas a esas inquietudes que llevan al aula. En este contexto educativo es posible que los medios de comunicación adquieran mayor relevancia, en la medida que permite la participación activa de los estudiantes, a partir de sus propios temas, con los relatos de los acontecimientos más importantes de la institución y de la comunidad, con sus opiniones y con sus propuestas, de manera que la información sea de interés general. Giroux señala que el "aprendizaje útil" es la valoración que hace el maestro de las experiencias que tienen los estudiantes en su vida cotidiana y que "dan lugar a las distintas 'voces' que ellos emplean para dar significado a sus propios mundos" (2003, p. 170). De esta manera, se convierten en historias significativas que reflejan las experiencias y los sentires propios que viven los estudiantes u otras personas de la comunidad educativa o del contexto social. No hay una preocupación por la promoción de las "competencias" del lenguaje, sino por darle al contenido un valor

\footnotetext{
${ }^{48}$ Huergo señala que la cultura escolar es una manera de organizar racionalmente la vida social. La cultura escolar transforma desde adentro la cotidianidad social, imprimiendo en ella formas de distribución, disciplinamiento y control de prácticas, saberes y representaciones aún más allá de los ámbitos identificados como la 'institución escolar'” (2000, p. 268). Por su parte, Parra (1997) sostiene que la cultura escolar se refiere a las formas de organización social, los valores y las normas que la informan, al manejo y concepto de poder, la participación, las formas de resolver los conflictos, las relaciones entre maestros y alumnos, la disciplina, la naturaleza del conocimiento y la manera de tratarlo. Añade además que la cultura escolar se manifiesta en la vida cotidiana y es en ella y no en los discursos escolares donde se crean normas y valores, formas de ver y vivir la vida (p. 130)
} 
comunicacional significativo que sea de interés general e influya en la comunidad educativa e imprimirle el sello de "escolar" a los medios de comunicación.

Por eso, existe una relación entre una educación problematizadora o crítica, una escuela concebida como esfera pública democrática y unos medios de comunicación en perspectiva comunicacional, "articulada con prácticas y procesos culturales", como propone Huergo, con los cuales se pueden establecer relaciones de reconocimiento. De ahí que sea importante que los contenidos que se comunican en los medios escolares generen reconocimiento, no distanciamiento; generen interés, no aburrición; generen conocimientos nuevos, no repetición de contenidos y de esa manera incida en la cultura escolar.

\subsection{Ciudadanía}

Ciudadanía y Formación Ciudadana. En primera instancia, Chaux y Ruíz destacan que en los Lineamientos curriculares en Constitución Política, establecidos por el Ministerio de Educación de Colombia, se señala la necesidad de formar desde la escuela sujetos autónomos ${ }^{49}$, que tengan capacidad de autodeterminación y consciencia de su dignidad, además orientados hacia el bien común (2005, p. 13). Y esto lleva a clarificar aquellos elementos que identifican al ciudadano y a la ciudadanía, lo cual no se logra solo con la tradicional educación cívica y moral que ofrecen los textos académicos, sino que es necesario relacionarlo con las experiencias de vida. Como indica Cortina (1995) a los niños y jóvenes hay que involucrarlos en el ejercicio de la ciudadanía, porque ello es esencial para lograr la madurez moral del individuo, la participación en la

\footnotetext{
${ }^{49}$ Cullen analiza la autonomía como la capacidad que tenemos los hombres de actuar siguiendo los imperativos del uso de la razón práctica y esta autonomía nos obliga a no tratar al otro como medio, sino como un fín en sí. La autonomía es el valor que le da sentido a la libertad ciudadana (2007, p. 27).
} 
comunidad destruye la inercia y la consideración del bien común alimenta el altruismo (p. 51).Y aquí se hace necesario definir algunos conceptos de ciudadanía. Cortina, propone además un modelo de ciudadanía nacional y universal que tiene como características: la autonomía personal, conciencias de derechos que deben ser respetados, sentimiento de vínculo cívico con los conciudadanos, con quienes comparte proyectos comunes; la participación responsable en el desarrollo de los mismos y agrega que la participación responsable en proyectos debe estar encaminada a la transformación de la "aldea global" (p. 52). Valderrama (2007), por su parte, sostiene que la ciudadanía es una práctica, un ejercicio histórico contextualizado, en contraposición a la idea de que es un estatus que otorga el Estado o la Nación; en oposición de que el ciudadano es un sujeto pasivo, poseedor de unos derechos y un cumplidor acrítico. Cortina concluye: "estamos hablando de sujetos políticos que se encuentran inscritos en sociedades concretas, transitan por comunidades también concretas y viven condiciones socioeconómicas particulares" (2007, p. 186). Por su parte, Cullen señala que la ciudadanía es la suma de las interacciones establecidas entre pertenencia, autonomía, cuidado de sí y la responsabilidad, “es la que constituye el valor de la ciudadanía democrática, porque la convierten en identidad concreta, en libertad plena, en creatividad alternativa $y$, en definitiva, en justicia, simplemente, justicia"(2007, p. 39). Se destaca en esta reflexión que el autor se centra en la justicia y en la solidaridad como algo constitutivo de la ciudadanía, lo cual adquiere mayor relieve en el marco de una sociedad que pregona el individualismo y la indiferencia.

Por su parte, Ruíz propone un concepto de ciudadanía como un "constructo" que integra otro tipo de principios filosóficos: "igualdad, equidad, justicia, inclusión; pero es, asimismo, el resultado de prácticas sociales encaminadas a reducir o a eliminar las condiciones reales de desigualdad. En 
suma, es aquello que, mediante la acción política, enlaza proyecciones y anhelos de sociedad" (Ruíz, 2007, p. 104). Ruíz propone entonces un concepto de ciudadanía que no se da en abstracto, sino que da cuenta de las condiciones de injusticia y desigualdad que se viven en nuestras sociedades. Por eso, trabajar en pro de una sociedad justa y equitativa requiere del compromiso de lo que Ruíz plantea como "ciudadanía activa" que no es otra cosa que ejercer con responsabilidad el rol político, que se concreta en la participación en proyectos colectivos, en los que se hace tangible la idea de construcción o reconstrucción de un orden social justo e incluyente (2007, p. 89-90). Contrario a la idea que se tiene de ser ciudadano "titular de derechos" (Ruíz, 2008), caracterizado por el acatamiento de las normas y las leyes, el ejercicio del derecho al voto, los cuales se constituyen en condiciones formales de la ciudadanía, pero no garantizan su ejercicio (p. 117) y esto es lo que prevalece en nuestras sociedades.

Ruíz insiste en la necesidad de "acatar la ciudadanía" y explica que implica otra serie de cuestiones como tomar consciencia que se hace parte de un "orden social e institucional" que cuenta con una serie de normas de convivencia comunes a todos y ello además "implica una comprensión básica de las costumbres, valores, tradiciones, formas de interacción e intercambio simbólico del lugar que habitamos. Ello a la vez constituye el fundamento de la civilidad" (Ruíz, 2008, p. 117). Y es aquí donde la escuela juega un papel importante en la educación de la ciudadanía que si bien incluye contenidos académicos y orientaciones de civilidad, debe encaminar su accionar en asumir actitudes de justicia, equidad e inclusión, caracterizadas por ser racionales y pacíficas. Como bien afirma Ruíz "una escuela que orienta su proyecto hacia la formación de sujetos políticos, ciudadanos participativos y propositivos, contribuye, en serio, a la construcción de un orden social justo e incluyente” (2008, p. 124). ¿La escuela asume esta labor? 
Tiene el reto y en algunos casos la institución educativa, directivos y maestros entienden la importancia de abrir las puertas de la institución y tratar de acoger las experiencias y conocimientos que se dan en su entorno, para integrarlos a los planes educativos, esto es, “articular las realidades educativas, con contextos sociales más amplios (...) significa conocer, al menos en forma parcial, el contexto político, cultural y económico que constituyen la sociedad y la comunidad en la cual se vive" ( 2008, p. 139), lo cual favorece la dinámica de la escuela desde una perspectiva de esfera pública y democrática que acoge y reflexiona lo que el entorno le proporciona, con el fin de transformarlo.

Resulta necesario aclarar qué se entiende en la escuela por educación ciudadana y por formación ciudadana, ¿será lo mismo? En cuanto la educación ciudadana es Giroux quien indica que "es una forma de producción cultural” (2003, p. 36) y debe fundamentarse en una filosofía pública que ayude a descubrir fuentes de opresión y sufrimiento, y enfrentarlo desde la legitimación de aquellas prácticas sociales orientadas al mejoramiento de la vida humana (2003, p. 63). Complementando esta idea, (Valderrama, 2007, p.189) propone que la educación de ciudadanos requiere el desarrollo de competencias comunicativas ${ }^{50}$, esto es, que los estudiantes puedan expresar sus ideas, opiniones, propuestas, argumentos por diferentes lenguajes comunicacionales: orales, visuales, escritos, electrónicos, digitales.

Formación ciudadana y escuela. Sobre estos temas son varios autores quienes aportan a su discusión. Pérez (1998) destaca que la formación es posible en centros educativos flexibles y

\footnotetext{
${ }^{50}$ Ruíz y Chaux definen las competencias comunicativas como "las habilidades que nos permiten como ciudadanos entablar diálogos constructivos, comunicar nuestros puntos de vista, posiciones, necesidades, intereses e ideas, en general, y comprender aquellas que los demás ciudadanos desean comunicar" (2005, p. 36).
} 
abiertos, porque posibilitan la participación, construir alternativas a problemas individuales y sociales, fomentar iniciativas e integrar propuestas (p. 258) y en esto coincide con Ruíz, Toro, Morante, Monsalve \& Giraldo (2006) quienes entienden la formación ciudadana como un proceso pedagógico soportado en las relaciones de poder y autoridad, las transformaciones de los conflictos, la aceptación del otro, el bien común y lo público (p. 144). Por su parte, Ruíz y Chaux (2005) señalan al respecto que la escuela debe orientarse hacia el interés de reorientar las prácticas educativas de la escuela, hacerlas participativas, incluyentes y pertinentes (p. 71) y Martín Barbero sostiene que una de las razones para que exista la escuela es la formación ciudadana, encaminada a preparar personas que piensen con cabeza propia y que participen de manera activa en la construcción de una sociedad justa y democrática (2008, p.68). Pero son Valerio, López, Ospina \& Alvarado (2006) quienes sostienen que la misma no se puede dar solo en el aula, sino que precisa de experiencias compartidas, intercambio y apoyo entre los estudiantes, y sobre todo, reclaman que la misma debe ser resultado de un proceso colaborativo y se constituye en una reivindicación necesaria en sociedades que privilegian el individualismo (p.111).

Estos planteamientos llevan a la siguiente reflexión: si bien es importante que la escuela ofrezca conocimientos acerca de la Constitución, el funcionamiento del Estado y de las instituciones, es también clave que la institución educativa fomente entre sus estudiantes la participación, con sus ideas, opiniones y propuestas; en el desarrollo de su capacidad de expresión; y motive el acercamiento a las realidades sociales, y desde ellas los comprometan a trabajar por la transformación de sus sociedades, para asumir así su papel de “ciudadanos activos". Cuando el 
estudiante ve que sus ideas, sus reflexiones y sus propuestas son tenidas en cuenta se siente parte de una sociedad y trabaja por ella.

Reguillo (2008) sostiene que los jóvenes están desencantados con la política, debido a que no se sienten escuchados y acogidos con sus propuestas, sobre todo los sectores más marginados, lo que genera una falta de garantía para incorporarse a la sociedad (p. 127) y de desvincularse poco a poco de las asociaciones, las normas de civilidad y ciudadanas, los pactos sociales (p. 135). Por eso se le pide a la escuela no solo incluir contenidos curriculares sobre este tema, sino que posibilite otros escenarios en los que sea posible "la participación en la construcción de una sociedad más justa y equitativa" (Valerio et. al, 2006, p. 73).

Los medios de comunicación en la escuela pueden ser uno de ellos, como proyectos que faciliten la participación y el compromiso de los estudiantes, fuera de los académicos, desde donde se posibilite el análisis de las realidades con el fin de impactarlas y, sobre todo "generar transformaciones importantes en las personas y en los contextos" (Valerio et. al, 2006, p. 88) y a mejorar sus competencias democráticas, participativas y de liderazgo (p. 88). Esto es posible lograrlo en un medio de comunicación, porque la producción de un medio requiere el trabajo en equipo, tomar decisiones en común sobre los temas que van a ser publicados, es un espacio que propicia la crítica y la reflexión, se reconoce la diferencia y la diversidad de ideas, se asume la responsabilidad de brindar información de interés general si se tiene en cuenta que la información es un derecho; hace visible situaciones y busca comprometer a las soluciones de los problemas que denuncia. 
Ruíz et. al (2006) sostienen que para la construcción de una ciudadanía escolar, hay tener en cuenta asuntos relevantes que también se pueden aplicar en los proyectos de los medios de comunicación, por ejemplo: creación de espacios para el ejercicio ciudadano (p. 145), porque en ellos la argumentación y la deliberación son centrales en el proceso; otro es propiciar las condiciones para el análisis del contexto y la comunicación intersubjetiva (p. 145), labor que pueden hacer los estudiantes desde un medio de comunicación en el colegio y, por último, poner en práctica habilidades democráticas, como trabajar en colectivo y comprometerse con la transformación social, necesarias en la producción de un medio de comunicación.

\subsection{Los Caminos de la Comunicación/Educación}

Tres autores ${ }^{51}$ reseñan lo que fue el inicio de la Comunicación/Educación. En 1924 en una escuela rural de los Alpes Marítimos, en un pueblo llamado Bar-sur-Loup, Célestine Freinet introdujo una imprenta Cinup en el aula de clase. Pero no se trató de un asunto "modernizador", sino de poner en marcha el Libro de la vida, que luego evolucionó y se convirtió en periódico escolar, sobre todo, se constituyó en el eje y motor del proceso educativo, más no en una actividad extracurricular (Kaplún, 1998; Huergo \& Fernández, 2000). Esta experiencia rompió con el sistema educativo tradicional. Los chicos se sumergieron con la realidad, hacían entrevistas, observaciones, encuestas, investigaban para producir sus artículos periodísticos. Huergo y Fernández (2000) afirman que esta experiencia permitió tejer la memoria colectiva del grupo que vivía un proceso de construcción de conocimientos (p. 58). Por eso vale la pena conocer en qué se basó Freinet para llevar a cabo esta propuesta.

\footnotetext{
${ }^{51}$ Kaplún (1998) y Huergo y Fernández (2000) son quienes contribuyen a buscar las raíces de la Comunicación/Educación y permiten un acercamiento, dejarse asombrar por la obra Freinet, educador francés, y descubrir con ellos la profundidad de su propuesta que no puede dejarse pasar de largo.
} 
La misma tuvo un fundamento psicológico y pedagógico: la expresión de la vida de los niños ${ }^{52}$, pero no fue algo que se trataba solo de ponerlos a hablar sobre lo que habían visto u oído, el reto fue mayor: debían escribir para ser leídos por sus compañeros, sus maestros, sus padres de familias y otras personas, por ello asumieron la responsabilidad de producir un texto que ameritaba ser publicado en el periódico de la escuela. No se trataba de la tarea, sino de un tema en el que el chico proponía ante sus compañeros y luego publicaban. La esencia de este trabajo estaba, como lo sostenía Freinet en los textos libres, porque no obedecían a los intereses o a los temas impuestos por los adultos, sino a "los verdaderos intereses de los niños" (1977, p. 40) y con los que daban respuestas a las necesidades informativas que solicitaban los corresponsales escolares $^{53}$.

Así se generan los fundamentos de la Comunicación Educativa o Educación Comunicativa de la que habla Kaplún: una educación basada en la experiencia de vida, en los conocimientos producidos y la expresión libre de los estudiantes; una comunicación relacionada con la vida cotidiana, en resaltar la cultura propia de las regiones donde vivían los estudiantes, por tanto, la comunicación no estaba centrada en el medio, sino en la cotidianidad. La imprenta fue la excusa para cimentar esta propuesta educativa. Y una visión de educación ciudadana, basado en que la producción de un medio escolar es el resultado de un trabajo colectivo, en la perspectiva de comunicar contenidos de interés general. Todo esto lleva a confirmar que Freinet fue uno de los pioneros de la relación Comunicación/Educación/Ciudadanía.

\footnotetext{
${ }^{52}$ Como se ve esta idea está en consonancia con lo que propone la pedagogía crítica, en el sentido de llevar a la escuela la experiencia de vida de los estudiantes.

${ }^{53}$ Freinet compartió esta experiencia con otros profesores de Francia, de países europeos y de África, por eso creó una red y los niños intercambiaban sus periódicos con otros niños de diferentes instituciones educativas y se generó lo que llamaron los corresponsales escolares, quienes debían compartir entre sí sus periódicos que contenían información de sus vidas y las regiones de donde vivían, para conocer más sobre ellas.
} 
A pesar de ser una experiencia tan significativa que tuvo un impacto grande en Francia ${ }^{54}$, algunos países de la región y otros del mundo, incluso de América Latina, la visión instrumentalista de la comunicación fue y es la que predomina en la escuela ${ }^{55}$. Martín Barbero (1996-1997) sostiene que el problema es cómo insertar la escuela en un ecosistema comunicativo, cuando se quedó centrada en el libro y la experiencia educativa en él, mientras que está rodeada de un entorno informacional $\mathrm{y}$ un espacio educacional difuso $\mathrm{y}$ descentrado que ofrece los medios de comunicación; por eso propone que la escuela deje de ver los medios como instrumentos de ilustración o difusión y los incorpore como "tecnologías intelectuales" (Levy, 1993, citado en Martín Barbero, 1996-1997), como estrategias de conocimiento. Kaplún (1998) también insiste en que el diálogo entre educación y comunicación en lugar de ser fructífero y fluido, se ha quedado en asuntos instrumentales, en medios como vehículos "multiplicadores y distribuidores de contenidos" (p. 201). Por eso, se hace necesario buscar los nexos de esa relación Comunicación/Educación.

Siguiendo con Kaplún (2010) sostiene que de acuerdo con la comunicación que se práctica le corresponde un tipo de educación y viceversa. Así, a una educación interesada en los contenidos y en moldear comportamientos, corresponde una comunicación- monólogo, de locutores a oyentes; pero si la aspiración desde la educación es formar sujetos autónomos, críticos y creativos, ciudadanos que participen de la comunicación-diálogo, se potenciarán interlocutores

\footnotetext{
${ }^{54}$ La propuesta de Freinet llegó a ser considerada una metodología pedagógica válida y fue aplicada en instituciones educativas públicas.

${ }^{55}$ La definición de Huergo y Fernández indica que la escuela "denota una parcela del espacio social. El espacio social presenta parcelas que son las instituciones, una de ellas es la institución escuela, la cual es un producto histórico definido, por un mandato social fundante, que se expresa en el currículum prescripto. Este actúa como organizador de la actividad de la institución educativa y redefine los contratos encadenados pedagógicos-didácticos en cada aula, en la relación docente-alumno" (2000, p. 141).
} 
(p. 59). Y en este marco, Kaplún señala algo que debe ser tenido en cuenta en los medios de comunicación en la escuela, si los estudiantes asumen el rol de "emisores", como resultado de la "apropiación del conocimiento" que debe ser comunicado a otros, "su proceso de aprendizaje se ve favorecido e incrementado por la realización de productos comunicables y efectivamente comunicados" (2010, p. 61).

En la búsqueda de una definición más concreta sobre Comunicación/Educación ${ }^{56}$ Huergo trazó a lo largo de los últimos diez años una reflexión situada en Latinoamérica. Llama la atención el autor que esta relación, por tradición se reduce a lo instrumental, "separándolo de los procesos culturales y políticos que le sirven de contexto y lo atraviesan" (Huergo 2010, p. 66). Para designar esta relación, a lo largo de los años se establecieron múltiples denominaciones que para juicio del autor alude más a la potencialización de los conceptos, "que a la densidad y espesor de un campo ${ }^{57}$ que crece al ritmo de la complejidad, la conflictividad y la persistencia de las crisis orgánicas en nuestras sociedades" (Huergo, 2010, p. 66). Sostiene que este tipo de relación no debe ignorar las relaciones tensas ${ }^{58}$ y conflictivas que se puedan emerger de la misma. Indica que esta relación lleva a un reduccionismo que tiene que ver con el "uso de los medios en educación", enmarcado en un modelo informacional que busca incrementar la información en una linealidad

\footnotetext{
${ }^{56}$ Los propósitos de establecer esa relación Comunicación/Educación obedece a varios aspectos: 1. Recuperación de procesos: vinculación/expresión/liberación; 2. Reconocimiento de contextos históricos, socioculturales y políticos. 3. La construcción de un espacio teórico transdisciplinario, movido por un espacio común de relaciones tensas, que lleve a devolver el carácter éticopolítico de la relación Comunicación/Educación (Huergo, 2001, p. 28)

${ }^{57}$ En otro de sus trabajos, Huergo plantea ya la configuración del campo Comunicación/Educación, que alude a un proceso histórico/social, en el que la configuración del "objeto" es multifacético, complejo y problemático. Toma a a Bourdieu para afirmar que un campo es una estructura de relaciones objetivas, que posee propiedades específicas y en el que se ponen en juego un capital que se vuelve simbólico en la medida que es reconocido. Añade: "un campo es un ámbito de lucha; el capital social está distribuido inequitativamente entre los miembros de un campo... el campo se define defiendo aquello que está en juego (como lo puesto en escena y como objeto de lucha)" (Huergo, 2004, p. 47).

${ }^{58} \mathrm{Al}$ respecto Morabes (2006) acierta en indicar que a la comunicación hay que dejar de verla en perspectiva de lo transparente, ajeno al conflicto y a lo evidente. Afirma Morabes que en términos marxistas clásicos, "estamos convirtiendo la comunicación en un fetiche" (p. 72).
} 
de transmisión. Se utiliza el instrumento para transmitir determinados contenidos, con lo que se reemplaza la autoridad del maestro y del libro de texto (Huergo, 2004, p. 169).

Ante este panorama, la propuesta es establecer esta relación Comunicación/Educación desde una mirada cultural, como lo apunta Morabes (2006), posibilita ensanchar los horizontes de los problemas sociales que de manera tradicional se estudian desde la Comunicación/Educación, y lleva, a "considerar la producción de conocimientos a partir de las prácticas sociales de los sujetos" (Morabes, 2006, p. 68). Desde la perspectiva cultural, Huergo (2001) empieza a referir que la relación Comunicación/Educación obedece a procesos y prácticas que se dan en contextos de interrelación entre cultura y política. "En este sentido sería posible sostener que el objeto de este campo es la articulación entre formación de sujetos (objeto de la educación) y producción de sentidos (objeto de la comunicación)" (2001, p. 28). De esta manera se empieza a establecer una distancia a las miradas instrumentales hasta el momento expuestas, para adentrarse en los enfoques culturales, en los que hay que tener en cuenta la vida cotidiana y las "prácticas sociales" de los sujetos, en este caso, los estudiantes.

En esta perspectiva de Huergo se empieza a visualizar un campo de la Comunicación/Educación en la que se pueden enmarcar los proyectos de los medios de comunicación en la escuela y, a la vez, visualizar si desde ese campo los mismos se pueden constituir en espacios propicios para la formación de ciudadanos. Así, la experiencia de los medios de comunicación en la escuela no se reduce a la producción de unos contenidos "académicos" con fines evaluativos, sino que permita la conexión con la realidad que viven sus estudiantes, lugar de expresión de sus experiencias y espacio de comunicación democrática. 
En definitiva, esta investigación asume la definición que hace Huergo sobre Comunicación/Educación:

Significa un territorio común, tejido por un estar en ese lugar con otros, configurados por memorias, por luchas, por proyectos. Significan el reconocimiento del otro en la trama del 'nosotros'. Significa un encuentro y reconstrucción permanente de sentidos, de núcleos arquetípicos, de utopías, transidos por un magma que llamamos cultura. En este sentido, Comunicación y Educación deben ser comprendidas en las coordenadas de la cultura, entendida como espacio de hegemonía. Cultura a la vez como proceso (inseguro) y como estancia (segura) (...) Las palabras Comunicación y educación expresan un deseo y a la vez un interés (en el sentido de racionalidad), plasmado en una voluntad: una voluntad de transformación (2001, p. 35).

Asumir esta definición de Comunicación/Educación conlleva a pensar la experiencia de los medios de comunicación desde una perspectiva más amplia que trascienda a la tradicional y aún más experimentada que la visión instrumental. Es asumir un reto en la medida que se complejiza la relación desde la mirada cultural, la cual se construye en la vida cotidiana, en las biografías de las personas, en las luchas por el reconocimiento en una sociedad, en la valoración del otro como único y diferente; además por el reto de la apropiación de la palabra, para expresar ese mundo, relatar esas vidas, expresar esas luchas que se viven tanto al interior de la institución educativa, como en su contexto social y cultural. Desde el punto de vista de esta definición de Comunicación/Educación, el reto que tienen los medios de comunicación producidos en la escuela es propiciar la "transformación" no solo de unos estudiantes y maestros vinculados con el proyecto, sino de la comunidad educativa que se vea interpelada por lo que se publica en ellos. 


\subsection{Comunicación y Ciudadanía: la Apropiación de la Palabra para Expresarse}

Las instituciones educativas tienen una posibilidad de desarrollar proyectos de medios de comunicación, -ejes del proceso educativo- como el llevado a cabo por Freinet, que combina varios conceptos: educación, comunicación y ciudadanía. Y ello es posible siempre y cuando rompan con esas miradas instrumentales y de transmisión de contenidos en la que se enmarcan este tipo de proyectos. En este aparte, se tratará de establecer una relación más concreta entre comunicación y ciudadanía.

Para iniciar es importante tener en cuenta que a partir de la idea de Martín Barbero, desde las mediaciones, de convertir al receptor pasivo en productor de significados, requiere un elemento esencial, que tal vez está en las fronteras de esta discusión y es la palabra. Palabra como materia prima, como invención de la humanidad que posee una carga cultural, poseedora de significados que dan nombre e identidad a lo que rodea e inventa el hombre. Pero al igual, y aquí está la paradoja, gracias a otro de los inventos y desarrollos acelerados de los mismos, los medios de comunicación, las palabras pierden su sentido y se vuelven "triviales": "las palabras han perdido su peso, las palabras no significan" (Schmucler, 1997, p. 197). Es un reto que debe asumir la comunicación en perspectiva de producir memoria, lo cual se logra a partir de hacerse responsable de la palabra, y de esta manera asumir la memoria como acto ético (Schmucler, 1997). Esto le da otra identidad y otra razón de ser a la comunicación y a los medios escolares, porque dimensionan aún más la importancia que pueden adquirir al asumirse como "memoria colectiva del grupo" (Kaplún, 1998, p. 205) y por consiguiente en la historia de la institución educativa y del contextos social construida por los propios estudiantes y maestros. 
En este caso, un medio de comunicación en la escuela se construye desde la palabra. Y ello se logra si se tiene en cuenta a Freire cuando dice que "existir, humanamente, es pronunciar el mundo, es transformarlo. El mundo pronunciado, a su vez, retorna problematizado a los sujetos pronunciantes, exigiendo de ellos un nuevo pronunciamiento (1985, p. 100). Y en este sentido, la palabra tiene un peso mayor, una responsabilidad mayúscula, porque se hace colectiva y se comparte con los otros: compañeros, maestros, padres de familia, vecinos y cercanos de la institución educativa. Una responsabilidad que implica cambio: "Decir la palabra, referida al mundo que se ha de transformar, implica un encuentro de los hombres para transformarlo" (Freire, 1992, p. 101). Ahí está la responsabilidad social de la comunicación y, en especial los medios en la escuela: poner en la "mente colectiva" de una comunidad una información, para tomar decisiones, para actuar, en este sentido, deben ofrecer información de interés general.

McLaren, por su parte, reta a la escuela, no solo a escuchar al estudiante, sino a motivarlo a contar su historia, esto es, recuperar su memoria personal y para ello necesita de la palabra para relatarla. El resultado de esto es la construcción de un nuevo sujeto histórico, crítico, propositivo, un "intelectual transformador" 59 , que se hace consciente de su realidad personal y de la de su contexto social y cultural. Es por eso que debe abrirse la comunicación desde una dinámica diferente, como un motivador para que los niños y jóvenes relaten sus vidas y asuman la responsabilidad de narrar las historias de los otros.

\footnotetext{
${ }^{59}$ Este es un concepto expuesto por Giroux que retoma McLaren, para referirse a los jóvenes como sujetos móviles, sensibles a los cambiantes contextos contemporáneos (...) El intelectual transformador se halla involucrado en el acto de lucha cultural en la que se conciben nuevas formas de identidad y nuevas formaciones subjetivas" (Giroux citado en McLaren, 1994).
} 
En esta línea, Giroux plantea el asunto desde la cultura, como algo que los estudiantes construyen y se apropian, para ejercer como agentes comprometidos en la tarea de la reconstrucción social y política. Esto implica hablar con sus propias voces, recobrar sus propias experiencias y producir "textos" en los que se reflejen los aspectos sociales y políticos que son importantes en sus vidas (Giroux, 2008, p. 286). Es una idea muy relacionada al concepto de "productores de significados", a decir algo "interesante" e importante para todos en la medida que es producto de la propia experiencia de vida. Información que adquiere otro sentido y valor para todos, porque también aporta análisis, reflexión y "otro conocimiento" que puede interesar a la comunidad educativa en general.

Sobre todo, los jóvenes reclaman espacios para ser escuchados y para expresar sus ideas, sus conocimientos, sus preguntas, sus inquietudes, sus diversas maneras de ver y vivir la vida, sus deseos de integrarse a la sociedad a partir de la diferencia. Bacher (2009) sostiene que existe un desafío social y es promover escenarios en los que los jóvenes descubran el poder de la palabra. "Que la perciban como herramienta para la transformación del tiempo en el que viven y que comprendan que ejercer el derecho a la comunicación es una oportunidad para establecer vías de participación ciudadana, de reflexión y creatividad" (p. 117). Y la escuela puede ser ese escenario en el que la palabra recobre el sentido y el valor, donde circulen los pensamientos propios, los relatos del mundo social y cultural, las propuestas de construir una sociedad más justa y equitativa. En este sentido, los jóvenes tienen la palabra. 


\subsection{El valor de la comunicación y otras maneras de ejercer la ciudadanía}

Valderrama (2010) establece una reflexión de la comunicación y la ciudadanía, en un entorno educativo. Insiste en que si la escuela concibe solo la comunicación como transmisión de información y reduce los medios a herramientas para el logro de las eficiencia y la eficacia pedagógica (p. 282) y si a esto le sumamos la idea tradicional de la ciudadanía, enmarcada en derechos y deberes que alude al cumplimiento de la norma, no encaja en una sociedad que cambia e impone un reordenamiento de la cultura política, otras maneras de ejercer la ciudadanía y de valorar el lugar que ocupa la información y comunicación en la construcción del tejido social, se hace necesario entonces generar otras reflexiones.

Valderrama ofrece las claves para establecer una relación entre comunicación y ciudadanía: el diálogo, la narración, la hermenéutica y la dimensión tecnológica y mediática. Toma al primero como concepto inicial, expone, desde varios autores (Cortina, Touraine, Freire) que es uno de los ejes fundamentales para el ejercicio ciudadano y de convivencia en una sociedad democrática (2010, p. 284). Acoge de Freire la idea de que el diálogo es un encuentro solidario de reflexión y acción de los sujetos que pronuncian el mundo para transformarlo (p. 285).Y la escuela tiene la tarea de preparar a sus estudiantes como ciudadanos críticos, para hacer frente a una sociedad fragmentada y multicultural, dominada por el mercado y con el reto de superar las injusticias y desigualdades sociales que en ella se presentan.

En cuanto a la narración, Valderrama sostiene que no basta con las "representaciones agonísticas de las representaciones hegemónicas de la construcción de nación y ciudadanía” (2010, p. 286), 
sino que lo que tiene verdadero valor representativo es narrar historias en las que lo que cuente sea el propio relato,

... no existe identidad sin narración ya que ésta no es solo expresiva, sino constitutiva de lo que somos (...) muchas de las posibilidades de ser reconocidos, tenidos en cuenta, contar en las decisiones que nos afectan, dependen de la veracidad y legitimidad de los relatos en que contamos la tensión entre lo que somos y lo que queremos ser" (Martín Barbero, 2001, citado en Valderrama, 2010).

De ahí la importancia, en el caso de la escuela y sus medios de comunicación de contar esas historias propias de la institución educativa y del contexto cultural que la rodea, para hacerlas visibles y reconocidas por los integrantes de la misma y los pobladores de las comunidades locales.

Valderrama propone algo que se pone a consideración de los medios de comunicación en la escuela escolar y es considerar a los nuevos y viejos medios de comunicación, como actores políticos, configuradores de nuevos espacios de lo público y generadores de horizontes de sentido ético-político (p. 287). La escuela puede asumir los medios (como espacios de encuentro y diálogo) en un contexto educativo, como espacios políticos que hagan visible a los actores, situaciones, problemas que se presentan en la institución educativa y en su contexto social. Al respecto Valderrama sostiene: "se pueden transformar en condiciones y ambientes comunicativos de la actuación pública y del ejercicio político, de la visibilización de actores, temas, y procesos relativamente contra hegemónicos, o sea, en la dimensión verdaderamente comunicativa de la esfera pública" (2010, p. 287). Al respecto, la institución educativa y los medios de comunicación escolar tienen una oportunidad de convertirse en espacios de formación ciudadana. 
Para concluir, dos aspectos importantes que propone Valderrama: uno, que la formación del ciudadano comunicativo y tecnológico, en la institución educativa, no basta con la incorporación instrumental de la tecnología y las múltiples posibilidades que ofrece; es necesario contar con una educación política ${ }^{60}$ que potencie en los ciudadanos (en este caso estudiantes) las múltiples posibilidades que ofrece la tecnología para expresar lo que ven en su mundo, en su contexto social y cultural. Y dos: reconocer la relación que se establece, tanto individual como colectiva con el contexto en el cual se mueven los actores (2010, p. 301), en este caso, estudiantes, maestros, padres de familia. Así, en la medida que las tecnologías permiten viajar por otros espacios más amplios y universales (globales), la realidad cotidiana lleva a reconocer el barrio, los vecindarios, la ciudad que se habita, que es próxima con sus problemas, sus servicios, sus tensiones y frente a los cuales se puede generar procesos de participación. Se requiere de ciudadanos con capacidad de análisis y de presentación de propuestas para intervenir en las situaciones que afectan a una comunidad, en esta medida puede llegar a reconocerse como ciudadano que pertenece a una sociedad específica, de la cual es responsable, como individuo y como integrante de un colectivo.

\subsection{Buscando una definición de los medios de comunicación escolar}

No existe una definición sobre los medios de comunicación escolar. Solo Ander-Edd (1997) se refiere específicamente al "periódico escolar" en dos sentidos: como recurso didáctico y como medio de comunicación. Sobre el primero de ellos indica que se da cuando se prepara y confecciona el periódico en los que ejercitan la redacción, el dibujo y la ilustración; sobre el

\footnotetext{
${ }^{60}$ Lo cual debería ser una intencionalidad explícita en este tipo de proyectos, así como sucede con el desarrollo de competencias comunicativas y competencias del lenguaje.
} 
segundo, le otorga otra dimensión a la comunicación entre alumnos que permite vincular a la escuela y la familia, desarrollar capacidad de cooperación y trabajo en equipo, con todo lo que ello implica la comunicación interpersonal y grupal (p. 134-135). Por su parte, para Freinet (1977), la imprenta fue una excusa para impulsar su propuesta pedagógica y el periódico escolar fue el reflejo de la vida y las ideas de sus estudiantes que compartían con otros lectores y se constituyó en el centro del proceso educativo.

La escuela ahora produce medios de comunicación bajo las miradas instrumentalistas y de transmisión de contenidos que se originan al interior de las instituciones educativas. En otros casos son experiencias que simulan actividades periodísticas, como presentar notas o entrevistas a ciertos personajes, lo que Aparici (2006) denomina como "técnicas del rol playing", como un modelo educomunicador que existe en la actualidad y que no deja de ser un juego de reproducción de modelos estandarizados de representación (p. 29) de los modelos de divulgación de mensajes que imponen los medios de comunicación de masas.

Bajo esta perspectiva instrumental, los medios de comunicación en la escuela son dispositivos que se producen en las instituciones educativas, con el propósito de divulgar y transmitir información sobre los eventos o acontecimientos que se consideran de más importancia para la institución, para que la comunidad educativa esté enterada de lo que sucede en ella. En este tipo de experiencias si bien se generan, en algunos casos concretos, aprendizajes en la responsabilidad y en la labor de informar, la incidencia en la comunidad educativa en general es poca.

Se hace necesario proponer una definición que oriente esta investigación sobre los medios de comunicación en la escuela, en la perspectiva de adquirir la categoría de "escolares". La primera 
consideración a tener en cuenta es la comunicación, no centrada en el medio, en el canal, en el instrumento, sino la comunicación como espacio de intercambio, diálogo, transformación, común-unión. $\mathrm{Y}$ en ese sentido, comunicación que propicia unos actores con palabra, con capacidad de pronunciar el mundo, de relatar o si se prefiere narrar la cotidianidad y las propias experiencias de vida; y esos actores son productores de significados y sentidos, no meros reproductores de datos; productores de mensajes significativos que tienen en cuenta la experiencia de vida y que reflejan el contexto cultural en que se desenvuelven. No se trata solo de contar algo, sino de contar algo con sentido y significado para el otro que necesita conocer, comprender y actuar frente a lo que plantea ese relato ${ }^{61}$; es generar la posibilidad de estar juntos.

Y para lograr ello, para que los mensajes sean significativos y generen esa sensación de no estar solos, es importante rescatar algo esencial: la palabra. La que permite la expresión libre, relatar la experiencia de vida, narrar el mundo propio y el de los demás. Una de las tareas que deben asumir proyectos de los medios de comunicación escolar es devolver el sentido y el peso que tienen las palabras. Sin la palabra no es posible producir los mensajes significativos y para ello hay que asumirla en clave de cultura, más que de regla y norma. La primera imprime compromiso, la segunda competencia.

La atención de la comunicación se centra en el medio como canal, que trae como resultado la instrumentalización. El medio es el dispositivo tecnológico que sirve de contenedor de información y de transmisión de contenidos, lugar por donde pasan los datos. El medio posibilita

\footnotetext{
${ }^{61}$ Nakache sostiene que la producción de los medios en la escuela tiene como objetivo explícito traspasar sus fronteras y señala que la práctica de producción es un tránsito entre distintas culturas: mediática, escolar y cotidiana, donde cada una interpela a la otra (s.f, p. 19).
} 
el surgimiento de otros lenguajes además del escrito (que ayudó a propagar gracias a la imprenta): el visual, el oral, el hipertextual. Gracias a los medios circulan por el mundo millones de mensajes, a través de cualquier tipo de dispositivos. En este sentido, la escuela puede cambiar la idea de sus medios de comunicación y considerarlos más que una herramienta un espacio de construcción colaborativa y cooperativa, un espacio por donde circulan los contenidos significantes y desde los cuales se genera y promueve una cultura comunicacional que se irradia en toda la comunidad educativa. Se trata de ofrecer "otros" contenidos que llamen la atención y, ante todo, interpelen a las personas, ofrezcan elementos para la discusión y el diálogo, generen reflexión y compromiso.

Desde esta perspectiva, un medio en la escuela debe ser un espacio por el que circulen significados y sentidos; un punto de encuentro de ideas, reflexiones, experiencias de vida, que comparten a estudiantes, maestros, directivos, padres de familia y, porque no, habitantes de las comunidades locales. Es una esfera pública moderna, donde sea posible el debate y la discusión, el reconocimiento y respeto por la diferencia, el respeto y el reconocimiento del otro como diferente, por tanto, un espacio de convivencia. Es un Producto Social, porque es un espacio construido de manera colectiva, con los temas y las experiencias de vida que se guardan en la memoria compartida por los productores de significados y sentidos, los estudiantes y maestros.

También es educación, en la medida que permite llevar a la escuela, la experiencia de vida, la cotidianidad cultural para relatarla en estos espacios. No es el conocimiento académico repetido, sino el conocimiento construido en la vida cotidiana, en las relaciones con el entorno social, en los aprendizajes de la familia. Expresar ese mundo propio de los estudiantes en los medios 
escolares, es posibilitar lo que Freire (1985) señaló: pronunciar el mundo para comprenderlo y transformarlo. En esa medida hay que enriquecer la escuela, tal como lo propuso Giroux, como una esfera pública democrática que acoja el mundo que lleva el estudiante a la escuela y que tenga espacio para ser expresado y ser escuchado. La idea es cambiar un tanto la operación: pasar de ser un medio para la escuela, a ser un medio con la escuela, esto, es, un espacio en el que también se educa en la expresión, en la palabra, en la discusión, en la diferencia, en la propuesta, en la reflexión, en las tensiones, en el compromiso por construir una sociedad más justa y equitativa.

Y bajo esta perspectiva, también es un espacio propicio para la formación ciudadana, en la medida que se asume la responsabilidad de informar, en este caso, producir mensajes significativos y de interés general; donde se hace visible la diferencia; en el que circulan las ideas y pensamientos resultados de la "expresión libre"; un espacio para el reconocimiento social, el análisis de las situaciones internas y externas de la institución educativa. Además, en la medida que se vean reflejada sus propias voces en los medios escolares se pueden generar procesos de identidad y aceptación de la palabra, como elemento esencial para la participación en la construcción de una sociedad justa y equitativa.

Bajo las perspectivas teóricas planteadas en este documento, una propuesta de definición de medios de comunicación escolar que promueva la formación ciudadana, sería: un espacio de comunicación y educación que se construye de manera colectiva en una comunidad educativa, en el que se posibilita la circulación de significados y sentidos, se fomenta la expresión libre de ideas a partir de la experiencia de vida de estudiantes, maestros, padres de familia y habitantes de 
las comunidades locales circundantes y los conocimientos propios adquiridos en un contexto cultural específico del que hace parte la institución educativa, con el fin de promover la apropiación de la palabra, para generar procesos de participación, reflexión y creatividad. Y desde esta definición generar otra perspectiva que le dé un valor más significativo y relevante al trabajo que se hace con los medios de comunicación escolar en la escuela. 


\section{La construcción metodológica}

El acercamiento a unas experiencias concretas de producción de medios de comunicación en instituciones educativas requería comprender las particularidades de cada una de ellas, dada por los enfoques filosóficos, la manera de entender la educación, los valores que proclama, los modelos pedagógicos o educativos que orientan su labor educativa y la manera de relacionarse al interior (maestros, directivos, estudiantes y padres de familia), como con el exterior (el contexto social, las entidades educativas). Ahora, para entender las dinámicas de producción de sus medios de comunicación en estos contextos fue necesario plantear una metodología acorde a los planteos teóricos expuestos y desde los cuales era necesario construir los diferentes instrumentos con los que se recopilaría la información.

Sostienen Orozco y González (2012, p. 29) que tomar decisiones acertadas sobre la metodología a utilizar permite acercarse a unas realidades, en este caso instituciones educativas, y recopilar los datos necesarios para el análisis adecuado del objeto de estudio. Por eso, esta investigación valoró el conocimiento y las ideas propias de los actores (maestros y estudiantes) acerca de unas experiencias de producción de medios de comunicación en instituciones educativas; ello hizo necesario hacer observaciones de las experiencias, aplicar entrevistas abiertas, grupos focales y además dialogar con materiales como periódicos y programas de televisión, por todo esto en conjunto se decidió abordar el objeto desde una metodología cualitativa, pero de igual manera, se aplicaron encuestas a los destinatarios de los productos -estudiantes y maestros-, con el propósito de tener una lectura más completa del asunto a estudiar. 
La decisión de asumir un enfoque cualitativo obedece a que permite captar la realidad social como lo sostienen Toro y Parra, con dominio de la cualitativa social a través de las personas que son estudiadas (2010, p. 75). Las técnicas e instrumentos permitieron acercarse a los maestros y estudiantes para obtener de ellos sus conocimientos, reflexiones e ideas logrados en las experiencias de producir medios de comunicación en sus instituciones educativas. Como indican Toro y Parra, de esta manera se buscó conceptuar sobre la realidad social con base en el comportamiento, los conocimientos, las actividades y los valores que guían las acciones de los sujetos (2010, p. 75). También se estableció un diálogo con los medios de comunicación producidos, utilizando técnicas de análisis de contenido de manera semántica, en este caso los periódicos y programas de televisión para hacer emerger las ideas, los enfoques y las intencionalidades que subyacen en los contenidos que se publican en ellos.

Por su parte, se acudió a las encuestas con estudiantes y maestros al final del proceso de recopilación de información en el segundo semestre de 2012, para acercarse a las percepciones y la incidencia que tienen los contenidos finales en los destinatarios de los mismos, en este caso estudiantes y maestros.

Durante el proceso de trabajo de campo, los datos recopilados fueron sometidos a los conceptos expuestos en el marco teórico construido para esta investigación, porque como indica Bourdieu, las propuestas metodológicas requieren de una estructura teórica que la sustente y le permita hacer una interpretación adecuada del objeto de estudio, (2008, p. 16). La teoría era necesaria para reflexionar sobre lo que emergía, además para construir los instrumentos de recopilación de información: protocolos de observación, protocolos de entrevistas y grupos focales, y matrices de 
análisis de los materiales. Así, los elementos conceptuales estuvieron presentes a lo largo de la investigación con el fin de garantizar la rigurosidad y la fuerza a la verificación experimental.

\subsection{La selección de las instituciones educativas}

Una vez se tuvo construido el marco teórico, establecidos los objetivos y definida la metodología se procedió a seleccionar las instituciones educativas que tuvieran proyectos de medios de comunicación en ellas. En primera instancia, se tomó la decisión que la misma fuera en Medellín, por los antecedentes que existen en la ciudad de producir medios de comunicación en los colegios apoyados por proyectos como Prensa Escuela, Escuela Electrónica y Educar mientras se informa, liderados en diferentes momentos por los periódicos de la ciudad (El Colombiano, El Tiempo y El Mundo). Además, son numerosas las instituciones educativas que cuentan con medios de comunicación y en este sentido existe un saber acumulado, pero de igual manera era necesario someter a un análisis crítico a este tipo de proyectos, para conocer en dónde enmarcaban este tipo de experiencias desde la Comunicación y la Educación, además de los alcances y las incidencias de las mismas en las comunidades educativas.

Para realizar el trabajo de campo (observación, entrevistas a profundidad, grupos focales), se eligió una institución educativa pública y una privada, con el fin de contar con referentes diferentes de manera que permitieran lograr una lectura desde diversas perspectivas. Durante los meses de mayo y junio de 2012 se realizó un trabajo de sondeo en instituciones educativas públicas y privadas que tuvieran proyectos de medios de comunicación y así seleccionar los colegios en donde se haría el trabajo de campo, aplicar los instrumentos y técnicas, lo cual se 
llevó a cabo en el segundo semestre de 2012, entre julio y noviembre. (Anexo 1. Selección instituciones educativas).

Con base en la información recopilada y el análisis se escogió al PM (siglas de la institución), colegio privado. La institución tenía hasta el momento del trabajo de campo (2012) dos medios de comunicación: un magazine televisivo que se emitía mensual y el periódico que circula cuatro veces al año. Son proyectos consolidados: el periódico tiene más de 12 años (al finalizar el proceso llegaron al número 60) y un programa de tv que funciona desde el 2007 que en el mes de noviembre de 2012 llegó a su emisión 100. En ellos participaban 25 estudiantes. La coordinación de estos medios se hacía desde la oficina de Comunicaciones, caracterizada por la producción audiovisual. En ese momento era coordinado por una profesional de Comunicación Audiovisual. Se reunían los miércoles y los viernes entre 3:00 p.m. y 5:00 p.m. lo que posibilitó hacer una observación permanente.

El colegio privado está ubicado en un sector al suroccidente de Medellín, caracterizado por estar conformado por familias de una clase social media-alta. La institución está rodeada de unidades residenciales en un sector tradicional y prestigioso de la ciudad, cuenta con excelentes vías de acceso y tiene todos los servicios públicos cubiertos. El colegio tenía 1500 estudiantes desde Preescolar hasta el grado $11^{\circ}$, el número total de profesores era de 70 . En cuanto al modelo pedagógico si bien no está definido, lo reconocen como uno propio basado en valores. La formación que ofrecen es académica y la institución tiene carácter confesional.

Por su parte, el colegio público seleccionado fue el J.V.A. En esta institución el proyecto de medios escolares viene desde 2007 y se caracterizaba por explorar el trabajo con diferentes 
medios: wiki, blog, periódico mural, emisora, noticiero, periódico y en el momento de la investigación trabajaban con Facebook. En un principio la experiencia de los medios se construyó con las historias de barrio que publicaban en un blog; luego se enfocó en el cubrimiento de eventos institucionales: torneos, celebraciones patrias y entrevistas a diferentes personajes del colegio: directivos, maestros, estudiantes, vigilantes y personal del servicio de aseo. El proyecto de medios era liderado en su momento por una profesora de Lenguaje, que luego pasó a ser Coordinadora de Disciplina de la institución y era una convencida de las posibilidades formativas que tiene los medios escolares. La institución educativa está ubicada en un barrio del Centro oriente de la ciudad y sus habitantes son de clase social baja. El barrio está ubicado en una zona que en las últimas décadas recibió población desplazada y se asienta en sectores periféricos. Los problemas que viven sus habitantes van desde el desempleo, hasta la carencia de servicios básicos como el agua y el alcantarillado. La institución cuenta con 2000 estudiantes desde Preescolar hasta el grado $11^{\circ}$ y 67 profesores para toda la población estudiantil. Por su parte, el modelo

pedagógico definido es el Cognitivo Social, con un enfoque constructivista; en cuanto a la metodología de trabajo se fundamenta la modalidad de proyectos y en la pregunta problematizadora.

\subsection{Aplicación de técnicas}

Ahora, el acercamiento a los procesos de producción de medios de comunicación en instituciones educativas con este tipo de características y en unos contextos sociales como los descritos requerían de metodologías cualitativas como la etnografía, para comprender las situaciones sociales que se estudian (Woods, 1987, p. 65). Para ello, la etnografía aporta una serie de técnicas 
que llevan al investigador a diferentes procesos de inmersión, con el fin de hacer lectura de esas realidades que investiga, a partir del andamiaje teórico que haya logrado construir.

Entre las técnicas utilizadas estuvieron: Observación participante. Señala Guber que la "participación" está en la experiencia que vive el investigador, con la intención de "estar adentro" de la sociedad estudiada y ello compromete al investigador a estar alerta, "incluso aunque participe, lo hace con el fin de observar y registrar los distintos momentos y eventos de la vida social" (2001, p. 57). Sostiene la autora que este tipo de técnica tiene dos aspectos: una participación sistemática y controlada de lo que sucede en torno al investigador y participar en una o varias actividades de la población, en este caso concreto en las reuniones "extraclase" que tenían la maestra o la comunicadora con sus estudiantes, en los horarios programados, donde planeaba, discutían, establecían responsabilidades, delegaban funciones y evaluaban los trabajos que serían publicados.

Por su parte, Reynaga Obregón apunta a que el investigador, en la observación participante, "se ubica en el lugar de los sujetos investigados" y los estudia desde la observación de sus relaciones sociales, en lo que llama estado natural (1999, p. 131). Y comparte que la observación participante le permite al investigador "compartir códigos de comunicación, socialización y prácticas de la vida diaria de los sujetos involucrados en el problema o acontecimiento a observar" (1999, p.132).

Fue así como se participó en 12 reuniones en el colegio público, entre los meses de julio y octubre. Esta técnica permitió comprender cómo era la dinámica de producir un medio de comunicación en una institución educativa pública, las dificultades de índole administrativo, la 
falta de recursos tecnológicos y de tiempo para la maestra encargada, la inestabilidad y la falta de compromiso de los estudiantes (falta de empoderamiento de la experiencia). A partir de esta técnica surgieron las preguntas que fueron aplicadas en las entrevistas y los grupos focales, con la maestra y con el grupo de estudiantes.

Por su parte, en el colegio privado se participó en 18 sesiones, dos reuniones semanales: una los miércoles con los estudiantes más experimentados y los viernes con los que iniciaban el proceso, este último con más participantes. (Anexo 2. Protocolos de observación). A diferencia de la anterior, este fue un trabajo más constante, por la estabilidad del proyecto. La misma contaba con el apoyo y los recursos de parte de las directivas y los padres de familia. Dado el orden y la constancia del proyecto se pudo observar la producción de varias grabaciones, sobre todo los llamados "ines" o presentaciones que hicieron los estudiantes y las que fueron objeto de análisis. Al igual que la anterior experiencia, los asuntos observados dieron pie para establecer preguntas que fueron aplicadas en las entrevistas y grupos focales, en los que participaron los estudiantes y la comunicadora responsable del proyecto.

Otra de las técnicas aplicadas fue la entrevista abierta. En este caso se acogió la definición de entrevista que comparte Alonso (1998, p. 225) como un proceso comunicativo del cual el investigador extrae información de una persona (informante), la cual ha sido "experimentada y absorbida" (Alonso, 1998, p. 226). En este caso, interesaba acercarse a los conocimientos y pensamientos adquiridos por los maestros y estudiantes sobre la experiencia de producir un medio de comunicación. Se asume esta técnica, porque desde ella los sujetos reflexionan sobre sus acciones "y reconstruyen el sistema de representaciones sociales en sus prácticas 
individuales". Señala además que la "entrevista abierta no se sitúa en el campo puro de la conducta -el orden del hacer -, ni en el lugar puro de lo lingüístico -el orden del decir- sino en un campo intermedio en el que se encuentra su pleno rendimiento metodológico: algo así como el decir del hacer, basado fundamentalmente en que el hecho del hablar con los interlocutores de lo que hacen y lo que son (lo que creen ser y hacer) es el primer paso de toda etnografía (Catani, 1990, citado en Alonso, 1998)”.

Las entrevistas permitieron conocer el sentir y el pensar de la maestra, la comunicadora y los estudiantes acerca de su participación en la producción de un medio de comunicación en una institución educativa. Se programaron entrevistas semiestructuradas (Anexo 3, protocolo entrevistas semiestructuradas), para tener un acercamiento a las experiencias, de manera que se facilitará el relato de cómo se produce un medio de comunicación. En total fueron cinco: una con la comunicadora y una con estudiantes del colegio privado; y dos con la maestra y una con dos egresados del colegio público, dado que ellos hicieron parte de una experiencia significativa entre los años 2009 y 2010. Luego se aplicó una entrevista en profundidad (Anexo 4, protocolo entrevista en profundidad) para trabajar los conceptos que tenían acerca de la comunicación, la educación, la ciudadanía, los medios de comunicación, que permitieran comprender las ideas que tenían la maestra y la comunicadora sobre los mismos, que de alguna manera se refleja en el trabajo que hacen en los medios de comunicación.

Por su parte, se recurrió a los grupos focales o grupos de discusión, entendidos como espacios de “opinión grupal”, donde los participantes ejercen el derecho al habla y es regulada por el intercambio grupal. En él se establece una discusión entre sujetos opinantes, bajo un dominio de 
responsabilidad y poder del hablante, mientras exista el grupo. Las opiniones que surgen de esta discusión serán el material para el análisis (Canales y Peinado, 1998, p. 293).

Los grupos focales se llevaron a cabo con los estudiantes de cada institución educativa (Anexo 5, protocolo grupos focales). En los mismos se abordaron los temas propuestos a los maestros en las entrevistas en profundidad y otros que surgieron en el desarrollo de la técnica y permitieron comprender las ideas que tienen los estudiantes sobre la comunicación, la educación, la ciudadanía y los medios de comunicación, además del rol que tienen en la producción de los mismos.

También se consideró necesario acercarse a otros materiales: los periódicos y programas de televisión, de manera concreta informes de texto y televisivos. Es así como para el análisis de las páginas seleccionadas se siguió la propuesta de Galeano (2004, p. 132) que se centra más en lo semántico que en lo sintáctico, lo que permitió dialogar con los textos producidos y publicados por directivos, maestros y estudiantes. Por su parte, el acercamiento a los contenidos de los programas de televisión se tomó como base los análisis textuales de audiovisuales propuestos por Vilches (2011), quien indica que un programa de televisión es un texto audiovisual, desde el que se permitió hacer una lectura también del orden semiótico, a los productos estudiados: entrevistas e informes que pasan por el canal interno de televisión del colegio privado o por el Facebook del colegio público.

Y por último, con el fin de conocer la percepción que tenían las comunidades educativas sobre los medios de comunicación de sus colegios, se aplicaron una encuesta a los estudiantes (Anexo 6, diseño cuestionario estudiantes) y otra a los maestros (Anexo 7, diseño cuestionario maestros), 
como destinatarios de los contenidos. En total se aplicaron 383 encuestas a estudiantes (195 en el colegio privado y 188 en el colegio público) que estuvieran entre los grados $5^{\circ}$ y $11^{\circ}$. Por su parte, la encuesta de los profesores fue respondida por 29 de diferentes áreas de saber. La aplicación de las encuestas permitió confrontar la información obtenida en las observaciones, entrevistas y grupos de discusión, en otros espacios y con otros actores, con el fin de obtener datos estadísticos. El análisis estadístico contribuye a hacer posible la construcción de relaciones nuevas (Bourdieu, 2008, p. 33), aunque en este caso la lectura fue de índole descriptiva.

El carácter de esta investigación es explicativo, porque el interés de este tipo de estudio está centrado "en explicar por qué ocurre un fenómeno y en qué condiciones se da éste" (Toro y Parra, 2010, p. 248). En el caso concreto de esta investigación pretende explicar por qué las experiencias de los medios de comunicación todavía reproducen esquemas instrumentales (privilegian los medios) y de transmisión de información, influenciadas por modelos tradicionales de educación y divulgativos en comunicación; y con base en lo anterior, trazar una perspectiva diferente sobre las condiciones requeridas en las instituciones educativas para transformar estos proyectos en espacios de construcción colectiva, en los que sea posible otro tipo de comunicación a la luz de las mediaciones.

\subsection{Categorías}

Una vez recopilada la información se procedió a analizar cada una de las observaciones, entrevistas y grupos focales para identificar los temas centrales que emergen de ellos. Luego de este primer análisis se procedió a identificar a su vez los conceptos más frecuentes y se agruparon 
de tal forma que permitieran entrar en discusión con los materiales obtenidos. Después de este ejercicio se determinaron las siguientes categorías.

\begin{tabular}{|c|c|}
\hline Categoría & Subcategoría \\
\hline Discursos & $\begin{array}{l}\text { Textos/contextos } \\
\text { Libre/censura } \\
\text { Narratividad } \\
\text { Relatos: escrito, oral, visual, hipertextual } \\
\text { Producción de sentidos }\end{array}$ \\
\hline Comunicación/Educación & $\begin{array}{l}\text { Comunicación/cultura } \\
\text { Divulgativa/institucional } \\
\text { Transmisionista/Instrumental } \\
\text { Recepción/obligatoriedad } \\
\text { Producción de sentidos } \\
\text { Multidimensionalidad } \\
\text { Educación tradicional/educación crítica } \\
\text { Educación desde libros/educación } \\
\text { desde experiencia }\end{array}$ \\
\hline Información & $\begin{array}{l}\text { Palabra/memoria } \\
\text { Circulación datos } \\
\text { Circulación experiencia vida } \\
\text { Derecho } \\
\text { Poder } \\
\text { Institucionalidad/contexto } \\
\text { Aceptar/rechazar }\end{array}$ \\
\hline Micro medios & $\begin{array}{l}\text { Estables internos } \\
\text { Estables vinculados con el contexto social } \\
\text { Exploratorios estable } \\
\text { Exploratorio inestable } \\
\text { Permanencia o vigencia }\end{array}$ \\
\hline Currículo & $\begin{array}{l}\text { Dentro/afuera } \\
\text { Comunicación en la escuela } \\
\text { Transversalidad }\end{array}$ \\
\hline Ciudadanía & $\begin{array}{l}\text { Participación } \\
\text { Activa/Pasiva } \\
\text { Comunicación como derecho } \\
\text { Palabra y política } \\
\text { Libertad de expresión }\end{array}$ \\
\hline
\end{tabular}

Cuadro 1. Categorías y subcategorías. Elaboración del autor. 


\section{Rutas trazadas para el análisis y obtención de los resultados}

Una vez adelantado el trabajo de campo y definida las categorías se procedió a desarrollar el análisis de los datos y la información recabada con los diferentes instrumentos. Es importante anotar que este análisis fue una ruta trazada que tuvo en cuenta los objetivos y las preguntas planteadas para esta investigación y para el mismo se definieron una serie de etapas y fases, como se describe a continuación.

Etapa 1. Contextualización. Descripción de las instituciones educativas y la historia de los medios de comunicación que se producen en ellos. Se incluyen características, contextos, historia y enfoque metodológico.

Etapa 2. Fase Emisión. Producción de Contenidos. Con base en la información obtenida en las observaciones, entrevistas y grupos focales se identifican las características propias de la producción de un medio de comunicación en una institución educativa, también el papel de los actores, los intereses y las tensiones que se presentan. Está relacionada con el objetivo "indagar cómo y desde quiénes la escuela construye los procesos de producción de los medios de comunicación, que hacen circular informaciones y contenidos a estudiantes, maestros, directivos, padres de familia y comunidad aledaña a la IE.".

Etapa 3. Fase Emisión. Los conceptos. Se trabaja con base en las ideas o conceptos claves de este estudio, que tienen los maestros y estudiantes integrantes de los equipos de trabajo de medios de comunicación en los colegios. La etapa corresponde al objetivo "examinar los modelos y 
conceptos de comunicación (medios de comunicación escolares), educación, información y ciudadanía que tienen los maestros y estudiantes que participan en los proyectos de medios de comunicación escolar".

Etapa 4. Fase de Mensajes. Análisis de contenido. En esta se entra a analizar los materiales producidos por maestros y estudiantes, basado en los periódicos y programas de televisión, corresponde al objetivo "revelar las tendencias y las intencionalidades de los temas publicados en los medios escolares en las instituciones y comunidades educativas desde el análisis de los contenidos de las publicaciones impresas y audiovisuales".

Etapa 5. Fase Recepción. Recepción de contenidos. En ella se trabaja con los resultados de las encuestas aplicadas a los maestros y estudiantes, destinatarios de los contenidos publicados en los medios de comunicación de las instituciones educativas. El objetivo para esta etapa es “comprender la importancia que le otorga la comunidad educativa (estudiantes, maestros, directivos y padres de familia) a los medios de comunicación escolar que se producen en las instituciones educativas, teniendo en cuenta la pertinencia y la relevancia de los informes que se publican en ellos".

Etapa 6. Fase conclusiones. Conclusiones. En la misma se aporta la reflexión sobre los diferentes hallazgos encontrados en las etapas previas, como conclusiones del estudio y se procede a argumentar las razones de por qué es necesario que los proyectos de medios de comunicación en las instituciones educativas deben ser abordados por perspectivas comunicacionales y educativas diferentes a las divulgativas y tradicionales. Se propone hacer una lectura de las mismas desde las Mediaciones y desde la relación Comunicación/Cultura. El 
objetivo de esta etapa es "reflexionar las experiencias de los medios de comunicación escolar desde las mediaciones que propone la producción de significados y la relación entre escuela y contexto social, como alternativa frente a los proyectos actuales que privilegian el enfoque divulgativo/instrumental y la transmisión de información en la escuela”.

Teniendo como base la anterior ruta se procede a compartir el desarrollo analítico de esta tesis. 


\subsection{Etapa 1. Fase previa. Contextualización.}

Dos instituciones educativas permitieron acercarse a sus experiencias de producción de medios de comunicación, en el segundo semestre de 2012. El colegio privado llevaba hasta ese entonces 12 años ininterrumpidos de emisión de un programa de televisión que se pasaba por un circuito cerrado de televisión y un periódico publicado cada dos meses. Cuenta con una sala de edición de videos, que a lo largo de los años ha sido mejorada, al igual que los equipos de grabación que son actualizados gracias al apoyo de los padres de familia y de las directivas del colegio. Ese año emitieron el programa de televisión 100 y publicaron el número 60 del periódico. $D$, la comunicadora del colegio, coordina estos proyectos y contaba con un practicante de comunicación audiovisual que apoya este tipo de proyectos. Ella tiene a su cargo la Extracurricular de televisión, un espacio extraclase al que asistían 25 estudiantes en total, dos días diferentes: miércoles y viernes. La institución educativa está ubicada al suroccidente de la ciudad de Medellín, en un sector de clase social media-alta, y acogía en su momento a 1500 estudiantes desde el Preescolar, hasta el último año de bachillerato. La institución fue inaugurada en el año de 1994 y es de carácter confesional, su propuesta pedagógica está basada en los valores y en la familia. El entorno del colegio lo conforman unidades residenciales, un barrio tradicional y también colindan con un barrio de clase baja, en el que se presentan diversas problemáticas sociales.

Al otro extremo, en el centro oriente de la ciudad, se yergue una mole de cemento entre un bosque. Ahí se construyó en el 2007 uno de los llamados Colegios de Calidad que hacía parte del programa de gobierno del alcalde Medellín, Sergio Fajardo. Las casas que rodean la institución educativa están construidas sobre la montaña, una a una se levantaron sin ninguna norma de 
planeación, con problemas de abastecimiento de agua potable, carencia de servicios de alcantarillado y de energía eléctrica. Una vía estrecha, pavimentada y empinada es la que permite la comunicación de los habitantes de este sector con el centro de la ciudad. La mayoría de ellos fueron desplazados de sus regiones de origen, ya fuera del Departamento ${ }^{62}$ de Antioquia o de otros aledaños. La mayoría de sus habitantes son desempleados o subempleados, vendedores ambulantes o empleadas de servicio doméstico. En este colegio existe una convencida del trabajo que se puede lograr con los medios de comunicación, es la profesora Isb, licenciada en Educación y profesora de Lengua Castellana, con algunos semestres de Periodismo en la Universidad de Antioquia.

Desde el 2007 la profesora Isb comenzó a “experimentar” con diferentes medios en la institución: una wiki, un blog, una emisora escolar, unas carteleras, un periódico, un noticiero de televisión y, por último, una red social: Facebook. La profesora Isb tiene que sortear los escasos recursos que tiene la institución para sacar adelante el Semillero de Periodismo. En el momento de la investigación tenía ocho estudiantes, con participación intermitente. Además de los problemas económicos, lo cual impide la impresión de periódicos (solo publicaron tres en seis años), también tiene limitantes con la tecnología, a pesar de ser un colegio de "Calidad", la "Internet llega cansada", como dice la profesora. Esto impedía que, por ejemplo, la comunidad educativa no hubiera visto la wiki en la que publicaron varios informes periodísticos sobre historias de barrio. A pesar de esto, durante un "periodo de gloria" lograron publicar un blog que contenía información del colegio (eventos culturales, deportivos, personajes) y del barrio: sus personajes,

\footnotetext{
${ }^{62}$ En Colombia, los Departamentos corresponden a la división territorial, administrativa y cultural en que se divide el país, es lo correspondiente a las Provincias en Argentina.
} 
problemáticas sociales, entre otros. Hasta el año 2012 ejecutaban un proyecto de microentrevistas de cinco minutos, con personajes de la institución: estudiantes destacados, el personero, profesores y la rectora que fueron emitidas por el Facebook del colegio.

Estas dos experiencias, una permanente y apoyada por la institución, y la otra llena de dificultades, en un contexto social complejo, abrieron sus puertas y permitieron desde las observaciones y las entrevistas comprender los procesos de producción de medios de comunicación al interior de la escuela. Cada experiencia es diferente y tiene su propia identidad; ellas aportaron la esencia para este análisis. 


\subsection{Etapa 2.Fase Emisión. Producción de contenidos}

El interés de la tesis está centrado en analizar el proceso de producción de los medios, aunque también se entraron a dialogar con los productos y contenidos, como parte importante de esta investigación, para tener una visión más completa del asunto. Por ello se utilizó como técnica investigativa la Observación participante en las sesiones de trabajo a donde asistían estudiantes y maestros. También se hizo un acercamiento a las reflexiones de los maestros y estudiantes en su calidad de "emisores", con entrevistas y grupos focales.

La aplicación de métodos cualitativos - la observación participante- tiene como intención comprender los procesos de producción de esos medios escolares y problematizarlos a partir de lo que emergía en cada sesión de trabajo. Por su parte, con las entrevistas semiestructuradas y en profundidad, más los grupos focales, fue posible acercarse a los conocimientos, las reflexiones, opiniones y comentarios que los estudiantes y maestros adquirieron en el transcurso de estas experiencias.

La conjugación de la teoría (expuesta en el marco teórico) y el acercamiento metodológico llevan, por un lado, a generar categorías "éticas", porque se crean y se fundamentan desde las teorías trabajadas; pero a su vez adquieren otra significación desde las representaciones y comentarios que hacen los actores implicados, en este caso estudiantes y maestros, que llevan a adquirir una dimensión "émica" (Angrosino, 2012, p. 99-100).

En este caso, el análisis de la producción de contenidos se focaliza en las sesiones de trabajo observados y en las entrevistas y grupos focales utilizados. Ello permite dar cuenta de la 
complejidad y la riqueza que hay detrás de este tipo de experiencias, en el que se mezclan factores como la filosofía institucional, los enfoques pedagógicos, las concepciones de la comunicación, los intereses y los compromisos de los estudiantes con los proyectos, como también el papel asumido por los profesores en este tipo de experiencias. Por eso, sus aportes tienen un especial valor en este análisis.

\section{La difícil tarea de producir un "discurso"}

Basados en las dos experiencias de medios escolares observados, se procedió a dar cuenta del primer objetivo: "indagar cómo y desde quiénes la escuela construye los procesos de producción de los medios de comunicación, que hacen circular informaciones y contenidos a estudiantes, maestros, directivos, padres de familia y comunidad aledaña a la IE.”.

Detrás de la publicación de un periódico, una entrevista que se divulga en el Facebook institucional, la emisión de un programa de televisión (magazine) existe un complejo proceso de producción de un discurso, que parte de quién y cómo proponen los temas, pasan luego por la recopilación de la información necesaria (investigación), análisis de los mismos, escritura, hasta llegar a su publicación. Los procesos son diferentes en cada institución y arrojan resultados particulares, no necesariamente complementarios. Para realizar este análisis se establecieron seis categorías: Discurso, Micro-medios, Comunicación/Educación, Información, Ciudadanía y Currículo.

La primera categoría a analizar es el "Discurso" y los temas emergen en los materiales (observaciones, entrevistas y grupos focales) son los siguientes: 


\subsubsection{Discurso}

\begin{tabular}{|l|l|}
\hline \multicolumn{1}{|c|}{ Categoría } & \multicolumn{1}{c|}{ Temas claves } \\
\hline Discurso & - Los maestros (adultos) son quienes proponen las ideas, autorizan los \\
& contenidos y los producen. \\
& - Los estudiantes esperan que los maestros les den los temas que deben \\
& ser trabajados, reproducen algunos de los contenidos elaborados por los \\
& maestros y los producen bajo perspectivas institucionales. \\
& - Los estudiantes hacen circular las historias del barrio en los medios de \\
& comunicación del colegio. \\
& - Los estudiantes no publican sus informes en los medios de \\
& comunicación del colegio. \\
\hline
\end{tabular}

Cuadro 2.Categoría Discurso. Elaborada por el autor a partir del análisis de las entrevistas y grupos focales

\subsubsection{Generación de ideas}

En las dos instituciones educativas los procesos de producción de los contenidos son diferentes, aunque en ambas participen estudiantes y algunos maestros. De ahí que vale la pena preguntar: ¿cómo es la participación de cada uno de ellos en este proceso de producción? y ¿cuáles son las dinámicas grupales que marcan la producción de los medios escolares en estas instituciones? Este análisis parte de la generación de las ideas, porque señala cuáles son los temas que se consideran importantes para la comunidad educativa y, sobre todo, quién los propone y por qué.

\section{Colegio 1 (privado)}

\section{Las temáticas salen de las actividades del colegio}

Observación 9 (septiembre 5, 2012). ${ }^{63}$ La comunicadora $D$ se reunió con cinco estudiantes en la oficina de televisión del colegio, para definir el tema de una campaña que publicarían en el periódico y en el $M g z$ de la institución. La comunicadora se sienta en una silla gris y los chicos lo ${ }^{63}$ Las observaciones seleccionadas en este aparte, entre las 30 aplicadas en las instituciones públicas y privadas, obedecen a los
aportes específicos relacionados con las categorías analizadas. 
hacen en el piso. Ella les dice: "vamos a seleccionar un tema relacionado con la soledad que viven los niños y los jóvenes", y los puso a escoger entre el perdón y el acompañamiento de los padres. Los chicos eligieron el segundo. ¿De dónde parte esta inquietud de la comunicadora? Ella dice: "estos temas surgieron por una conversación que tuve con el sicólogo del colegio y me habló de los casos de soledad que se están viviendo entre los estudiantes (...) vamos a hacer una campaña en el próximo Mgz y en el periódico dirigido a los padres de familia para que presten atención a los hijos". (Observación 9, septiembre 5, 2012).

En este caso la idea de la campaña surge de la comunicadora, preocupada por una situación que viven los estudiantes y detectada por el psicólogo de la institución; en este sentido, ella como adulta, quiere hacer visible una situación para "llamar la atención de los padres de familia", es decir, el contenido de la campaña propuesta está dirigida a los padres de familia (adultos), no a los estudiantes. Si bien la comunicadora construyó el contenido de la campaña con los estudiantes, ellos se limitaron a aceptar la propuesta, porque en ningún momento cuestionaron la idea llevada por $D$.

Las reuniones de la Extracurricular ${ }^{64}$ era el espacio utilizado para realizar este tipo de trabajo. Sin embargo, surgen varias preguntas: Si no son los estudiantes que participan de la extracurricular ¿quién propone los temas que se publican en los medios del colegio?; si no son los estudiantes ¿quién escribe los textos que se publican en el periódico o los de las "presentaciones" que graban los estudiantes? En las observaciones hechas (18 en total) los estudiantes no tomaron la iniciativa

${ }^{64}$ En el Manual de Convivencia del Colegio privado se define la Extracurricular como "una serie de actividades recreativas, deportivas y culturales, como complemento a la formación académica de los alumnos, contribuyendo a la formación integral del alumno y a la utilización adecuada del tiempo libre”. (Capítulo XI, Normas Generales, p. 102). 
de proponer temas y tampoco la comunicadora motivó a los chicos a plantearlos. La comunicadora, en el caso de las campañas, dice que yo solo hablé del tema y ellos propusieron el resto (Entrevista, noviembre 21 de 2012) ${ }^{65}$. Con lo cual ratifica que la idea de la campaña la propuso ella, basada en los comentarios de otros profesionales (psicólogo en este caso).

Fuera de lo anterior y frente a la pregunta de dónde salen los temas que se publican tanto en el periódico como en el Mgz - que son la mayoría- la comunicadora señala que la base de ello es lo que sucede en el colegio, porque proporciona demasiada información en muchísimos aspectos (entrevista, agosto 17 de 2012), es decir, el colegio es la propia fuente de información, donde se destacan aspectos administrativos y los eventos institucionales ya sean culturales, deportivos o espirituales. Esa es la base de los temas que serán publicados.

Por eso, vale la pena preguntarse: si en la Extracurricular con los estudiantes no se proponen los temas, entonces ¿quién y en dónde se hace este ejercicio? Dice la comunicadora: El Comité de Comunicaciones está conformado por docentes de la institución, con ellos me reúno (...) y con ellos es que yo hablo las temáticas a tratar (...) la profesora de español (se encarga) de la parte de literatura y del Mgz de la nota formativa; la parte de literatura ella lo hace con sus estudiantes, los dos mejores artículos ella me los presenta (entrevista, agosto 17 de 2012).

Los temas surgen en un espacio conformado por los docentes y ellos son quienes direccionan los temas: "hablo de las temáticas a tratar" y la producción de los textos es el resultado de trabajos propios del aula de clase y de actividades académicas que se hacen con este propósito, de manera

\footnotetext{
${ }^{65}$ Los fragmentos de las entrevistas utilizadas en este aparte, están relacionados con las diferentes categorías sometidas al análisis.
} 
que la otra maestra pueda seleccionar "los dos mejores". Es la dinámica en la que los estudiantes escriben para el maestro, buscando un reconocimiento, una recompensa académica y el premio: ser publicado. Con este tipo de prácticas no se forma a los estudiantes en la proposición de sus ideas y temas, menos en la expresión de las mismas, generando actitudes pasivas y poco críticas.

Así, el Comité de Comunicación tiene como funciones proponer los temas que se publican en los medios de comunicación del colegio y también avalar las propuestas presentadas por los estudiantes. Al respecto la comunicadora dice que ella lleva las ideas y el Comité mira y analiza las cosas; ellos no lo sesgan, ni dicen cosas. ¿Qué hacen ellos? Están abiertos y también contribuyen con ideas (Entrevista noviembre 21 de 2012). Los temas que se publican en los medios del colegio son propuestos por los profesores -los adultos-quienes además tienen el poder de decidir lo qué se publica. El Comité es el órgano consultivo, decisivo y por qué no controlador de las temáticas.

Los estudiantes aceptan esto. Al plantearles la pregunta ¿quién propone los temas? Ellos dicen: "un comité" y señalan que el Comité está integrado por las directivas, coordinadores, rector, administración y la comunicadora (Entrevista estudiantes, septiembre 21 de 2012).Una de las estudiantes $\mathrm{Mar}^{66}$ - del curso $10^{\circ}$ y con más tiempo de permanencia en el proyecto, señala que la comunicadora nos propone a partir del tema, ideas para desarrollarla. Por su parte, Man -quien llevaba ocho años en esta experiencia-dice: la mayoría de las temáticas del Mgz salen de las actividades que se realizan en el colegio, es como una agenda, como algo que se hizo en el mes, se toman los eventos más grandes y las otras temáticas si son decisión del colegio (Entrevista

${ }^{66}$ Se utilizan las iniciales de los nombres de los estudiantes, tanto de la I.E. pública, como privado, como reserva de sus identidades. 
estudiantes, septiembre 21 de 2012), con lo que se ratifica lo expuesto por la comunicadora con anterioridad.

En el caso concreto del Colegio 1 se corrobora aún la idea de que son los adultos quienes deciden las temáticas que se publican en sus medios de comunicación, como una expresión de una educación tradicional, caracterizada entre otros aspectos, por la imposición de los contenidos, práctica propia de una "educación bancaria" (Freire, 1985), cuyo propósito es llenar de contenidos a los estudiantes. Los aportes ofrecidos por la comunicadora y por los estudiantes dan pie para indicar que en la generación de ideas (propuestas de los temas) predomina la mirada de los adultos y un interés por destacar aquello que desde su punto de vista es significativo: los trabajos de clase y la divulgación de los eventos institucionales. La construcción de una agenda a partir de los estudiantes es aún una tarea pendiente; es evidente la ausencia de ellos en estos espacios. De igual forma, los estudiantes tampoco asumen una actitud de liderazgo para hacer de estos medios espacios en los que se reflejen sus intereses y sus "necesidades informativas", entendidas como aquello que comunique sus experiencias de vida.

\section{Colegio 2 (público)}

\section{"La maestra nos da los temas"}

Observación 1. (Julio 16 de 2012). En la primera reunión la profesora $I s b^{67}$ les dice que deben "desatrazarse" (sic) de los trabajos pendientes: los videos que divulgan cada 15 días y los

${ }^{67}$ Como en el caso de los estudiantes también se reserva la identidad de los maestros que sirvieron de informantes para este trabajo. 
periódicos que publicarán en Facebook. El proyecto más firme que tienen para ese año son las entrevistas de cinco minutos ("P con...") con algún personaje de la institución, ya sea un estudiante, un maestro, el celador, el personero o la rectora. Para esa semana tenían un trabajo pendiente: el cubrimiento del Día de la Independencia. Los responsables eran $A l$, en la mañana y Yn en la tarde. La indicación que les dio la profesora fue la siguiente: ¿Qué deben entregar? Imágenes del evento y un texto, que debe ser más racional que emotivo. Por último les dijo que llevaran puesto el chaleco de periodistas.

Esas fueron las únicas indicaciones de la profesora Isb acerca del tema, institucional por demás. Llama la atención es el término periodístico que utiliza "cubrimiento", pero no señala en qué deben enfocar el trabajo, el propósito que tiene y menos una posible fecha de entrega. Por su parte, los estudiantes tampoco preguntan qué puede ser importante destacar, si se debe entrevistar a alguien en particular, si el texto es corto o largo, qué tipo de imágenes pueden ser interesantes; solo acatan la indicación que les da la profesora. En esa misma reunión, se pregunta a los estudiantes quién propone los temas. Al, un estudiante de tez morena, responde: la profe propone los temas y nosotros aceptamos. En este caso sucede algo similar que en el otro colegio: es el profesor quien lleva los temas y los estudiantes se limitan a aceptarlos. Y es así, porque ellos, las pocas veces que asisten, no tienen una actitud propositiva y menos aún un deseo de empoderarse del medio de comunicación, cayendo en un facilismo y en un conformismo. El interés por hacer de estos medios un espacio construido con las ideas de los estudiantes para la comunidad educativa no existe. 


\section{La otra cara: la experiencia de los estudiantes}

El Colegio 2 vivió un momento de “esplendor" entre los años 2009-2010, porque un grupo de estudiantes asumieron el medio escolar, hecho que se recuerda por sus aciertos y errores. En ese momento ¿Cuáles eran los temas que proponían los estudiantes? La profesora Isb dice: Ah, el barrio. Ese es el tema preferido de los muchachos y cubrir eventos (...) en los temas del barrio se ha utilizado mucho las cosas que aquejan a la gente en general (...) la ausencia del agua, las dificultades sanitarias por falta de alcantarillado, el poco avance del barrio en comparación con la ciudad, (...) se ha visto un poco el historial (del barrio), la junta de acción comunal (...) también se ha hablado de situaciones peligrosas como el transporte del gas o el gas en lugares que no son como seguros (Entrevista noviembre 7 de 2012).

En ese caso, los estudiantes hablaron desde sus vivencias en el barrio, por eso, la profesora señala que era "el tema preferido". Los estudiantes asumieron esa labor de "lectura de su contexto", dado que viven en un barrio marginal donde faltan servicios básicos como el agua, el alcantarillado y eso los afecta a ellos ${ }^{68}$ y a sus familias, de ahí que el blog que tenían servía de espacio para publicar lo que sucedía en su comunidad local.

Por eso es importante que se conociera la "historia" del barrio en colegio, basado en las voces y la memoria de los propios habitantes, porque la institución educativa permitía narrar los orígenes y las luchas de los habitantes por abrirse un espacio en una ciudad, en su medio de comunicación,

\footnotetext{
${ }^{68}$ La portería del colegio está al lado de un gran tanque de agua que cubre alguna parte del sector de este derecho, pero los barrios que están ubicados en la parte superior del colegio no reciben el servicio, es por eso que se observa a niños, jóvenes y adultos llevando diferentes recipientes para surtirse del agua que necesitan. Parte de esa deficiencia la cubren con un tanque comunitario, manejado por un fontanero local, sin embargo, tampoco logra cubrir a todos los habitantes. La solución definitiva por parte de las autoridades municipales aún no llega.
} 
convirtiéndose en un relato propio que circula en la comunidad educativa. Estos temas surgían en las reuniones que hacían cada semana y permitían "conectar" a la institución educativa con lo que sucedía en la cotidianidad del barrio, dice la maestra Isb: Ahí llegan todos los comentarios de los estudiantes, allí llegan las cosas que pasan en el barrio, porque llega lo que pasa un fin de semana y uno no sabe (maestro), ellos si tienen conocimiento de causa, puede ser un método de reflexión cómo están las cosas y cómo mejorarlas... (Entrevista, marzo 26 de 2012). Un aspecto a resaltar tiene que ver con el reconocimiento que hace la maestra de los saberes de los estudiantes desde su experiencia: "ellos sí tienen conocimiento de causa", además porque posibilita un ejercicio de reflexión - un método como dice ella- diferente en las instituciones educativas para hacer consciente la propia realidad con el propósito de mejorar esos contextos sociales o en términos de Freire, para transformarlas.

Un egresado de la institución, quien hizo parte del proyecto en ese momento histórico de la experiencia, relata cómo realizaban ese ejercicio: nosotros como habitantes del barrio a diario estábamos pasando y recorriendo las calles (...), nos reuníamos ocho días antes y decíamos: bueno qué noticias podemos sacar y decíamos en el barrio está pasando esto, en el barrio pasando aquello, escribamos acerca de esto; en el colegio esto y aquello, entonces escribíamos acerca de esto. (Entrevista, septiembre 3 de 2012). Estos chicos llevaban "el recorrido cotidiano del barrio" al colegio, lo hicieron visible como tema para ser publicado y, por tanto, para que circulara en la comunidad educativa. El barrio fue el centro para la generación de ideas y para la información. Ellos leían "el texto" social y lo escribían para la comunidad educativa. En este sentido, la producción de contenidos del medio de comunicación cambia cuándo son los estudiantes quienes toman la iniciativa y proponen los temas para ser publicados, basado en su 
“cultura experiencial”, diferente a lo que sucede cuándo es el maestro quien toma esta iniciativa, basados en la información que surge en la institución educativa o en la lógica de los trabajos de clase, para ser calificados.

En el siguiente relato, Ed, comparte la forma cómo elegían los temas: eran opiniones muy divididas, porque era un grupo muy competitivo, entonces donde hay un grupo competitivo todos tienen ideas, y para que una idea fluya entre todos tiene que ser muy buena. (Entrevista, septiembre 3 de 2012). En primera instancia, existía diversidad de ideas y entre ellos una sana competencia y un convencimiento de que entre todos tenían que seleccionar las ideas mejor sustentadas, el resultado era la elección colectiva de los temas que se publicaron.

Continúa el relato de Ed: yo era de las personas que decía que eso no era para publicar cualquier cosa, tenían que ser cosas interesantes y que valiera la pena (Entrevista, septiembre 3 de 2012). En este aspecto, el egresado lleva a plantear la siguiente pregunta: ¿qué temas pueden ser de interés para una comunidad educativa? Las respuestas pueden ser diversas, sin embargo con el comentario de este joven se marca un criterio valioso: "no publicar cualquier cosa". Y en este patrón caben aquellos trabajos que se hacen para el profesor, los pasatiempos que no faltan y la información de eventos que ya perdieron vigencia, porque sucedieron meses atrás; se trata de generar otros contenidos que propicien deliberación y discusión alrededor de un tema.

Volviendo al relato de $E d$, la dinámica que tenían los estudiantes para proponer temas era la siguiente, dice Ed: todos llegábamos con un tema, de hecho varios temas y los proponíamos: muchachos está pasando esto en el colegio (...) está pasando esto en el barrio, tengo esta y esta noticia: ¿cuál de todas vamos a escoger? Y decíamos ese tema está bueno, ese tema no 
(Entrevista, septiembre 3 de 2012). Primer asunto a resaltar: los estudiantes "llegaban" con un tema, no eran los del maestro; segundo, eran varios temas, lo que daba la posibilidad de seleccionar y tercero, la decisión de publicar o no publicar era "colectiva" entre los estudiantes, esto brinda una visión diferente, porque el enfoque está centrado en los intereses y los puntos de vista de los estudiantes, no del profesor.

Las opiniones expuestas por el egresado demuestran que la experiencia de los medios de comunicación en un colegio es diferente cuando son los estudiantes quienes se preocupan por comunicar los temas que sean de interés para los compañeros y para los maestros. El foco de su trabajo está en el barrio y lo que sucede en él. Se genera además un trabajo colaborativo, deciden sobre los temas o como mejorar las propuestas de los compañeros, además se convierte en un espacio de decisiones colectivas y sienten que hacen algo importante para su comunidad, porque tienen un acercamiento a sus realidades y luego las narran a través de sus historias. Como dice la profesora Isb: los muchachos tienen muchas historias para contar (...) (esto es) apropiarse de su contexto y cuando un chico se apropia de su contexto y tiene cosas que narrar de sí mismo o de la gente que está a su alrededor, es significativo para ellos. (Entrevista, marzo 26 de 2012). Este testimonio, según Freire posibilita que el estudiante se apropie de la palabra, para relatar el mundo, para transformarlo (1985, p. 100).

Los medios de comunicación en la escuela adquieren otro sentido en el momento que los estudiantes se apropian de este tipo de espacios comunicativos y educativos, que inician con la generación de las ideas. Así, cuando los estudiantes dan cuenta de su realidad y son conscientes de que contar sus historias tiene un significado especial, es dar cabida a la consciencia crítica, 
como lo expone Freire (1992) cuando se integra con la realidad (p.102), en este caso, a lo que sucede en el barrio y que a ellos los motiva a dar cuenta de ello o como plantea Freire (1985), es la posibilidad de "pronunciar" el propio mundo, con un compromiso: transformarlo (p. 100) y esto implica un encuentro con los otros, es decir, con los habitantes del lugar y la de sus compañeros.

También, desde el planteamiento de las mediaciones comunicacionales (Martín Barbero, 1998) se cambian los roles. Es diferente un "emisor/trasmisor" enfocado en un trabajo de comunicación institucional (divulgar eventos o actividades) o de hacer trabajos en clase para que el maestro apruebe y sea publicado como un "premio", pero con el propósito de obtener una nota académica; pero el "emisor/trasmisor" puede convertirse en un "productor de significaciones", cuando se compromete a dar cuenta del propio contexto social, la vida cotidiana y la realidad del barrio, para que la comunidad educativa no solo se informe, sino que tenga contenidos relevantes para hablar, debatir y deliberar, en definitiva para encontrarse con el otro en el diálogo.

Por su parte, Bacher (2009) conjuga ambos elementos educativos y comunicativos. De un lado, señala que en la escuela es necesario que existan "escenarios comunicativos", para que los jóvenes descubran el inagotable poder de la palabra y con ella lograr las transformaciones que requiere en su época (p.117), y de otro lado, estos medios son la posibilidad que tienen los niños y jóvenes para "expresar sus ideas, inquietudes y anhelos", que no se quedarán en un aula de clase, sino que "trascenderán para llegar a oídos desconocidos, da al mensaje un sentido especial" (p. 134) y otro sentido para que sean los estudiantes quienes asuman esa labor de producir los discursos con los que interpelaran a sus pares y con los que producirán otros conocimientos a 
partir de sus experiencias de vida, con un sentido y valor diferente a los contenidos académicos ofrecidos en la escuela.

De ahí que, una vez generadas las ideas y tomadas las decisiones sobre lo que se va a publicar, el siguiente paso es la producción de los contenidos. ¿Quién escribe los textos de los periódicos y las notas de televisión? ¿Qué responsabilidad asumen los estudiantes en este proceso? ¿Qué papel cumplen los maestros? Las respuestas a estos interrogantes permitirán comprender la dinámica de estos medios en el proceso de producción de los contenidos dirigidos a la comunidad educativa.

\subsubsection{La producción de contenidos}

\section{Colegio 1 (Privado)}

Tres, dos, uno... grabando

(Observación $\mathbf{N}^{\circ}$ 5, agosto 10, 2012). $D$ entra al primer salón de clases del segundo piso. Lleva en sus manos dos hojas color azul. Los chicos están sentados en los pupitres y esperan las indicaciones. Esa tarde grabaran las presentaciones de los informes. La comunicadora recorta las hojas en tiras, luego llama a los estudiantes por parejas y les entrega a cada una de ellas los papeles. $C s$ y $C t$ dos preadolescentes son los primeros que salen del salón y se quedan en el corredor leyendo el texto, son dos frases que deben memorizar: una $C s$ y otra $C t$. Los otros compañeros también buscan un espacio a lo largo del pasillo, algunos optan por irse a un salón. A los pocos minutos $C s$ y $C t$ empiezan a simular con un lapicero (a modo de micrófono) lo que van a decir ante la cámara. Lo hacen tres, cuatro veces y aparece $D$ quien les dice: "muéstrenme cómo lo van a hacer". $C s$, quien está con la camisa por fuera del pantalón, el pelo sin peinar y el cuello 
de la camisa torcido, repite la frase en pocos segundos y luego lo hace $C t$, quien está bien peinada y organizada; ella también repite la frase, pero en un tono de voz muy bajo. $D$ les pide que repitan de nuevo el ejercicio y les hace algunas observaciones.

Luego llama a $J D$, el practicante de comunicaciones, quien sale con una cámara Cannon, un trípode y el micrófono. Lo acompaña $M n$, la chica que lleva ocho años en la Extracurricular de televisión. ‘¿Cuáles son las notas que vamos a grabar?’, pregunta $J D$ para buscar los lugares donde harán las presentaciones. A $C s$ y $C t$ les corresponde las obras en el coliseo, entonces bajan a un patio, donde estaban trabajando. Los otros chicos los siguen. Empieza la grabación: “Tres, dos, uno..." Cs repite su frase con mucha rapidez y pone el micrófono a $C t$ quien se equivoca. Tienen que parar y repetir. A la tercera vez queda lista la presentación. JD dedicará la siguiente hora para hacer este trabajo con los demás chicos en diferentes espacios del colegio: corredores y zonas verdes.

En el Colegio 1 la Extracurricular es el espacio para preparar las presentaciones del Mgz y los textos del periódico. Esa tarde, los chicos grabaron los "ines", las entradas de las notas (las presentaciones como les dicen ellos), esa es la principal función de los estudiantes, porque ellos no escriben los textos, sino que los memorizan y los repiten ante la cámara. Los textos los escribe la comunicadora en sus jornadas de trabajo, quien además decide los temas que se van a publicar con el Comité de Comunicaciones.

¿Quién escribe las notas? JD, el asistente, dice: las hago yo con la coordinación de D. Las voces en off son de estudiantes de cursos superiores recomendadas por la profesora de español. (Observación $\mathrm{N}^{\circ} 5$, agosto 10, 2012). Este testimonio coincide con lo que dice la comunicadora 
sobre quienes producen los contenidos de Mgz: las notas y el off, todo eso lo hacemos nosotros, el Comité de Comunicaciones (Entrevista, agosto 17 de 2012).

Por su parte, $D$ indica que son los estudiantes quienes escriben sus propios textos: Yo les digo, muchacho ud. me va a presentar esto, me hacen el favor y escriben la presentación y ahorita yo se las corrijo y ya. (...) A veces por cuestiones de tiempo no se puede, el semestre pasado como para dos Mgzs ellos hicieron las presentaciones y bien, no es sino arreglarles algunas cositas (Entrevista, agosto 17 de 2012). Sin embargo, son los mismos estudiantes quienes admiten que la coordinadora es quien propone los temas, orienta y escribe los textos, como dice $J D$ del Grado 6: ella se encarga de darnos el tema y el texto que debemos decir. Solo en algunos casos extraños, nos dice que debemos copiar nuestra nota, que tenemos que hablar de tal cosa, pero que debe tener mucha coherencia y que debe ser que siempre dé la idea del tema (Entrevista, septiembre 21 de 2012). Para los estudiantes es la comunicadora quien cumplen esa doble función de "dar el tema" y escribir los textos que ellos memorizan. Solo en "casos extraños" son ellos quienes escriben las notas, es una excepción cuándo lo hacen.

Pero también falta empoderamiento por parte de los estudiantes. Al respecto, Mar del grado $10^{\circ}$ dice: si yo me adueñara de una sección, sinceramente no tendría tiempo de hacer una nota del $M g z$ (Entrevista, septiembre 21 de 2012). Aquí se presenta una coincidencia con la comunicadora por el factor tiempo, como uno de los impedimentos que tienen los estudiantes para asumir su responsabilidad de proponer y producir sus contenidos. Y para completar aún más la idea, Mar compartía esta respuesta: yo pienso que lo del Mgz (...) lo hacen los directivos y D., porque realmente el tiempo de cualquier estudiante, del grado que sea, es muy limitado, ya que el 
horario del colegio es muy extenso, (...) muy pesado, el cual así no tengas muchas tareas vas a llegar muy cansado a tu casa y no vas a tener ganas de nada. (Entrevista, septiembre 21 de 2012). Así, los tiempos destinados en la Extracurricular del Colegio 1 para producir los contenidos es muy poco y ello lleva a que sean los de Comunicaciones y los del Comité quienes se responsabilicen de los contenidos.

Entonces, si no hay tiempo para "adueñarse" como dice la estudiante de una sección, ¿quién busca la información para los contenidos que se publicarán?, ¿cuál es la participación de los estudiantes en esta labor? Dice D: Eso es lo que ellos (estudiantes) no han entendido, esa ha sido la parte más dura para mí, que ellos adquieran información cualquiera día de la semana que no sea en clase, (...). La parte de la investigación si es durita con ellos y les da pereza. (Entrevista, agosto 17 de 2012).

La Extracurricular en el Colegio 1 está centrada en el cómo (cómo hacer una presentación ante cámaras, cómo escribir un texto para el periódico) y en ese marco se realizan las actividades semanales. No es un espacio en el que se motive a los estudiantes a hablar de sus temas y de cómo y para qué obtener la información que requiere, por tanto, es raro para los estudiantes entrar en una dinámica de la investigación y la búsqueda de la información necesario para escribir un texto (así sean dos líneas para hacer una “presentación” ante cámaras).

Es la lógica que prevalece entre los estudiantes y esto lleva a "repetir" lo que los maestros y la comunicadora escriben por ellos. Los estudiantes asumen como normal que sea la comunicadora y el Comité quienes provean los contenidos; ellos se limitan a asistir a las clases y a esperar las indicaciones que les brinde la comunicadora; ella a su vez hace este trabajo como parte de sus 
funciones y tareas. Esto da pie para afirmar que los estudiantes son unos "emisores replicadores", porque hacen lo que los adultos les indiquen, memorizan lo que ellos escriben para las presentaciones, publican lo que los maestros autoricen; más no se asumen como productores de contenidos que sean de interés para los estudiantes.

Los contenidos que se producen son una recopilación de los acontecimientos institucionales, más no el resultado de los temas que surgen de las reflexiones, discusiones, interpelaciones, deliberaciones o diálogos en la comunidad educativa propuestas por los estudiantes. Con Freire (1985) como referencia estas prácticas que se realizan en los medios del Colegio 1 son el reflejo de la educación tradicional que se imparte en la institución, donde es el maestro quien determina los contenidos y los estudiantes "memorizan", práctica muy propia de la educación bancaria (p.72). De ahí la pregunta:¿cuál es el papel que tienen los estudiantes en esta fase de producción?

\section{Emisores replicadores}

El sentido de los estudiantes quienes se inician en la Extracurricular del colegio privado es aparecer ante las cámaras. Es lo que llaman la "presentación" de las notas que prepara la comunicadora y que ellos memorizan. Más que un productor de contenidos, emerge la figura descrita antes: el "emisor replicador", caracterizado por aprenderse un texto y repetirlo ante una cámara. El interés de este "replicador" es ser reconocido en la comunidad educativa, porque su preocupación no está en investigar y escribir sus propios contenidos, sino en tener a disposición unos recursos de la institución para aparecer ante sus compañeros y padres de familia en la televisión del colegio. 
$D$, la comunicadora, reconoce que ese es el propósito de los estudiantes de cursos inferiores: el sueño de ellos, cuando entran a la extracurricular, es presentar. (Entrevista, agosto 17 de 2012). Es tanto el interés que tienen de ser presentadores que cuando no aparecen en el producto final que se emite en el circuito cerrado del colegio, se enojan, tal como sucedió con Cs. Esto fue lo que pasó: (Observación 10, septiembre 7, 2012). La reunión estuvo tensa, algunos estudiantes empezaron a hablar del Mgz y a decir que no les había gustado, entre ellos Cs, quien había grabado una presentación junto con $C t 20$ días atrás, pero no apareció en la versión definitiva. $C s$ era de los más disgustados y decía: no me gustó el $\mathrm{Mgz}$, porque no aparecí, no salí. Esto generó una discusión entre $D$, la comunicadora, $J D$, su asistente y algunos estudiantes del grupo. $D$ preguntó quiénes eran los responsables de la sección de deportes, dos de ellos levantaron la mano y les dijo: no hay notas de deportes, porque uds. no traen información, luego les dice a todos los chicos: si no cuentan lo que hacen es dificil realizar los informes y nosotros (D y JD) no podemos estar produciendo todas las notas, al final les dice: la responsabilidad es de uds., necesitamos trabajar en equipo, todo es posible si uds. ponen de su parte.

En primer lugar, el reclamo del estudiante porque no salió obedecía más a su interés personal de ser visto por sus compañeros y los padres de familia. Esto demuestra que lo importante es hacer parte del "rol playing", simular que son presentadores de televisión (Aparici, 2006, p. 29), lo cual marca esta experiencia. Y en segunda instancia, la comunicadora reconoce que ella y su asistente son quienes producen las notas (los adultos); también hay que resaltar el reclamo que les hace a los estudiantes para que cuenten sus propios temas y se responsabilicen de otras secciones y, sobre todo, la necesidad de trabajar en equipo. De esta manera, se demuestra que la generación de ideas y la producción de contenidos en esta experiencia siguen la lógica de una educación 
tradicional, interesada en producir contenidos y una comunicación divulgativa que solo busca trasmitir información, fomentando además una participación pasiva por parte de los estudiantes.

Así, los estudiantes de esta Extracurricular, hasta ese momento, no se habían apropiado de los medios de comunicación del colegio, a pesar de tener los recursos necesarios (técnicos y profesionales) para expresar sus ideas y conocimientos. Por eso, la comunicadora, en el grupo focal (Octubre 31 de 2012) les recalcó esta idea: El poder de esos medios de comunicación lo tienen uds. Lo que pasa es que si uds. no lo usan, yo no me puedo ir detrás de cada uno de uds. a decirles: muchachos vea, muchachos esto, ;no! Uds. saben que deben tener ese motorcito que los muevan y que digan: vamos a sacar esto adelante, porque es para nosotros y para beneficio de nosotros. Apropiarse de la palabra, implica asumir las responsabilidades que conlleva producir contenidos, en la perspectiva que sean mensajes de utilidad para la comunidad educativa, pero en este caso, los estudiantes prefieren la comodidad que les brinden todo (textos, equipos, personal capacitado) para "aparecer", más no en comprometerse con la proposición de ideas para expresarlas con sus propias palabras.

Otra manera tradicional de producir los textos se da en el aula o desde el aula de clase, cuando el profesor propone escribir un relato, según el tema que él escoja: Los mismos profesores en clase van trabajando un tema y les hacen un texto (los estudiantes) y se les monta en el periódico, como una forma de reconocer el trabajo que hacen los muchachos en clase, (entrevista agosto 17 de 2012). Esta es una práctica común en los colegios, el maestro propone un tema académico y los estudiantes escriben un texto pensando en el maestro y en una buena calificación, por tanto, la 
su participación obedece a un estímulo; además es pasiva e interesada, porque busca un interés propio.

De esta manera se muestra cómo es la producción de los contenidos en el Colegio 1. La proposición de ideas es un trabajo de los maestros y la comunicadora; la redacción de los contenidos, la mayoría, también corre por cuenta de ellos. La participación de los estudiantes es interesada, porque quieren aparecer, actitud que genera un individualismo o porque tienen el estímulo de una nota académica; también es pasiva, porque no asumen iniciativas, ni compromisos, aceptan que sean los maestros y la comunicadora quienes realicen este trabajo.

\section{Colegio 2}

\section{Aún no me siento periodista}

(Observación $\mathbf{N}^{\circ}$ 10. Septiembre 28, 2012). Visita al Parque Explora. El Parque Explora es un lugar en la ciudad que promueve la ciencia y el conocimiento. En esos días de septiembre realizaban una Feria de la Ciencia en la que participaban estudiantes de diferentes colegios, públicos y privados, con algún tipo de proyecto científico. El Colegio 2 tenía un stand en el que un grupo de estudiantes exponía un proyecto de Ciencias, sobre reciclaje de elementos que tuvieran caucho como llantas o guantes. La profesora Isb vio que esto era una oportunidad para que los chicos del Semillero de Periodismo salieran del colegio a "cubrir" el evento.

A las 10:15 de la mañana llegaron al lugar. Eran ocho estudiantes del Semillero de Periodismo y llevaban puesto el chaleco negro que los distinguía como periodistas. La profesora les dio la 
libertad de ir por los diferentes stands, la idea era hacer el trabajo en equipos. Dn, Yn y Drl se fueron juntas. Pasaron por varios stands: en el primero exponían un proyecto de vivienda para familias desplazadas en un municipio cercano a Medellín. Las expositoras eran de un colegio del lugar y explicaron su proyecto; $D n$ apuntó algunos datos en una pequeña libreta y $Y n$ y $D r l$ tomaron las fotos. Dn preguntó: ¿por qué pensaron hacer este proyecto? Y una de las expositoras respondió: 'porque queríamos aportar una solución social y ambiental al municipio'. No hubo más preguntas. Luego se dirigieron a otro stand, uno internacional. Eran dos chicas provenientes del Perú y exponían un producto (una semilla) con la que hacen tinturas para diferentes productos. Dn de nuevo pregunta: ¿por qué trajeron este proyecto? Y una de las chicas respondió: 'con esta semilla se producen unos tintes naturales para paletas (helados), plumas o prendas de vestir. Dn apuntó datos y sus dos compañeras tomaron fotos. La visita terminó a las 10:49 a.m.

(Observación 11. Octubre 1, 2012). Retroalimentación de la experiencia.

La profesora $I s b$ se encuentra con los estudiantes en el salón 406 y allí inicia una conversación con Dn:

¿Qué te gustó de la Feria de la Ciencia?, pregunta la profesora y Dn responde: el proyecto de bioarquitectura

Isb: ¿Fuiste con la idea de ser periodista? 
Dn: Todavía me da pena, como que no soy capaz. Me cuesta preguntar; en mi casa me relajo, me guio por los periodistas y ahi hago las preguntas; pero cuando estoy ahí (en el lugar y con las personas) no soy capaz de preguntar o hacer preguntas.

Isb. ¿Qué sentías tener puesto el chaleco de periodista?

Dn. Nos miraban los chalecos y el carné, nos preguntaban de qué colegio éramos, que si éramos periodistas, pero me sentí normal.

En esta primera parte de la conversación se destaca la pregunta de ir con la "idea de ser periodista", lo cual hace parte de los propósitos del Semillero de Periodismo, a los que se integran estudiantes del colegio que pensaban en ese momento estudiar Comunicación Social o Periodismo. Se destaca las respuestas de la estudiante en la que reconoce algunas dificultades: "no soy capaz de preguntar". Al respecto, la escuela y estos proyectos tienen un reto: generar en los estudiantes la capacidad de preguntar y de mantener una actitud crítica frente a lo que sucede en el colegio y en el entorno social donde vive. Por esto, los proyectos de medios de comunicación en la escuela deben considerar la posibilidad de formar en la problematización de la realidad, siguiendo a Freire, de manera que los estudiantes aprendan a cuestionar lo que ven en sus espacios cotidianos y de esta manera, empiecen a asumirse como responsables de la comunicación.

Isb. ¿Cómo seleccionaron las partes a las que fueron? 
Dn. Un tema que nos gustó fue el de Perú. Aunque no tomé notas me acuerdo lo que nos dijeron, que de una semilla sacaban la materia para producir pigmentos, fue el que más me gustó y el de bioarquitectura, pero hablaron mucho.

Isb. ¿Llevaban una idea de lo que iban a preguntar?

Dn. No, cuando llegué, formulé preguntas que iban con todo.

Isb. ¿Preguntaron lo mismo?

Dn. Casi no preguntaba, exponían y entendía; no tenía que preguntar ... se hacía fácil.

Se percibe que no hay un trabajo en equipo para preparar unas preguntas entre los estudiantes del Semillero, establecer criterios de selección de las experiencias que iban a consultar y qué se publicaría. Resultado de esta situación es la improvisación: la estudiante no preparó preguntas, tampoco tenía una idea clara de por qué fueron a diferentes stands; además se conforma con que “no tenía que preguntar", “exponían y entendía”.

Isb. ¿Qué vamos a escribir?

Dn. Un reporte de todo, recoger de todos y hacer uno solo.

Isb. ¿Por qué?

Dn. Se haría más fácil.

Isb. ¿O sea como editora dices que es mejor hacer uno? 
Dn. Por todas las facilidades, hacer uno y ya.

En este caso se opta por el facilismo. Si no hay un propósito comunicativo sólido la responsabilidad de la estudiante es menor. Producir un relato para que los integrantes de la comunidad educativa tengan la posibilidad de conocer sobre un tema o aportar conocimientos sobre algo que no conocen, debe ir más allá de pensar que "se haría más fácil”; el compromiso de la estudiante debería estar centrado en escribir para "atraer" (Freinet, 1977) la atención de sus compañeros (en un colegio con 2 mil estudiantes) y maestros (67 profesores), aportarles nuevos conocimientos, algo que vas más allá de escribir solo para el docente o para ella misma.

Isb. ¿Qué concluyes del ejercicio?

Dn No me acordaba cómo empezar, es difícil. Lo del Perú, no copié, me acuerdo de todo; del colegio cómo deshacían el caucho, los guantes; de las niñas (del colegio privado) cultivos en la luna; lo de las casas. Todo lo tengo en la cabeza, lo recuerdo todo.

La estudiante tiene una confianza absoluta en la memoria: "todo lo tengo en la cabeza, lo recuerdo todo". Sin embargo, no se publicó nada de esta experiencia. Se pierde así el sentido de un ejercicio de comunicación escolar, porque los contenidos no se comparten con la comunidad educativa. 


\subsubsection{Micromedios}

\begin{tabular}{|l|l|}
\hline Categoría & Temas clave \\
\hline - Micro medios & - Los medios en la escuela sirven de mecanismos para reforzar los \\
& valores y la filosofía institucional \\
& - Predomina el enfoque instrumental en los proyectos de medios en la \\
& escuela y como un apoyo a la labor docente \\
& - Los medios sirven para reflejar las situaciones sociales que rodean al \\
& colegio \\
& - La inestabilidad del proyecto de medios es reflejo de la inestabilidad \\
& institucional. \\
\hline
\end{tabular}

Cuadro 3.Categoría Micromedios. Elaborado por el autor a partir del análisis de las entrevistas y grupos focales

Los medios de comunicación de las instituciones educativas se crean para informar sobre los acontecimientos de interés a sus estudiantes, maestros, directivos, padres de familia y, con algunas excepciones, vecinos y organizaciones que viven o están ubicados en lugares aledaños a la institución educativa. Así, por los contenidos y el alcance de los mismos al ser publicados, la temporalidad con la que se producen, las personas que participan en la elaboración de los contenidos y la influencia en quienes reciben los mensajes producidos, a estos medios hay que denominarlos como "Micro medios".

Por eso, es necesario comprender cuáles son las motivaciones y los propósitos que llevan a una institución educativa a crear y mantener unos proyecto de medios de comunicación ${ }^{69}$. Esto supone apoyos logísticos (académicos y administrativos), conformación de equipos de trabajo con maestros y estudiantes, y unos aprendizajes que subyacen de la inexperiencia de publicar medios de comunicación en un colegio. Entender estas inquietudes contribuyen a clarificar los

\footnotetext{
69 En el Colegio 1 (privado) en el Manual de Convivencia se tiene establecido que la Sala de televisión es el centro de preparación y emisión del mgz y, además, para asesorar a los alumnos que pertenezcan al equipo de televisión, en la producción de programas y en el uso de medios que disponen. Por su parte, en el Colegio 2 (público) no tenía definida ninguna función sobre los medios de comunicación en su Manual de Convivencia.
} 
por qué se dan las situaciones planteadas en la Categoría 1, acerca de la generación de las ideas y la producción de los contenidos.

\section{Colegio 1}

\section{Contribución a la educación integral}

Al principio del siglo XXI, en el año 2000, el colegio instaló televisores en todas las aulas como un recurso que complementara las labores del quehacer docente dice el profesor $D g$ quien junto con la profesora St iniciaron el proyecto del Mgz de acuerdo con las indicaciones del Rector del colegio, a quien le pareció muy interesante poder aprovechar los televisores con un proyecto de televisión, como una especie de un programa institucional. Ambos profesores se animaron con la propuesta y pensamos como en un magazine (...) la cual tenía varios propósitos: queríamos a través de ese medio contribuir a la educación integral de los muchachos a través de notas, de eventos (Entrevista profesores, septiembre 12 de 2012).

Por su parte, la profesora $S t$ señala otro propósito que tuvo el proyecto en su nacimiento: hacer la historia de la institución para que los estudiantes actuales tengan la posibilidad de entender y comprender cómo nació el colegio, que se vivió, cómo ha evolucionado. Además complementa que era una propuesta para que los estudiantes y padres de familia vieran una recopilación de los principales eventos del colegio (Entrevista profesores, septiembre 12 de 2012).

El inicio de los medios de comunicación en este colegio obedece a la instalación de televisores en el aula, asumido como "un recurso didáctico", una práctica que es frecuente en las instituciones 
educativas en la que la comunicación es asociada a los medios -televisores en este caso-cuya función es “complementar" el conocimiento de los maestros (Álvarez, 2003, p. 73). En ese marco, el rector en su momento consideró importante "aprovechar" los televisores para un "programa institucional" que tenía un propósito: "contribuir a la educación integral" y para lograrlo consideraron los profesores encargados que lo mejor era divulgar "notas y eventos". Estas palabras claves contribuyen a entender que desde los maestros, como adultos, un programa de televisión aporta a la educación de los estudiantes, divulgando los eventos que sucedían en el colegio, esto desde una mirada de la educación tradicional y es además una concepción instrumental de la comunicación, enfocada a la trasmisión de eventos institucionales.

La profesora aporta que la contribución del proyecto era "hacer la historia de la institución", entendida como la historia oficial basada en los acontecimientos que marcaron la consolidación como institución educativa, enfoque que prevalecía, porque desde el principio el cubrimiento de los eventos fue uno de los pilares en los que se fundamentó el proyecto, esto es generar una comunicación enfocada en la divulgación/transmisión.

¿Cuál es el papel de los maestros y estudiantes en el proyecto? Al respecto la profesora St se refiere al Comité de Comunicaciones y los profesores que hacen parte de él, quienes aportan ideas y los estudiantes se vinculan en un espacio que se llama Extracurricular (...) ellos vienen, se capacitan, hacen talleres, trabajos de campo dice el profesor $D g$. Desde un principio, el proyecto tuvo la misma estructura que le permite tener continuidad por más de 12 años: un comité conformado por maestros que "aportan" las ideas y unos estudiantes que se capacitan para “presentar" las notas (el rol playing), aspectos sobre los que se reflexionaron en el aparte anterior. 
Es un enfoque tradicional que no asume el reto de insertarse en el ecosistema comunicativo (Martín Barbero, 1996-1997).

¿Qué movía a los maestros a participar en esta experiencia? ¿Establecieron criterios para consolidar el proyecto o fue algo intuitivo? Comparte el profesor Dg: cuando hay amor, uno hace las cosas así no sepa, porque le pusimos tanta ilusión, tanto amor, no teníamos horario, nos matábamos lo que fuera, hacíamos hasta cosas heroicas para poder alcanzar una nota como fuera, lo hicimos con mucha ilusión, con muchas ganas, con mucho empeño (Entrevista, septiembre 12 de 2012). La identidad de este proyecto de medios en el Colegio 1 la dan los maestros, donde prevalecen sus visiones como adultos; en esta declaración no se revela un propósito por comunicar los intereses de los estudiantes. De ahí que, desde el principio los estudiantes vieron a sus maestros haciendo el programa y eso generó la idea de continuar con lo que ellos iniciaron bajo el mismo esquema. Es un proyecto forjado en la pasión de los maestros, de entrada son ellos quienes tienen la iniciativa y quienes marcan la pauta de trabajo, lógica que prevalecía en el momento de hacer la investigación.

\section{Reforzar la filosofía institucional y generar sentido de pertenencia}

¿El programa de televisión se caracteriza por cumplir esa función informativa? Fue otra inquietud que se planteó a los profesores fundadores de la experiencia. Al respecto expusieron dos asuntos: es informativa-pedagógica para recordarles cómo hay que hacer las cosas, dice el profesor Dg, esto es, un asunto de normatización, de regulación del comportamiento de los estudiantes. El segundo es el trabajo de valores, nuestra filosofía está reflejada ahí, es lo que plantea la profesora St. Desde la visión de los maestros el trabajo con los medios en el colegio tienen un 
sentido: reforzar los fundamentos institucionales, más que servir de medio para permitir que emerjan los intereses temáticos de los estudiantes.

Desde un punto de vista de educación tradicional es aceptable esta labor, porque permite llevar a cabo su proyecto educativo basado en los valores y en la familia. Asimismo, desde una comunicación organizacional cumple con los parámetros de reforzar el conocimiento de la institución y sus normas. Sin embargo, desde una perspectiva crítica no se considera lo que puede ser real, importante e interesante para los estudiantes.

Y esa mirada tradicional de la educación y la intención de encausar a los estudiantes por ese modelo, a través de un programa de televisión producido en el Colegio se evidencia en la intervención del profesor Dg: uno de los enfoques que le hemos querido dar al programa es que lo que se vea y se diga contribuya, jale, genere en ese niño, en ese joven, en esa persona que lo está viendo, un cuestionamiento y diga: ah es que mira como se ve uno de bien haciendo las cosas así, mira el uniforme como debe llevarse y como se ve cuando está descachalandrado, porque va entrando por la parte visual, por la parte auditiva; estamos con esa herramienta atrapándolos, incentivándolos (...) ah es que mira cómo lleva de bonitos los cuadernos, practica un deporte, mira cómo le va de bien en el estudio. En el mgz no sale un niño cochino, comiendo chicle, con la cola y un arete $^{70}$. (Entrevista, septiembre 12 de 2012).

\footnotetext{
${ }^{70}$ Estas ideas son consecuentes con el perfil del alumno del colegio, en el que se define como ordenado, limpio, aseado, puntual, no alborotador, disciplinado, veraz, no murmurador, definición publicada en el Manual de Convivencia (2014-2015, p. 20).
} 
El cuestionamiento al que se refiere el maestro está enmarcado en la moral y el buen comportamiento y en este caso los medios sirven para reforzar la propuesta educativa de la institución, en la que se resalta el orden, el acatamiento de la norma, el cumplimiento del deber y el rechazo a lo que sale de este esquema. Así los medios de comunicación de la institución reflejan lo que es la misma y su papel es el de una "herramienta" que permite "atrapar" la atención de los estudiantes y marcar en ellos la fidelidad al proyecto educacional que recibían.

\section{Fortalecer los valores y la información}

Ese camino iniciado por los maestros en el año 2000 lo sigue la comunicadora responsable de estos proyectos en el Colegio 1. Ella indica que estos medios nacen por las ganas de trasmitir algo y porque se vio en eso un apoyo a la parte formativa de los estudiantes y con el propósito de fortalecer la parte de valores (...) y fortalecer la información entre padres, hijos y comunidad educativa. Y concluye que los medios en el colegio nacieron con una inquietud por la parte de comunicación y por afianzar la parte de valores que es nuestro fuerte como institución (Entrevista, agosto 17 de 2012). En este sentido coincide con los "fundadores" de los medios en el colegio y en la que prevalecía la idea que los medios están para inculcar los valores de la institución en la comunidad educativa y también como un recurso para "fortalecer" la información entre padres e hijos, bajo ese esquema de la divulgación de los acontecimientos.

Y estas ideas tan arraigadas entre los maestros y la comunicadora son las que permiten que los medios de comunicación del colegio tengan permanencia en el tiempo. Durante 12 años llegaron a la emisión 100 del programa de televisión y al número 60 del periódico, apoyados por los padres de familia y los directivos. Desde este punto de vista son los adultos quienes soportan el 
proyecto, sin embargo queda la inquietud sobre el papel y los aportes de los estudiantes en esta propuesta.

Frente a este aspecto, la comunicadora señala que los medios en ese momento estaban en manos de los estudiantes, porque los artículos -refiriéndose al periódico- son más originales, no montamos nada de Internet (Entrevista, agosto 17 de 2012). Los estudiantes colaboran con artículos que presentan a la comunicadora, sin embargo, no son resultado de un trabajo en equipo donde se discutan los temas y se dé la posibilidad de elegir entre todos el que se va a publicar, según el método Freinet. Y el otro aspecto que identifica este trabajo tiene que ver con la información. Es un ejercicio exógeno (Kaplún, 1998, p. 18) porque el énfasis está puesto en los contenidos y en la trasmisión de los mismos.

\section{Colegio 2}

\section{Los caminos inciertos para llegar a consolidar un medio escolar}

Todo parte de un ejercicio de clase de la profesora Isb que trabajaba los medios de comunicación y los géneros periodísticos con los estudiantes de $11^{\circ}$ (el último de la educación secundaria en Colombia) en el año 2006. A partir del proyecto se vio la necesidad de dar información a las personas y habia mucho que contar (Entrevista, marzo 26 de 2012). En el 2008 (como uno de los Colegios de Calidad) se formó el Semillero de Prensa Escuela y empezaron dos proyectos alternos: uno virtual $J I$, con los estudiantes de secundaria y otro impreso, $E V$ con los estudiantes de primaria. La razón por la cual se pensó que fuera virtual también obedeció a que el colegio se tenía pensado que la virtualidad y la tecnología iban a ser el eje transversal, dice la profesora 
(Entrevista, agosto 27 de 2012), además porque no contaban con dinero para pagar la impresión de los periódicos. Aclara la profesora que en el área de Humanidades, de la que hace parte el curso de Lengua Castellana, existe un proyecto líder que es Comunicaciones y en este se encuentra el proyecto del periódico escolar.

En el 2010, aparece otro "experimento": el primer informativo audiovisual, interno, escolar, como lo denomina la profesora y lo compartían por Internet: ya se veía más y era un referente más próximo a estos chicos que los veían no como los usuarios, sino como los que producían las notas (Entrevista, marzo 26 de 2012). En estas experiencias participaron los estudiantes de $11^{\circ} \mathrm{y}$ en la medida que se graduaban de bachilleres el proyecto quedaba sin integrantes, no había relevo. En el 2011, pasó a ser el Semillero de Periodismo, integrado por estudiantes de grados $8^{\circ}$, $9^{\circ}, 10^{\circ}$ y $11^{\circ}$, quienes participaron en una capacitación de medios escolares ofrecida por parte de uno de los periódicos de la ciudad. Producto de ello se publicó un número de $J I$ que inicio en la virtualidad. A 2012, solo se había impreso dos ejemplares de $E V$ y uno de $J I$. En este año la experiencia tuvo otra variante: nace "P con..."71 entrevistas de cinco minutos que se publican en Facebook. La razón es la siguiente: todos estos muchachos están "faceibifutiados” viven pegados del Facebook y es un medio de comunicación efectivo. ¿Qué teníamos nosotros que pensar? Cómo hacer efectivo este proceso que hacen estos muchachos, nada se ganan ellos escribiendo si nadie los va a leer (Entrevista, marzo 26 de 2012). Desde esta perspectiva se favorece la inserción en el ecosistema comunicativo propuesto por Martín Babero (1996-1997).

\footnotetext{
${ }^{71}$ Para este experimento solo cuentan con una pequeña cámara fotográfica, como recurso tecnológico disponible.
} 
Dice la maestra: En la institución nos volvimos expertos en cubrir los eventos y los chicos tienen mucha apropiación en ese sentido, pero también es un pretexto para traer las historias que ellos tienen. A través de crónicas y perfiles, que para ellos son las más complicados, pero que más nos enriquecen a nosotros (los profesores), podemos saber cuáles son las dificultades con el agua que tiene el barrio, podemos saber las dificultades de alcantarillado que es de las cosas más complicadas, la parte de desplazamiento, el origen del barrio, un perfil de un personaje que para ellos es muy significativo y lo traen acá (al colegio). El año pasado (2011) hicieron entrevistas audiovisuales de raperos, de egresados que están saliendo adelante, son historias de afuera que a nosotros nos están enriqueciendo acá, porque dan razón de ser de que nosotros estemos, de que hayan hecho una mole de este tamaño (refiriéndose al colegio) para que ellos empiecen a transformar el medio, además porque la visión de nuestro colegio es transformar el medio donde ellos están. (Entrevista, marzo 26 de 2012).

La experiencia de los medios de comunicación en el Colegio 2 tiene una identidad más escolar, en el sentido que parte de una práctica de aula, pero se abre de la misma porque la maestra descubre que los estudiantes tienen "muchas historias para contar", para relatar. Y es una búsqueda por el medio, que más se adapte a los recursos tecnológicos que tienen (Internet) y a los que les falta presupuesto para imprimir. Es una experiencia basada en el experimento, en la búsqueda, en el fracaso, en la frustración y en la persistencia. Por un lado, intentan con lo virtual y con lo impreso, experimentan con lo audiovisual y terminan en las redes sociales: Facebook.

Esa misma experimentación es la que lleva a descubrir en los estudiantes no son los "usuarios", sino los "productores de notas", así los estudiantes son los protagonistas. Si bien la maestra es la 
guía, ella interpreta que lo relevante del proyecto es posibilitar que otros "lean", lo que los estudiantes producen, por eso, busca alternativas como el Facebook, para sustentar esa idea: "que se ganan con escribir si nadie los va a leer”, razón fundamental del Diario escolar propuesto por Freinet.

Un asunto relevante en el relato de la maestra está en lo "otro", en lo no divulgativo, en la cotidianidad y las narraciones de las carencias que rodean a los estudiantes de esta institución educativa: la falta del servicio del agua y alcantarillado, la población desplazada que llega al barrio para asentarse y reclamar su derecho de estar en la ciudad, la historia del barrio o de un personaje que a juicio de los estudiantes es importante darlo a conocer y la de sus egresados "que salen adelante". Es un "pretexto", como dice la maestra, para que la institución conozca los relatos de los estudiantes y "se enriquezca" con esa otra información y conocimiento que llega de la experiencia de vida de los estudiantes y que no está en los libros oficiales, ni publicada en los grandes medios. Esto es lo que marca el "sentido", la "razón de ser" de una institución para estar en un lugar, porque tiene un propósito: "contribuir a la transformación” de ese contexto social y los medios sirven para abrir las miradas a otros asuntos "no académicos".

Esta experiencia presenta una sintonía con la propuesta de Freinet (1977), en el sentido que la maestra piensa que estos proyectos tienen sentido sí sirven para que los estudiantes cuenten sus historias y, sobre todo, para que las mismas sean leídas y conocidas en la comunidad educativa. Se acerca a lo que propone Freire, porque los estudiantes relatan su mundo, se apropian de la palabra para contar sus experiencias de vida en el barrio, para hacer visibles sus problemáticas sociales (servicios públicos, población desplazada) y todo ello para que la escuela haga reflexión 
sobre lo qué debe hacer para contribuir a la transformación de los estudiantes y con ellos, del contexto social. Y tiene de Martín Barbero (1998), con su propuesta de las mediaciones, aquello de no verse como "usuarios", sino como productores de notas a partir de los relatos cotidianos que los estudiantes escriben, es decir, la fortaleza de la propuesta no está en el medio -sobre todo cuando migra de uno a otro- sino en la producción de lo realmente significativo para ellos: la experiencia de vida.

\section{Ideal, pero cojea}

A pesar de cumplir con esos parámetros "ideales" para un perfil de medio escolar en perspectiva de mediaciones, la propuesta no está consolidada y es inestable por varias razones:

- Carencia de recursos económicos. Es un colegio oficial y obtener rubros económicos para financiar la impresión de un periódico o para mantener unos equipos es complicado. El apoyo institucional está dado por los espacios físicos - contaban con una oficina- .

- Al proyecto le falta posicionamiento institucional: porque la maestra es la única responsable, la "doliente", se debe direccionar más desde lo académico, dice la maestra (Entrevista, agosto 27 de 2012).

- Falta de empoderamiento y de responsabilidad de los estudiantes: los aprendizajes de los estudiantes se van con ellos, una vez terminan sus estudios, no hay relevos generacionales. Los estudiantes que conformaban el equipo de trabajo el año 2012, no asistían a las reuniones: Creo que fallan aspectos de responsabilidad de los chicos, porque esto es una actividad extracurricular, es contar con la buena voluntad de ellos, y a veces hay buena voluntad pero falta responsabilidad, dice la maestra (Entrevista, agosto 27 de 2012). 
- Falta rigor académico. En términos de Bourdieu a los estudiantes les falta "capital cultural", desconocen el lenguaje y sus normatividades, por ello limitaciones para expresar sus ideas y escribir sus textos. Es una limitante que se convierte en un reto pedagógico y comunicativo, para ello la institución educativa debe trabajar en la apropiación del lenguaje como un elemento cultural que permita a los estudiantes, en este caso, contar sus relatos.

- La inestabilidad del proyecto, es producto de la inestabilidad del colegio. El contexto social y sus problemáticas donde está ubicado el colegio, la población que atiende, la falta de recursos, la rotación de maestros y directivos, entre otros, incide en la inestabilidad de la institución y del proyecto. Dice la maestra: la inestabilidad del medio no es solo la inestabilidad del medio, sino la inestabilidad institucional, porque somos una institución nueva, y estamos prueba error, prueba error, hasta que funcione (Entrevista, agosto 27 de 2012).

Desde la reflexión la maestra tiene claro que un medio es relevante porque es un espacio para que los estudiantes cuenten sus historias, para acercarse al contexto social, para llevar la cotidianidad del barrio a la institución educativa; pero esas ideas y esa producción no son permanentes, por las razones expuestas y ello lleva a que el medio pierda visibilidad y recordación en la comunidad educativa, la permanencia y la producción de los medios tienen muchas dificultades que no sortearon, de ahí que fuera un proyecto inestable. 


\subsubsection{Comunicación/educación}

\begin{tabular}{|l|l|}
\hline Categoría & Temas claves \\
\hline Comunicación/educación & - El medio escolar es una herramienta de trabajo \\
& - Los medios escolares reproduce la información que se genera en \\
& la escuela \\
& - La lectura de los medios escolares se hace más por obligación que \\
& por necesidad de estar informados. \\
& - El medio escolar como espacio para relatar los acontecimientos \\
& del barrio y los problemas del contexto social \\
\hline
\end{tabular}

Cuadro 4.Categoría Comunicación/Educación. Elaborado por el autor a partir del análisis de las entrevistas y

grupos focales

Lo que emerge en el análisis tanto en las categorías Discurso y Micromedios requiere de la categoría Comunicación/Educación, porque brinda más posibilidades de comprender los enfoques en los que se basan las instituciones educativas para producir sus medios; los mismos obedecen más a un asunto práctico que reflexivo, por eso, es necesario hacer evidente esa relación que densifica y compromete aún más las experiencias de los medios de comunicación en las instituciones educativas.

\section{Colegio 1}

\section{Metodología "espontánea"}

(Observación 1. Julio 25, 2012). La primera reunión tuvo lugar en un aula de clases. Hay 36 sillas grises distribuidas en seis filas, los siete estudiantes (un chico y seis chicas) que asisten a la primera reunión ocupan las primeras sillas. Varias imágenes de santos están pegadas en las paredes. $D$, la comunicadora, explica las actividades de ese día: hacer un dibujo de cada uno y luego una improvisación sobre un tema. Para la primera actividad le entrega a los estudiantes un papel de reciclaje a cada uno en el que cada uno se pinta, como un autorretrato y que luego 
intercambian con los otros compañeros. Después hacen una retroalimentación acerca de lo que cada uno percibe en esas imágenes dibujadas. Así describieron a sus compañeros y $D$ interviene diciéndoles que 'no pueden quedarse en las percepciones de las personas' y, por eso, los invita a 'preparar sus notas de manera objetiva, obtener los datos adecuados' para lograr una historia.

Esta actividad salió de un reality que $D$ vio en un canal privado y creyó que funcionaría con los estudiantes. Ella comparte que no es educadora, sino comunicadora con énfasis en audiovisual, y dice que si debe ponerle un nombre a su modelo sería "espontáneo", porque es lo que se le ocurre a partir de lo que ve en los medios. En una entrevista aplicada después afirma que su metodología es de "identificación", con lo que ellos se identifican en la clase, irnos pegando de esa parte para irlos metiendo a conocer cómo contar una historia, cómo mostrar una historia, cómo transmitir sentimientos y lo más importante que ellos aprendan el poder de la información (Entrevista, agosto 17 de 2012).

En este trabajo emprendido por la comunicadora no existe una reflexión acerca de la educación y la pedagogía. Logra clasificar su propia metodología como de "identificación”, sin embargo, no hay una sistematización y una reflexión desde la educación y la comunicación de la propuesta que permita consolidar su forma de trabajo. Lo que busca con esta labor es brindar a los estudiantes elementos prácticos: cómo hacer una entrevista, cómo hablar frente a una cámara, cómo trasmitir sentimientos y generar una idea acerca del poder de la información; predomina el "hacer", sobre la reflexión y en ese sentido se percibe que predomina un modelo de educación tradicional: el maestro brinda los conocimientos, los contenidos y las orientaciones que a su juicio los estudiantes deben aprender. 
En cuanto la comunicación, esta experiencia de medios en una institución educativa, la comunicadora indica que el propósito de ella en este trabajo es entregar herramientas para que ellos puedan realizar el trabajo que ellos quieren llegar a hacer, sin importar el que sea: presentador, radio, televisión, cualquier medio de comunicación (Entrevista, agosto 17 de 2012). En esta reflexión compartida por la comunicadora, se hace evidente aún más la concepción instrumentalista de la comunicación, porque se centra en ofrecer "herramientas" para que los estudiantes se apropien de ellas y les permitan desempeñar alguna actividad en diferentes campos de los medios. ¿Y si los estudiantes no quieren trabajar en medios o ser comunicadores?

De otro lado, ¿qué se puede hacer con los contenidos producidos por maestros y estudiantes y publicados en los medios del colegio? Dice $D$ : introducirlo más en la parte pedagógica los medios escolares, que sean más pedagógicos, que los pongan a analizar lo que ven, que les pregunten sobre lo que ven (Entrevista, noviembre 21 de 2012).Y en esto coinciden con Dg, el maestro que empezó la experiencia de los medios en el Colegio: podría sacarse alguna emisión del Mgz, colocársela y vamos a hablar sobre eso, ¿uds. qué opinan?, hacer una apuesta en común, puede servir como un recurso (Entrevista, septiembre 12 de 2012). Aquí, lo pedagógico se asocia al "hablar sobre unos temas" y analizar lo que se publica en los medios en el aula de clase, como una actividad, pero no guardan ninguna relación con las experiencias de vida de los estudiantes. Sigue latente la idea que los medios son un "recurso", que sirve de apoyo a la labor del maestro.

En la lógica de la producción del discurso -desde el adulto, hacia el estudiante- la idea del medio, como recurso y apoyo a la labor del docente, bajo un enfoque instrumental, en la que prevalece 
una idea de un estudiante "vacío" de conocimientos e información, llevan a realizar prácticas de divulgación de la información "impositivas", el resultado es poca importancia que le dan los estudiantes a lo que se publica en estos medios. Así lo expresan los estudiantes quienes participan en el equipo de trabajo: realmente lo leen o lo ven por obligación, no lo valoran, dice MrE (Entrevista estudiantes, septiembre 21 de 2012). Sobre el periódico, la estudiante afirma: el periódico se ha vuelto más de los papás y de los profesores, son los que más lo leen, a pesar que está enfocado más a los jóvenes(...) a los jóvenes no les gusta leer (...) no le prestan tanta atención (Entrevista estudiantes, septiembre 21 de 2012).

Las actitudes de los estudiantes cuando emiten el Mgz es muy diciente, como lo indica $D v$, un preadolescente que participó de la experiencia: hay personas que ven el Mgz como una pérdida de tiempo y es una pérdida de clase, se duermen y todo (Entrevista estudiantes, septiembre 21 de 2012) y también en ello coincide $J D n$, otro de los preadolescentes que participaba en el proyecto: a Mgz lo ven como una pérdida de clase (...) ¿a qué hora hay Mgz?, ¿qué nos toca a tal hora? ¡Física! Ah bien, hoy hay examen, no lo hacemos. Lo demás es como una pérdida de clase (Entrevista estudiantes, septiembre 21 de 2012).

Y este tipo de situaciones lleva a los mismos estudiantes a reflexionar sobre las alternativas para que los medios y lo que se publica en ellos tenga más acogida entre los estudiantes, propone MrE: que los profesores implementen metodologías que tengan que ver con el Mgz y el periódico (...) un día que llevaron el periódico iban a hacer una actividad con el periódico, se veía que los estudiantes lo botaban y tenían que ir a pedirlo prestarlo a otro salón, eso no es; es que valoren, es que lean, es que cuando entreguen el periódico se tomen la tarea de leerlo(...) algo así que 
motive a los estudiantes, que no sea un deber, sino también una motivación (Entrevista estudiantes, septiembre 21 de 2012).

Estas situaciones expuestas por los estudiantes demuestran que la obligatoriedad no funciona como estrategia pedagógica para que se interesen por los contenidos de los medios, porque cuándo le llegan los contenidos de manera impositiva (según los modelos de la educación tradicional y de la comunicación divulgativa, informativa y vertical), es rechazada por los estudiantes que reciben los mensajes. Desde el punto de vista de los adultos -quienes deciden sobre los contenidos y los producen- puede tener sentido y valor, pero para los estudiantes no porque no se sienten representados o identificados en los temas que a ellos los convocan.

\section{Colegio 2}

\section{Aprender vocabulario}

(Observación 3, julio 23, 2012). La profesora $I s b$ dice que esta experiencia de medios posibilita a quienes participan en ella: aprenden a expresarse mejor, a tener claro que quieren ir a la Universidad y "despegan”, gracias al proceso que tienen en el Semillero. El despegue está relacionado con una mayor apropiación del lenguaje, en ese sentido la experiencia adquiere un carácter académico, en la medida que contribuye a reforzar los vacíos que tienen los estudiantes con el vocabulario y las normas gramaticales: es asunto de forma en la producción textual, la comprensión lectora; contribuye a los procesos lógicos, verbales, adquieren competencias enciclopédica, porque estos chicos no tienen tanta función enciclopédica, entonces adquieren vocabulario (Entrevista, marzo 26 de 2012). Y también es un despegue actitudinal: cuando 
hacemos la parte audiovisual, esos muchachos se transforman, dejan de tener tantos miedos que tienen ellos como personas, tienen tantas cohibiciones, no sé si por la problemática de vida que han tenido o están acostumbrados a estar opacos, entonces empiezan a brillar con luz propia (Entrevista, marzo 26 de 2012).

Esta experiencia, centrada en los estudiantes, se aprovecha para que ellos puedan escribir más y se aprovecha para reforzar las "competencias del lenguaje" con el propósito de "adquirir vocabulario" de manera que puedan expresar y relatar mejor sus historias. De otro lado, está la idea que es una experiencia que permita "transformar" la vida de los estudiantes, en el sentido que adquiera mayor confianza en ellos mismos para que les permita superar las "cohibiciones", los "miedos", la "opacidad", porque se sientan parte de algo y logren ser reconocidos por sus compañeros y maestros.

Cuando el proyecto de los medios en el colegio funcionó con los egresados, permitió a sus integrantes adquirir esa capacidad de relacionarse con su entorno y expresarse mejor, como lo corrobora Ed: A mí me sirvió en la parte social a conocer a las personas, saber expresarme. Yo era de los que poco sabía expresarme (...). En ortografía no me ayudó mucho, eso sí tenía yo, era pésimo para la ortografía, pero me ayudó a expresarme demasiado, a conocer el mundo y a gustarme el cuento del periodismo; me gusta informar, me di cuenta que me gusta informar y que me gusta servirle a la gente (Entrevista, septiembre 3 de 2012). La participación en el Semillero de Comunicación permitió a este joven adquirir habilidades sociales que le permitieron "conocer el mundo" (su mundo, el barrio), relacionarse con las personas, "servirle a la gente" desde su función de informar y producir contenidos; además, darse cuenta de sus tendencias profesionales, 
que es otra coincidencia con la maestra, que en ese contexto de marginalidad tiene aún más sentido, porque es algo que los estudiantes no tienen como una prioridad, para ellos "pasar a la universidad" es casi un imposible.

Desde estos puntos de vista - maestra y egresado- se percibe otra idea de educación, la misma no está muy atada a los aprendizajes académicos, sino a una educación conectada con el entorno social. En cuanto a la comunicación, más que pensar en una función divulgadora e informadora, aparece la idea de descubrir un "gusto por informar" desde el servicio a la gente, es decir, con un sentido más social, comprometido con las problemáticas que viven los habitantes del barrio, lo que le da otro sentido y valor a la experiencia.

A pesar de mostrar visos de ser una experiencia diferente, aparecen asuntos comunes con lo que sucede en la otra institución educativa; se supondría que el acceso a los contenidos tuviera otra motivación y otra valoración diferente por parte de los estudiantes y de la comunidad educativa en general. Sin embargo, la imposición para que lean lo que se publica también aparece en esta experiencia: lo leen porque les gusta o se lo leen porque les toca leerlo, porque si no ¿cuál es el sentido de que escriban y nadie los lea? Entonces yo como doliente número uno, yo si en mi clase promuevo, promulgo y obligo prácticamente a que eso se lea. (Entrevista, agosto 27 de 2012).

Esto muestra la complejidad del tema de la producción de medios en la escuela y más cuando se asumen los modelos tradicionales de educación para imponer la lectura de los propios medios de comunicación elaborados por los estudiantes. Se pierde el sentido de “escribir para ser leídos”, en la medida que los compañeros no acceden a la información desde la motivación y el deseo de conocer algo nuevo o algo que les pueda aportar, sino desde la imposición del maestro. 
Se suscitan además varios cuestionamientos acerca de si los estudiantes les interesa tener información o contenidos en los que se refleje su experiencia de vida, si existe entre los estudiantes la idea que la información es un derecho que les posibilita una mejor participación en la sociedad o prevalece en ellos la idea que la información es un producto de consumo y entretenimiento. Entonces, cuando en la escuela se obliga a los estudiantes a leer lo que publican en sus medios, menos posibilidades existen para que ellos comprendan que la información es un bien social y cultural al que tienen derecho de acceder.

A pesar de estas deficiencias presentadas en la práctica, la maestra señala que este tipo de proyectos en el colegio, ubicado en un contexto social complejo, debe continuar, por varias razones: Porque transforma vidas, porque la educación no se rige únicamente para llenar de contenidos una cabeza que viene en blanco; primero, porque no viene en blanco; segundo, porque no somos cabeza, somos seres humanos y esto fortalece integralmente, trae aprendizajes significativos para los pelados y si una experiencia como esta que sé y he visto que transforma miradas, se deja morir, ¿entonces que les estamos ofreciendo de diferente a los chicos de llenarles la cabeza de información y nada más? Tienen que existir diferentes opciones en la vida de los muchachos para que ellos se orienten y tomen decisiones, pero si no tienen experiencias ¿qué decisiones van a tomar? (Entrevista, agosto 27 de 2012).

En esta reflexión compartida por la maestra reconoce que los estudiantes tienen unos conocimientos previos $\mathrm{y}$, por tanto, sus cabezas no están "vacías"; es una llamado a la humanización de la educación y a la posibilidad que tienen los estudiantes, sobre todo los de este colegio, a "transformar" sus miradas a partir de una experiencia con medios de comunicación que 
les permite preguntar, analizar, buscar información y comunicarla a otras personas, una práctica educativa diferente a la de "llenar la cabeza de información", la educación bancaria de Freire (1985). Por eso, la maestra resalta, que este tipo de experiencias comunicativo/educativas deben permanecer en este tipo de instituciones como alternativa, "opción de vida" para unos estudiantes que empiezan a considerar la posibilidad de estudiar en una universidad, está relacionado de manera directa con la existencia de ellos y les brinda otras posibilidades para que aprendan a tomar decisiones sobre sus propias vidas, muy diferente a pensar la educación solo como un asunto de acumulación de información para obtener unas notas académicas.

En definitiva, hay que darle un carácter "comunicacional" a los medios que se producen en la escuela, como lo plantea Huergo, en la medida que se vean como espacios en los que se articulen prácticas, procesos sociales y culturales desde los cuales los integrantes de la comunidad educativa se sientan interpelados y se reconozcan (o no), y a la vez sean asumidos también como espacios con los cuales es posible educar y formar (2001, p. 31) a quienes accedan a los contenidos y conocimientos que se ponen a circular desde ellos. 


\subsubsection{Información}

\begin{tabular}{|l|l|}
\hline Categoría & Temas claves \\
\hline Información & - La información que se comparte en los medios escolares no es acogida por la \\
& comunidad educativa \\
& - La información está enfocada a brindar herramientas para los padres de \\
& familia \\
& - Los estudiantes sienten que deben ser responsables con la información que se \\
& comparte en los medios escolares \\
\hline
\end{tabular}

Cuadro 5.Categoría Información. Elaborado por el autor a partir del análisis de las entrevistas y grupos focales

\section{Colegio 1}

\section{El filtro de la información es lo institucional}

Para la comunicadora, $D$, tanto el programa de tv (Mgz) como el periódico que coordina tienen un enfoque institucional, es decir, las publicaciones están centradas en las actividades, eventos y en los personajes (estudiantes, empleados, maestros) del colegio. La información que viene de afuera, de su entorno social y lo que los estudiantes llevan de sus experiencias de vida no tiene cabida en los espacios de los medios, lo que marca una forma particular de producir información para y en un medio de comunicación en el colegio.

La lógica de este trabajo parte del hecho que es un colegio que proporciona demasiada información en muchísimos aspectos y como se trabaja con jóvenes de tantas edades nos permite meternos por todas las temáticas sin tener ningún problema (Entrevista, agosto 17 de 2012). Es una necesidad, en el sentido de canalizar la información por unos medios institucionales, aunque tiene ese tinte institucional de informar acerca de lo que el mismo colegio produce, referente a las decisiones, acontecimientos y personajes, como una manera de mantener al día a los estudiantes, maestros y padres de familia. 
Esto es una política establecida por la comunicadora y con la que enfoca su trabajo, que parte de la filosofía del colegio: siempre tener en cuenta la filosofía, lo que pretende el colegio; todo el enfoque institucional que hay para poder ser el filtro adecuado a toda la información que te llega. Porque obviamente la información es válida, siempre y cuando se guarde respeto a las directrices institucionales que hay (Entrevista, noviembre 21 de 2012). Como indica la comunicadora, en este colegio, existen "filtros" y unas "directrices" enmarcados en el pensamiento del colegio (confesional) que sirven de control a lo que se publica: "la información es válida si guarda las directrices”. Es la ratificación de lo expuesto por Kaplún, que es una experiencia en la que prevalece una comunicación unidireccional y transmisionista, que imponen unos contenidos (informaciones) desde el punto de vista de los adultos (maestros y profesionales) y se dejan de lado otros que podrían ser de interés para los estudiantes.

En el plan institucional del colegio, Mgz y el periódico están concebidos como un apoyo a la promulgación de valores y formación a los estudiantes, sostiene $D$, y en ese sentido se refuerza esta labor cuando los medios tienen ese enfoque divulgativo: el Mgz, el periódico, son medios informativos, que informan de las actividades, pues se trasmiten las actividades institucionales (Entrevista, noviembre 21 de 2012). En esta experiencia se apuesta por informar sobre lo que sucede "adentro" y en esa lógica se inscriben los maestros y los estudiantes. De esta manera se garantiza que la comunidad educativa esté informada acerca del acontecer en el colegio y que circule la información oficial. 


\section{Darle poder a la gente}

De acuerdo con lo expuesto antes, los estudiantes en el Colegio 1 además de no proponer ideas, tampoco buscan la información. Ese solo hecho que a los estudiantes les den los temas y les escriban lo que van a decir frente a las cámaras son una limitante, porque no valoran el hecho de producir una nota o un relato con base en la información obtenida por ellos mismos. Sin embargo, algunos estudiantes tienen una idea diferente sobre la información. Dice $D v$ : uno trasmite información importante que la gente puede entender y ponerlo en práctica o estar informado o de lo que ha pasado en el colegio de noticias. (Entrevista, septiembre 21 de 2012). Información asociada a transmisión y valorada como "importante" en la medida que puede llevar a los compañeros a poner en práctica lo que se publica o garantizar que la misma llegue a la comunidad educativa. Es esta una visión propia de los parámetros establecidos en el quehacer de los medios tradicionales.

Por su parte, $M n$, una de las estudiantes con más tiempo en el proyecto, sostenía: tener la oportunidad de hacer eso, de darle a alguien información, educar al pueblo es la actividad que uno puede hacer en la vida. Es darle a la gente poder, porque la gente cuando sabe y conoce, critica, indaga y actúa; me parece que informar a la gente es darle eso: poder para llevar a cabo cosas buenas (Entrevista, septiembre 21 de 2012). En esta intervención la información cambia sentido, porque parte de la consciencia que la misma es relevante, es decir, de utilidad cuando contribuye a tomar decisiones o para comprender situaciones personales o sociales. Asume, desde ese punto de vista, la responsabilidad de "dar información" y agrega un elemento nuevo "educar". Si en realidad existe entre los estudiantes estos dos elementos la información puede ir 
más allá de una trasmisión de datos, fríos, neutros, para que adquieran otro sentido: valorarla como un requisito esencial para "actuar", es decir, participar en la construcción de algo, como bien lo señala ella en la parte final de la intervención: darle poder a la gente para "hacer cosas buenas".

Es importante otorgarles el poder a los estudiantes de informar acerca de los temas que a ellos los convocan, porque ellos mismos son conscientes que es un asunto de responsabilidad, como lo expresa $M G$, otra de las estudiantes con más experiencia en los medios del colegio: $L a$ responsabilidad de nosotros es que la información o lo que queramos decir sea bien dada, pues tener un punto de vista claro para que la otra persona lo entienda, (...) yo tengo el poder de la voz de mis compañeros, de mis profesores, entonces yo creo que la responsabilidad es muy grande porque estoy representando no solo lo que yo siento, mi opinión, sino la opinión de muchas personas (Grupo focal, octubre 31 de 2012). Este tipo de experiencias puede contribuir a que los estudiantes adquieran criterios específicos: claridad en lo que expresan, para que quien reciba la información la comprenda; asumir la vocería de los otros, en este caso de los estudiantes, implica desde la visión de la estudiante, "una responsabilidad muy grande" porque ella "representa" la voz de los otros. En esta intervención pueden estar los parámetros que orienten el manejo de la información por parte de los estudiantes, que garantizan la libre expresión y que supera incluso los parámetros institucionales ocupados en limitar la misma.

Estas ideas expuestas por los estudiantes abren otras perspectivas de la información. El interés está centrado en quienes reciben la información: los estudiantes; más que estar informados, es 
recibir información que les permita "saber", "conocer" sobre algo y de esa forma tomar sus propias decisiones y participar (actuar).

De esta forma, en términos de Martín Barbero se abre la posibilidad de que los estudiantes asuman esa responsabilidad de ser "productores de significaciones", porque asumen la "voz de sus compañeros y maestros", es decir, que no sean los receptores que se duermen en clase o que no valoran la información que reciben, sino que se apropien de la misma y hagan sus propios relatos a partir de los contenidos recibidos y los compartan a su vez con otras personas (familiares, amigos, maestros).

\section{Colegio 2}

\section{Si los estudiantes no se informan los vamos a llevar a una opresión}

La inestabilidad del proyecto de medios de comunicación en el Colegio 2 lleva incluso a tener una reflexión profunda sobre el sentido de la información. La maestra direcciona esta función desde el cubrimiento de los eventos del colegio y la narración de las historias que suceden en el barrio; en ellos está la esencia informativa de los medios, en la medida que lo publicado sea significativo para los propios estudiantes. Esta idea contiene la "filosofía" del trabajo que hacen los estudiantes con la información. Para la maestra lo relevante es permitir que los estudiantes se vean como los "productores" de sus propios contenidos y que los mismos tengan un valor importante. 
Ahora, la práctica con los medios, por parte de los estudiantes y de quienes participaban de la experiencia, lleva a que ellos mismos reflexionen y valoren el sentido de informar. Por ejemplo, las que comparte el egresado, $E d$.

En primera instancia, lo primero que resaltó de su labor cuando estuvo en el periódico del colegio fue porque les dábamos a conocer a los muchachos qué estaba pasado en el barrio, qué estaba pasando en su colegio (Entrevista egresado, septiembre 3 de 2012). "Dar a conocer" implica brindar historias o relatos periodísticos que permitan a los compañeros "saber" algo más de lo que pasa en su barrio y que no sabían o pasaban desapercibidos, como una labor informativa básica, para tener otra visión de los acontecimientos.

Esta labor tenía un sentido especial cuándo este joven asume la crítica en sus contenidos, sobre todo cuando cuestionó la gestión y administración de la rectoría del colegio. Esta situación provocó muchos comentarios no solo del directivo, sino de los estudiantes y maestros. Ed compartió las razones que lo llevaron publicar el informe: yo era muy amigo del Rector, siempre me la llevé bien con él, pero para la parte de informar siempre creí que era un cuento aparte. Entonces él era uno que me decía: ¿por qué esas publicaciones? Y yo le decía que los muchachos deben estar informados de qué está pasando, en que estamos invirtiendo los recursos, por qué el colegio no está avanzando, ¿qué es lo que está pasando? (Entrevista, septiembre 3 de 2012). Aquí hay un cuestionamiento a la autoridad (el Rector), desde un estudiante que se atreve, en el buen sentido del término, a solicitar una explicación acerca de la gestión del rector. Además, porque asume la vocería de los estudiantes y otros personajes de la comunidad educativa. En esta situación hay que resaltar algo: el estudiante asume esa vocería, porque los "otros", en este caso 
los estudiantes, los "muchachos" como él los denomina "deben estar informados de lo qué está pasando", no está pensado para sí, sino en sus lectores. Incluso ahí hay otra ruptura, en el sentido que por lo general se informa "desde arriba", desde los directivos, hacia abajo, la comunidad educativa; en este caso es un estudiante quien "desde abajo" toma la palabra y pregunta, cuestiona e interpela a la autoridad. Así ejerce el derecho de estar informado, para cumplir con el deber de comunicar.

Y además de esto, $E d$ expone un argumento más sólido sobre esta decisión de cuestionar la gestión del Rector: yo decía si los estudiantes no se informan, si no conocen sus derechos, sobre sus deberes y libertades, los vamos a llevar a ellos a una opresión (...) ellos deben tener el conocimiento para después saber qué es lo que deben hacer y qué es lo que no deben hacer. (Entrevista, septiembre 3 de 2012). Con esto se demuestra que no es una posición crítica nacida desde "un parecer" personal, sino fundamentada en el deber ser de la información: el derecho de estar informados para tomar decisiones autónomas para sus propias vidas (que deben hacer y que no deben hacer). Y es también una reflexión acerca de la información: hay que acceder a ella y hay que compartirla para que los integrantes de una sociedad sepan que decisión deben tomar, por el contrario, si ello no se hace, se puede llegar a la "opresión", a la manipulación y a la confusión.

Por eso es importante que la escuela entienda que la información va más allá de unas actividades divulgativas, a veces oficial, a veces desde la óptica de los "adultos" (maestros); la escuela tiene la oportunidad de acercarse a las "necesidades" informativas de los estudiantes y a sus temas, para permitir que ellos también cuestionen y critiquen a la institucionalidad. Si en la escuela no se 
dan estos espacios, en ella misma se estará fomentando la "opresión” que expone este joven egresado.

Además, si se tiene en cuenta el contexto social donde está ubicada la institución educativa, los argumentos que exponía el egresado a la maestra tienen mayor relevancia, porque le otorgan a la información otro sentido más contextual, otro valor a la misma, siempre y cuando la escuela este abierta a este tipo de reflexiones: yo le decía a la profesora: el que tiene el conocimiento tiene el poder y si ellos se informan y ellos conocen qué está pasando van a tener mejor educación, van a tener más habilidades para afrontar las cosas después. (Entrevista, septiembre 3 de 2012). Es tal vez el reto que tienen los medios de comunicación en la escuela: trascender la mirada divulgativa, para llevar a que los estudiantes que publican en estos espacios generen "contenidos con sentido", es decir, la información que construyan esté basada en sus propias ideas, partan de sus conocimientos y de sus preguntas, de manera que se conviertan en "otro" conocimiento que también circule en la escuela, a la par con los contenidos oficiales. Es un conocimiento para la vida, no solo para prepararse para el mundo laboral, como se pregona desde los enfoques competitivos de la educación, sino que permita a los estudiantes comprender el mundo donde vive (el barrio), sus vivencias (los temas propios de los niños y jóvenes a partir de las relaciones con la familia y sus pares) y sus preguntas (acerca de la sociedad y lo que concierne a ella). El poder de esa información está en que brinda elementos de vida para afrontar la vida, sobre todo, si se tienen más elementos de análisis y reflexión. Por eso, basado en estos puntos de vista de la información entre la comunicadora y los estudiantes, se establece el siguiente cuadro comparativo. 


\begin{tabular}{|c|c|}
\hline Información desde adultos & Información desde jóvenes \\
\hline - Tiene un carácter divulgativo & $\begin{array}{l}\text { - Consideran que la información } \\
\text { tienen un carácter educativo }\end{array}$ \\
\hline $\begin{array}{l}\text { - Está enmarcado en la filosofía y las } \\
\text { directrices institucionales }\end{array}$ & $\begin{array}{l}\text { - Debe contener las voces de los } \\
\text { estudiantes }\end{array}$ \\
\hline $\begin{array}{l}\text { - Limita la publicación de los } \\
\text { contenidos de los estudiantes }\end{array}$ & $\begin{array}{l}\text { - Busca romper los esquemas } \\
\text { institucionales: critica, cuestiona, } \\
\text { propone y promueve la autonomía. }\end{array}$ \\
\hline $\begin{array}{l}\text { - Se nutre de los acontecimientos de } \\
\text { la institución }\end{array}$ & $\begin{array}{l}\text { - Es reflexiva y busca aportar } \\
\text { elementos de análisis para la toma } \\
\text { de decisiones }\end{array}$ \\
\hline - Es elaborada por los maestros & $\begin{array}{l}\text { - Parte de las inquietudes de los } \\
\text { estudiantes }\end{array}$ \\
\hline - $\quad$ Es un instrumento & - Es un derecho y un deber \\
\hline $\begin{array}{l}\text { - Cuenta lo que sucede en la } \\
\text { institución }\end{array}$ & $\begin{array}{l}\text { - Relata lo que sucede en el barrio y } \\
\text { en la vida de los jóvenes }\end{array}$ \\
\hline - Parte de la visión de los adultos & $\begin{array}{l}\text { - Se construye desde el pensamiento y } \\
\text { las necesidades informativas de los } \\
\text { jóvenes }\end{array}$ \\
\hline
\end{tabular}

Cuadro 6. Comparación puntos de vista maestros-estudiantes. Elaborado por el autor

\section{Recuperar la memoria}

Cuando la escuela asume la información como "una trasmisión de datos" (Aparici, 2006, p. 40) o como un mecanismo que "permite retomar datos de su ambiente y estructurarlos de una manera determinada" (Paoli, 2004, p. 15), con el interés de dar cuenta sobre los acontecimientos de tipo social, académico, deportivo, cultural, entre otros, que tienen lugar en ella, generan prácticas 
comunicativas de tipo funcionalistas y divulgativas, con las intenciones de que la comunidad educativa esté enterada de lo que sucede en la institución.

Desde los intereses de los adultos, este tipo de enfoque pretende garantizar la circulación de datos en la comunidad educativa: estudiantes, maestros, directivos y padres de familia. Sin embargo, es una práctica que puede llevar a que se pierda el sentido de la información, sobre todo con los estudiantes, porque se remite a reiterar lo que se ya se conoce y llegar así a la trivialización de la información (Schmucler, 1997).

Así, como indica Schmucler, cuando se genera una cantidad de datos que se reciben por diferentes canales la información puede perder valor y relevancia, sobre todo, porque los contenidos y las palabras están desconectados del mundo propio del estudiante y se asocia más al discurso cotidiano institucional y académico. El hecho de recibir cada mes el reporte de los diferentes eventos acontecidos y de manera reiterativa, hacen que la información se convierta en un acto trivial, poco significativo para la vida y los intereses de los estudiantes.

El gran riesgo de enfocar la información para fines divulgativos institucionales es provocar en los estudiantes la idea que las palabras van a decir lo mismo, llevándolas a un estado de intrascendencia, en la que pierden peso y significado. Utilizar las palabras decir lo básico es llevarla a un estado de irresponsabilidad y de la trivialidad (Schmucler, 1997, p.204). Esto es un llamado de atención a la escuela, porque en lugar de propiciar la apropiación de la palabra para “pronunciar" el propio mundo, según lo planteado por Freire, con este tipo de acciones se llega a un reduccionismo en el uso de la palabra y del lenguaje, a pronunciar palabras huecas e 
inauténticas, porque no logran atraer la atención de los estudiantes y tampoco provoca la necesidad de expresar sus ideas y comunicar sus propias vivencias.

Por eso, conceder a los estudiantes que participan en este tipo de experiencias el "poder" de la información para asumir la vocería de los "otros", para compartir información de interés, “educar” a quienes reciben los contenidos, propiciar la expresión libre de sus ideas, generar reflexiones entre sus compañeros, asumirla como un derecho, un deber y un servicio público, y relatar sus propios temas a partir de la experiencia de vida, requiere que la palabra recupere el valor y significado propio, para que adquiera así otro sentido: información que posibilite la circulación de los conocimientos de la vida.

Concebir que la información como un conocimiento es aceptar que la misma sea una construcción social (Giroux, 2003, p. 186), esto implica que los jóvenes que participan en estos proyectos deben comprometerse en alimentar los temas propios con investigación, observaciones y diálogo con las personas; deben ser creativos en la forma de narrar, para que como resultado de lo anterior reconozcan su propia voz y con ella producir relatos más auténticos. De esta manera, se adquiere un compromiso diferente con la información: hacerse responsables de las palabras es asumir la responsabilidad de construir memoria (Schmucler, 1997, p. 197) a partir de sus vivencias, interrogantes y reflexiones.

Además, con los planteamientos de la pedagogía crítica (Giroux, McLaren) la información en la escuela puede adquirir otro sentido si se concibe como un conocimiento que se construye de manera colectiva con los maestros y estudiantes, y con el propósito de hacerlo circular entre la comunidad educativa. 


\subsubsection{Ciudadanía}

\begin{tabular}{|c|c|}
\hline Categoría & Temas claves \\
\hline Ciudadanía & $\begin{array}{l}\text { - La escuela limita la expresión de las ideas de los estudiantes } \\
\text { - Los estudiantes aceptan las limitaciones para expresar sus ideas } \\
\text { - La expresión de las ideas se limitan a hablar de lo "bueno" } \\
\text { - Los estudiantes sienten que los directivos los privan de hablar de } \\
\text { los temas que los afectan }\end{array}$ \\
\hline
\end{tabular}

Cuadro 7.Categoría Ciudadanía. Elaborado por el autor a partir del análisis de las entrevistas y grupos focales

\section{La "no expresión" de la palabra}

El proceso de producción de textos (discursos) escritos, orales, audiovisuales e hipertextuales para los medios escolares es un asunto complejo, porque existe un "control" por parte de los directivos y los maestros de los colegios, acerca de los enfoques y contenidos de los temas que proponen los temas que pueden ser publicados en los medios de la institución educativa. Este tipo de experiencias en la escuela debe servir para formar a sus estudiantes en la responsabilidad de informar, en el fomento de la libertad de expresión y de opinión, además, garantizar la publicación de los temas y los pensamientos de ellos.

Sin embargo, en las instituciones estudiadas, estas posibilidades están limitadas porque la prioridad está en la divulgación y se deja de lado un trabajo más profundo y significativo: asumirse como "productores críticos", comprometidos en la elaboración de contenidos de mayor significado, en la medida que reflejen los interés, los pensamientos y la experiencia de vida de los estudiantes, con la posibilidad de ir más allá de las aulas de clase. Complejo sí, más cuando el tema emerge de las conversaciones y de los relatos que comparten los estudiantes y maestros. 


\section{Colegio 1}

\section{"Ud. sabe de qué trata el colegio"}

En el Colegio 1, de una manera muy sutil $D$, la comunicadora, orienta sobre los criterios para publicar un tema: ellos vienen y me preguntan si son libres, yo les digo: hágalo, pero ud. sabe de qué se trata la institución, ud. sabe qué puede y qué no puede hacer, no haga que yo de pronto le diga eso no lo puede hacer, para que no piense que yo no quiero dejar sacar eso. Hay unos parámetros que ud. tiene que cumplir (Entrevista, agosto 17 de 2012). De manera aparente existe libertad, pero de inmediato aparece la advertencia: "hágalo, pero ud. sabe de qué trata la institución", "hay parámetros que ud. tiene que cumplir". En este caso, se superpone la institucionalidad sobre la motivación y el interés del estudiante por comunicar sus ideas.

Los estudiantes admiten que existen límites en los temas: Man. Obviamente los temas tienen sus límites, este es un colegio católico y no podés venir a hablar aquí no sé del 31 de octubre (Halloween), aquí no se puede hablar de eso, un especial de disfraces, no se puede y Mar, otra compañera intervienen: Un concierto de reggaeton tampoco (Entrevista, septiembre 21 de 2012).

En términos de la comunicadora "parámetros", en términos de la estudiante "límite". La institucionalidad impide que se hable de aquellos temas que hacen parte del mundo social de los estudiantes: Halloween, como fiesta comercial y el reggaeton, desde la aceptación y la apropiación de este género musical en los jóvenes. Impedir que se hable de estos temas es limitar la posibilidad de una discusión crítica sobre los orígenes y las intencionalidades de ambos temas, a partir de la pregunta (pedagogía crítica) y a partir de las experiencias y las ideas que tienen los 
estudiantes sobre ambas temáticas, para construir desde ahí los contenidos que serán $\operatorname{comunicados}^{72}$.

De igual manera, admiten que existe censura: Man. En un espacio universitario y la vida diaria se supone que la prensa no debe tener censura, eso es lo que se dice que la libertad de prensa, pero cuando vos te metes a este colegio, vos sabes para lo que vas, el colegio es de una congregación católica (...). Vos no podes contradecir la educación que se supone que está recibiendo (Entrevista, septiembre 21 de 2012).

La tradición comunicativa del colegio está en la divulgación de los eventos y eso facilita la estandarización de la información, a tener una posición "neutra", pero cuando se enfrenta a los temas que vienen de "afuera" que llevan los estudiantes aparece la norma y las limitaciones. La libertad de prensa existe afuera, pero no adentro; en la escuela se genera una burbuja que aísla y desconecta con la sociedad, lo cual resulta contradictorio, porque debe ser el espacio que aporte a la formación para que los estudiantes empiecen a integrarse a la sociedad, como lo plantea Bacher (2009).

La norma es la que está por encima de todo: Vos no podes contradecir la educación que se supone que está recibiendo. Existe una sumisión a la censura y una práctica de aceptar lo que se impone, propio de la educación tradicional. Los cuestionamientos, la crítica y la expresión de ideas propias es algo que no se aprende en esta experiencia de comunicación.

${ }^{72}$ Resulta paradójico, sobre todo, cuando en el Manual de Convivencia está planteado un perfil humano del estudiante caracterizado por su espíritu crítico, que piensa por sí mismo, con capacidad de análisis y objetivo. 
Entre los estudiantes el ejercicio en los medios escolares está marcado por un patrón: los límites. $D v$, un preadolescente que participó de esta experiencia, así lo expresa: Sería muy bueno que uno pudiera hacer sus propias notas, pero con el tema que a uno le pongan y con sus límites (Entrevista estudiantes, septiembre 21 de 2012). Coincide con lo que compartieron sus compañeras antes: los temas tienen límites en este colegio. Esto es admitir que los estudiantes prefieren seguir en la posición de hacer lo que les proponen los adultos (la comunicadora y el Comité), antes que exponer sus puntos de vista, sus intereses, es un riesgo que no quieren asumir.

Para corroborar aún más el tema de la censura, en otro espacio, en el grupo focal, (Octubre 31 de 2012) el tema volvió a emerger, a partir de la pregunta: ¿los estudiantes pueden publicar cualquier tipo de tema que sea de interés para ellos?

Mar. Depende del enfoque no tanto, sino de las normas educativas del colegio.

Man. El colegio como institución tiene una filosofía, un pensamiento que trata de transmitir a los estudiantes. Los medios siendo parte del colegio no pueden salirse de lo que el colegio promueve.

Moderadora ${ }^{73}$ ¿ ¿Cómo que temas no pueden tratarse?

$D$ (comunicadora). ¿Cuál es el tema que siempre han peleado uds? Uds. no pueden hablar de reggaetón, por ejemplo, es un tema del que ellos no pueden hablar.

Mar. Yo también lo pensé, de eventos ... como que no esté dentro de la norma educativa.

\footnotetext{
${ }^{73}$ El grupo focal estuvo moderado por una pasante de la Especialización de Periodismo Electrónico e integrante del Grupo de Investigación en Comunicación Urbana, GICU, quien orientó la actividad a partir de los parámetros construidos por el investigador, a su vez, el investigador intervino en los momentos que consideró necesario profundizar en determinados temas de su interés.
} 
Man. O si alguien decide hacer un artículo sobre Halloween, en el colegio no se celebra Halloween porque es un colegio católico, si vamos a hacer un artículo de Halloween no se puede.

"Normas educativas", "filosofía", "pensamiento que trata de trasmitir", "reggaetón es el tema que no pueden hablar", "eventos que no estén dentro de la norma educativa", "es un colegio católico”. El colegio generó y promovió unos moldes con las normas educativas de la institución que limitan la libertad de expresión de los estudiantes. Ello influye en lo que se publica y, sobre todo, enfatiza en lo que se puede publicar: aquello que refuerce los valores institucionales.

En cuanto los criterios de publicación establecidos en el colegio, la comunicadora respondió: cumplir con la filosofía institucional, no salirse de ese parámetro y no hablar de reggaetón. Esos son los dos parámetros que hay (Entrevista, noviembre 21 de 2012).

Si bien existe ya una aceptación y una explicación de por qué existen las limitaciones o la censura de la que hablan los estudiantes y porque "está prohibido", la cual obedece a que "eran contenidos muy fuertes y muy pegados" y visto esto desde la moral cristiana puede llegarse a la conclusión a que esto era algo "malo". Sin embargo, no hay que desconocer que eso es lo que viven los estudiantes fuera del colegio y en los espacios donde tienen vida social. De ahí la confrontación cuando ellos llevan su vida al colegio y les "prohíbe" hablar del tema, restringe los comentarios. Llevar a estos extremos este tema en el colegio, es algo que limita la formación en la expresión de las ideas y niega la posibilidad de compartir la experiencia de vida de los estudiantes y evita que circule en la institución educativa, para que en ella se hable del tema. Para la comunicadora debe haber cabida a los diferentes temas, por eso sostiene: 
D. Yo pienso que no debe haber un tema vetado en los medios escolares, ni en ninguno, porque precisamente de eso se trata la formación, de enseñar al estudiante lo que hay en el mundo (...) Yo pienso que en medios de comunicación no es el tema, sino la forma como se enfoque. (Entrevista, noviembre 21 de 2012).

Si bien la comunicadora admite que no deberían existir temas vetados, tampoco la solución está en la forma, ni el enfoque del tema, requiere una visión crítica desde la educación para que los estudiantes puedan interpretar y expresar su propio mundo, sin riesgo de ser callados. Se requiere crear las condiciones necesarias para que los estudiantes hablen con sus propias voces para que autentiquen sus experiencias de vida (Giroux, 2008, p. 256). La perspectiva que se debe mantener es publicar para aportar al conocimiento de los otros, por eso, debe ser un tema de interés general, no de unos pocos, para que motive a quien recibe estos mensajes a compartirlo con otros más.

\section{Colegio 2}

\section{Nos iban a cerrar el medio}

La censura también apareció en el Colegio 2 (público); si bien existe una apertura hacia diferentes temas, también se dan las limitaciones y hasta situaciones de autocensura, por parte de los estudiantes. Hubo un momento, cuando los estudiantes estaban apropiados del periódico y sus contenidos que llegaron al punto de cuestionar la gestión del propio rector de la institución: tuvimos una discusión con el rector acerca de unos hechos que estaban pasando en el colegio. Yo entro a criticar las partes que no me gustan (...) se estaban presentando algunos errores $y$ 
publiqué una noticia que al rector no le gustó y dijo que nos podía cerrar el medio si se seguían presentando esa clase de noticias $^{74}$. (Entrevista, egresado, septiembre 3 de 2012).

Este testimonio se presta para varias interpretaciones: primero, que los estudiantes tenían la iniciativa y la vocería para cuestionar lo que ellos consideraban no funcionaba, es un tema que parte de abajo (los estudiantes) hacia arriba, el rector; segundo, que el estudiante asuma una posición crítica: "criticar las partes que no me gustan", "se estaban presentando algunos errores"; tercero, los estudiantes tenían autonomía, porque el mismo rector no había leído con anterioridad la información y por eso al ver lo publicado les dice que "puede cerrar el medio"; cuarto y conclusión: la responsabilidad de informar. Los estudiantes deben aprender a expresar sus ideas y medir las consecuencias de lo que se dice, por eso, es importante preguntar sí el informe obedeció a un asunto emotivo o tenía la intención de aportar una información importante para la comunidad educativa.

Esto generó consecuencias para la experiencia de los medios en el colegio. La profesora Isb sostiene que trajo enseñanzas: Tuvimos un tiempo con un poco de censura, pero digamos que eso es normal (...) habia chicos muy críticos, entonces empezaron a escribir un poquito pasado de tono sobre los aspectos que para ellos no eran los más adecuados frente a la institución, entonces hubo un poquito de censura, nos pararon un poquito el ritmo, pero pienso que es normal. (Entrevista, marzo 26 de 2012).

\footnotetext{
${ }^{74}$ En el Manual de Convivencia está establecido en los Derechos de los estudiantes que pueden expresar en forma libre y responsables sus inquietudes y manifestaciones personales, sin contraversión de las normas y usos de la sana convivencia.
} 
La maestra reconoce que existió una censura por la forma de tratar la información, por el tono que utilizaron y, sobre todo, porque "había chicos muy críticos", y para hacer crítica deben existir argumentos y fundamentos para expresar los puntos de vista o para sustentar la veracidad de la información que se comparte, porque la "crítica" tiene el riesgo de ser asociado a problemas y ello puede traer consecuencias, como cerrar el medio de comunicación. Queda la idea de cómo formar en la crítica. Sostiene Giroux (2003) que formar en la crítica implica la problematización de temas y situaciones que se presentan en escenarios públicos. En este caso, por ser un colegio público es el escenario para que los estudiantes planteen interrogantes a quien representa la autoridad: el rector, y narren desde su perspectiva aquello que les parece inconveniente, porque incide en un bien común: el colegio, y en quienes lo integran: sus estudiantes y sus maestros. Si la escuela es capaz de asumir este tipo de prácticas, es porque está preparada para formar ciudadanos críticos y activos (Giroux, 2003, p. 221).

\section{La rectora da el permiso}

Para los estudiantes que hacían parte del Semillero de Periodismo en 2012, la rectora era quien autorizaba o rechazaba los informes que se publicaban. Entre los estudiantes que participaron en el grupo focal se generó una discusión al respecto (Grupo focal, noviembre 7 de 2012).

Sn señaló: yo puedo decir que este medio escolar de esta institución, no es tan correcto (...)todas las noticias que nosotros saquemos o hagamos, no las podemos publicar sin que la rectora dé su permiso, entonces, ella podría decir si-no-sí, dependiendo como le convenga a ella. Entra de nuevo la figura de autoridad como censor, la que autoriza o no lo que se publica en el medio, porque los informes que ellos realicen están supeditados a la aprobación de la rectora, por algo 
que el estudiante señala: depende "como le convenga a ella". Esta situación plantea un reto pedagógico: formar a los estudiantes, a los maestros y, sobre todo, a los directivos en la confianza para permitir que en esos espacios se expresen ideas con libertad y responsabilidad.

Sn continúa con su reflexión encaminada a la autoevaluación y a la autocrítica: Si nosotros nos pondríamos a decir, criticar la institución tal como está, se vería mal entre otros colegios y eso afectaría a nuestra institución. Está en juego la imagen del colegio y aunque se deduce que en esta reflexión que no todo marcha bien, es parte de la madurez institucional reconocer que existen falencias, pero a su vez permite que los mismos estudiantes hagan "criticas" al colegio, por el contrario, no se gana nada con evitar que esto salga a la luz pública. A raíz de esto $S n$ reflexiona sobre las posibilidades que tiene el medio escolar y cuestiona a sus compañeros acerca de la función de ese medio: ¿Qué hacemos nosotros? Nos tocaría como medio comunicativo (...) hacer noticias no de los problemas que tenga la institución, sino de los acontecimientos que tenga.

Es interesante observar una pregunta que busca aclarar la función que tienen en el medio ¿qué hacemos nosotros? Y a su vez una respuesta, "nos tocaría" como un deber implícito comunicar no desde la problematización, sino desde la limitación y esto es la divulgación de los eventos, es entrar en los terrenos de lo "neutro", porque no genera compromisos, ni discusiones. Y esto responde a lo que sucede en el Colegio 1, que a la luz de esta reflexión del estudiante, muestra una explicación de los enfoques que asumen los medios en las instituciones educativas, que evitan en buena parte la crítica o la expresión de otros temas a los que la escuela no puede controlar, pero que hacen parte de la vida de los estudiantes. 
Sn cuestiona cuál es la función de los medios escolares: Mi pregunta es ¿un medio de comunicación se encarga de mostrar lo malo o mostrar las cosas buenas?

Aquí la discusión toma un tinte moralista de calificar como bueno o malo lo que se publica en los medios en la escuela. Lo bueno asociado a la divulgación de los eventos o acontecimientos que contribuyen a resaltar la imagen de la institución, los estudiantes destacados, los logros deportivos y hasta los pasatiempos, -estereotipos que identifican a este tipo de medios-; por su parte, "mostrar lo malo" es problematizar y cuestionar aquellos temas que no funcionan desde el punto de vista de los estudiantes.

Sn vuelve a intervenir: mi pregunta es: si el caso de este periódico es solo mostrar las cosas buenas de la institución, ¿para qué estamos aquí nosotros? Y es de resaltar esa idea, porque subyace un cuestionamiento del papel del "reportero escolar": o es una caja de resonancia, un emisor/repetidor que dice, escribe y publica solo aquello que los maestros aprueban o, por el contrario, es un ser autónomo, crítico, propositivo y responsable con lo que dice y cómo lo dice. Estas son también formas de promover la censura, en el sentido de permitir que se publiquen solo aquellos temas que el profesor o el rector aprueban o, por el contrario, favorecer que sean espacios en los que la voz de los estudiantes sea escuchada y comprendida, como plantea Giroux, y que ese ejercicio posibilite el reconocimiento de ellos como participantes activos en el mundo (2003, p. 300) con otro tipo de ideas, reflexiones y narraciones relacionadas con los conocimientos propios de los estudiantes.

Otro de los compañeros del Semillero de Periodismo y participante en el Grupo focal, $\mathrm{Cm}$, señala: Y lo mismo está pasando en el colegio, nos están privando de hablar de temas que nos 
aquejan, entonces no nos dan la oportunidad de plantear esos problemas, (...)la rectora, si eso es verdad, ella revisa todo el periódico y si hay algún tema o asunto que involucre a ella o algún profesor, o al colegio o algún problema del colegio pues no lo va a dejar publicar. Entre los estudiantes persiste esa idea que los directivos coartan la libertad de expresión. Por eso, un medio de comunicación que se produce en un colegio, debe ser una propuesta alternativa en la que más que difusión de acontecimientos, circulen los conocimientos que construyen los estudiantes a partir de la "lectura" que hacen del mundo (su pequeña sociedad) en el que viven, la cual incluye la institución educativa, sí el propósito es hacer de estos proyectos de comunicación, espacios de libre expresión de los estudiantes, más que de censura y limitación de las ideas.

De igual manera, este tipo de acciones y decisiones por parte de las directivas lleva a generar otras actitudes como la autocensura, como dice Sn: Si nosotros empezamos a decir las cosas malas que tiene la institución todos los alumnos nos van a coger con nosotros, muy chismosos, que tal; en cambio, si decimos las cosas buenas, solo resaltaríamos las cosas buenas y así no nos veríamos involucrados en los diferentes problemas que han pasado. De alguna manera, es renunciar a empoderarse del proyecto, a la expresión responsable de sus ideas, a la problematización del mundo escolar; es acomodarse y dejar de lado la crítica para evitar involucrarse en los problemas que puedan acarrear lo que comuniquen, por tanto, renunciar a marcar la diferencia entre las experiencias de los medios escolares. Así, se pierde la oportunidad de que los estudiantes aprendan a cuestionar la escuela, a preguntarle a su contexto social, a responsabilizarse de lo que publican, en definitiva a formarse como ciudadanos comprometidos con la transformación de su sociedad. 


\section{Consecuencias de la censura}

Por eso, resulta paradójico que sean las instituciones educativas, espacios en los que debe promoverse la participación y la formación ciudadana, en donde se gesta otro tipo de aprendizaje relacionada con la no expresión de las ideas y la censura. Prima, según lo expuesto, los valores y la filosofía institucional, en un caso; y el control frente a lo que se publica, en otro caso, frente a los lineamientos universales y nacionales, consagrados en la Carta Universal de los Derechos Humanos y en la Constitución Nacional de Colombia. Estos documentos que garantizan los derechos de los ciudadanos no están presentes en la discusión.

Dice el Artículo 19 de la Declaración Universal de los Derechos Humanos: Todo individuo tiene derecho a la libertad de opinión y de expresión; este derecho incluye el no ser molestado a causa de sus opiniones, el de investigar y recibir informaciones y opiniones, y el de difundirlas, sin limitación de fronteras, por cualquier medio de expresión. Por su parte, la Constitución Política de Colombia, en el artículo 20 plantea: Se garantiza a toda persona la libertad de expresar y difundir su pensamiento y opiniones, la de informar y recibir información veraz e imparcial, y la de fundar medios masivos de comunicación. Estos son libres y tienen responsabilidad social. Se garantiza el derecho a la rectificación en condiciones de equidad. No habrá censura.

Ambos colegios están llamados a promover el conocimiento y la aplicación de los Derechos fundamentales y, sobre todo, inculcar en sus estudiantes y en general a la comunidad educativa en la apropiación de los mismos como parte de la formación ciudadana. Resulta contradictorio que sea en las instituciones educativas donde se preparan los futuros ciudadanos exista un desconocimiento de los deberes y derechos de los ciudadanos en formación. Los medios 
escolares cuando reducen su accionar al mejoramiento de las "competencias" de redacción y escritura de los estudiantes y a la divulgación de la información institucional, pueden ganar en visibilidad, pero pierden el sentido y la esencia de este tipo de experiencia: aprender a ser autónomos, críticos, responsables de sus propias voces, a luchar por sus deberes, en general, a prepararse para la transformación de la sociedad en que viven.

A continuación se presentan dos esquemas que ilustran cómo se enfoca el trabajo de los medios en las instituciones educativas: una desde el maestro como centro y protagonista del proceso y la otra desde los estudiantes. 


\section{Esquema 1. Centrado en maestros}

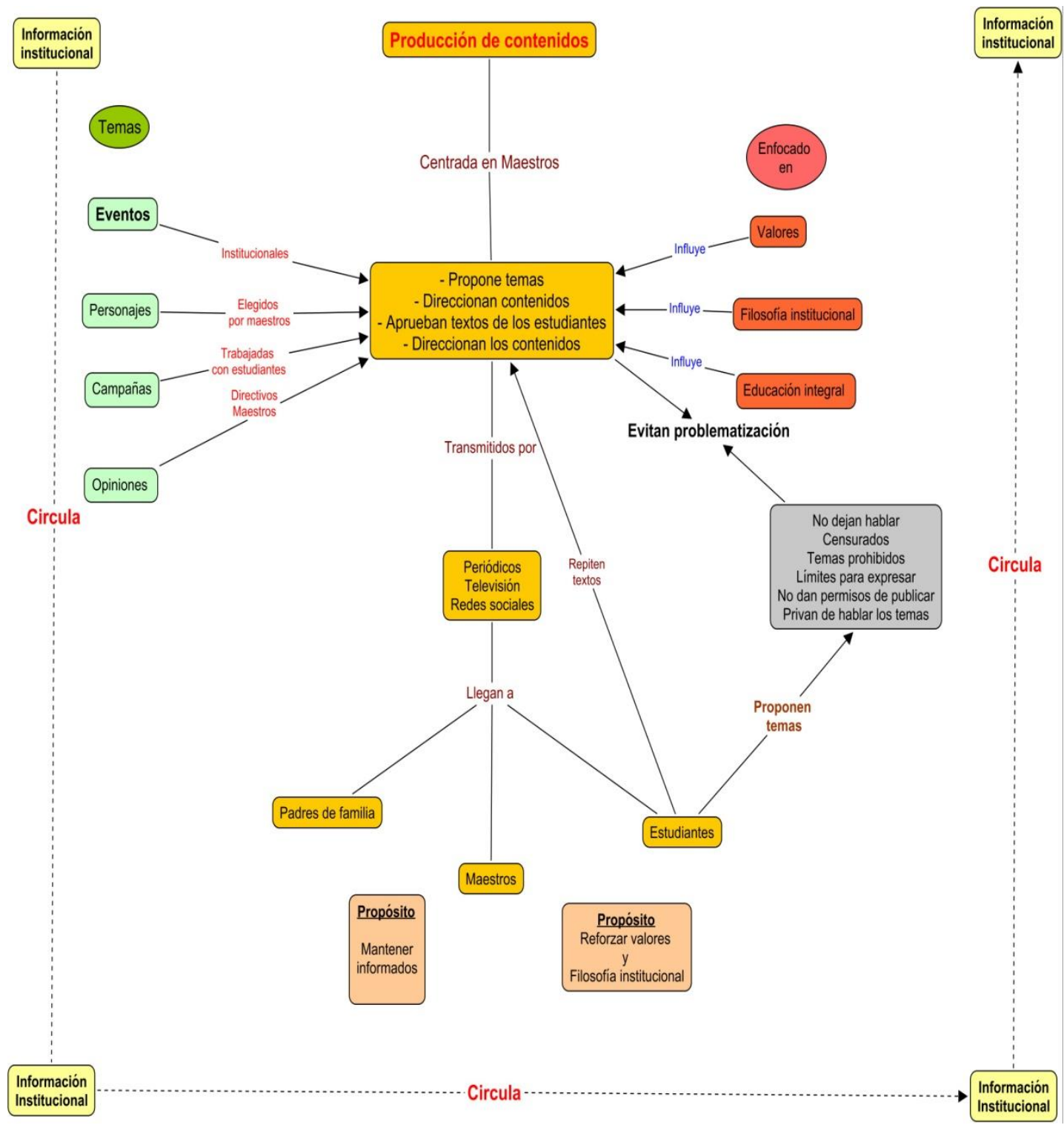

Esquema 1 elaborado por el autor Juan Carlos Ceballos Sepúlveda 


\section{Esquema 2. Centrado en los estudiantes}
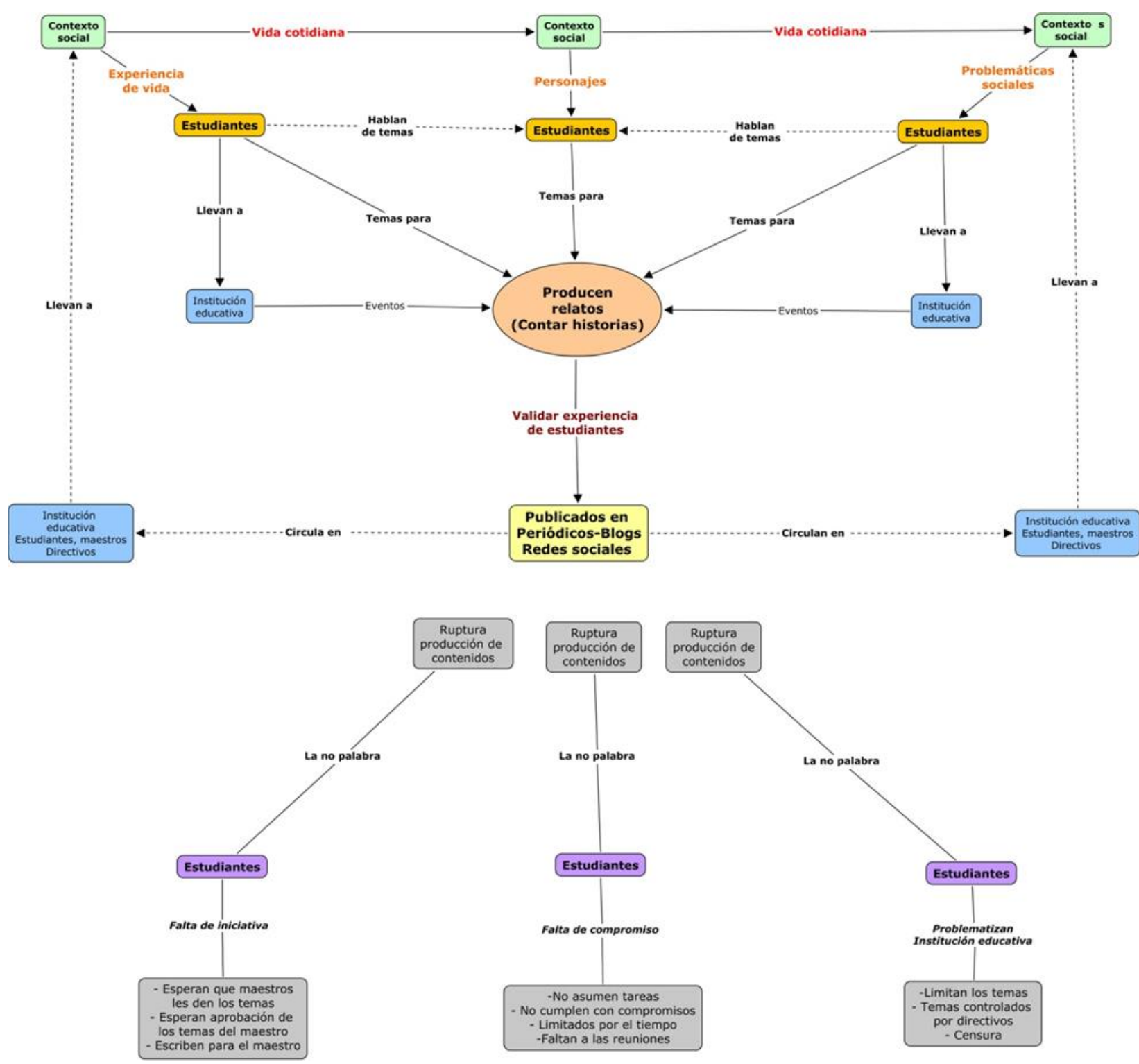

Esquema 2 elaborado por el autor Juan Carlos Ceballos Sepúlveda 


\subsubsection{Currículo}

\begin{tabular}{|l|l|}
\hline Categoría & Temas claves \\
\hline Currículo & - Las experiencias de medios escolares se desarrollan en espacio \\
& "extracurriculares" \\
& - La experiencia de los medios escolares transforma a los \\
& estudiantes \\
& - Los medios escolares posibilitan entrar en contacto con el \\
& contexto social \\
& - Solo si los medios escolares se transversalizan pueden \\
& comprometer a otros profesores \\
& - Los medios escolares mejoran la capacidad de expresión de los \\
& estudiantes \\
& - Los medios escolares son espacios de preparación para una \\
& profesión \\
\hline
\end{tabular}

Cuadro 8. Categoría Currículo. Elaborado por el autor a partir del análisis de las entrevistas y grupos focales

En propuesta de Freinet, el Diario escolar fue el centro del proceso educativo, el "motor" pedagógico para que los niños aprendieran a "escribir para ser leídos”, partían de sus propios intereses; en los proyectos de medios de comunicación en las instituciones educativas investigadas se llevan a cabo como actividades "extracurriculares", espacios creados en los colegios fuera del plan de estudio y con el propósito de reforzar ciertas habilidades y “competencias" en el lenguaje, como se verá a continuación.

\section{Colegio 1}

En 2012, la Extracurricular de televisión tenía dos momentos: miércoles y viernes, entre las 3:00 p.m. y las 5:00 p.m., una vez terminaban las clases. En el grupo de los miércoles participaban en promedio ocho estudiantes, integrado en su mayoría por estudiantes de últimos años de secundaria, algunas de ellas hasta con ocho o cinco años en este proyecto; lo interesante del grupo era que en ese momento iniciaban el proceso tres preadolescentes, quienes en la medida que avanzaron las sesiones de trabajo recibieron los conocimientos y las experiencias de las 
“veteranas" y, poco a poco, mostraron avances en las labores que realizaban. Este grupo centraba su participación en la producción - estar detrás de cámara- como afirmaban y en el apoyo al trabajo de la comunicadora.

Por su parte, el grupo de los viernes era más numeroso. En promedio asistían 15 estudiantes, todos preadolescentes. Las reuniones con ellos eran más dinámicas, porque era necesario tenerlos atentos y ocupados. El interés de este grupo estaba centrado en la "presentación”, ellos querían aparecer en los Mgz que se emitían cada mes por los televisores instalados en las aulas de clase, para que sus compañeros los vieran. Tanto en uno como en otro, la participación en este tipo de espacios es voluntaria y los estudiantes no reciben "notas" o calificaciones.

¿Cómo se estructura la Extracurricular? El profesor $D g$, quien inició con otros dos maestros la experiencia de los medios de comunicación el colegio, indica que la misma es un espacio donde los estudiantes se capacitan, aprenden, hacen talleres, trabajos de campo y se van formando grupos donde cada niño va mostrando un poquito su interés, algunos desde la parte de presentación, otros de la parte del manejo de cámaras, a otros les gusta escribir (Entrevista, septiembre 12 de 2012). Para la comunicadora el propósito de la Extracurricular está en que los estudiantes "aprendan": no que aprendan desde el texto y desde lo literal, sino desde la experiencia en sí y desde su propio análisis (Entrevista, agosto17 de 2012).

En los planteamientos del maestro y de la comunicadora existe la coincidencia que el espacio de la Extracurricular es para “aprender”, la diferencia está en que para uno ese aprendizaje está más relacionado con la capacitación instrumental: unos para presentar, otros para manejar las cámaras 
y otros para escribir, de acuerdo con el interés de cada uno; en cambio para la otra, el "aprender" está centrado en la propia experiencia y el propio análisis de las situaciones personales.

El hecho de que este tipo de experiencias sean desarrolladas como "actividades" extracurriculares genera limitaciones, como la falta de tiempo. Los estudiantes concentran sus energías y su trabajo en el trabajo académico, por eso relegan a un segundo plano este tipo de actividades "extras". De ahí que sean los maestros quienes asuman el liderazgo de estas propuestas; por ser una actividad secundaria para los estudiantes, el empoderamiento de los medios deja de ser una prioridad. De ahí que fueran el "apoyo" para el trabajo de la comunicadora, para quien la extracurricular es el espacio en que ella recibe la colaboración de los estudiantes: yo pienso que si no tuviera la extracurricular para mí sería más difícil hacer el Mgz, porque ellos son un aporte muy valioso a todo lo que se haga (Noviembre 21 de 2012). En este sentido, la producción de los medios de comunicación en este colegio está bajo la responsabilidad de la comunicadora y el aporte de los estudiantes son las "presentaciones" de las notas o con algunos escritos.

Esto permite comprender aún más que el interés de la experiencia está centrada en la divulgación de las actividades institucionales; para la comunicadora esto hace parte de su trabajo y lo hace con mucha pasión y compromiso, pero para los estudiantes es una labor secundaria, como lo indica el mismo nombre del espacio, es algo "extra", secundario, por tanto, el tiempo que le dedican son unas pocas horas a la semana, en las que se limitan al aprendizaje de algunas "herramientas" y a la grabación de las presentaciones. Así, la participación de los estudiantes es limitada en tiempo y en responsabilidades. 


\section{Colegio 2}

\section{Pedir permisos a los profesores}

(Observación 3, julio 23, 2012). Las reuniones del Semillero de Periodismo en el segundo semestre de 2012 se hacían en el aula 406, donde la profesora Isb daba su curso de Lengua Castellana. Entre las dificultades que debía sortear estaban los permisos que debía pedir a los profesores, para que los estudiantes pudieran asistir a las reuniones. Una semana antes acordó con los estudiantes que las reuniones serían los lunes entre las 11:30 y las 12:15 del día, es decir, en las mismas horas de clase, por lo que los de mañana tendrían que 'perder' la última clase y los de la tarde llegar unos minutos después a la primera clase. En casos como los de $A l$, de los pocos que llevaba más tiempo en la experiencia, la ausencia fue notable, porque perdía una materia y el profesor se negó a darle permisos.

La experiencia de los medios escolares inició en 2006 como un ejercicio de la clase de Lengua Castellana: hay una parte del año en la que se trabaja toda la parte de medios, de géneros informativos (Entrevista, Isb, marzo 26 de 2012), esto lo hace con los estudiantes de $11^{\circ}$. Entre los años 2008 y 2009 tuvo un grupo consolidado, en el participaba $E d$, el egresado y fue convocado por la profesora Isb quien pensó sobre todo en quienes les gustara el cuento de la comunicación (Entrevista, septiembre 3 de 2012).

Desde este punto de vista fue un espacio pensado para quienes tuvieran una inclinación profesional hacia la Comunicación social o el Periodismo y así como la anterior experiencia, este proyecto aunque nació como una actividad escolar pasó a un proyecto que se desarrollaba 
"contraclase", como indició la profesora. Así lo recuerda el egresado: sabíamos que la reunión era todos los miércoles luego de salir de clase, entonces ahí estábamos todos pendientes, faltaba uno o dos que por problemas de tareas, un examen, una cosa u otro, pero el grupo siempre estaba ahí dispuesto. El trabajo estaba centrado en la capacitación, sobre todo en los géneros periodísticos: llegamos a hacer directamente lo que es noticia y a proponer que esta página puede ser así o ser así, qué colores le vamos a meter, cuál va a ser el nombre del periódico. Nosotros presentábamos tres días antes la noticia, la profe nos la corregía, nos decía muchachos esto sí, esto no; agreguémosle esto, quitémosle esto y nosotros íbamos a la corregíamos y ya se la pasábamos a ella. (Entrevista, septiembre 3 de 2012).

Pero este proyecto, hasta el 2012, no se consolidó por varias razones: es una experiencia que tenía un carácter más personal que institucional, dependía de manera exclusiva de la profesora y el respaldo de los directivos era poco; por parte de los estudiantes, una vez terminaban sus estudios de secundaria se iban del colegio y no había una renovación generacional, porque además no existía un proyecto académico desde la comunicación/educación consolidado y reflexivo sobre los propósitos de este espacio. En ese momento, los estudiantes que estaban en el Semillero en el 2012 se distinguían por su falta de compromiso, fueron pocas las reuniones a las que asistieron. Así, lo extracurricular estaba supeditado a la voluntad de los estudiantes.

Y, último aspecto, lo académico influye mucho en los estudiantes: cuando llega la quinta semana escolar estos chicos se desestabilizan enormemente, porque la exigencia aumenta, en el periodo académico; al aumentarse la exigencia pasa a un segundo plano el compromiso del periodismo, además porque no tienen nota, porque no va no a ver una sanción académica y se le da 
relevancia, se le da primer plano pues a la parte académica. (Entrevista, agosto 27 de 2012). Esta es la demostración que lo extracurricular fuera algo secundario para los estudiantes.

Ante este panorama la profesora Isb tenía esta reflexión: el medio tendría que ser una herramienta más para mejorar el proceso educativo, un aliado; no porque la educación sea más y la comunicación menos, sino porque desde el principio decimos que educación implica muchos ambientes, muchos terrenos, muchas miradas. El motor de nosotros tiene que ser educar estos muchachos, con las herramientas que haya, con lo que tengamos a mano y hasta con lo que no tengamos a mano, para que ellos sean realmente en todos los aspectos como deben ser. (Entrevista, noviembre 7 de 2012).

Basado en las palabras de la profesora, mientras los medios fueran considerados en la escuela como "herramientas" desde las cuales se trasmite una información, difícilmente serán el "motor" del proceso educativo, por tanto, se reduce a una actividad en la que participan algunos estudiantes con unos intereses de índole personal o académico. Así, estos proyectos continuarán en el formato de lo "extra", lo que está por fuera del conocimiento considerado como válido y con poca relevancia; "neutros" desde la perspectiva instrumental que impiden la reflexión, la interpelación, la discusión y la propuesta; implica para los estudiantes evitar la responsabilidad y los compromisos que traen consigo la expresión libre y asumirse como productores de sentidos.

Sin embargo, la profesora también considera la posibilidad que los medios sean "aliados" de la educación -sobre todo en el caso del colegio oficial que está inserto en un contexto social complejo, donde predominan las carencias de toda índole- porque este tipo de experiencias es otro "terreno" desde el que es posible construir conocimientos a partir de la producción que 
hagan los estudiantes de los temas que a ellos los convocan y que permitan, a su vez, entrar en diálogo con los conocimientos formales que propone la escuela.

Y más que los medios, el proceso que conlleva producir un contenido con sentido puede llegar a ser un espacio educativo y formativo, en la medida que los estudiantes construyan esos conocimientos desde sus intereses, sus preguntas y reflexiones; es llevarlos a convertirse en "productores" de sus propios saberes para compartirlos con sus pares, con los maestros y otros integrantes de la comunidad educativa, de manera que desde estos saberes se generen otros discursos paralelos que también sea posible ponerlos a circular en la comunidad educativa, no tanto desde la obligatoriedad, sino desde la motivación y la necesidad de acercarse a nuevos conocimientos.

Así, habría que pensar la necesaria transformación de los medios de comunicación en la escuela, para que dejen ese carácter de "extra". Para que estas experiencias trasciendan el papel de divulgadores de la información en la escuela, hay que comprenderlas desde otra perspectiva, como un espacio en el que se construye conocimiento con los estudiantes y en lo posible con otros integrantes de la comunidad educativa.

Desde este punto de vista se requiere entonces cambiar la mirada y ubicar la experiencia como un espacio central en el proceso educativo, en el que sea necesaria la sumatoria de diferentes discursos, saberes y conocimientos - tanto formales como emergentes- así como metodologías de investigación adecuadas para generar preguntas y buscar las respuestas necesarias y básicas para proceder a elaborar un nuevo contenido. Es la posibilidad de generar un conocimiento activo, 
porque se construye permanentemente en la dinámica de la escuela; y social, porque se comparte con los otros.

\section{Esquema del medio como un asunto "Extracurricular"}

\section{Esquema de Producción de Contenidos} desde un espacio Extracurricular
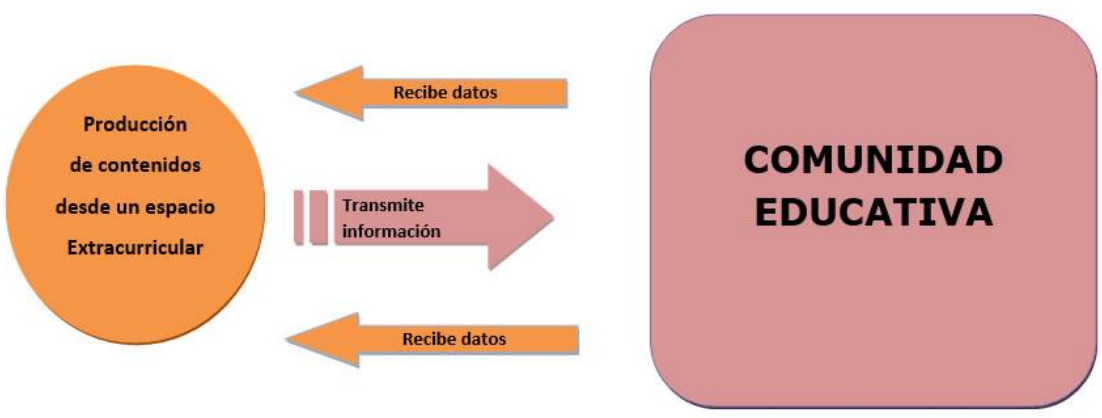

Esquema 3 elaborado por el autor Juan Carlos Ceballos Sepúlveda

\section{El motor del proceso}

Considerar que las experiencias de medios de comunicación en la institución educativa como un asunto extra-curricular indica el lugar que ocupan en el proceso formativo de los estudiantes y la relevancia que tiene para la comunidad educativa. Visto así, las experiencias están centradas en el medio, en el canal, como recurso divulgativo, didáctico o como apoyo a la labor docente; es el instrumento que posibilita llevar a la comunidad educativa una serie de información centrada en los eventos institucionales y en la mirada de los adultos. Para los estudiantes son actividades “extras" para apropiarse de ciertas habilidades y aprendizajes: repetir algunas palabras frente a una cámara, manipular instrumentos, aparecer ante los demás, el rol playing (Aparici, 2006). 
Actos mecánicos, poco reflexivos y contenidos alejados de los intereses, experiencias de vida y desconectados del contexto social.

Es necesaria otra mirada. Dejar de ver el "medio", como el objeto de estudio, visto solo en perspectiva de instrumento o una herramienta para trasmitir datos. Si el propósito es darle una vuelta a la discusión, entonces más que centrarla en el medio y sus alcances, hay que ampliar la discusión a la comunicación, en una perspectiva de las Mediaciones (Martín Barbero, 1998) abierta sobre todo a la cultura, a la vida cotidiana, a los conocimientos adquiridos, a las otras miradas, para ponerlas a dialogar con la institucionalidad (escuela).

Por eso, a partir de los planteamientos de las mediaciones comunicacionales, en la que se privilegia las experiencias de la vida cotidiana, los saberes aprendidos en el contexto social y las formas de interpretar el propio mundo, la información cambia de perspectiva, porque deja de ser asumida como un contenedor de datos y pasa a ser conocimiento. Y a eso está llamada la escuela a construir conocimiento y compartirlo en los medios de comunicación escolar, que adquieren ese carácter cuando permiten que sean los estudiantes quienes se empoderen de la palabra y de sus propias voces, sus experiencias y a partir de ello producen contenidos desde sus propios intereses.

Pensar la comunicación como centro del proceso educativo implica evitar la tentación de encerrarlo en un "curso" formal que se incorpora en un plan de estudios, como objeto para ser analizado y evaluado; por el contrario, la comunicación hay que incorporarla como experiencia (producción de sentidos), apropiación (de la palabra para pronunciar el mundo) y proyección (compartir los contenidos con los otros). En estos términos, la comunicación puede ser centro o motor de aprendizaje del currículo cuando sirve de sombrilla en la que se despliegan diferentes 
elementos culturales, entendidos como conocimientos, valores, creencias, costumbres y hábitos (De Alba, 1998). Así, no es un contenido estanco, (un curso, una materia), sino un conocimiento que se irradia y se mezcla entre los saberes formales, los atraviesa, para entrar en diálogo con ellos y dinamizarlos.

Con este foco, los medios en los que participan los estudiantes adquieren otro sentido: son los espacios que permiten socializar los conocimientos construidos por los alumnos y maestros, por tanto, son un bien común; son espacios que permiten la formación de ciudadanos responsables a partir de esos conocimientos y de esa manera se convierten en un "producto social" por ser una construcción colectiva (Kaplún, 1998, p. 205). Como se visualiza a continuación, cuando la Comunicación, más que el medio, es el centro de la producción de los contenidos. (Siguiente página). 


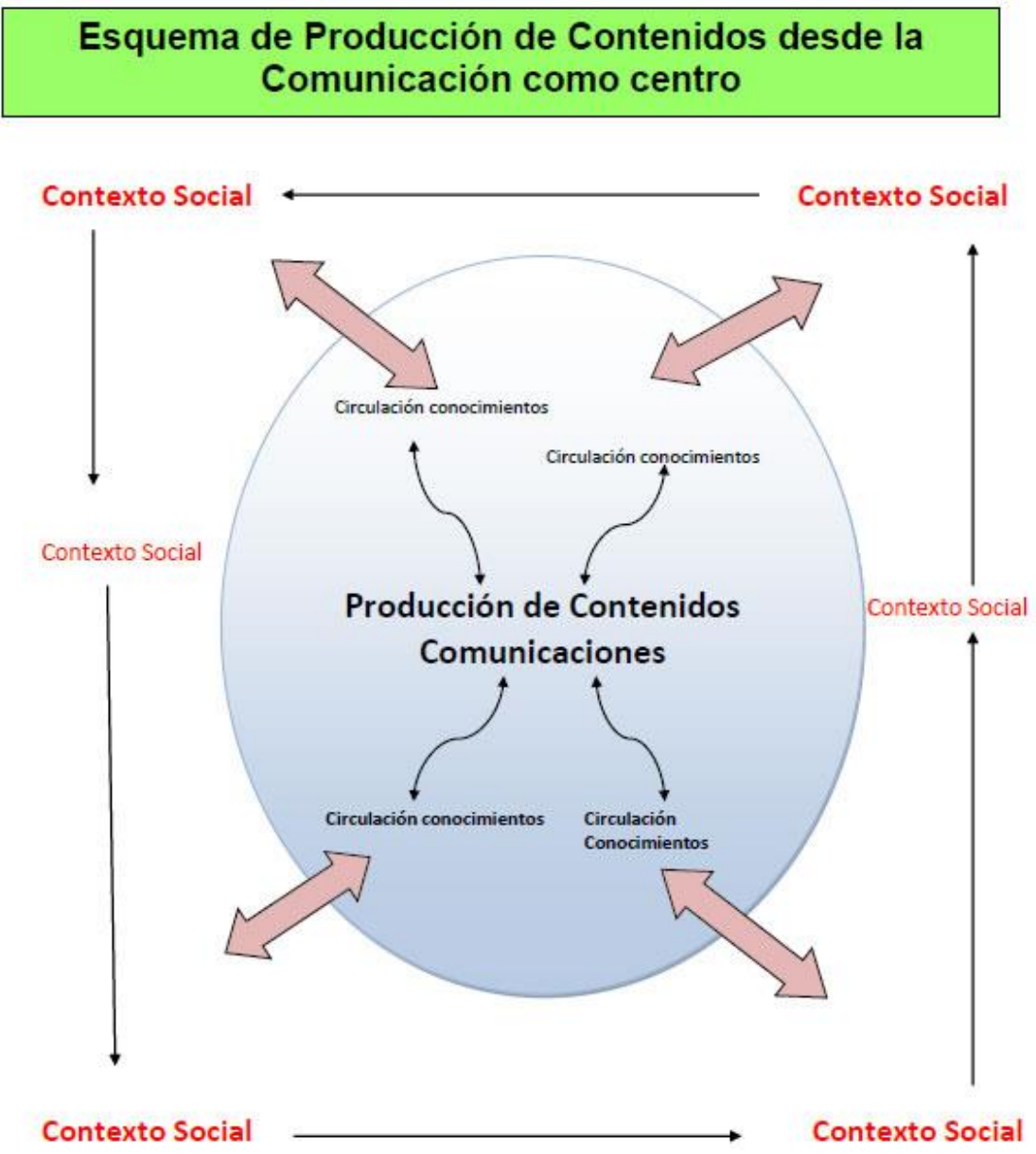

Esquema 4 elaborado por el autor Juan Carlos Ceballos Sepúlveda 


\subsubsection{Categorías, reflexiones emergentes y cruce teórico}

\begin{tabular}{|c|c|c|c|}
\hline Categoría & Temas claves & Reflexión emergente & Aproximación teórica \\
\hline Discurso & $\begin{array}{l}\text { - Los maestros (adultos) } \\
\text { son quienes proponen } \\
\text { las ideas, autorizan y } \\
\text { producen los } \\
\text { contenidos. } \\
\text { - Los estudiantes esperan } \\
\text { que los maestros les } \\
\text { den los temas que } \\
\text { deben ser trabajados, } \\
\text { reproducen algunos de } \\
\text { los contenidos } \\
\text { elaborados por los } \\
\text { maestros y producen } \\
\text { contenidos bajo } \\
\text { perspectivas } \\
\text { institucionales. } \\
\text { - Los estudiantes hacen } \\
\text { circular las historias del } \\
\text { barrio en los medios de } \\
\text { comunicación del } \\
\text { colegio. }\end{array}$ & $\begin{array}{l}\text { En esta categoría se debe } \\
\text { considerar que el Discurso } \\
\text { se construye a partir de una } \\
\text { generación de ideas y una } \\
\text { producción de contenidos. } \\
\text { En los colegios estudiados } \\
\text { son los adultos (maestros y } \\
\text { otros profesionales) quienes } \\
\text { imponen los temas y en } \\
\text { algunos momentos producen } \\
\text { los contenidos. La } \\
\text { participación de los } \\
\text { estudiantes es pasiva y } \\
\text { sometida a los intereses de } \\
\text { sus maestros. Por eso, la } \\
\text { formación de unos } \\
\text { "productores" de sentidos } \\
\text { (los estudiantes) requiere ser } \\
\text { considerada por fuera de los } \\
\text { esquemas educativos } \\
\text { tradicionales, es decir, dejar } \\
\text { de replicar lo que sucede en } \\
\text { las instituciones educativas, } \\
\text { (modelo difusionista), si no } \\
\text { permitir que el estudiante } \\
\text { asuma el protagonismo y la } \\
\text { responsabilidad de un } \\
\text { productor de "discursos" a } \\
\text { partir de lo que vive en sus } \\
\text { contextos sociales y } \\
\text { considere necesario ser } \\
\text { comunicado. Ese es el foco } \\
\text { generador de ideas (temas) } \\
\text { desde los cuales se empieza } \\
\text { a construir los contenidos } \\
\text { alternos y propios (escritos, } \\
\text { orales, visuales, } \\
\text { hipertextuales), de manera } \\
\text { que circulen en el ámbito } \\
\text { escolar a manera de "otros" } \\
\text { conocimientos que entren en } \\
\text { diálogo con los contenidos } \\
\text { oficiales establecidos en la } \\
\text { escuela. }\end{array}$ & $\begin{array}{l}\text { Las prácticas } \\
\text { comunicacionales están } \\
\text { influidas por los modelos } \\
\text { tradicionales educativos, } \\
\text { lo que incide en la } \\
\text { producción de los } \\
\text { Discursos. En este sentido } \\
\text { Freire (1985, 72) señala } \\
\text { que una educación donde } \\
\text { el educador es el } \\
\text { protagonista lleva a los } \\
\text { educandos a la } \\
\text { memorización y repetición } \\
\text { de los contenidos a narrar, } \\
\text { más que a la producción } \\
\text { de los mismos. Es a lo que } \\
\text { Kaplún (1998, 25) } \\
\text { denominó también como } \\
\text { "comunicación bancaria", } \\
\text { en el sentido que se } \\
\text { limitan a trasmitir } \\
\text { informaciones, en estos } \\
\text { casos de los medios en los } \\
\text { colegios, información } \\
\text { institucional (eventos } \\
\text { culturales, deportivos, } \\
\text { religiosos y directrices } \\
\text { institucionales), con el fin } \\
\text { de mantener informada a } \\
\text { la comunidad educativa. } \\
\text { Pero si se trata de formar } \\
\text { "productores de } \\
\text { significaciones", Martín } \\
\text { Barbero (1998, p. 291), } \\
\text { son los estudiantes quienes } \\
\text { proponen temas acerca de } \\
\text { lo que sucede en sus } \\
\text { entornos sociales; es la } \\
\text { posibilidad de elegir los } \\
\text { mejores por voto y escribir } \\
\text { sobre ellos (Freinet, 1977, } \\
\text { p.22); es la posibilidad de } \\
\text { apropiarse de la palabra } \\
\text { para hablar de su mundo y } \\
\text { transformarlo (Freire, }\end{array}$ \\
\hline
\end{tabular}




\begin{tabular}{|c|c|c|c|}
\hline & & & $\begin{array}{l}\text { 1985, p. 101) como una } \\
\text { alternativa para construir } \\
\text { Discursos (contenidos } \\
\text { propios); es posibilitar el } \\
\text { poder de la palabra en } \\
\text { niños y jóvenes para que } \\
\text { expresen sus ideas, } \\
\text { anhelos e inquietudes, a } \\
\text { otras personas ya sea en el } \\
\text { colegio o fuera de él, con } \\
\text { lo que el ejercicio adquiere } \\
\text { un sentido especial } \\
\text { (Bacher, 2009, p. 134). La } \\
\text { producción del Discurso } \\
\text { (los contenidos en los } \\
\text { medios del colegio) debe } \\
\text { estar permeada por la idea } \\
\text { de Freinet: "escribir para } \\
\text { ser leídos" (1983, p. 92) } \\
\text { por toda la comunidad } \\
\text { educativa, incluida la } \\
\text { circundante al colegio. } \\
\text { Aproximación teórica }\end{array}$ \\
\hline Categoría & Temas clave & Reflexión emergente & Aproximación teórica \\
\hline $\begin{array}{l}\text { Micro } \\
\text { medios }\end{array}$ & $\begin{array}{l}\text { - Los medios en la } \\
\text { escuela sirven de } \\
\text { mecanismos para } \\
\text { reforzar los valores y la } \\
\text { filosofía institucional } \\
\text { - Predomina el enfoque } \\
\text { instrumental en los } \\
\text { proyectos de medios en } \\
\text { la escuela y como un } \\
\text { apoyo a la labor } \\
\text { docente } \\
\text { - Los medios sirven para } \\
\text { reflejar las situaciones } \\
\text { sociales que rodean al } \\
\text { colegio } \\
\text { - La inestabilidad del } \\
\text { proyecto de medios es } \\
\text { reflejo de la } \\
\text { inestabilidad } \\
\text { institucional. }\end{array}$ & $\begin{array}{l}\text { En los colegios es necesario } \\
\text { dejar de considerar los } \\
\text { medios de comunicación en } \\
\text { su carácter instrumental, } \\
\text { como mecanismo útil para } \\
\text { divulgar/transmitir } \\
\text { contenidos oficiales, } \\
\text { reforzamiento de las normas } \\
\text { institucionales y el sentido } \\
\text { de pertenencia. } \\
\text { Contrario a lo anterior, es } \\
\text { necesario que la escuela } \\
\text { reflexione el sentido que } \\
\text { tiene un medio de } \\
\text { comunicación en un ámbito } \\
\text { educativo, más que unos } \\
\text { instrumentos es la } \\
\text { posibilidad de asumirlo } \\
\text { como un espacio de } \\
\text { construcción colectiva, en } \\
\text { los que prevalezcan los } \\
\text { intereses de los estudiantes: } \\
\text { donde "aparezcan" sus } \\
\text { discursos (contenidos) } \\
\text { publicados, a manera de } \\
\text { narración de sus "textos }\end{array}$ & $\begin{array}{l}\text { Lo que aparece en los } \\
\text { medios de las instituciones } \\
\text { educativas, ante todo, } \\
\text { deben atraer la atención de } \\
\text { los estudiantes (Freinet, } \\
\text { 1974, p. 20) más que } \\
\text { servir de instrumento para } \\
\text { reforzar la normatización y } \\
\text { el comportamiento de los } \\
\text { estudiantes; es lo que } \\
\text { Kaplún (1998, 18) llama } \\
\text { un ejercicio exógeno, } \\
\text { porque pone el énfasis en } \\
\text { los contenidos y la } \\
\text { transmisión de los } \\
\text { mismos. Desde esta } \\
\text { perspectiva, los medios } \\
\text { tienen un carácter } \\
\text { instrumentalista centrado } \\
\text { en el control y dominio } \\
\text { (Huergo y Fernández, } \\
\text { 2000, p. 128); o como un } \\
\text { lugar de esparcimiento o } \\
\text { transmisión de } \\
\text { información (Rodríguez, } \\
\text { 2004, p. 211) o para tratar }\end{array}$ \\
\hline
\end{tabular}




\begin{tabular}{|c|c|c|c|}
\hline & & $\begin{array}{l}\text { sociales" que surgen a partir } \\
\text { de la experiencia de vida; en } \\
\text { el que se permita expresar } \\
\text { con libertad sus opiniones y } \\
\text { preguntas a la institución } \\
\text { educativa, a sus maestros y } \\
\text { compañeros; un medio de } \\
\text { comunicación que } \\
\text { trascienda la "tarea" escolar } \\
\text { y se constituya en un punto } \\
\text { de encuentro entre } \\
\text { comunidad educativa y un } \\
\text { contexto social. Un medio } \\
\text { de comunicación entendido } \\
\text { como el centro del } \\
\text { conocimiento y un espacio } \\
\text { de circulación de saberes, } \\
\text { construido por los } \\
\text { estudiantes, con la compañía } \\
\text { de los maestros. }\end{array}$ & $\begin{array}{l}\text { de hacer dinámicas las } \\
\text { clases, (Valderrama, 2007, } \\
\text { p. 81), con lo cual se } \\
\text { concluye que la escuela no } \\
\text { reflexiona la } \\
\text { comunicación, ni tampoco } \\
\text { el carácter comunicacional } \\
\text { de los medios, más allá de } \\
\text { lo instrumental. Es por eso } \\
\text { que estos autores, se } \\
\text { refieren a que los medios } \\
\text { deben ser vistos y } \\
\text { asumidos como espacios } \\
\text { para mostrar las realidades } \\
\text { sociales y escolares } \\
\text { (Rodríguez, p. 216) o } \\
\text { como medios de expresión } \\
\text { del ser (Valderrama, p. } \\
\text { 190), para que adquieran } \\
\text { otro sentido diferente. } \\
\text { Estos medios sobre todo } \\
\text { en el contexto educativo, } \\
\text { deben promoverse como } \\
\text { espacios de construcción } \\
\text { colectiva que trasciendan } \\
\text { la institucionalidad, para } \\
\text { llegar a las "diferentes } \\
\text { esferas de los sujetos" o } \\
\text { hacerlas como “cajas de } \\
\text { resonancia” por donde } \\
\text { circulen los conocimientos } \\
\text { de los estudiantes y } \\
\text { posibilitar la proyección } \\
\text { social de su palabra } \\
\text { (Kaplún, 1998, p. 51); es } \\
\text { considerar entonces las } \\
\text { mediaciones planteadas } \\
\text { por Martín Barbero, para } \\
\text { que la escuela encuentre } \\
\text { en sus medios la } \\
\text { posibilidad de conectarse } \\
\text { con su entornos sociales y } \\
\text { culturales. } \\
\text { Anrimín tóxios }\end{array}$ \\
\hline Categoría & Temas claves & Reflexión emergente & Aproximación teórica \\
\hline $\begin{array}{l}\text { Comunicac } \\
\text { ión/educa } \\
\text { ción }\end{array}$ & $\begin{array}{l}\text { - El medio de } \\
\text { comunicación es una } \\
\text { herramienta de trabajo } \\
\text { - Los medios de } \\
\text { comunicación }\end{array}$ & $\begin{array}{l}\text { En ambas instituciones } \\
\text { educativas, aunque una de } \\
\text { ellas tenga establecido un } \\
\text { modelo pedagógico } \\
\text { "cognitivo social", }\end{array}$ & $\begin{array}{l}\text { Para romper con la idea } \\
\text { fija de comunicación } \\
\text { asociada a transmisión, } \\
\text { Kaplún (2010) propone } \\
\text { densificar el tema de la }\end{array}$ \\
\hline
\end{tabular}




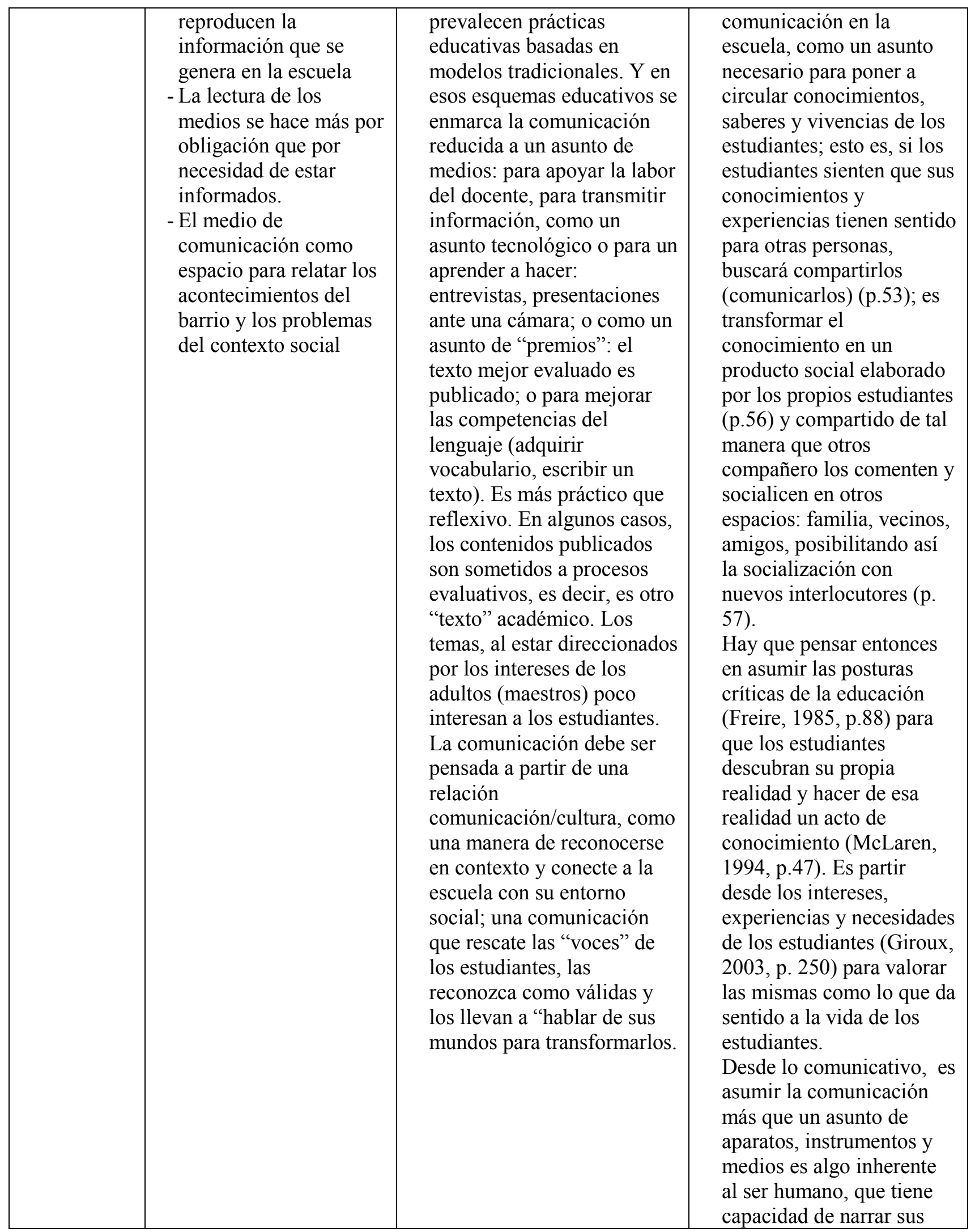




\begin{tabular}{|c|c|c|c|}
\hline & & & $\begin{array}{l}\text { experiencias de vida, de } \\
\text { producir más que de } \\
\text { reproducir, desde los } \\
\text { cuales se potencia su } \\
\text { capacidad de creación } \\
\text { (Saintout, 2003, p. 82). En } \\
\text { el caso de la escuela, no se } \\
\text { trata de ver a los } \\
\text { estudiantes en su función } \\
\text { de "reproductores", sino } \\
\text { de "productores de } \\
\text { significaciones" (Martín } \\
\text { Barbero). }\end{array}$ \\
\hline Categoría & Temas claves & Reflexión emergente & Aproximación teórica \\
\hline $\begin{array}{l}\text { Informaci } \\
\text { ón }\end{array}$ & $\begin{array}{l}\text { - La información que se } \\
\text { comparte en los medios } \\
\text { escolares no es acogida } \\
\text { por la comunidad } \\
\text { educativa } \\
\text { - La información está } \\
\text { enfocada a brindar } \\
\text { herramientas para los } \\
\text { padres de familia } \\
\text { - Los estudiantes sienten } \\
\text { que deben ser } \\
\text { responsables con la } \\
\text { información que se } \\
\text { comparte en los medios } \\
\text { escolares. }\end{array}$ & $\begin{array}{l}\text { El carácter instrumental de } \\
\text { la comunicación es aún más } \\
\text { evidente en la información, } \\
\text { entendida como transmisión } \\
\text { de datos oficiales, con el } \\
\text { propósito de "mantener } \\
\text { informada" a la comunidad } \\
\text { educativa. Información } \\
\text { atada a las directrices } \\
\text { institucionales. Información } \\
\text { que brinda la misma } \\
\text { institución y circula dentro } \\
\text { de ella. Información } \\
\text { transmisionista e impuesta } \\
\text { por los adultos. } \\
\text { Y son los estudiantes } \\
\text { quienes marcan las pautas } \\
\text { para que la información } \\
\text { tenga otro sentido: } \\
\text { información para que otros } \\
\text { conozcan más acerca de } \\
\text { algo (educar); información } \\
\text { para que puedan tomar } \\
\text { decisiones (poder); } \\
\text { información como } \\
\text { posibilidad de expresar algo } \\
\text { (hablar del propio mundo); } \\
\text { información como } \\
\text { responsabilidad (asumir las } \\
\text { voces de otros); información } \\
\text { que se construye con las } \\
\text { preguntas y opiniones de } \\
\text { otros; información que } \\
\text { refleja un contexto social y } \\
\text { unas experiencias de vida. }\end{array}$ & $\begin{array}{l}\text { Hace falta una reflexión } \\
\text { sobre la información en la } \\
\text { escuela en general, porque } \\
\text { en ella predomina una idea } \\
\text { asociada la transmisión de } \\
\text { datos (Aparici, 2006, } \\
\text { p.40), de ahí que por el } \\
\text { hecho de recibir una } \\
\text { cantidad de datos sobre la } \\
\text { institución educativa, a } \\
\text { través de los medios, la } \\
\text { información en la misma } \\
\text { puede caer en la } \\
\text { trivilización (Schmucler, } \\
\text { 1997, p. 204) y llevar a } \\
\text { que la información pierda } \\
\text { sentido. Por eso, para darle } \\
\text { un nuevo sentido a la } \\
\text { información en el ámbito } \\
\text { escolar es necesario } \\
\text { entenderla como } \\
\text { conocimiento, como una } \\
\text { construcción social } \\
\text { (Giroux, 2003, p.186), un } \\
\text { conocimiento construido a } \\
\text { partir de la experiencia de } \\
\text { vida de los estudiantes. Y } \\
\text { de llegarse a ello, entonces } \\
\text { la información puede } \\
\text { adquirir un carácter } \\
\text { diferente en la medida que } \\
\text { el estudiante debe hacerse } \\
\text { responsable frente a lo que } \\
\text { dice, cómo lo dice y con } \\
\text { qué valor: es hacerse }\end{array}$ \\
\hline
\end{tabular}




\begin{tabular}{|c|c|c|c|}
\hline & & $\begin{array}{l}\text { Información que sirva para } \\
\text { emancipar a los niños y } \\
\text { jóvenes de las instituciones } \\
\text { educativas. Reflexiones que } \\
\text { apuntan a darle otro sentido } \\
\text { a la información que circula } \\
\text { en los medios de } \\
\text { comunicación de los } \\
\text { colegios. }\end{array}$ & $\begin{array}{l}\text { responsable de las palabras } \\
\text { y a partir de ello asumir la } \\
\text { responsabilidad de } \\
\text { construir memoria } \\
\text { (Schmucler, 1997, } \\
\text { p.197).Es también la } \\
\text { posibilidad de construir un } \\
\text { conocimiento colectivo } \\
\text { (Giroux y McLaren) en la } \\
\text { medida que participan en } \\
\text { este proyecto estudiantes y } \\
\text { maestros y la hacen } \\
\text { circular en la escuela. }\end{array}$ \\
\hline Categoría & Temas claves & Reflexión emergente & Aproximación teórica \\
\hline $\begin{array}{l}\text { Ciudadan } \\
\text { ía }\end{array}$ & $\begin{array}{l}\text { - La escuela limita la } \\
\text { expresión de las ideas } \\
\text { de los estudiantes } \\
\text { - Los estudiantes aceptan } \\
\text { las limitaciones para } \\
\text { expresar sus ideas } \\
\text { - La expresión de las } \\
\text { ideas se limitan a } \\
\text { hablar de lo "bueno" } \\
\text { - Los estudiantes sienten } \\
\text { que los directivos los } \\
\text { privan de hablar de los } \\
\text { temas que los afectan } \\
\text { - La palabra elemento } \\
\text { esencial para la } \\
\text { formación ciudadana }\end{array}$ & $\begin{array}{l}\text { Posibilitar la expresión de la } \\
\text { palabra es uno de los pasos } \\
\text { fundamentales para formar } \\
\text { en ciudadanía. Pero en los } \\
\text { colegios estudiados sucede } \\
\text { lo contrario: hablar de } \\
\text { ciertos temas (de los } \\
\text { estudiantes) no está } \\
\text { permitido; cuestionar la } \\
\text { "institucionalidad" } \\
\text { educativa trae } \\
\text { consecuencias; controlar lo } \\
\text { que se publicará coarta las } \\
\text { voces de los estudiantes. } \\
\text { Solo es permitido hablar de } \\
\text { lo bueno (los eventos), no } \\
\text { de lo malo (problemáticas). } \\
\text { Los medios de } \\
\text { comunicación en un colegio } \\
\text { deben promulgar la libertad } \\
\text { de expresión y formar en la } \\
\text { responsabilidad de informar, } \\
\text { efecto contrario sucede } \\
\text { cuando se impide "hablar" a } \\
\text { los estudiantes de sus temas, } \\
\text { sus inquietudes. Prevalece } \\
\text { los parámetros } \\
\text { institucionales a los } \\
\text { derechos constitucionales } \\
\text { (no habrá censura). } \\
\text { La formación en } \\
\text { participación ciudadana } \\
\text { parte de la posibilidad de } \\
\text { apropiarse de la palabra } \\
\text { (como un derecho y un }\end{array}$ & $\begin{array}{l}\text { Desde los medios en los } \\
\text { colegios se deben } \\
\text { propiciar las condiciones } \\
\text { necesarias para que los } \\
\text { estudiantes hablen con sus } \\
\text { propias voces, autentiquen } \\
\text { sus experiencias de vida } \\
\text { (Giroux, 2008, p. 56), } \\
\text { como parte esencial de la } \\
\text { formación ciudadana. Y } \\
\text { uno de esos pasos es la } \\
\text { formación en la crítica, de } \\
\text { ahí que como sostiene } \\
\text { Giroux (2003, p. 221) en } \\
\text { estos espacios llamado } \\
\text { medios, es importante que } \\
\text { se problematicen temas y } \\
\text { situaciones que se } \\
\text { presentan en escenarios } \\
\text { públicos, como es el caso } \\
\text { de los colegios oficiales. } \\
\text { De igual manera, es en } \\
\text { esos espacios, donde las } \\
\text { voces de los estudiantes } \\
\text { sean publicadas, } \\
\text { escuchadas y } \\
\text { comprendidas (no } \\
\text { censuradas) y de esa } \\
\text { manera sean reconocidos } \\
\text { como participes activos de } \\
\text { la sociedad (Giroux, } 2003 \text {, } \\
\text { p. } 300 \text { ). Los medios en la } \\
\text { escuela pueden ser un } \\
\text { escenario donde los } \\
\text { estudiantes empiecen a }\end{array}$ \\
\hline
\end{tabular}




\begin{tabular}{|c|c|c|c|}
\hline & & $\begin{array}{l}\text { deber) para expresar por } \\
\text { medio de ella ideas, } \\
\text { opiniones, criticas, } \\
\text { propuestas, algo que los } \\
\text { colegios están en mora de } \\
\text { emprender desde este tipo } \\
\text { de experiencias. }\end{array}$ & $\begin{array}{l}\text { ejercer la ciudadanía, tal } \\
\text { como lo sostiene Bacher } \\
\text { cuando se refiere que en la } \\
\text { escuela la producción de } \\
\text { medios con la } \\
\text { participación de los } \\
\text { estudiantes, emerjan otros } \\
\text { espacios de pensamiento } \\
\text { crítico con los que se } \\
\text { estimulen la capacidad de } \\
\text { preguntar, interpelar, } \\
\text { analizar e incidir en la } \\
\text { transformación de sujetos } \\
\text { autónomos (2009, p. 29- } \\
\text { 30). Como afirma } \\
\text { McLaren (1994) que los } \\
\text { estudiantes asuman el } \\
\text { papel de "ciudadanos } \\
\text { creativos", porque pueden } \\
\text { visibilizar su particular } \\
\text { manera de participar en la } \\
\text { sociedad. Y como indica } \\
\text { Bacher: ejercer el derecho } \\
\text { a la comunicación es una } \\
\text { oportunidad para } \\
\text { establecer vías de } \\
\text { participación ciudadana } \\
\text { (2009, p. 117). }\end{array}$ \\
\hline Categoría & Temas claves & Reflexión emergente & Aproximación teórica \\
\hline Currículo & $\begin{array}{l}\text { - Las experiencias de } \\
\text { medios escolares se } \\
\text { desarrollan en espacios } \\
\text { "extracurriculares" } \\
\text { - La experiencia de los } \\
\text { medios escolares } \\
\text { transforma a los } \\
\text { estudiantes } \\
\text { - Los medios escolares } \\
\text { posibilitan entrar en } \\
\text { contacto con el } \\
\text { contexto social } \\
\text { - Solo si los medios } \\
\text { escolares se } \\
\text { transversalizan pueden } \\
\text { comprometer a otros } \\
\text { profesores } \\
\text { - Los medios escolares } \\
\text { mejoran la capacidad } \\
\text { de expresión de los }\end{array}$ & $\begin{array}{l}\text { Más que encasillar la } \\
\text { "comunicación" o los } \\
\text { "medios de comunicación" } \\
\text { como una materia } \\
\text { académica o relegarla como } \\
\text { un asunto "extra" para } \\
\text { aprender asuntos prácticos, } \\
\text { la misma debe ser } \\
\text { considerada en su } \\
\text { dimensión cultural y social, } \\
\text { que posibilite interpretar lo } \\
\text { que sucede en los entornos } \\
\text { sociales, comprenderlo y } \\
\text { compartirlo por diversos } \\
\text { lenguajes comunicativos } \\
\text { (textuales, orales, visuales, } \\
\text { hipertextuales) a la } \\
\text { comunidad educativa. Es } \\
\text { volver a los Discursos } \\
\text { convertidos en }\end{array}$ & $\begin{array}{l}\text { Desde el punto de vista de } \\
\text { Freinet, el medio de } \\
\text { comunicación en el aula } \\
\text { fue la posibilidad de } \\
\text { desarrollar una propuesta } \\
\text { pedagógica, en la que el } \\
\text { estudiante era el centro del } \\
\text { proceso: proponía los } \\
\text { temas y escribía de ellos } \\
\text { (producción de } \\
\text { contenidos); contrario a } \\
\text { que los medios o los } \\
\text { proyectos de medios en la } \\
\text { escuela sea considerados } \\
\text { una actividad extra para } \\
\text { divulgar información que } \\
\text { produce la propia } \\
\text { institución (Kaplún, 1998, } \\
\text { p. 204). Este esquema } \\
\text { puede ser reconfigurado si }\end{array}$ \\
\hline
\end{tabular}




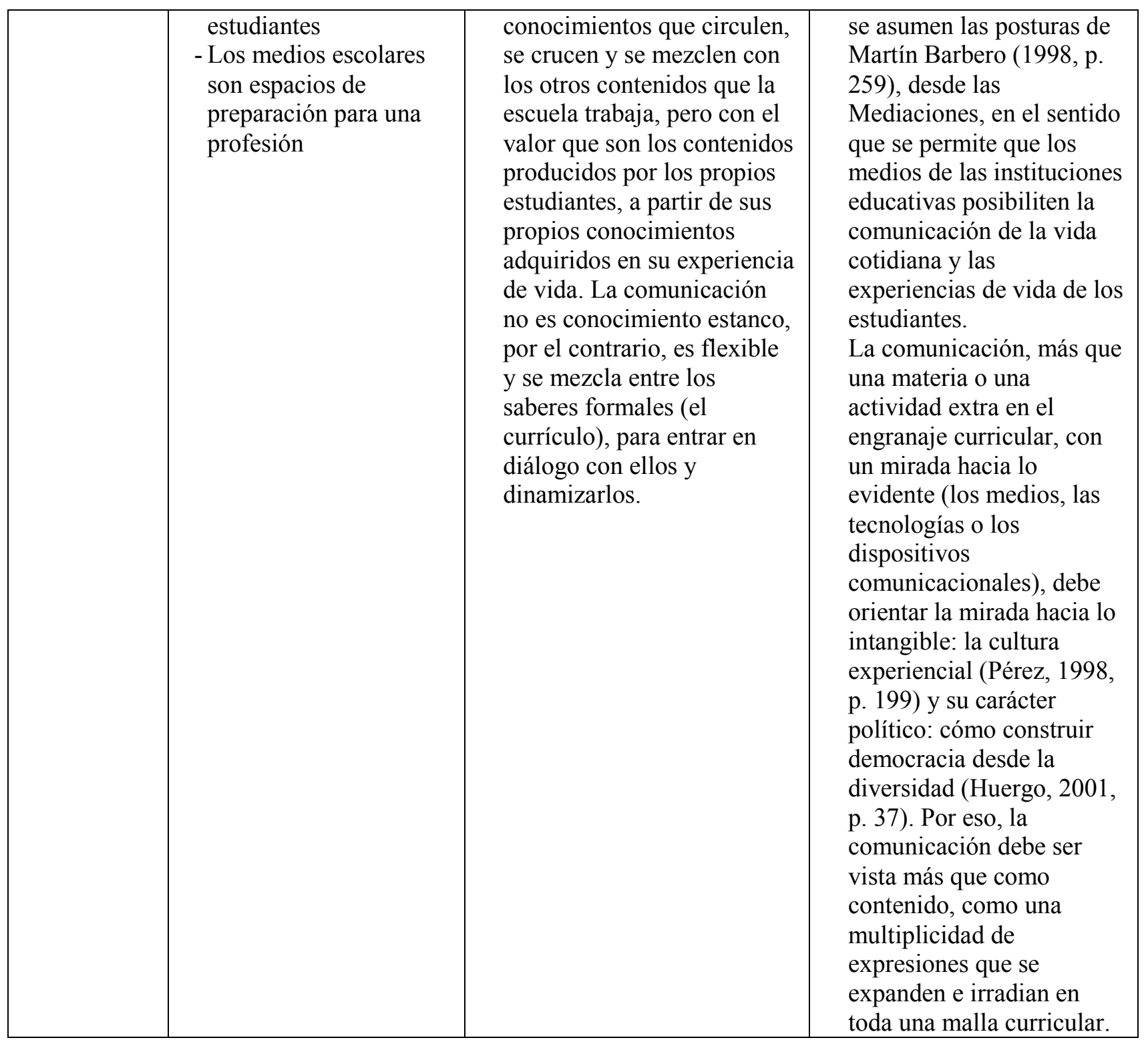

Cuadro 9. Categorías, reflexiones emergentes, cruces teóricos. Elaborado por el autor a partir de los resultados obtenidos 


\subsection{Etapa 3. Fase de Emisión. Los conceptos}

\section{Producción de Conceptos}

Según los resultados arrojados en el capítulo anterior, se convocó a los actores (maestros y estudiantes) a compartir qué idea tenían acerca de algunos conceptos relacionados con la producción de medios de comunicación en los colegios: comunicación, información, educación, medio de comunicación escolar, producción de sentidos y ciudadanía.

De esta manera, se acudió a su propia reflexión, para comprender las ideas con las que orientan y llevan a la práctica la producción de medios en sus instituciones educativas, además de los enfoques y puntos de vista que predominan en los temas y contenidos que en ellos se publican. Se partió de la premisa que la producción de medios en la escuela se caracteriza más por el "hacer" que por el "reflexionar" el sentido comunicativo y educativo de estas experiencias. Para consultar los conceptos mencionados se acudió a las entrevistas y grupos focales.

Como indica Alonso (1998, p. 225) las entrevistas son la posibilidad de obtener una información que el actor comparte con el investigador, a partir de sus propias experiencias y reflexiones. Por su parte, las entrevistas en profundidad son un constructo comunicativo, más que un simple registro del discurso (p. 230). Desde este punto de vista, el investigador provoca a los actores a expresarlas ideas, en este caso, sobre los conceptos mencionados antes.

De igual manera, se acudió a los grupos de discusión basado en la propuesta de Reguillo (1999) de utilizar esta técnica para "detonar procesos reflexivos" (p. 33), en este caso con los estudiantes, para que compartieran sus puntos de vista sobre los conceptos mencionados, a partir 
de sus propias ideas y conocimientos que resultan de la participación en la producción de medios de comunicación en las instituciones educativas.

Con base en los mismos conceptos se analizaron los resultados obtenidos en la aplicación de estas técnicas. En este caso, se tuvo en cuenta lo propuesto por Soler (2011, p. 222) de analizar los textos obtenidos a la luz de una categoría (en este caso concepto) y luego, a partir de la trascripción del texto ("verbatim") se procede al análisis de los temas que emergen de los mismos y después se hace un cruce o relación entre ellos para enriquecer el concepto consultado. Este ejercicio permite identificar cuáles son las ideas que prevalecen en los actores, posibilita comprender qué entienden y qué idea propia tienen de los conceptos consultados. De esta manera, se pretende dar cuenta del segundo objetivo específico de la investigación: "Examinar los modelos y conceptos de comunicación, educación, información, medios de comunicación escolares y ciudadanía que tienen los maestros y estudiantes que participan en los proyectos de producción de medios en la escuela”.

Así, con el propósito de propiciar la reflexión de un concepto, basado en la propia experiencia de participar en un proyecto de producción de un medio de comunicación, en una institución educativa, se planteó la pregunta ¿ud. que entiende por...? tanto a la comunicadora y a la maestra que coordinan estas actividades en los colegios consultados, como a los estudiantes que hacían parte de los equipos de trabajo. A continuación se comparten las ideas que emergen de esta pregunta planteada para cada concepto. 


\subsubsection{Comunicación}

Colegio 1. Privado (entrevista realizada a la comunicadora $D$ de la institución, noviembre 21 de 2012).

\section{¿Qué entiende ud. por Comunicación?}

D. Para mí comunicación es transmitir un mensaje claro, a la comunidad, hablando de mi entorno, a la comunidad educativa, (...), a través de los diferentes medios que se manejan en la institución. Para mí comunicación va ligada a transmitir de cualquier forma: verbal, oral...

Inv. ¿Esa transmisión está unida a los medios o es una transmisión de otra índole?

D. La que yo hago (en el colegio) para mí está ligada a los medios, porque yo manejo esa parte y ese es mi fuerte, así es como yo transmito a los demás la información que recibo.

Por su parte, en el grupo focal realizado con los estudiantes de la institución (31 de octubre de 2012), también se preguntó para ellos qué es la Comunicación:

Est.1 Expresar algo, dar a entender un mensaje y comprenderlo.

Est.2 Comunicación es como información propia.

Colegio 2. Público. Entrevista realizada a la maestra Isb, (Noviembre 7 de 2012).

Isb. Es un poder que tienen los seres humanos, donde además de que se mueve información y la gente está al tanto de lo que sucede y hace conexión; conecta a las personas unas con otras y 
tiene el poder también de educar de que la gente adquiera una postura específica frente a un tema determinado.

Los estudiantes compartieron sus reflexiones sobre la Comunicación en el Grupo focal (Noviembre 7 de 2012).

Est.1 La comunicación es una forma de expresarse con las demás personas, como la misma palabra dice, es comunicarse, hablarse, expresar, contarles a las demás personas lo que uno siente o lo que uno ha vivido.

Est.2 Comunicar principalmente es como dialogar con las otras personas, dando a conocer un tema y las opiniones de cada quien.

Est.3 Necesariamente no dialogar, puede ser fisica, pueden ser palabras, verbalmente, por escrito, por señales, ya depende de cada persona.

Est.4 Comunicar, informar, dar a conocer.

Est.5 Comunicación: relatividad de saber dar una información

\section{Análisis de los textos (Qué es comunicación)}

De las ideas expuestas por los adultos (comunicadora y maestra) surgen varios conceptos asociados:

Trasmisión: para la profesional en el campo, la comunicación es un asunto de "trasmitir un mensaje claro" y está dirigido a la comunidad educativa. Ese mensaje está relacionado con lo que sucede en el colegio, “en mi entorno", en este caso lo que sucede al interior. Y a su vez, esa idea 
de comunicación está atada con los medios: “los diferentes medios que maneja la institución”, en este caso periódico y el programa de televisión. Y, por último reitera que la comunicación "va ligada a trasmitir de cualquier forma: verbal, oral...”. De otra manera considera que la comunicación es "trasmisión" y está "ligada a los medios", por ser espacio de trabajo, y en el que ella se asume como un puente "trasmito la información que recibo". Estas ideas dan cuenta de que los criterios para proponer y escoger los temas, redactar los textos o grabar imágenes tienen un propósito: mantener informada a una comunidad educativa, sobre lo que acontece al interior de la institución.

Poder: para la maestra del colegio público es una capacidad esencial del ser humano para compartir información y así "mantener al tanto" -informada- a una comunidad sobre diversos acontecimientos. También asocia ese poder a la manera de brindar la misma a las personas para que asuman "una postura específica frente a un tema determinado". Esta es otra visión de la comunicación, en la que se otorga una función esencial: formar, porque no se trata de difundir datos, sino de brindar una información completa para que las personas adquieran una ilustración suficiente que los lleve a tomar decisiones frente a asuntos que afecten su vida privada o social.

Conexión: puede contribuir a que las personas se "encuentren", para compartir e intercambiar sus ideas y sus conocimientos. En la medida que las personas se "conectan unas con otras", para generar un proceso de diálogo y compartir entre los destinatarios. Así la Comunicación no es algo exclusivo de quien posee una información o algo instrumental, sino que la misma puede dar pie para que los integrantes de la comunidad educativa inicien y propaguen procesos de conversación acerca de los temas que los convoquen en sus propios círculos sociales. 
De las ideas expuestas por los estudiantes se desprenden otros conceptos asociados:

Expresar: existen algunas coincidencias entre algunos estudiantes del colegio privado y del colegio público. "Es una forma de expresarse con las demás personas (...) expresar, contar a las otras personas lo que uno siente, lo que uno ha vivido". Los jóvenes desean compartir sus ideas y sus vivencias, en esta medida el término "expresar" adquiere sentido, porque es la posibilidad que tienen de compartir aquello relacionado con su experiencia de vida y que no es conocido (sobre todo por los adultos), para hacerlo público a otras personas. Por eso, adquiere relevancia la idea del estudiante quien afirma que (comunicar) es expresar lo que "uno siente, lo que uno ha vivido" (información propia), que puede servir de criterio para publicar en un medio de comunicación escolar.

Dialogar: el diálogo como la posibilidad de entrar en contacto con el otro, para hablar sobre un tema o para dar a conocer una opinión. Así el mismo se convierte en algo cercano y próximo entre iguales, entre pares; aquí no existe una idea manifiesta que para el diálogo sea necesario un "medio" (un canal o un dispositivo). En la medida que un tema convoque y provoque a otras personas a hablar sobre el mismo, puede motivar a nuevas conversaciones entre ellas.

Informar: aparece de una manera escueta la relación comunicar=informar, relacionada como “dar a conocer" algo que es novedoso o algo de lo que las personas requieren enterarse. De igual manera, está relacionado con la labor de "saber dar una información", es decir, organizar los datos para compartirlos con las otras personas, las mismas requieren unas normas, unas orientaciones, unos parámetros a tener en cuenta para compartirlos con otras personas. 


\section{Relación de los conceptos}

Trasmisión/difusión \# Poder/conexión: si bien persiste la idea de asociar la comunicación con llevar un mensaje claro a otros, al utilizar diferentes medios (periódicos, tv, páginas web), bajo el paradigma difusionista que prevalece en las experiencias de estas instituciones, existe la posibilidad que el concepto de Comunicación adquiera otras maneras de ser pensada y reflexionada. Es así como aparecen conceptos que la asocian más como un asunto relacional en el que las personas puedan establecer "conexión” y encuentro. Desde esta mirada, la Comunicación en el ámbito educativo puede obtener otra perspectiva (facilitar el encontrarnos) y otro sentido (compartir los propios conocimientos). Es posible plantear la posibilidad de generar una evolución de la idea transmisionista (difundir datos para mantener informada a un grupo de personas) hacia una idea relacional (generar procesos de encuentro a partir de los relatos).

Expresar/contar/dar a conocer: desde la perspectiva y aportes de los estudiantes, estos tres conceptos están relacionados con el para qué (el sentido) de participar en las experiencias de producción de medios en el colegio. Así, la comunicación es la posibilidad de tener la palabra para expresar lo que se piensa, para reflexionar sobre determinado tema y para producir conocimiento; por eso, se relaciona con el contar y el relatar para hacer que los otros accedan a aquellas historias que escriben los estudiantes en el que expresan la propia visión del mundo y, de esa manera, dar a conocer, compartir con los otros nuevos ideas o profundizar en aquello de lo que apenas se tiene una idea superficial. Por eso, para los estudiantes la Comunicación es una alternativa que les permite hablar de sus temas y hacerse visibles con sus pensamientos $\mathrm{y}$ propuestas a los demás. 
El siguiente mapa ilustra el concepto de la Comunicación desde la perspectiva de los maestros y de los estudiantes:

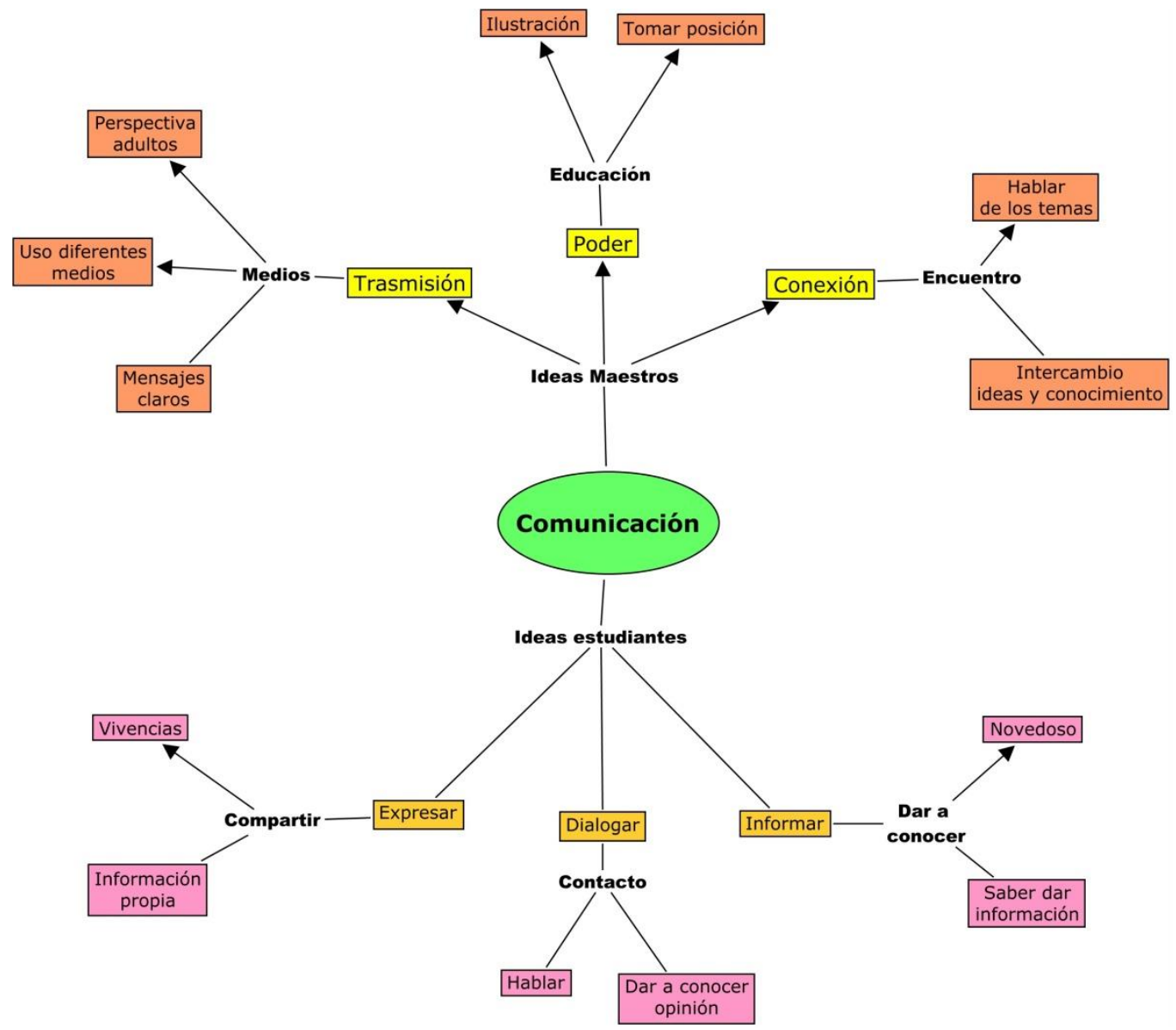

Mapa 1. Comunicación. Elaborado por el autor. 


\title{
9.3.2 Información
}

\author{
Colegio 1. Privado
}

\section{¿Qué idea tienen de la información?}

(Entrevista realizada a la comunicadora $D$ de la institución, noviembre 21 de 2012)

D. Información es una serie de datos que se recolectan sea de eventos futuros o pasados acerca de la institución, porque todavía no hemos salido de este enfoque de la institución, para transmitírselo, comunicárselo a las demás personas. (...) la información es válida, siempre y cuando se guarde respeto a las directrices institucionales que hay.

Una de las estudiantes comparte esta idea acerca de la información. (Entrevista estudiantes, septiembre 21 de 2012).

Est.1 Para mí informar implica dos cosas: implica tiempo de investigación, de indagación y de crecimiento intelectual de la persona, además también implica como el no mantener la información para uno, sino darla a los demás, y al darla a los demás vos mismo volvés y te informas, (...) y te complementas.

\section{Colegio 2. Público}

(Entrevista realizada a la maestra Isb, noviembre 7 de 2012)

Isb....para mí información en el sentido amplio de la palabra es que una persona además que se le está dando el dato entiende y comprende ese dato, eso para mí debería ser realmente la información. No solamente el hecho de trasmitir, sino que haya una comprensión en aquello que se trasmitió. 
Los estudiantes tienen estas ideas acerca de la información. (Grupo focal estudiantes, noviembre 7 de 2012).

Est.1 La información es como tener un concepto de algo, sobre diversos temas.

Inv. ¿Tenés algún ejemplo?

Est.1 ¿De información? Por ejemplo cuando le dicen a uno que mañana va a entrar a distinta hora o que el profesor no va a venir, o por ejemplo la mamá le dice que le deja las llaves en tal parte y así.

Est.2 La comunicación televisiva, la radial, todo lo que los medios nos muestran, toda la información de noticias, de lo que ha pasado, de lo que va a pasar, de lo que la gente espera, (...) los medios se preocupan de informar lo que la gente quiere saber.

Est.3 Es cuando nos dan a conocer algún tema, alguna conversación, algún acontecimiento que vaya a suceder o vaya a pasar.

Inv. ¿Por qué es importante la información?

Est.1 Si la información no existiría, pues nosotros qué seríamos, nadie. Mediante la información nos comunicamos y se desarrollan nuestras vidas, nos volvemos más inteligentes, otras personas pues consiguen nuevos trabajos, así.

Est.2 Información nos da nuevos conceptos, nuevas ideas, la evolución de las tecnologías, de las sociedad, de todo.

Est.3 La información es la que nos da a conocer las diferentes causas de algo.

Est.2 La información nos puede evolucionar más allá de lo que queremos saber o de lo que sabemos, nos puede suministrar la forma de saberlo. 


\section{Análisis de los textos (Qué es información)}

Sobre la información surgen estos conceptos, desde la visión de la comunicadora y la maestra:

Datos: aparecen dos enfoques: uno institucional, es el insumo para trasmitir a la comunidad educativa aquello que sucedió o que pasará en el colegio. Además tiene un condicionamiento: es válida si respeta las "directrices institucionales". En esta mirada prevalece el paradigma difusionista de dar cuenta de lo que sucede en la institución como prioridad, además es un enfoque controlador y limitante, porque lo que se difunda debe estar supeditado a las normatividades y no favorece la expresión de las ideas, ni tampoco compartir el conocimiento propio de la experiencia de vida de los estudiantes. Estos dos últimos aspectos requieren traspasar la idea de la información como dato, para transformarla en información como conocimiento: no se trata solo de aportar un dato para que las personas queden informadas de algo, sino de un relato que contenga otras ideas, reflexiones y preguntas producto de una información más elaborada y desarrollada.

Otro enfoque que aparece, desde la maestra, es la "información-dato" que tendrá sentido si quien lo recibe lo comprende, además indica que la información no puede reducirse a la trasmisión del mismo, sino que debe favorecer su comprensión. Esto implica pensar en las necesidades informativas del destinatario, de manera que lo que se publique favorezca y garantice el entendimiento de esa información. Por eso, en estos proyectos enmarcados en la escuela, hay que cuestionar el paradigma informativo que se da en ellos (trasmisión de las noticias que se dan en la institución) y se hace necesario proponer la información como un elemento cultural, desde la que se posibilité el conocimiento del contexto social que rodea a la institución educativa y se 
privilegie el conocimiento adquirido de la propia experiencia de vida de los estudiantes en relación con ese contexto y con el mismo colegio.

De las ideas expuestas por los estudiantes se desprenden otros conceptos asociados:

Conocimiento: los estudiantes son quienes dan pie para pensar la relevancia de la información como conocimiento. Este es resultado de un proceso que busca profundizar en un tema y para ello es necesario investigar el tema, lo cual conlleva a consultar diversas fuentes; también aplicar entrevistas y hacer observaciones de lo que "pasa a mi alrededor", para estar conectado con el contexto social. Esta idea de información como conocimiento se relaciona con las reflexiones de otro de los estudiantes del colegio público, quien resalta que información es la posibilidad de adquirir "nuevos conceptos", "nuevas ideas" y puede llevar a las personas a "evolucionar más allá de lo que sabemos". Basado en estos planteamientos de los estudiantes, se invita a los maestros a cambiar la mirada instrumental de la información reducida a la trasmisión de unos datos que no generan interés en los estudiantes, por una perspectiva cultural: tomar lo que me rodea y comprender el conocimiento propio de los estudiantes, para que a partir de ellos se construya un texto basado en su experiencia de vida.

Poder: la producción de la información para los medios de comunicación de las instituciones educativas, no debe ser una actividad orientada como tarea escolar: el maestro propone el tema, el estudiante escribe para obtener una buena calificación, y si el relato se ajusta a los parámetros evaluativos del maestro entonces se publica. Por eso, la estudiante del colegio privado propone dar otro sentido: ofrecer a la gente lo que necesita para que conozca más sobre algo y así tenga otra visión de los temas. Si la escuela entiende que la información que se publica en sus medios 
de comunicación aporta conocimiento y poder de acción, esta aporta a la formación en la participación social a toda la comunidad educativa.

Socialización: la información tiene sentido si se comparte con el otro, por eso adquiere ese carácter social, es un bien público. Sin dejar de mantener "informada a la comunidad educativa" es una labor importante cuando va más allá de los muros de la escuela y llega a "otros": estudiantes de diferentes colegios, a los vecinos de la institución educativa, a los padres de familia y egresados, y encuentren en los contenidos publicados conocimientos que aporten a la comprensión del mundo social y educativo desde la perspectiva de estudiantes y maestros. Esta es el sentido de "escribir para ser leídos".

\section{Relación de conceptos}

Interno/Trasmisión /Institucional/control: la información como dato es la que se utiliza para dar cuenta de las actividades o acontecimientos propios de la institución, bajo un paradigma divulgativo. El dato debe ser trasmitido a diferentes públicos: estudiantes, maestros, padres de familia bajo la perspectiva de mantenerlos "enterados" acerca del quehacer institucional. Se caracteriza por la "neutralidad", porque no cuestiona, no problematiza y está ceñida a los lineamientos institucionales y, por tanto, es controlable en la medida que solo permite expresar, relatar, opinar acerca de aquello que "no se salga de los parámetros institucionales". Es una información propia del modelo vertical de la comunicación.

Conocimiento/indagación/empoderamiento: la información puede constituirse en conocimiento si parte de la necesidad de ir más allá del dato y para ello es necesario querer profundizar en un 
tema. Debe partir de las propias preguntas personales o grupales o de situaciones que afectan a uno o varios integrantes (en este caso del colegio). Es una necesidad que debe nutrirse de preguntas que lleven a buscar respuestas a los interrogantes. Encontrar respuestas a esas inquietudes debe generar la necesidad de comunicar lo hallado, es decir, el conocimiento. Y en la medida que se comparta el mismo, se hable acerca de él es posible "evolucionar más allá de lo que se quiere saber", como compartía uno de los estudiantes, y hacerlo propio para comprender lo que sucede en sus contextos sociales y dar respuesta (interpretar) a las diversas situaciones que se presentan. Es tener la posibilidad de "hablar acerca de", darle "palabras" a experiencia de vida, a sus preguntas, a sus reflexiones, a lo que sucede en sus entornos sociales y publicarlo.

Comprender/relacionar/ hacerlo público: primera idea basada en la maestra: la información como la posibilidad de interpretarla de manera debida, para que el otro entienda la historia que se relata. Es comprometerse para que el otro entienda de qué trata el asunto, de manera que a su vez pueda comunicarlo al otro, es decir, que se convierta en intérprete y productor de un nuevo contenido para los otros. Información que permita generar diálogos, discusiones, debates y también conocer otros puntos de vista, para posibilitar otras relaciones entre las personas. La información adquirida no debe quedarse bajo el dominio de una sola persona, por el contrario, debe compartirse y hacerla pública, en esta medida la información se convierte en un bien común y en un bien social.

Social/educativo: la información es social, porque circula entre los estudiantes, los directivos y docentes, que pueden llegar a conocer y comprender las reflexiones y las ideas de los estudiantes, al igual que los padres de familia. La información es para que la gente conozca y comprenda más 
sobre un tema, ya sea porque es algo que sucede en la institución educativa o son situaciones sociales, culturales y políticas que se vive en los barrios o en la ciudad.

En el siguiente mapa se plasman las ideas que tienen los maestros y estudiantes sobre la información:

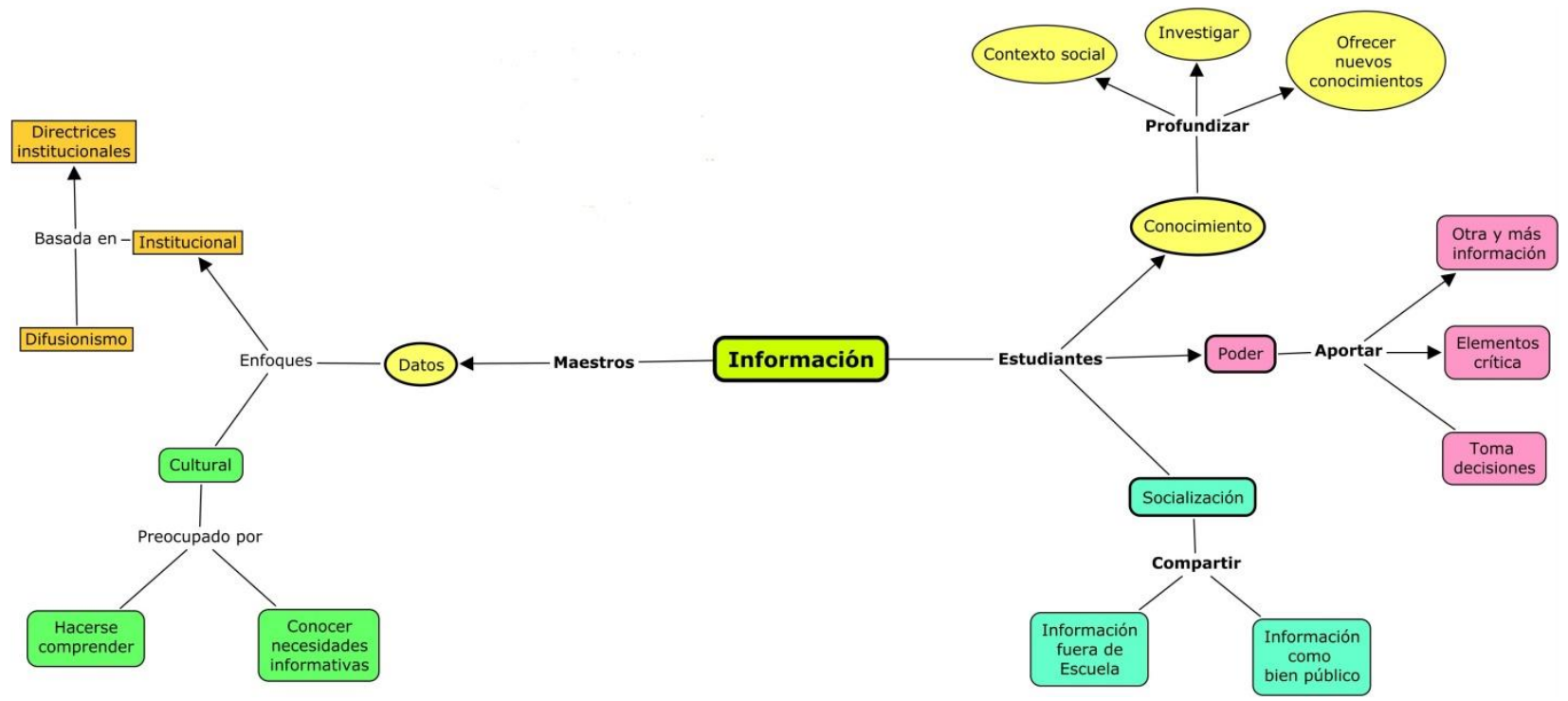




\subsubsection{Educación}

Colegio 1. Privado

\section{¿Qué entiende por Educación?}

(Entrevista realizada a la comunicadora $D$ de la institución, noviembre 21 de 2012)

D. (...) La educación no se trata solo de trasmitir lo que el estudiante necesita cumplir pa' pasar el año. Yo pienso que la educación se refiere más a que yo sea capaz a que el estudiante entienda que no solo está aprendiendo, sino que está disfrutando lo que está aprendiendo. Yo pienso que cuando el estudiante entiende que lo que está aprendiendo lo puede disfrutar mucho y nosotros como docentes entendemos que eso es una buena herramienta, que la clase no se trata de hacer silencio y leer un libro y copiar un libro y aprender lo que diga ese el libro, y lo que te decía siempre que todo salga de aquí (corazón).

Los estudiantes compartieron sus reflexiones sobre la Educación y otros conceptos, en el Grupo focal (Octubre 31 de 2012).

Est.1. Es lo que nos forma como una buena persona.

Est.2. Es lo que nos hace aprender para lo que nos sirve para toda la vida.

Est.3. Lo que nos inculcan y nos hace ser mejores personas y nuestra forma de ser, como las personas se desarrollan y ya tienen consciencia para decidir que quieren ser en la vida.

Est.4. Es como lo que nos ubica a nosotros en el mundo, porque ya aprendemos las nuevas cosas que hay y nos vamos ubicando más, aprendemos más sobre lo que hay a nuestro alrededor. 
Est. 5. La educación es una manera de erradicar violencia, erradicar el abandono, el abuso, yo creo que es una herramienta absolutamente poderosa para contrarrestar todo esto.

Colegio 2. Público

(Entrevista realizada a la profesora $I s b$, noviembre 7 de 2012)

Isb. Educación es una vocación. La educación es poder aportarle a un sujeto desde lo que conoce y desde lo que no conoce un maestro, herramientas para aprender a vivir, más allá que una suma de contenidos que se pueden olvidar en el transcurso del tiempo, es proporcionarle al chico confianza para que desarrolle sus habilidades y herramientas para que potencialice sus competencias, eso es educación para mí.(...) en el aula de clase se hace intencionadamente el acercamiento a ciertas cosas, pero un chico no puede decir que solamente es educado en el colegio, ni siquiera únicamente en la casa, como se dice que las cosas básicas vienen de casa; no, es el barrio, son los amigos, es la ciudad, es lo que ve, es lo que escucha, es lo que le trasmiten otros entes distintos a él;(...) educación es un aprendizaje personal de un ser humano.

Los estudiantes compartieron sus reflexiones sobre la Educación y otros conceptos, en el Grupo focal (Noviembre 7 de 2012).

Est.1 Yo creo que la educación es cuando nos preparan para hacer algo.

Est.2 La educación como es un derecho que todos tenemos que tener, la educación sirve para llegar a ser alguien en la vida, para adquirir conocimiento, adquirir experiencia.

Est.3 Actitud, información, integración y elaboración de proyectos

Est.4 La educación puede ser formación en un tipo de institución o de grupo, donde le dan a uno a conocer cosas, informarse sobre algo que uno no sabía o que ya sabía, pero que no lo tenía bien claro. 
Est.3 Pero no es solamente la escuela o las casas, también puede ser en las calles o por medio de grupos juveniles.

Est.4 Para mí la educación es enseñar a través no solo desde la pedagogía, sino desde la didáctica y la experiencia.

\section{Análisis de los textos (Qué es educación)}

Sobre la educación surgen estos conceptos, desde la visión de la comunicadora y la maestra:

Pedagogía: asociada a la capacidad del maestro de llevar a "entender" a los estudiantes diferentes temas, ya sea que estén contenidos en los planes de estudio, en los libros o en las propias experiencias de vida de los estudiantes. Bajo esa lógica los estudiantes aprenden, en la medida que comprenda algo y disfruten de ese aprendizaje.

Aprendizaje: relacionado con la vida cotidiana (el barrio, la ciudad, los vecinos) más que con los contenidos de los libros. Los aprendizajes se logran desde la confianza en sí mismos (los estudiantes), el conocimiento de sus propias capacidades sociales, intelectuales y humanas para que "aprendan" a vivir en comunidad y en sociedad.

De las ideas expuestas por los estudiantes se desprenden otros conceptos asociados a la educación:

Formación: orientada a la idea de llegar a ser "mejor persona", "una buena persona", a "ubicarse en el mundo". Es una argumentación basada en los valores y en la personalización, es una preocupación por el propio ser. Fuera de esta existe otra idea de la educación como formación 
cuando se concibe como una preparación para "hacer algo", o sea, que la educación brinda elementos que sirven para el desempeño de una labor o un trabajo.

Institucionalidad: educación asociada a la escuela, como el lugar donde se recibe formación, información y lo necesario para conocer lo que se no se sabía. En este sentido la educación se imparte en dos instituciones básicas: la escuela y la familia.

Derecho: uno de los estudiantes destaca que la educación es un "derecho" que deben ofrecer a todos, con el propósito de "llegar a ser alguien en la vida", es decir, una persona "formada" para participar en la sociedad y vivir con dignidad; para ello deben ofrecerle los bienes materiales (libros y tecnologías) que les permita acceder a los conocimientos que les permitan comprender lo que sucede en su vida personal y lo qué pasa en su sociedad; además, a tener unos educadores que le ayuden a relacionar los materiales académicos con su experiencia de vida. La educación como un Derecho puede ser un factor de equidad social que posibilite erradicar la violencia, las injusticias, los abusos y los abandonos por parte del Estado. La educación vista como un Derecho permite trascender el bien personal y reclamar la justicia social para todos los integrantes de la misma.

\section{Relación de conceptos}

Libro/información: aparecen como dos elementos con los que no se representa la educación. El conocimiento no solo está en los libros, la educación no se trata solo de copiar lo que hay en un libro y aprenderse lo que está en él: la información, los datos. Sin embargo, es el modelo de la educación tradicional que aún sigue vigente. A eso llevan a los estudiantes, a formarse como 
"respondedores de pruebas", a acumular contenidos que llegan "a olvidar en el trascurso del tiempo".

Contexto/vida cotidiana: en este aspecto se asocia la experiencia de vida en la calle, el barrio y la ciudad con la educación. Contraria a la relación anterior, el conocimiento circula en la vida cotidiana, en lo que los estudiantes viven de manera permanente, en el contacto con sus problemas sociales, en las nuevas experiencias de vida, en las preguntas que se suscitan al presenciar o ser testigos de algo. La vida cotidiana es un texto dinámico que aporta de manera permanente nuevos conocimientos, por eso la escuela debe abrir sus puertas para dialogar con ellos, porque la educación no es algo exclusivo de la escuela.

La siguiente imagen representa las ideas sobre Educación que tienen los maestros y los estudiantes:

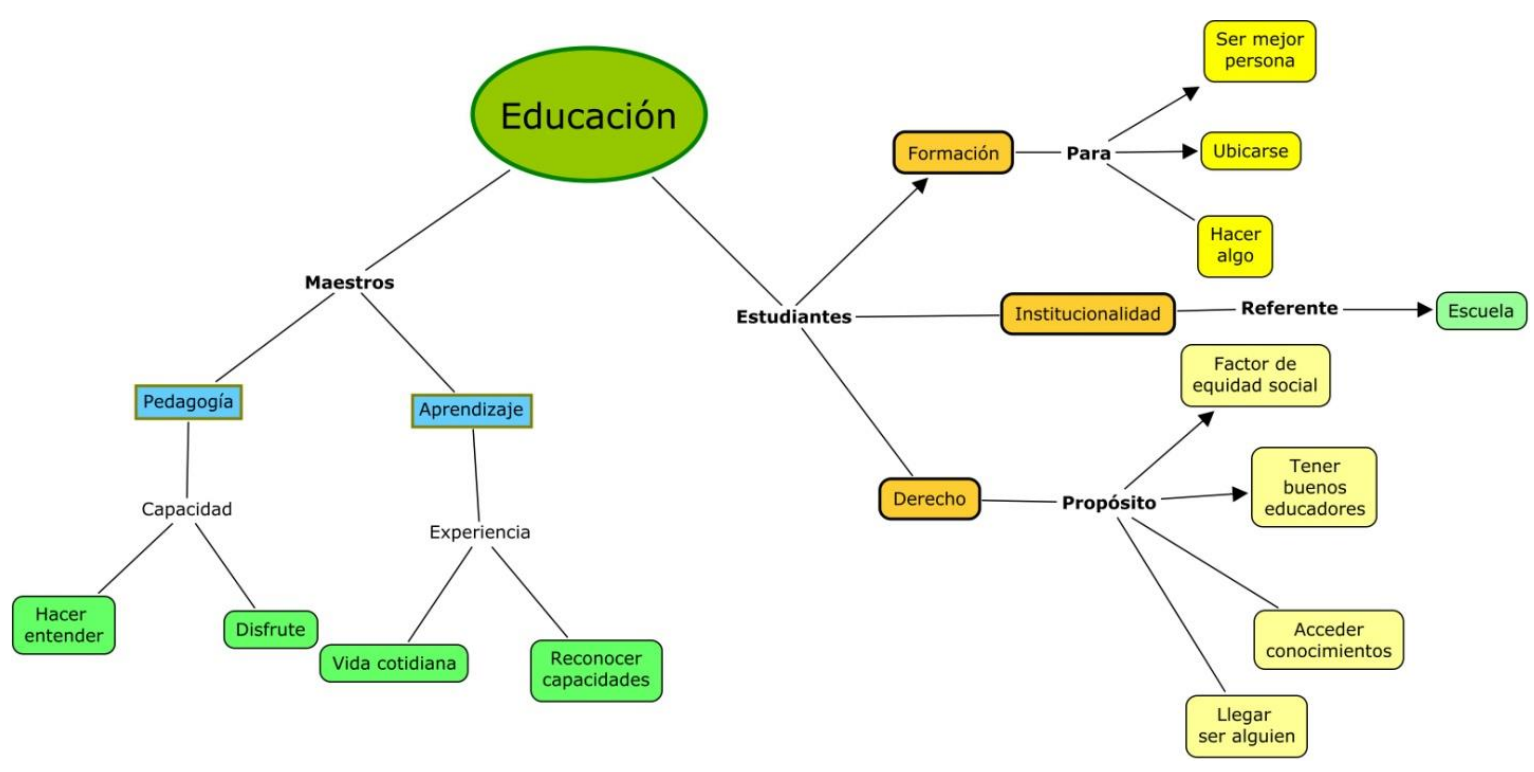

Mapa 3. Educación. Elaborado por el autor 


\title{
9.3.4 Medio de Comunicación Escolar
}

\author{
Colegio 1. Privado
}

\section{¿Qué entiende por Medio de Comunicación Escolar?}

(Entrevista realizada a la comunicadora $D$ de la institución, noviembre 21 de 2012)

D. es una herramienta que permite educar, formar, concientizar, sensibilizar a una comunidad en diferentes aspectos que me puedan rodear.

Los estudiantes compartieron sus reflexiones sobre los medios de comunicación escolar, en el Grupo focal (Octubre 31 de 2012).

Est. 1 Los medios, en este caso, es como una herramienta más que para trasmitir información es para educar, no tanto en conocimiento como han dicho, sino como personas integrales. (...) Yo creo que actualmente vivimos en un entorno muy difícil, pues tenemos muchas problemáticas como la violencia, el abandono, un montón de cosas y yo creo que los medios nos permiten enseñar a las personas que hay otras cosas distintas.

\section{Colegio 2. Público}

(Entrevista realizada a la profesora Isb, noviembre 7 de 2012)

Isb. El medio de comunicación escolar es permitirles inicialmente a los chicos, darse la oportunidad de ser entes de comunicación.(...) Que sean personajes reconocidos que además de ese reconocimiento tengan una responsabilidad a la hora de transmitir la información que le 
interesa a la comunidad. Y además de eso que ese reconocimiento también implique la responsabilidad de recibir lo que el otro dice de la forma más respetuosa posible para poder retroalimentar aquello que ya se dijo(...) el medio tendría que ser una herramienta más para mejorar el proceso educativo, un aliado (...). El motor de nosotros tiene que ser educar esos muchachos, con las herramientas que haya, con lo que tengamos a mano y hasta con lo que no tengamos a mano, para que ellos sean realmente en todos los aspectos como debe ser.

Los estudiantes compartieron sus reflexiones sobre los medios de comunicación escolar, en el Grupo focal (Noviembre 7 de 2012).

Est.1 Es lo que nos da a conocer lo que pasa dentro de la institución, lo que pasa con cada una de las personas de la institución.

Frente a la pregunta planteada se generó una discusión entre los estudiantes, de las cuáles se da cuenta en este aparte y está relacionada con la pregunta: Para ud. ¿qué es un medio de comunicación escolar?

Est.2 Como medio comunicativo que somos, (...) nos toca hacer noticias no de los problemas que tenga la institución, sino de los acontecimientos que tenga. Mi pregunta es iun medio de comunicación se encarga de mostrar lo malo o mostrar las cosas buenas?

Est.1 Se trata precisamente de mostrar lo que se quiere y no se quiere ver, porque no todo lo del colegio es malo.

Est.2 Pero entonces digamos una cosa: si nosotros como medio comunicativo que somos no podemos argumentar sobre nuestra situación que estamos viviendo en el colegio y publicamos solo las cosas buenas para que quede bien entre los otros colegios, nos estaríamos afectando a nosotros mismos; ya que no tenemos los beneficios y la manera, digamos los suficientes permisos 
para hacer nuestro trabajo como es, mi pregunta es: si el caso de este periódico es solo mostrar las cosas buenas de la institución, ¿para qué estamos aquí nosotros?

Est.3 Estoy un poco de acuerdo con lo que dice él y un poco de acuerdo con lo que dice ella. ¿Por qué?, porque las cosas malas se podrían publicar, con tal de dar a conocer la noticia y los perjuicios que tenemos en esta institución, para buscar un medio de solución.

\section{Análisis de los textos (Qué son los medios de comunicación escolar)}

Sobre los medios de comunicación escolar surgen estos conceptos, desde la visión de la comunicadora y la maestra:

Herramienta: asociado a la idea de instrumento, aunque en las definiciones de la maestra y la comunicadora se evidencia otra función diferente a la de trasmitir, más asociada a ser un punto de encuentro, proyección, socialización. Es un espacio formativo que favorece el reconocimiento de los estudiantes y también asumir las responsabilidades propias de lo que implica la información. Es una herramienta que funciona como "aliada", como un espacio alterno para educar y formar, sobre todo en comunidades más vulnerables: "el motor es educar a estos muchachos, con las herramientas que haya", en ese sentido el medio escolar adquiere sentido, porque puede utilizarse para ello.

De las ideas expuestas por los estudiantes se desprenden otros conceptos asociados a medios de comunicación:

Educación: es un espacio de educación "como personas integrales", por lo que adquiere otra razón de ser, diferente a trasmitir datos. Es un espacio que permite a los estudiantes "presentar" 
mensajes alternativos a los que se ven en los medios tradicionales. Por tanto, es el reto que tienen este tipo de proyectos o experiencias comunicacionales: ofrecer contenidos que posibiliten la reflexión, la problematización de los hechos y una interpretación diferente de los mismos.

Dar a conocer: es inherente a la función de los medios: compartir la información y los datos, relacionado con lo que "sucede" en la institución educativa o con las personas que la integran: directivos, maestros y estudiantes. Una mirada que le da el carácter institucional que adquieren la mayoría de estos medios de comunicación, bajo un paradigma divulgativo.

Conflicto: en un medio que divulga información institucional la crítica y la pregunta problematizadora no tiene cabida, por eso, la afirmación del estudiante suena como un detonante: hacer noticias (neutralidad), no presentar los problemas (problematización, conflicto) es evitar que los cuestionamientos surjan. Una problematización unida a la expresión "mostrar lo malo", asociada a lo que no funciona para los estudiantes y frente a lo cual sienten la necesidad de expresar, con el agravante que no es posible hacerlo. De ahí que la afirmación: si el caso de este periódico es solo mostrar las cosas buenas de la institución, ¿para qué estamos aquí nosotros? Un cuestionamiento que manifiesta "rebeldía", que reclama garantía para problematizar la realidad. Una pregunta que genera tensión, debate, deliberación, discusión y diálogo entre los estudiantes y con sus maestros frente a la función de los medios en la escuela.

Concertación: la idea entonces es pasar de la discusión de publicar solo lo bueno y lo malo no, publicar los acontecimientos y noticias, pero los problemas no; de ahí que sea necesario plantear una alternativa mediadora: dar las noticias malas, para buscar un “medio de solución”, es decir, 
no quedarse en la polarización, sino en ofrecer respuestas a aquello "malo" que sucede en la institución educativa y en los entornos sociales donde viven los estudiantes.

\section{Relación de conceptos}

Motor/proceso educativo: la visión instrumental de los medios lleva a que estas experiencias adquieran un carácter informativo y divulgativo; son un apéndice, porque no se integran a la propuesta curricular de las instituciones educativas $y$, de igual manera, los contenidos que se publican en ellos no son tomados desde una perspectiva del conocimiento. Por eso, la idea de la maestra tiene significado, en la medida que la producción de los medios escolares puede integrarse como un factor educativo, un espacio en el que los estudiantes aprendan el valor de la construcción de un mensaje-conocimiento. De ahí que sea necesario cambiar la perspectiva informativa de los medios en el colegio, por otra en la que confluyan los conocimientos que construyen los estudiantes y los hacen circular en sus medios de comunicación, como una posibilidad de validar la voz de los alumnos y a partir de estas experiencias sientan que hacen parte de una sociedad y que participan en su construcción.

Medio institucional/medio escolar: esta dicotomía parte del carácter "neutro" de un medio, cuando se limita a mostrar "solo lo bueno" que pasa en la institución. En esa medida los mensajes se construyen desde el acontecimiento institucional, la reseña de los eventos, la publicación de las directrices institucionales elaboradas por los directivos y maestros. Por eso, llamarse "medio escolar" implica un empoderamiento de parte de los estudiantes, porque deberían publicar los temas, las ideas, los análisis, las preguntas y las propuestas de ellos. Un medio escolar debe ser el espacio en el que los alumnos son los protagonistas, de manera que sea la posibilidad de "enseñar 
a las personas otros cosas distintas". Es la voz que reclama un espacio más visible en estos medios para adquirir esa categoría de "escolar".

Entes de comunicación/responsabilidad: hay que asumir la responsabilidad de ser un "productor de conocimiento", un "ente de la comunicación"; dejar de ser el receptor pasivo y asumir los riesgos que implica producir "otros" mensajes en el que se reflejen los conocimientos, las experiencias de vida, las preguntas y las propuestas de los estudiantes. Ello implica aprendizajes para la vida: tener responsabilidad en el proceso de conseguir la información necesaria, comunicar los mensajes de manera adecuada, ofrecer más y mejores conocimientos, porque eso que se comunique puede dar pie para que otros hablen, expresen, pregunten o amplíen su visión de la vida y compartan esas nuevas ideas con otras personas, y generan así una cadena comunicativa alterna.

El siguiente mapa representa las ideas sobre Medios de comunicación escolar que tienen los maestros y los estudiantes: 


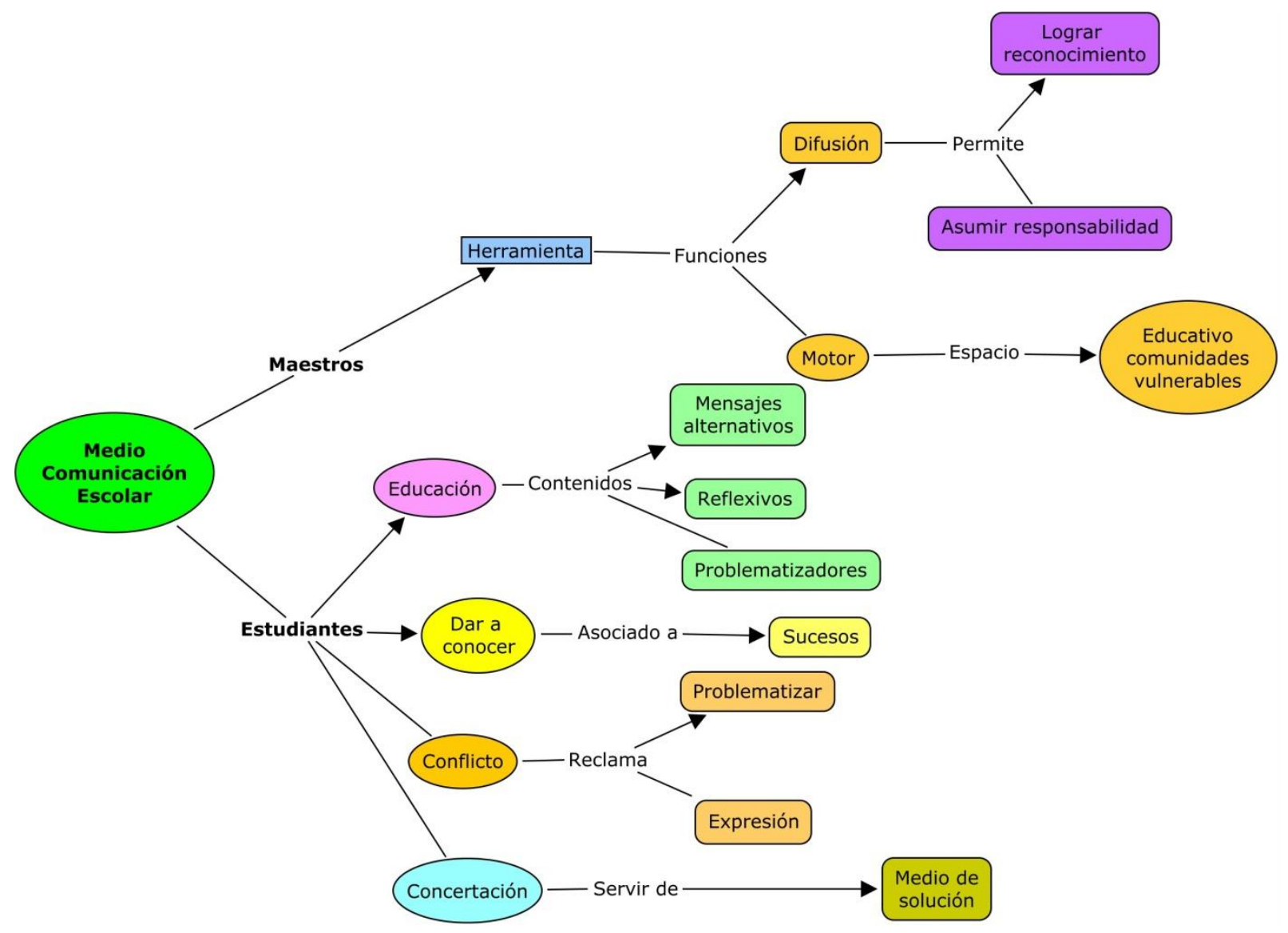

Mapa 4. Medio Escolar. Elaborado por el autor

\subsubsection{Productores de sentido}

Colegio 1. Privado

¿Qué entiende por productores de sentido?

(Entrevista realizada a la comunicadora $D$ de la institución, noviembre 21 de 2012) 
La comunicadora no brindó una definición sobre el concepto.

Los estudiantes compartieron sus reflexiones sobre la producción de sentido en el Grupo focal (Octubre 31 de 2012).

Est.1 A mi me parece que un contiendo debe tener significado y sentido. Yo creo que van absolutamente relacionados, son diferentes, pero un contenido que carece de significado $y$ sentido yo creo que no está aportando nada, entonces me parece que es absolutamente necesario y hay que relacionarlos en el contexto.

Est.2 Cuando uno presenta un tema, hablando del tema con contenido, mi intención no solo es mostrar el tema, es expresar algo o tratar que la otra persona tome la posición que yo quiero que tome frente al tema, de que la reciba de cierta manera, entonces cuando uno trasmite un tema, o sea un contenido está trasmitiendo un tema o significado que uno quiere que la gente entienda.

Colegio 2. Público

(Entrevista realizada a la profesora Isb, noviembre 7 de 2012)

Isb. Es construir sus propias cosas a partir de datos planos, desde por ejemplo una noticia un qué, cómo, cuándo, dónde y por qué, y qué, cómo, cuándo, dónde y que ellos empiecen a construir el por qué y ese por qué sería el sentido real del trabajo de un periodista, llegar al por qué, llegar al cómo, llegar a eso y tocar el cómo implicaría tocar el ser.

Los estudiantes compartieron sus reflexiones sobre los medios de comunicación escolar, en el Grupo focal (Noviembre 7 de 2012). 
Est.1 Para mí sería como producir sentido común, para mí sería como ayudarle a la gente a pensar, a reflexionar, a ir más allá de lo que ve, sería como profundizar lo que sabe, para mí eso sería ser productora de sentido.

Est.2 Y también un productor de sentido también podría ser alguien que informa, que no informa por informar, sino que informa...

Est.3 Para mí un productor de sentido es aquella persona que escribe algo que cause alguna sensación en los lectores, no sé si este en lo cierto.

Est.2 ¿Qué tipo de sensaciones?

Est.3 Por ejemplo estoy leyendo una noticia y diga: ¡cómo! ¿Si será verdad? Así, que cause tristeza, alegría.

\section{Análisis de los textos (Qué entiende por productores de sentido)}

Sobre los productores de sentido surgen estos conceptos, desde la visión de la maestra:

Construir sentido: de acuerdo con los parámetros del periodismo tradicional y su manera de estructurar la información a partir de la fórmula de las cinco preguntas base (qué, cómo, cuándo, dónde, a quién), la maestra considera que es necesario encontrar el porqué, es decir, el sentido del mensaje y eso compromete al estudiante (desde su visión como periodista) a incidir en las personas que acceden a sus trabajos. Se trata que el relato comunicado a los integrantes de la comunidad educativa vean que en esos relatos "producidos con sentido" aportan algo significativo para sus vidas: un nuevo conocimiento, la comprensión de una temática, la 
generación de reflexión $\mathrm{y}$, porque no, los fundamentos para actuar, por eso, tocar el cómo implicaría tocar el ser, como indica la maestra.

Empoderamiento: se puede asociar a la idea de construir sus propias cosas a partir de datos planos, es decir, producir sentidos rompe con el esquema de las experiencias de medios en las instituciones educativas en la que se impone el criterio, las temáticas y los trabajos de los maestros (adultos). "Producir sus propias cosas" es aceptar y promover que los estudiantes tienen una voz, una visión de su mundo, unas experiencias de vida que generan conocimiento; es un conocimiento alternativo que se fundamenta en la vida cotidiana, en sus costumbres y manera de ver el mundo (su mundo) que luego relata con sus propias palabras, a partir de sus propias preguntas o reflexiones. Posibilitar que esto suceda en este tipo de experiencias es propiciar que los estudiantes se apropien de la palabra para construir los relatos que muestren sus vidas y responsabilizarlos de los textos que comunican a los otros, porque los mismos deben aportar algo significativo a las personas que los "lean" en diferentes formatos.

De las ideas expuestas por los estudiantes se desprenden otros conceptos asociados a medios de comunicación:

Generación de otros conocimientos: los medios de las instituciones educativas son el espacio para que los estudiantes, como productores de sentido, aporten otros contenidos diferentes a los que se publican generalmente en ellos (bajo perspectivas institucionales) e incluso de los paradigmas informativos que pretenden emular; para ello requieren que los estudiantes se den cuenta que sus relatos tienen significado en la medida que aportan visiones diferentes, agregan otro tipo de datos y otra manera de contar, es ahí que adquiere valor la idea "escribir para ser 
leídos", porque solo se lee aquello que en realidad aporte algo para la vida de quien acceda a los relatos que produzcan los estudiantes.

Comprensión: relacionado con un contenido (que) está trasmitiendo un tema o significado que uno quiere que la gente entienda. Lograr que los destinatarios comprendan la esencia de los relatos que les llegan no se trata solo de "mostrar el tema", sino de presentar diversidad de datos, testimonios, puntos de vista que lleven a entender el tema en su dimensión global. Así, los relatos que se publiquen deben ser producto de la investigación y su propósito es propiciar la comprensión de los destinatarios, para que a su vez también compartan su versión del tema a otras personas y así el relato llegue a nuevos destinatarios.

Incidencia: un productor de sentidos influye en la toma de posiciones de los destinatarios, por eso, no se trata de "informar por informar", sino de incidir en lo que "piensa" y en lo que "reflexiona". Todo esto va atado a producir relatos con unos contenidos muy completos en información, entendida como conocimiento, que permita a los destinatarios comprenderla y, en esa medida, sirva de fundamento para tomar decisiones que beneficien a la comunidad educativa, es decir, propiciar reflexiones en el marco de lo público, generar actitudes de solidaridad entre estudiantes, maestros, directivos y, por qué no, la comunidad que rodea a la institución educativa.

Profundizar: un mensaje que se comprenda, que incida en la toma de decisiones de las personas (destinatarios) es un mensaje que debe ser profundo. Hay que ir más allá de lo que ve, sería como profundizar lo que sabe, como afirma uno de los estudiantes, es partir del propio conocimiento (lo que sabe), para investigar más sobre eso que sabe, para llegar a un conocimiento más completo de aquello que sabe; se trata de develar aquello que no se ha visto, es un ejercicio que 
bien valdría la pena ser tenido en cuenta en este tipo de experiencias de medios de comunicación en las instituciones educativas, para transformarlos de instrumentos difusores de datos a espacios en los que se entran a circular otros conocimientos, que permitan ver las realidades y la vivencias de los estudiantes desde diferentes perspectivas y puntos de vista.

\section{Relación de conceptos}

Pasivo/Activo: el estudiante es pasivo cuando el maestro motiva a escribir un texto para él y con propósitos evaluativos, sobre un tema que el docente propone; es pasivo, cuando replica los textos que el maestro escribe para que el estudiante repita ante una cámara; es pasivo, en la medida que sigue un paradigma informativo que da cuenta de los asuntos institucionales (eventos

deportivos y culturales). Por el contrario, es activo cuando se asume como "productor de sentidos", es decir, cuando produce sus relatos a partir de su propia experiencia de vida en el medio de la institución educativa, los temas que considera importantes y afecta la existencia de sus compañeros, la calidad de vida de su comunidad, la decisiones que inciden en el funcionamiento del colegio y los hechos que sirven de referente de vida para sus compañeros.

Cumplir la tarea/Involucrarse: si el propósito es publicar informaciones básicas, desde una perspectiva noticiosa para que los otros reciban los datos, se cumple una tarea de emisor/trasmisor de datos, el acto de comunicar se convierte en un asunto mecánico supeditado a un quehacer establecido desde el periodismo tradicional; pero si el asunto se concibe como una construcción de conocimientos, a partir de la propia experiencia de vida y con el propósito que se genere en los otros la sensación de querer más sobre el tema, reflexionar a partir de lo planteado en el relato e incluso cambiar de actitud o de forma de pensar, exige del estudiante involucrarse y 
asumir su rol de productor de sentidos que tiene como responsabilidad mostrar lo que pasa en su contexto social, interpretarlo y comunicarlo, para que los otros lo entiendan y lo compartan con más personas de la comunidad educativa. Involucrarse implica responsabilidad en lo que se dice y cómo se dice, como una alternativa que garantice la libertad de expresión.

Adentro/Afuera: bajo la perspectiva divulgativa e institucional, el interés está centrado en difundir el dato a la comunidad educativa, con el propósito de mantenerla informada y validar la importancia de los medios de comunicación como instrumento; desde la producción de sentidos, basada en la vida cotidiana y la dinámica del contexto social, el relato se construye en clave de cultura: aquello que afecta la vida de la comunidad; aquello que se expresa en la música, en las letras, en los bailes; en los triunfos deportivos y las expresiones de solidaridad; en las denuncias y en las propuestas; así la vida va a la institución educativa para que sea reconstruida en relato que se comparte en ella y afuera de ella, como una relación reciproca en que ambos se inciden mutuamente, para mirarse, comprenderse y comprometerse a mejorar en sus relaciones.

El siguiente mapa representa las ideas sobre Productores de sentido que tienen los maestros y los estudiantes: 


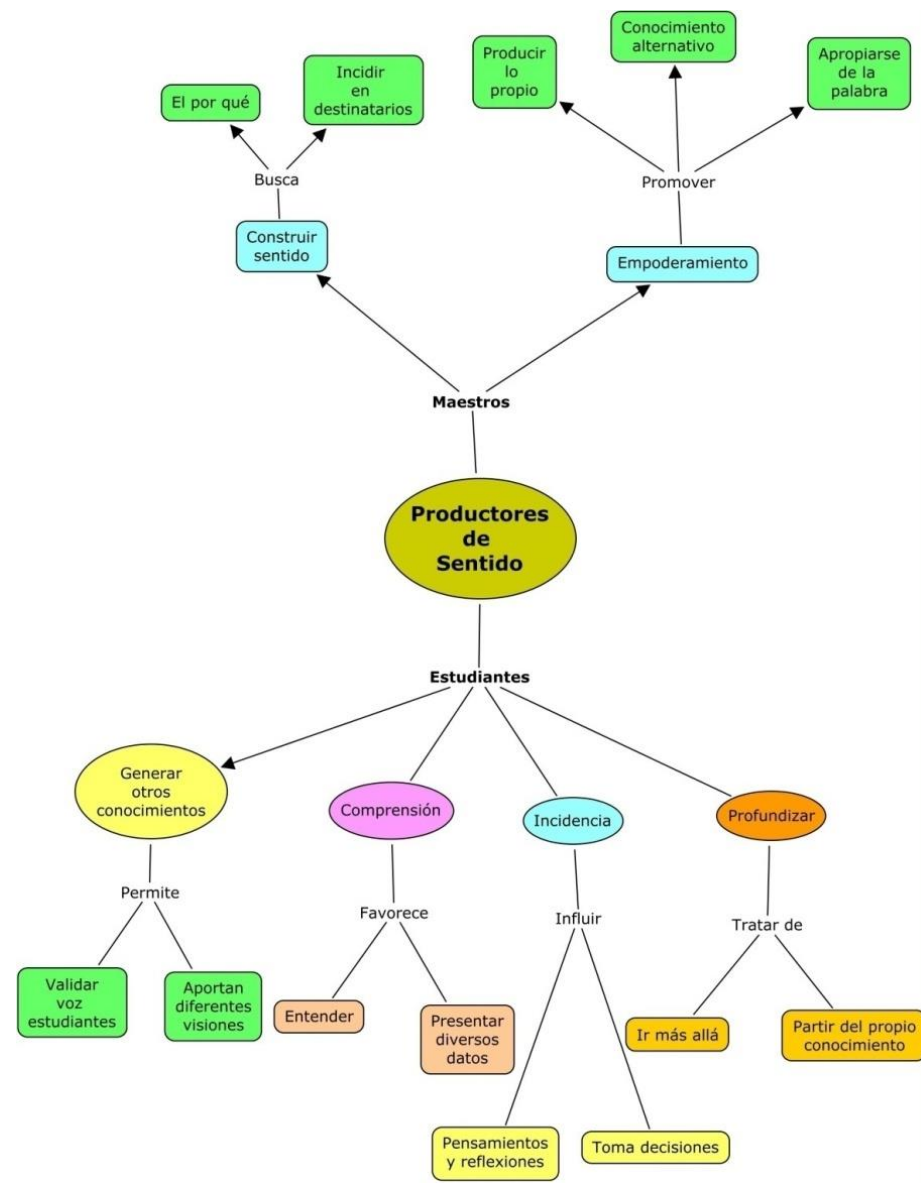

Mapa 5. Productores de sentido. Elaborado por el autor

\subsubsection{Ciudadanía}

Colegio 1. Privado

\section{¿Qué entiende por ciudadanía?}

(Entrevista realizada a la comunicadora $D$ de la institución, noviembre 21 de 2012)

La comunicadora no compartió el concepto 
Los estudiantes expusieron sus reflexiones sobre la ciudadanía en el Grupo focal (Octubre 31 de 2012).

Est.1 Una ciudad.

Est.2 Una responsabilidad que uno tiene

Inv. ¿Ante quién?

Est.2 Ante las personas que uno tiene y que se desarrollan en el entorno de uno y a uno...

Est.3 Es ejercer correctamente el papel que uno tiene en la sociedad, lo que yo hago para que los otros también estén bien, lo que yo hago y es necesario para mí misma, que eso afecte a los demás negativamente y ojalá fuera también positivamente.

\section{Colegio 2. Público}

(Entrevista realizada a la profesora Isb, noviembre 7 de 2012)

La profesora no compartió un concepto concreto sobre la ciudadanía

Los estudiantes compartieron sus reflexiones sobre los medios de comunicación escolar, en el Grupo focal (Noviembre 7 de 2012).

Est.1 A nosotros los de once nos dieron clase de Constitución, entonces según lo que nos dijo el abogado en el tiempo que estuvo, es que ser ciudadano es saber que yo tengo derechos, pero al igual que tengo derechos tengo deberes, si quiero un derecho debo cumplir un deber. Ser ciudadano es aprender a aceptar mis responsabilidades con el Estado, con la sociedad y conmigo mismo. 
Inv. ¿Y qué es la ciudadanía?

Est.2 La profesora nos explicó que la ciudadanía la adquirimos desde que nosotros nacemos, desde una personalidad propia de nuestra cultura, cómo somos, cómo nos vestimos y también podemos tener un documento.

Est.1 Eso, la ciudadanía es la que se obtiene con la cédula, pues con el documento de identidad.

Est.2 Pero él nos explicó que no solamente se adquiere con la cédula, sino desde chiquitos.

Inv. Formalmente si, formalmente cuando te dan la cédula, a ud. le dicen que es ciudadano, pero ¿si será que uno es ciudadano, porque le dan una cédula?

Est.3 Porque nacimos en el país, porque nos formamos aquí, tenemos las mismas costumbres que las demás personas y vivimos con las mismas condiciones, compartimos prácticas y creencias que muchas personas de otros países no conocen.

Est.4 Porque tenemos una identidad de donde vivimos, donde nacimos, departamento, ciudad.

Inv. ¿De una sociedad? En este caso una sociedad colombiana.

Est.4 Si, porque uno integra una sociedad, una comunidad, que nos identificamos en la ciudad, nacemos en ella.

Est.5 Para mí ciudadanía es cuando un grupo de personas hacen parte de una sociedad, teniendo en cuenta sus costumbres y posturas.

Inv. ¿Por qué es importante el tema de la ciudadanía?

Est.1 Porque la ciudadanía es sociedad y de ahi se desprende todo (...) La vida, la cultura, la religión, las costumbres, todo lo que conforma una sociedad. Hasta el idioma depende de eso. 
Est.3 Si no tuviéramos la ciudadanía sería dificil estudiar, trabajar, formarse...

\section{Análisis de los textos. (Qué entiende por ciudadanía)}

Sobre la ciudadanía la comunicadora y la maestra no aportaron al concepto, por tanto, el análisis se hará a partir de las ideas expuestas por los estudiantes de ambas instituciones.

Responsabilidad: es una idea basada en que las personas no están solas en una sociedad, sino que en conjunto la conforman, por tanto, implica compartir con los "otros", "con las personas que uno tiene", esto es, convivir y aceptar la diferencia; es la responsabilidad que cada quien tiene con los demás con quienes comparten el entorno social y cultural donde se desarrolla. Pero también la responsabilidad puede ser vista como el acatamiento de las normas establecidas por una sociedad: "aceptar las responsabilidades que uno tiene con el Estado"; como una manera de integrarse a ella y acceder a los derechos fundamentales que deben ofrecerle, en su condición de ciudadano.

Público: la ciudadanía implica compromiso y exposición, no se juega en el espacio de lo propio (privado), sino que se participa en la arena del bien común (lo público). La ciudadanía se adquiere cuando se asume ese rol protagónico de trabajar por lo "de todos"; en esto se incluye la lucha por reclamar el acceso a los derechos fundamentales, pero también es necesario involucrarse para que los "otros" también puedan recibirlos, en generar espacios de diálogos y discusión, en cuidar los bienes públicos, en expresar con libertad y responsabilidad las propias opiniones y respetar la de los otros, sobre todo, cuando son diferentes. Es necesario que los estudiantes sean conscientes que deben asumir un papel activo para ser parte de la construcción 
de una sociedad: el papel que uno tiene en la sociedad, lo que yo hago para que los otros también estén bien.

Normatividad: la idea de ciudadanía se asocia a la Constitución y las leyes; también se relaciona con los Derechos y los Deberes en la medida que la solicitud del uno implica el compromiso del otro: es saber que yo tengo derechos, pero al igual que tengo derechos tengo deberes, si quiero un derecho debo cumplir un deber. En la misma sintonía de la Constitución, como el marco que garantiza contar con unas normas comunes, desde las cuales sea posible establecer unos mínimos éticos para desenvolverse en la sociedad.

Documento: es la más común de las ideas: "La ciudadanía se obtiene con la cédula"; es el documento oficial que señala que a partir de ese momento asume las normativas del Estado o sociedad a la que pertenece; es el documento que lo acredita como "preparado" para ejercer derechos como el del voto. Esto es un acto administrativo asociado a llegar a una edad establecida que indica que los jóvenes tienen las capacidades para ganarse el título de la ciudadanía.

Identidad cultural: la ciudadanía es algo que comienza en el contexto familiar y social, es desde esos espacios que se empiezan a marcar una idea de la convivencia, el respeto por el otro, la negociación de las diferencias. Y esa identidad cultural está marcada por una idea más amplia de sociedad con sus costumbres, sus normas, su manera de resolver los problemas, su desarrollo cultural, económico y político, sus fundamentos religiosos: Porque nacimos en el país, porque nos formamos aquí, tenemos las mismas costumbres que las demás personas y vivimos con las mismas condiciones, compartimos prácticas y creencias que muchas personas de otros países no 
conocen. En ese sentido, la idea del estudiante ayuda a ampliar un enfoque más cultural de la ciudadanía, la cual se forma y ayuda a crecer lazos de identidad entre las personas.

Sociedad: asociada a una comunidad (barrio, ciudad, región), con unas características culturales concretas y diferenciadoras: un grupo de personas hacen parte de una sociedad, teniendo en cuenta sus costumbres y posturas. Para vivir la ciudadanía en una sociedad es necesario tener en cuenta los componentes que la integran y, a la vez, la diferencian de las otras: La vida, la cultura, la religión, las costumbres.

\section{Relación de conceptos}

Grupo de personas/los otros: la ciudadanía no se ejerce para sí mismo, ni en un espacio privado, se ejerce con los otros con quienes se encuentra en el espacio común y en la lucha por los derechos de todos (el bien público). La ciudadanía implica encuentro, discusión, diálogo y ello es posible en la medida que exista relación con los otros.

Edad/Cédula/Formación: existe la idea que para ejercer la ciudadanía o ser ciudadanos es necesario llegar a determinada edad y luego obtener un documento: la cédula de ciudadanía. Sin embargo, como lo indican los estudiantes, se puede ser ciudadano "desde chiquito", desde que nace porque empieza a integrar una sociedad en la que es necesario inculcar ideas (hace parte de una sociedad), fomentar actitudes de solidaridad (pensar en los otros), dialogar (para solucionar diferencias, para conocer otros puntos de vista), denunciar (capacidad de hacer ver lo que afecta el funcionamiento de su entorno social). Es necesario fomentar ese tipo de actitudes en la familia, 
en la escuela, en el contexto social, para que el niño y el joven generen la consciencia que integran una sociedad, en la que es necesaria su participación.

Personalidad/integración: la ciudadanía tiene una identidad que es creada y formada en un contexto social concreto (el barrio, la sociedad) en el que se desarrolla la persona (niño y joven), quienes aprenden una serie de prácticas e ideas acerca de la vida, las costumbres, las creencias religiosas, las ideas políticas; y la misma hace parte a su vez de un conjunto más amplio (el Estado) que también crea una personalidad propia en sus símbolos y en sus normas. En la medida que los niños y los jóvenes, sobre todo, reconocen y se identifican con ese contexto social y con la sociedad a la que pertenecen, generan lazos que la llevan a integrar, a sentirse parte de una sociedad en la que vivirá y proyectará sus ideas y conocimientos.

El siguiente mapa representa las ideas sobre Ciudadanía que tienen los estudiantes:

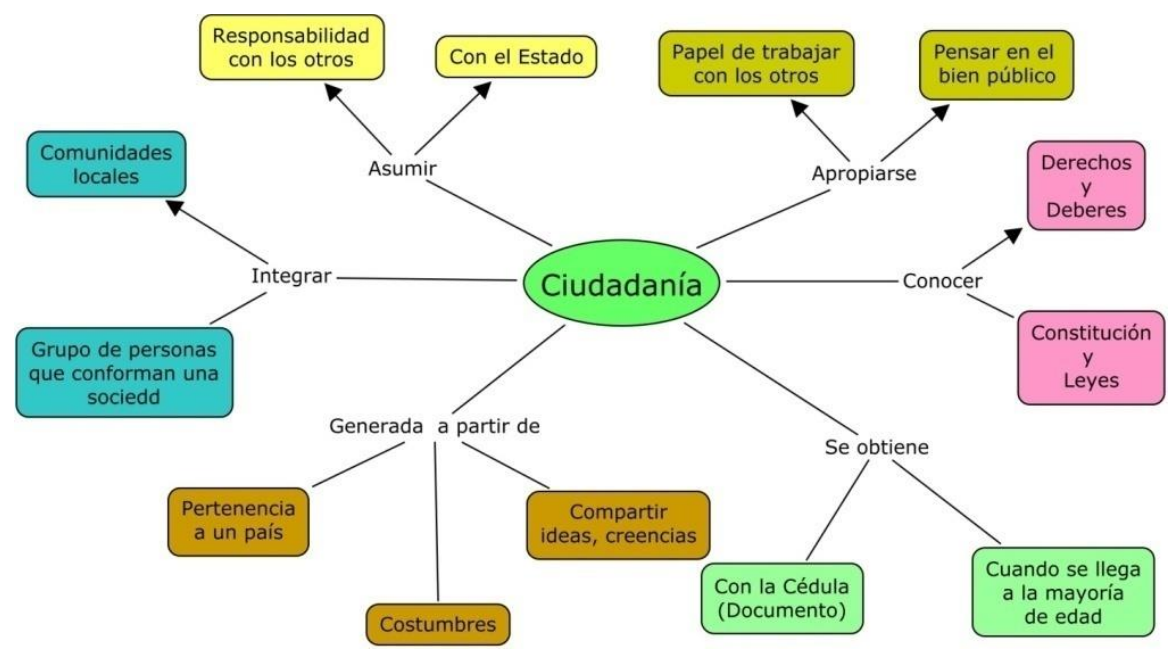

Mapa 6. Ciudadanía. Elaborado por el autor 
De esta manera, con este ejercicio consultivo se logra hacer emerger las ideas que tienen los maestros y estudiantes sobre los conceptos consultados, se establece un diálogo y una consciencia de parte de los actores acerca de la importancia de reflexionar acerca de la relevancia que tienen las experiencias de producción de medios de comunicación en las instituciones educativas, como espacios de socialización, confrontación y construcción de sentidos, además de los roles que deben asumir cada uno frente al ejercicio y la responsabilidad de comunicar un mensaje o contenido a una comunidad educativa, como también dimensionar la posibilidad de establecer estos espacios como alternativas de formación ciudadana. La recomendación es hacer este tipo de ejercicios de manera permanente, para que a partir de la acción reflexiva se le dé otro sentido y dinámica a este tipo de proyectos. 


\subsection{Etapa 4. Fase Mensajes. Análisis de contenido.}

Esta etapa se concentra en los Mensajes: Análisis de contenidos de los materiales (periódicos y programas de televisión producidos en los colegios seleccionados). Para esta etapa el objetivo planteado es "revelar las tendencias y las intencionalidades de los temas publicados en los medios escolares de las instituciones educativas, desde el análisis de contenido de las publicaciones impresas y audiovisuales"; por su parte, la pregunta planteada para entrar a dialogar con estos materiales es: ¿Quiénes son los que publican en los medios de comunicación de los colegios, qué tipos de temas son los que se dan a conocer desde los mismos y cómo emerge el contexto institucional y social de la institución educativa en las publicaciones?

La Muestra: se tuvieron en cuenta tres periódicos de cada colegio (privado y público), porque en que el colegio público solo imprimieron tres (3) números en un lapso de tres años y, por su parte, en el privado llegaron a 60 números en diez años (se publican 1 cada dos meses, 4 al año); basados en lo anterior, la muestra se hizo con base en los periódicos publicados en 2009, 2010 y 2011, fechas en las que coinciden los números de cada institución.

Para el análisis se tuvieron en cuenta las siguientes páginas de cada periódico: portada, porque es la que da cuenta de la temática general; la editorial, para analizar la posición de la institución frente a un tema determinado, además identificar el autor (institucional o una autoridad), el tema trabajado y el lenguaje utilizado; y dos notas o textos escritos por estudiantes y maestros, en aquellas páginas destinadas para ellos, con el fin de analizar lo qué dicen (temas) y cómo lo dicen (género periodístico o tipologías textuales). 
En el caso del Colegio 1 (privado) se tuvo en cuenta las notas publicadas en la página o sección llamada "Sucesos" en uno de los números, "Gente M" en otra o "De todo un poco" en otra, que son donde se evidencia más participación de maestros y estudiantes. Por su parte, en el Colegio 2 (público) se eligieron las notas publicadas en la sección "Escuela" en los dos primeros periódicos y en la Reseña relacionado con la historia de la institución, publicado en el último número y elaborados por los estudiantes.

Contextualización: los periódicos se publican en diferentes contextos educativos: uno privado y otro público. En el caso del Colegio 1 (privado), la actividad se lleva a cabo en un espacio denominado "Extracurricular". El periódico se ha imprimido durante diez años (hasta 2012) de manera ininterrumpida y circulaba cada dos meses, porque cuenta con el apoyo de las directivas y los padres de familia del colegio. Hasta 2012 la institución cumplió 20 años, es privada y de carácter confesional. La mayoría de estudiantes pertenecen a familias de clase social media y media alta, se imparte una educación tradicional, basada en valores y regida por normatividades de calidad empresarial, asunto que viene incursionando en el sistema educativo colombiano. A continuación se comparten las características de este medio.

\begin{tabular}{|c|c|c|c|}
\hline $\begin{array}{l}\text { Carácter de la } \\
\text { institución }\end{array}$ & $\begin{array}{l}\text { Medio } \\
\text { seleccionado }\end{array}$ & Características & $\begin{array}{l}\text { Criterios de } \\
\text { publicación }\end{array}$ \\
\hline Privada & Periódico & $\begin{array}{l}\text { - Se publica cada dos } \\
\text { meses } \\
\text { - Los temas los } \\
\text { deciden maestros } \\
\text { - Divulga eventos del } \\
\text { colegio } \\
\text { - Cuenta con los } \\
\text { recursos } \\
\text { económicos que } \\
\text { garantizan su } \\
\text { circulación }\end{array}$ & $\begin{array}{l}\text { - Filosofía } \\
\text { institucional } \\
\text { - Los valores que } \\
\text { promueve el colegio } \\
\text { - No hablar de } \\
\text { reggaeton }\end{array}$ \\
\hline
\end{tabular}




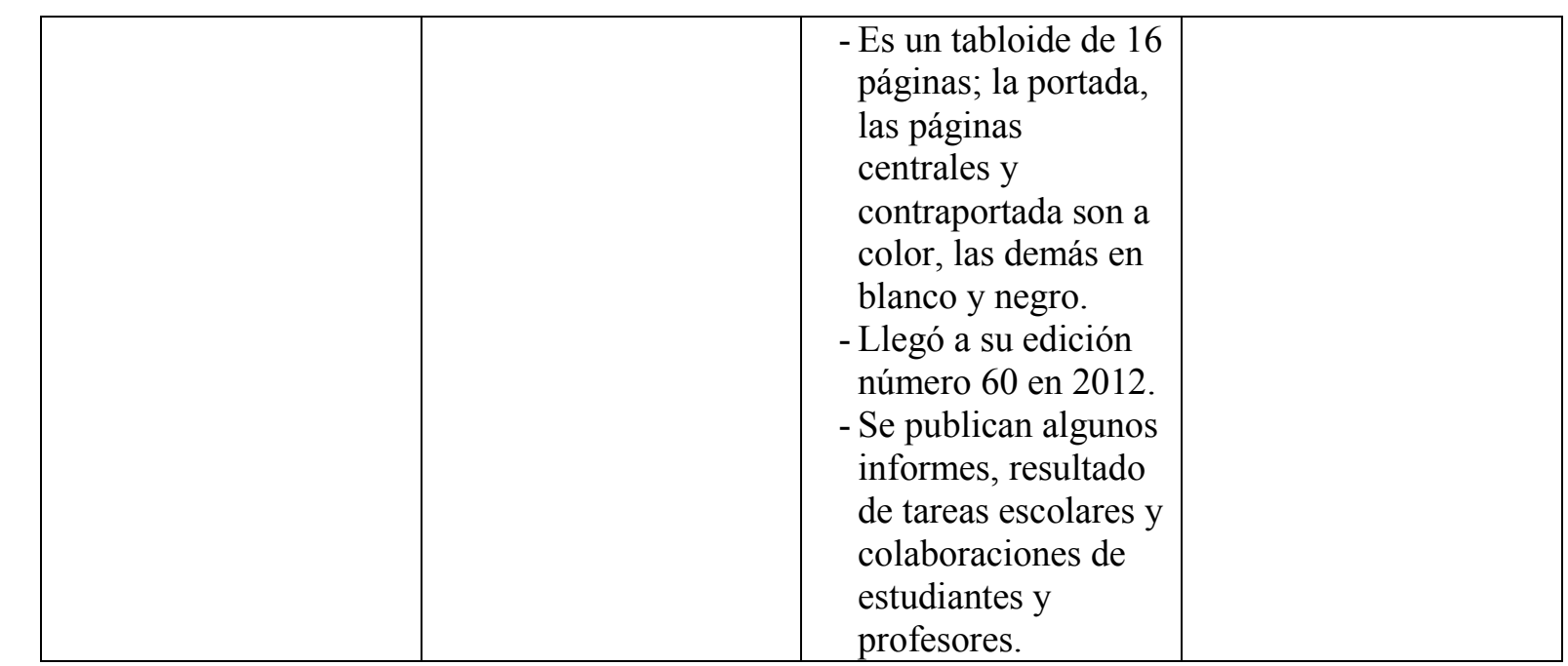

Cuadro 10. Características periódico colegio privado. Elaborado por el autor a partir del análisis de los periódicos

En el Colegio 2 (público) la experiencia de los medios de comunicación fue más exploratoria. Debido a la escasez de recursos económicos o con los recursos tecnológicos que contaban en su momento, trataron de crear y publicar varios medios: blogs, noticiero de televisión, carteleras, periódicos y pequeñas entrevistas emitidas por redes sociales (Facebook). Esto hace que la experiencia con los medios no sea "estable". Las mismas iniciaron como actividades de clase, pero luego se creó un espacio extracurricular denominado Semillero de Periodismo. El mismo es liderado por una maestra de Lengua Castellana, con la participación de docentes de otras áreas como tecnología y artística en algunos momentos. Los textos publicados en los tres periódicos tienen la autoría de algunos maestros y estudiantes. A continuación se comparten las características de este medio.

\begin{tabular}{|l|l|l|l|}
\hline $\begin{array}{l}\text { Carácter de la } \\
\text { institución }\end{array}$ & $\begin{array}{l}\text { Medio } \\
\text { seleccionado }\end{array}$ & Características & $\begin{array}{l}\text { Criterios de } \\
\text { publicación }\end{array}$ \\
\hline Pública & Periódico & $\begin{array}{l}\text { - Solo se publicaron } \\
\text { tres periódicos: dos } \\
\text { con recursos } \\
\text { propios y uno } \\
\text { financiado por un } \\
\text { proyecto de medios }\end{array}$ & $\begin{array}{l}\text { No publicación } \\
\text { establecidos }\end{array}$ \\
& & & \\
& & & \\
& & & \\
& &
\end{tabular}




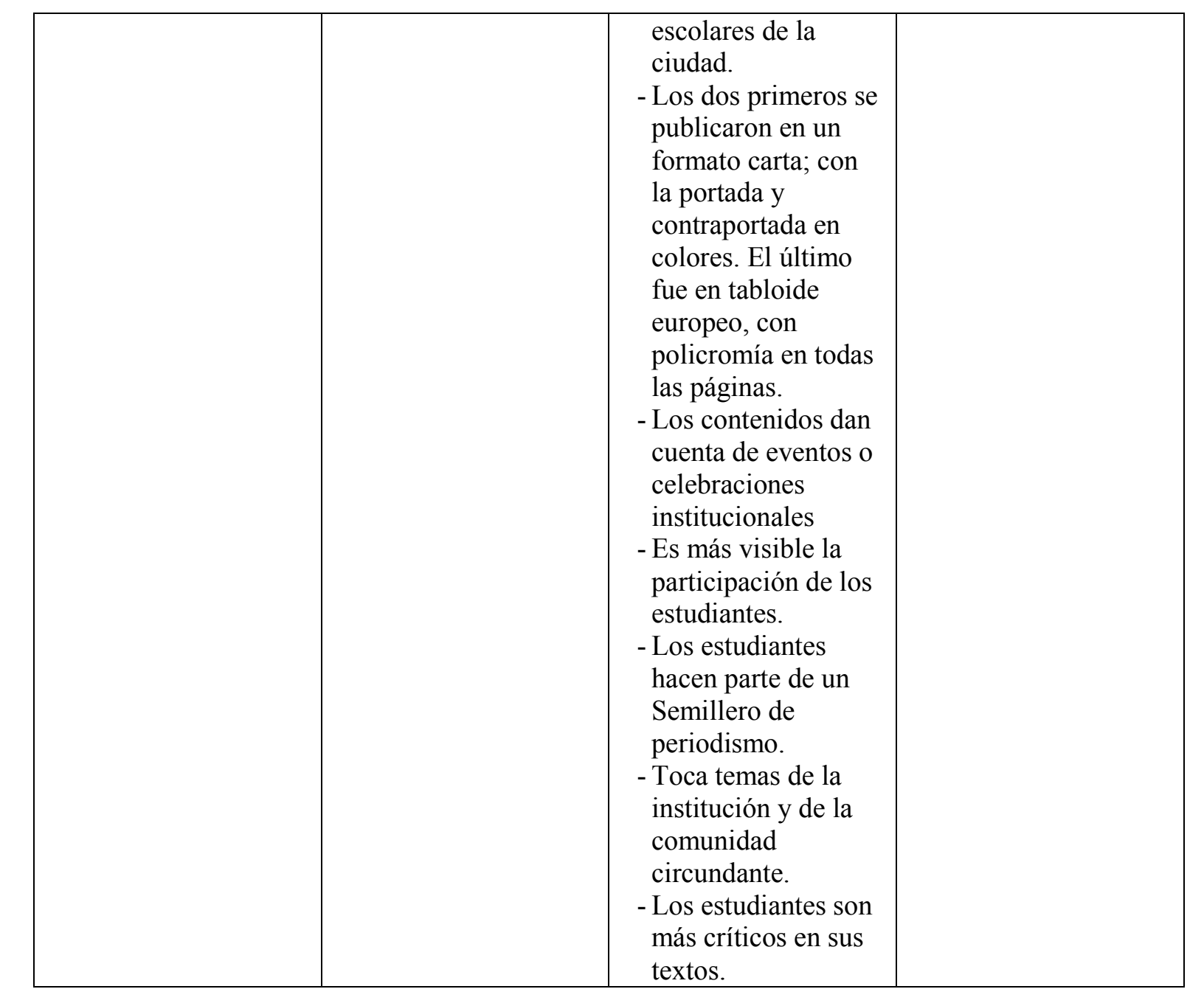

Cuadro 11. Características periódico colegio público. Elaborado por el autor a partir del análisis de los periódicos

\subsubsection{Análisis de los materiales}

Para entrar a dialogar y entrevistar los materiales seleccionados en esta muestra, se seguirá el enfoque de Análisis de contenido propuesto por Galeano (2004, p.123) para observar y analizar los documentos (periódicos) que posibiliten develar las estructuras de comunicación de los materiales: composición, organización y dinámica, como también el contexto donde se produce la información. 
Tal como se expresó antes la muestra o universo de análisis son las páginas señaladas de cada periódico (portada, editorial y aquellas en las que se hace evidente los textos producidos por los estudiantes y maestros); por su parte, las unidades de análisis tomadas son frases o párrafos con los que se pueda evidenciar lo que el autor quiso decir (Galeano, 2004, p. 128). Ellos son los elementos para lograr el objetivo propuesto para esta fase: revelar los temas, las tendencias e intencionalidades que tienen los mismos al ser publicados en estos medios de comunicación. Sin embargo, en este punto es necesario hacer una aclaración: el análisis se centra en lo semántico, porque lo que se busca es una dimensión comunicativa diferente a la descriptiva, esto es, una "dimensión de los valores asignados por el sujeto textual a las realidades que expresa" (Galeano, 2004, p. 132), lo cual es propio para entrar a dialogar con los materiales seleccionados: los textos publicados por maestros y estudiantes en las páginas de los periódicos.

Para llegar a develar lo que aparece publicado se establecen los siguientes parámetros: Quién dice (narrador), Qué dice (tema o temas), Cómo lo dice (tipologías textuales), Sobre quién dice y cómo se refiere a quién lo dice (actores: estudiantes, maestros).Este análisis se enfoca en la categoría Discurso propuesta como una de las categorías de análisis general en esta investigación.

Para el análisis de las portadas, por contener más elementos visuales se trabajó bajo la siguiente matriz:

\begin{tabular}{|l|l|l|}
\hline Descripción de la imagen & Texto & Comentario \\
\hline & & \\
\hline
\end{tabular}

Matriz 1 elaborada por el autor

La matriz para los textos publicados en las páginas es la siguiente: 


\begin{tabular}{|l|l|l|l|l|}
\hline $\begin{array}{l}\text { Quién lo dice } \\
\text { (Narrador) }\end{array}$ & $\begin{array}{l}\text { Qué dice } \\
\text { (Tema o temas) }\end{array}$ & $\begin{array}{l}\text { Cómo lo dice } \\
\text { (Tipologías } \\
\text { textuales o } \\
\text { géneros } \\
\text { periodísticos) }\end{array}$ & $\begin{array}{l}\text { Sobre quién dice } \\
\text { (actores: } \\
\text { autoridades, } \\
\text { maestros, } \\
\text { estudiantes) }\end{array}$ & $\begin{array}{l}\text { Imagen } \\
\text { Descripción } \\
\text { foto o } \\
\text { ilustración }\end{array}$ \\
\hline & & & \\
\hline Análisis & & & \\
\hline
\end{tabular}

Matriz 2 elaborada por el autor

\subsubsection{Análisis periódicos. Colegio privado.}

\section{Análisis de portada. (Anexo 8)}

\section{Análisis Editorial}

Medio: F

Sección: Editorial

Página: 2

Fecha: 2011

Número: 56

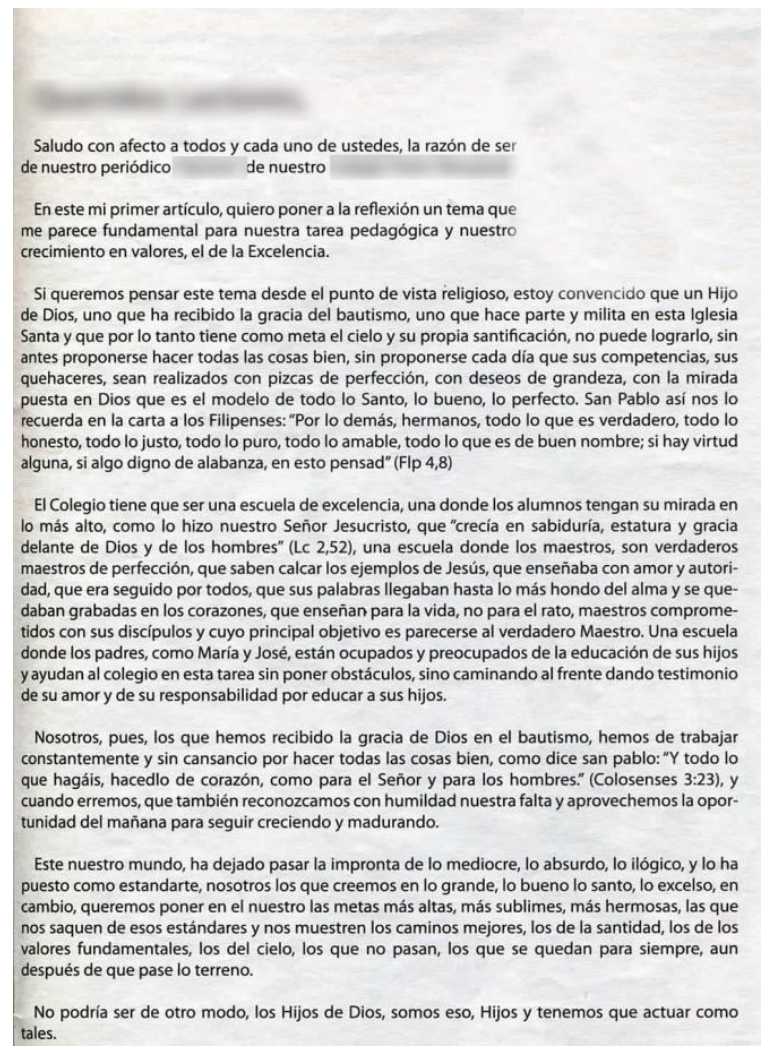




\begin{tabular}{|c|c|c|c|c|}
\hline $\begin{array}{l}\text { Qui } \\
\text { (Na }\end{array}$ & o temas) & $\begin{array}{l}\text { Cómo lo dice } \\
\text { (Tipologías } \\
\text { textuales o } \\
\text { géneros } \\
\text { periodísticos) }\end{array}$ & $\begin{array}{l}\text { Sobre quien dice } \\
\text { (actores: } \\
\text { autoridades, } \\
\text { maestros, } \\
\text { estudiantes) }\end{array}$ & $\begin{array}{l}\text { n } \\
\text { pción } \\
\text { ción }\end{array}$ \\
\hline Rector & $\begin{array}{l}a \\
\text { e } \\
a\end{array}$ & $\begin{array}{l}\text { Argumentativo. En } \\
\text { este sentido } \\
\text { expresa su opinión } \\
\text { sobre la excelencia } \\
\text { desde el punto de } \\
\text { vista religioso y } \\
\text { fundamenta sus } \\
\text { planteamientos con } \\
\text { citas bíblicas. }\end{array}$ & $\begin{array}{l}\text { Hijos de Dios. } \\
\text { Alumnos } \\
\text { Maestros de } \\
\text { "perfección", } \\
\text { comprometidos } \\
\text { con sus discípulos. } \\
\text { Padres de familia }\end{array}$ & $\begin{array}{l}\text { os en } \\
\text { y negro. } \\
\text { primer } \\
\text { el } \\
\text { la otra } \\
\text { ano } \\
\text { de uno } \\
\text { ostados } \\
\text { ión del }\end{array}$ \\
\hline \multicolumn{5}{|c|}{$\begin{array}{l}\text { Análisis } \\
\text { El autor está enfocado en la doctrina cristiana. Así se plantea desde el inicio: pensar este tema desde } \\
\text { el punto de vista religioso y a partir de ello se estructura el texto. Y en el mismo utiliza metáforas } \\
\text { que lo identifican como un ser religioso y desde su punto de vista orienta su discurso como rector: } \\
\text { la gracia del bautismo, uno que hace parte y milita en esta Iglesia Santa y que por lo tanto tiene } \\
\text { como meta el cielo y su propia santificación; y continúa con otros términos: la mirada puesta en } \\
\text { Dios que es el modelo de todo lo Santo, lo bueno, lo perfecto. Y sigue sus ideas fundamentadas en } \\
\text { este enfoque religioso: los maestros, son verdaderos maestros de perfección, que saben calcar los } \\
\text { ejemplos de Jesús, que enseñaba con amor y autoridad. Indica que la vida de los padres de familia } \\
\text { debe estar concentrada en el testimonio de su amor y de su responsabilidad por educar a sus hijos. } \\
\text { En general señala que hemos recibido la gracia de Dios en el bautismo y reconozcamos con } \\
\text { humildad nuestra falta. } \\
\text { Por su parte se refiere al "mundo", es decir, la sociedad en términos morales: Este nuestro mundo, } \\
\text { ha dejado pasar la impronta de lo mediocre, lo absurdo, lo ilógico, y en contraposición de ello } \\
\text { expone una serie de características de la vida cristiana: nosotros los que creemos en lo grande, lo } \\
\text { bueno, lo santo, lo excelso,(...)nuestras metas más altas, más sublimes, más hermosas, (...)nos } \\
\text { muestren los caminos mejores, los de la santidad, los de los valores fundamentales, los del cielo. El } \\
\text { texto apela a un asunto personal (la salvación) y deja de lado la discusión de la construcción de una } \\
\text { sociedad más justa, solidaria y equitativa, porque la crítica y la deja en el plano de lo moral. } \\
\text { Esta editorial muestra el tinte confesional de la institución, maneja un lenguaje moral y } \\
\text { especializado utilizado por los religiosos y que puede llegar a ser incomprensible para los } \\
\text { estudiantes, por el tipo de términos y expresiones especializadas; las mismas no son explicadas y } \\
\text { contextualizadas en el mundo y en las vivencias de los estudiantes. Es un lenguaje que apela a la } \\
\text { vida personal y al mundo privado (la salvación propia) y a lograr la excelencia basada en los } \\
\text { preceptos de la vida cristiana. }\end{array}$} \\
\hline
\end{tabular}

Matriz 3. Análisis editorial colegio privado, elaborada por el autor 


\section{Análisis contenidos}

\section{Texto 2. Evento}

Medio: F

Sección: Sucesos

Página: 15

Fecha: 2009

Número: 48

\section{Día de la antioqueñidad}

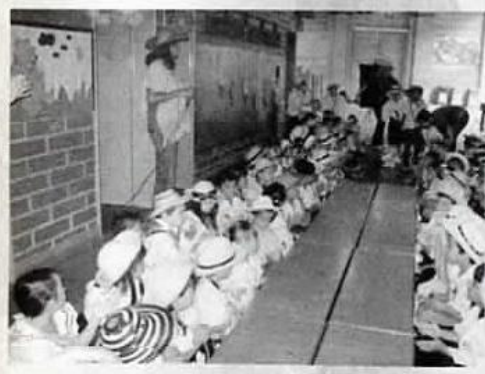

El pasado 14 de agosto, en la Eucaristía celebrada por nuestro rector, el se dio inicio a la celebración del día de la antioqueñidad, la cual festejamos cada año. El grado undécimo se encargó de repartir los temas, organizar las actividades y asesorar a los grados de Bachillerato en el planeamiento de las casetas, a escoger los personajes típicos y a elegir el mejor carro de rodillos. Los personajes del pueblo fueron muy variados desde la familia, los niños, el abogado, las prostitutas, las gomelas, el mafioso y la infaltable reina.

El carro de rodillos, las cometas y el trompo fueron los representativos juegos tradicionales, con los cuales los estudiantes pudieron demostrar sus habilidades y capacidades frente a todo el que quisiera verlos.

Esta fiesta no fue solo una celebración de nuestras costumbres sino también la oportunidad de unirnos como colegio, de integrarnos, conocernos, y de felicitarnos por tener la oportunidad de ser antioqueños.

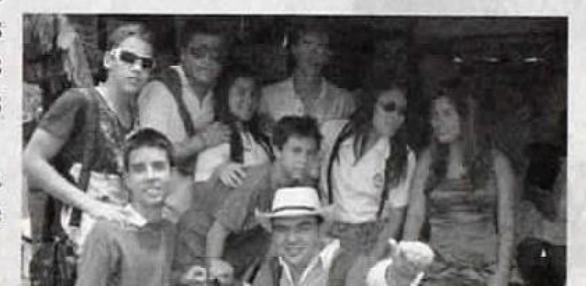

\begin{tabular}{|l|l|c|l|l|}
\hline $\begin{array}{l}\text { Quién lo dice } \\
\text { (Narrador) }\end{array}$ & $\begin{array}{l}\text { Qué dice } \\
\text { (Tema o temas) }\end{array}$ & $\begin{array}{l}\text { Cómo lo dice } \\
\text { (Tipologías } \\
\text { textuales o } \\
\text { géneros } \\
\text { periodísticos) }\end{array}$ & $\begin{array}{l}\text { Sobre quién dice } \\
\text { (actores: } \\
\text { autoridades, } \\
\text { maestros, } \\
\text { estudiantes) }\end{array}$ & $\begin{array}{l}\text { Imagen } \\
\text { (Descripción } \\
\text { foto o } \\
\text { ilustración) }\end{array}$ \\
\hline Estudiantes & $\begin{array}{l}\text { Expositivo y } \\
\text { descriptivo. } \\
\text { una fiesta } \\
\text { de latucional: Día } \\
\text { antioqueñidad }\end{array}$ & $\begin{array}{l}\text { El rector (padre } \\
\text { Antonio); el grado } \\
\text { undécimo } \\
\text { (estudiantes); } \\
\text { personajes del } \\
\text { pueblo } \\
\text { (estudiantes } \\
\text { disfrazados). }\end{array}$ & $\begin{array}{l}\text { Dos fotos en } \\
\text { blanco y negro: } \\
\text { una general, al } \\
\text { lado izquierdo } \\
\text { con un grupo } \\
\text { de niños y } \\
\text { niñas vestidos } \\
\text { con trajes } \\
\text { típicos y otra, } \\
\text { al lado derecho } \\
\text { con } \\
\text { adolescentes } \\
\text { disfrazados de } \\
\text { personajes de } \\
\text { la región. }\end{array}$ \\
\hline
\end{tabular}




\title{
Análisis
}

El texto da cuenta de una actividad cultural: el día de la antioqueñidad. La misma empezó con "la Eucaristía celebrada por nuestro rector (...)", señalan el carácter confesional de la institución (la editorial y este hacen referencia al rector). Es una nota típica para reseñar una celebración "tradicional" en el colegio está asociado a los valores de la región antioqueña y en ella se representan los personajes típicos (familia, niños, abogados), los juegos (carros de rodillos)" y otros personajes que se salen de los círculos morales y son aceptados en la sociedad antioqueña, (incluso en los colegios): las prostitutas, las "gomelas", el mafioso y la infaltable reina; personajes que a pesar de ser rechazados, ya son integrados como representativos en la sociedad antioqueña; y también aparecen las actividades "tradicionales", las que solo salen a relucir en este tipo de festividades: "el carro de rodillos, las cometas y el trompo fueron los representativos juegos tradicionales, con los cuales los estudiantes pudieron demostrar sus habilidades y capacidades frente a todo el que quisiera verlos".

Y como otro aspecto común en estos textos aparece el colofón, la enseñanza: "Esta fiesta no fue solo una celebración de nuestras costumbres, sino también la oportunidad de unirnos como colegio, de integrarnos, conocernos y de felicitarnos por tener la oportunidad de ser antioqueños". Se resalta la última frase "la oportunidad de ser antioqueños", con lo que se refuerza una ideología, una manera de ser propia de la región, caracterizada por la pujanza y el emprendimiento, la que se impregna en la mentalidad de los estudiantes y se propaga en las instituciones educativas con este tipo de celebraciones. En ningún momento hace referencia a la celebración histórica: la Independencia de Antioquia del dominio del Imperio Español, el 11 de agosto y a las consecuencias de este acontecimiento para la región.

Matriz 4. Análisis texto producido por estudiantes, elaborada por el autor

Análisis de texto elaborado por maestro. (Anexo 9)

\subsubsection{Análisis periódicos. Colegio público.}

Análisis de portada. (Anexo 10)

\author{
Análisis Editorial \\ Medio:JI \\ Sección: Editorial \\ Página: 2 \\ Fecha: Septiembre 2011 \\ Número: 1
}




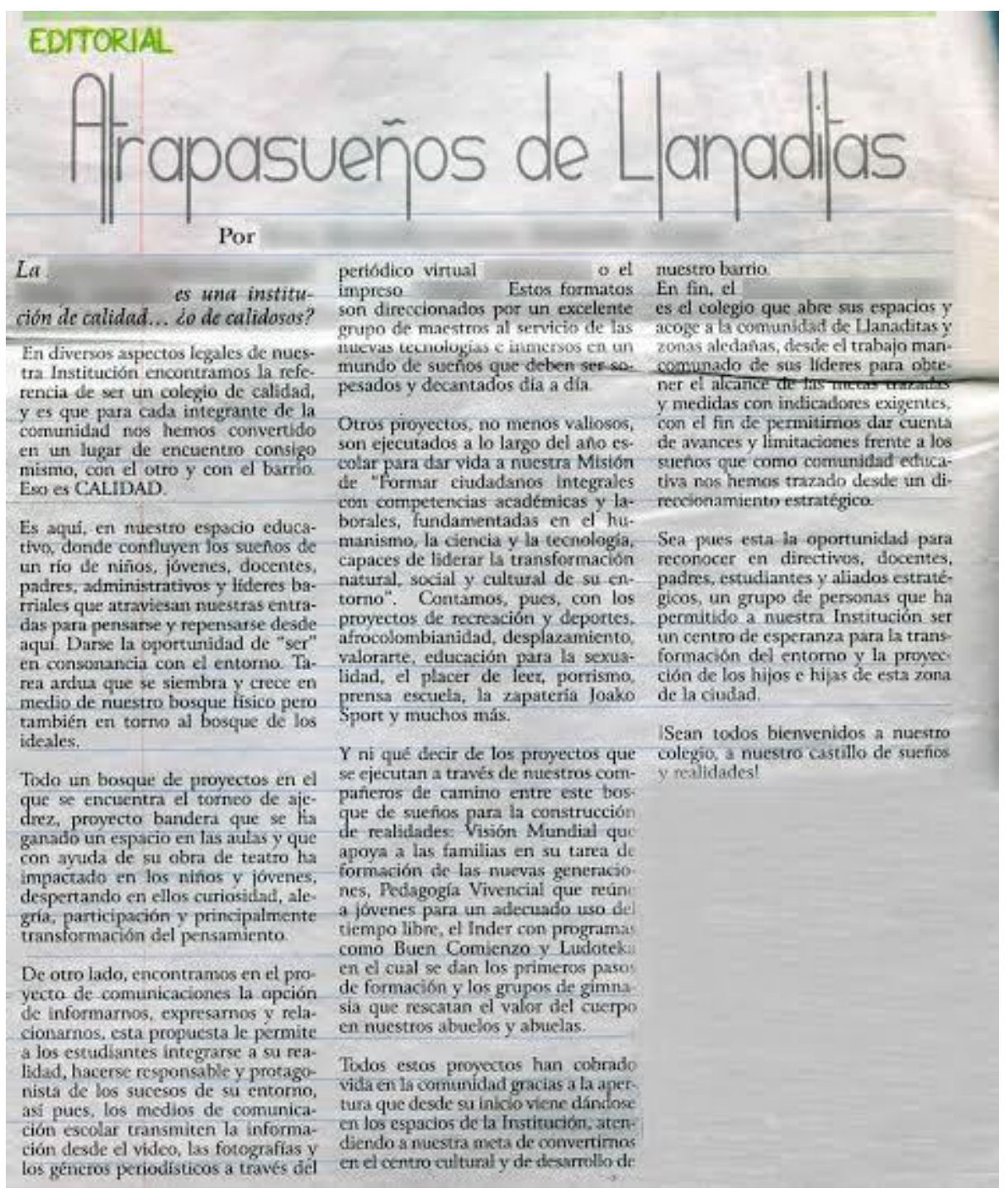

\begin{tabular}{|c|c|c|c|c|}
\hline $\begin{array}{l}\text { Quién lo dice } \\
\text { (Narrador) }\end{array}$ & $\begin{array}{l}\text { Qué dice } \\
\text { (Tema o temas) }\end{array}$ & $\begin{array}{l}\text { Cómo lo dice } \\
\text { (Tipologías } \\
\text { textuales o } \\
\text { géneros } \\
\text { periodísticos) }\end{array}$ & $\begin{array}{l}\text { Sobre quién dice } \\
\text { (actores: autoridades, } \\
\text { maestros, estudiantes) }\end{array}$ & $\begin{array}{l}\text { Imagen } \\
\text { Descripción } \\
\text { foto o } \\
\text { ilustración }\end{array}$ \\
\hline $\begin{array}{l}\text { Rectora } \\
\text { (autoridad) }\end{array}$ & $\begin{array}{ll}\text { - } & \text { Institución de } \\
& \text { Calidad. } \\
\text { - } & \text { La razón de ser } \\
& \text { de la Institución } \\
\text { educativa. } \\
\text { - } & \text { Interpretación de } \\
& \text { la Misión y la } \\
\text { Visión } \\
\text { institucional. } \\
\text { - } \quad \text { Los proyectos de }\end{array}$ & $\begin{array}{l}\text { Expositivo. La } \\
\text { autora parte de } \\
\text { una } \\
\text { interpretación } \\
\text { sobre el } \\
\text { concepto de } \\
\text { Calidad y luego } \\
\text { hace lo mismo } \\
\text { sobre la Misión } \\
\text { y la Visión. }\end{array}$ & $\begin{array}{l}\text { - Comunidad } \\
\text { educativa: } \\
\text { niños, jóvenes, } \\
\text { docentes, } \\
\text { padres, } \\
\text { administrativos } \\
\text { y líderes } \\
\text { barriales. } \\
\text { - Estudiantes: } \\
\text { niños y jóvenes. }\end{array}$ & $\begin{array}{l}\text { Foto a color, } \\
\text { en plano } \\
\text { medio de la } \\
\text { rectora. }\end{array}$ \\
\hline
\end{tabular}




\begin{tabular}{|c|c|c|c|}
\hline & $\begin{array}{l}\text { la institución. } \\
\text { La relación de la } \\
\text { institución con el } \\
\text { barrio y sus } \\
\text { habitantes. }\end{array}$ & $\begin{array}{l}\text { Después expone } \\
\text { los diferentes } \\
\text { proyectos que } \\
\text { tiene el colegio } \\
\text { y la manera } \\
\text { cómo se } \\
\text { integran a los } \\
\text { mismos } \\
\text { estudiantes y } \\
\text { maestros; } \\
\text { además indica la } \\
\text { conexión que } \\
\text { tiene el colegio } \\
\text { con el barrio y } \\
\text { lo denomina } \\
\text { como Centro } \\
\text { Cultural y de } \\
\text { desarrollo del } \\
\text { barrio. }\end{array}$ & \\
\hline \multicolumn{4}{|c|}{$\begin{array}{l}\text { Análisis } \\
\text { La autora enmarca el texto desde un concepto de calidad desde un enfoque humano y social; ofrece un } \\
\text { "sentido", un referente diferente: un lugar de encuentro consigo mismo, con el otro y con el barrio. Eso es } \\
\text { Calidad. Más que contextualizar el tema en las normatividades, lo orienta a esa triple dimensión de lo } \\
\text { personal, lo relacional y lo público (el contexto social). Y es una idea en la que se insiste en otros } \\
\text { fragmentos del texto, con lo que se clarifica la identidad y el compromiso de una institución oficial que se } \\
\text { concibe como un centro cultural y de desarrollo de nuestro barrio. El cual se proyecta al barrio y sus } \\
\text { habitantes, en quienes quiere impactar: es el colegio que abre sus espacios y acoge a la comunidad de } \\
\text { Llanaditas y zonas aledañas, desde el trabajo mancomunado de sus líderes para obtener el alcance de las } \\
\text { metas trazadas ... } \\
\text { Además de presentar esa idea de proyección y diálogo con su entorno social, el texto expone y comunica a } \\
\text { la comunidad educativa una serie de proyectos, en los que se cristaliza esa idea de calidad y posibilitar el } \\
\text { "ser" de cada estudiante que quiera involucrarse en los mismos. Es todo un bosque de proyectos así crea } \\
\text { una metáfora con el bosque físico que rodea a la institución y en el que aparecen los proyectos de ajedrez, } \\
\text { de comunicaciones, recreación y deportes, afrocolombianidad, desplazamiento, valorarte, entre otros. El } \\
\text { texto habla de ellos y le da un sentido, porque los enmarca en una Misión institucional planteada desde la } \\
\text { formación de ciudadanos íntegros. } \\
\text { Este es un texto oficialista, pero le da otro sentido a esa voz oficial, porque presenta y valora el } \\
\text { compromiso formativo de la institución educativa que se ocupa de sus estudiantes y trata de establecer } \\
\text { relaciones y vínculos con el barrio y sus habitantes, a quienes busca impactar para mejorar sus condiciones } \\
\text { de vida, como lo expone al final del texto en el que indica que la Institución puede ser un centro de } \\
\text { esperanza para la transformación del entorno y la proyección de hijos e hijas de esta zona de la ciudad. } \\
\text { Y aunque en general puede ser un texto denso para los estudiantes, logra interpretar y dar a conocer el } \\
\text { contexto en el que se desarrolla la función educativa de una institución oficial. }\end{array}$} \\
\hline
\end{tabular}

Matriz 5. Análisis editorial colegio público, elaborada por el autor 


\section{Análisis contenido}

\section{Texto 2. Opinión}

Medio: El V

Sección: Escuela

Página: 6

Fecha: Primer semestre de 2010

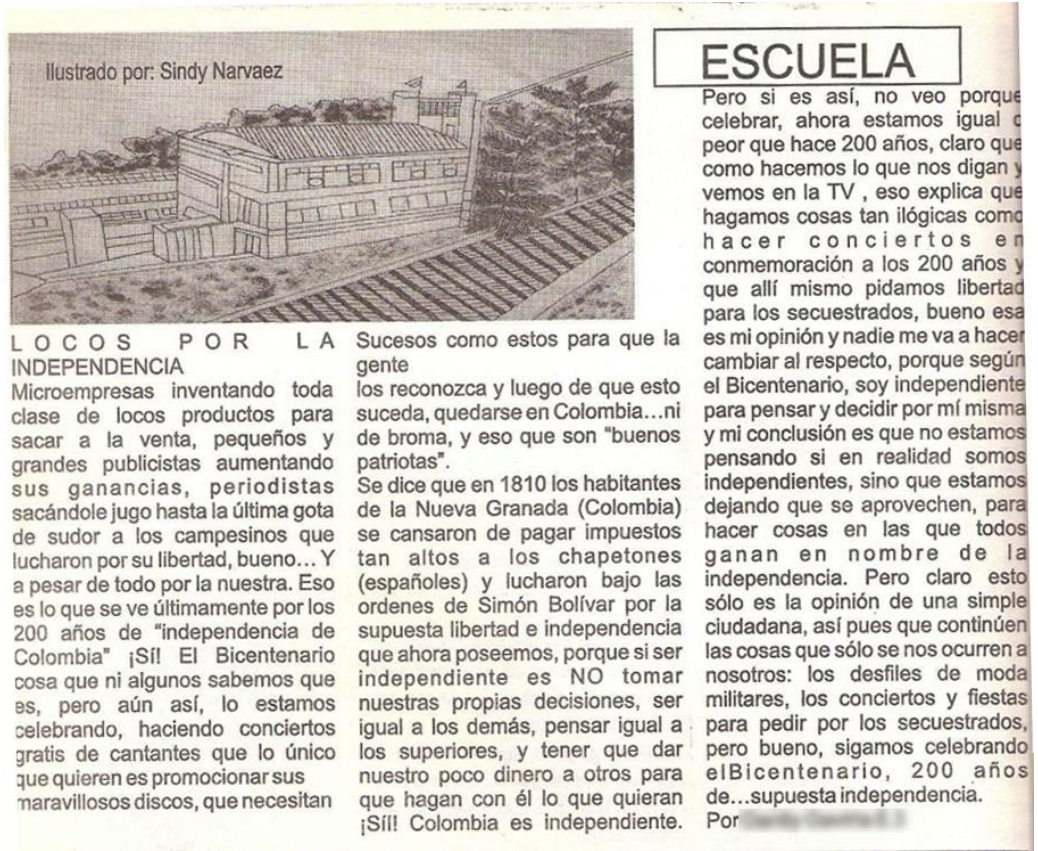

\begin{tabular}{|c|c|c|c|c|}
\hline $\begin{array}{l}\text { Quién lo dice } \\
\text { (Narrador) }\end{array}$ & $\begin{array}{c}\text { Qué dice } \\
\text { (Tema o temas) }\end{array}$ & $\begin{array}{l}\text { Cómo lo dice } \\
\text { (Tipologías } \\
\text { textuales o } \\
\text { géneros } \\
\text { periodísticos) }\end{array}$ & $\begin{array}{l}\text { Sobre quién dice } \\
\text { (actores: } \\
\text { autoridades, } \\
\text { maestros, } \\
\text { estudiantes) }\end{array}$ & $\begin{array}{l}\text { Imagen } \\
\text { Descripción } \\
\text { foto o } \\
\text { ilustración }\end{array}$ \\
\hline Estudiante & $\begin{array}{ll}\text { - } & \text { Independencia de } \\
& \text { Colombia. } \\
\text { - } & \text { Celebración del } \\
\text { Bicentenario. }\end{array}$ & $\begin{array}{l}\text { Argumentativo. } \\
\text { Trabaja la opinión } \\
\text { para expresar su } \\
\text { punto de vista, en } \\
\text { algunos momentos } \\
\text { se destaca la ironía } \\
\text { para expresar las } \\
\text { ideas. }\end{array}$ & $\begin{array}{l}\text { Personajes } \\
\text { externos al } \\
\text { colegio: } \\
\text { "cantantes" que } \\
\text { lo único que } \\
\text { quieren es } \\
\text { promocionar sus } \\
\text { maravillosos } \\
\text { discos. } \\
\text { Personajes } \\
\text { históricos (los } \\
\text { chapetones); el } \\
\text { libertador Simón } \\
\text { Bolívar. }\end{array}$ & $\begin{array}{l}\text { Ilustración de } \\
\text { las } \\
\text { instalaciones } \\
\text { de la } \\
\text { institución } \\
\text { educativa, en } \\
\text { blanco y } \\
\text { negro. }\end{array}$ \\
\hline
\end{tabular}




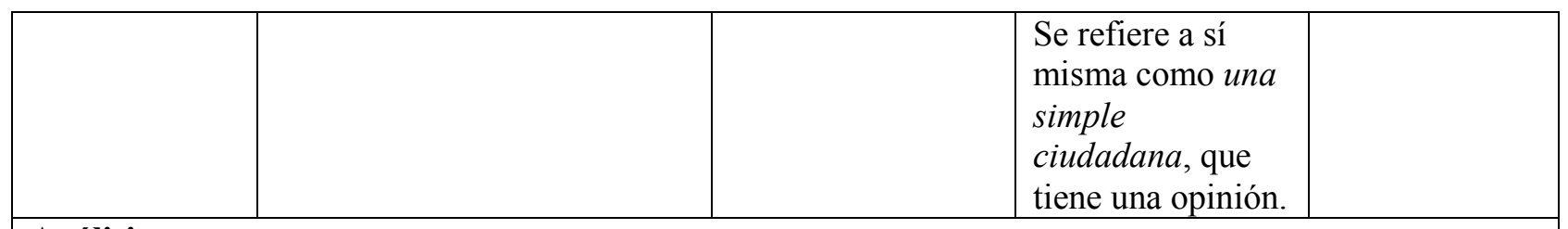

\section{Análisis}

El inicio es confuso, porque menciona una serie de actividades que no parecen tener relación, debido a la redacción de la estudiante, logra luego plantear una "lectura" curiosa sobre la celebración oficial como fue el Bicentenario de la Independencia en Colombia.

Este texto es la reflexión libre de la estudiante y eso se evidencia en varios aspectos.

Primero, admite un desconocimiento del acontecimiento histórico: El Bicentenario cosa que ni algunos sabemos que es, pero aun así lo estamos celebrando, lo cual puede ser consecuencia del desconocimiento y la falta de orientación sobre el tema en el colegio.

Segundo, la crítica: haciendo conciertos gratis de cantantes que lo único que quieren es promocionar sus maravillosos discos. De esta manera expresa su desacuerdo con la visión mercantilista del acontecimiento, porque se centró en el espectáculo y no en el hecho histórico.

Tercero, otra crítica: la supuesta libertad e independencia que ahora poseemos, porque si ser independiente es NO tomar nuestras propias decisiones, ser igual a los demás, pensar igual a los superiores, y tener que dar nuestro poco dinero a otros para que hagan con él lo que quieran iSí! Colombia es independiente. Es una lectura que hace la estudiante acerca de la "supuesta libertad", en la que se conjugan lo personal (No tomar las propias decisiones, no pensar igual a los superiores) y lo colectivo (dar los recursos a otros, entiéndase a las naciones poderosas). Desde estas perspectivas la estudiante señala que la libertad en esas condiciones no tiene sentido.

Cuarto: ironía. No veo porque celebrar, ahora estamos igual o peor que hace 200 años. Es de resaltar que es la voz de una adolescente que expresa su indignación porque vive en una sociedad injusta e inequitativa, sin justicia social, entonces ¿para qué celebrar?

Quinto: falta de criterio: hacemos lo que nos digan y vemos en $T V$, eso explica cosas tan ilógicas como hacer conciertos en conmemoración de los 200 años. Una sociedad con poca capacidad crítica está sometida a la manipulación y a someterse a este tipo de situaciones que plantea la estudiante.

Sexto: autonomía. Según el Bicentenario, soy independiente para pensar y decidir por mí misma y mi conclusión es que no estamos pensando si en realidad somos independientes, sino que estamos dejando que se aprovechen. Reclama el derecho de pensar y decidir por sí misma y cuestiona la falta de reflexión crítica sobre si realmente "somos independientes", situación que aprovechan otros para seguir creando dependencia.

Séptimo: segunda ironía. Concluye con esta frase: sigamos celebrando el Bicentenario, 200 años de... supuesta libertad. Luego de lo expuesto, la estudiante ratifica su posición que la libertad promovida desde la oficialidad, no es tal, es más una falacia para hacer creer que Colombia es un país independiente. En general, el texto es una crítica a una celebración que tuvieron los países latinoamericanos como Colombia, para conmemorar la independencia de los españoles; una crítica que la estudiante expone y sustenta en su relato, publicado en el periódico de un colegio.

Matriz 6. Análisis texto producido por estudiante colegio público, elaborada por el autor

\section{Análisis de texto estudiante. (Anexo 11)}




\section{Respuesta a una pregunta}

Luego de analizar los materiales impresos expuestos, periódicos de los colegios, se puede dar respuesta a la pregunta planteada en este capítulo: ¿Quiénes son los que publican en los medios de comunicación de los colegios, qué tipos de temas son los que se dan a conocer desde los mismos y cómo se refleja desde esto el contexto institucional y social de la institución educativa?

Sin ser este un estudio comparativo, la lectura de los textos refleja lo que es cada institución educativa. Y ello se evidencia en los autores de los textos, los temas trabajados y la forma de expresar las ideas que se desarrollan en cada artículo. Es lo que se compartirá a continuación.

\section{Colegio 1 (privado)}

¿Quién escribe? Con este ejercicio se evidencia que los artículos analizados fueron escritos por adultos, en este caso el Rector, responsable de las editoriales, y la bibliotecaria. Este detalle no es menor, porque ello da cuenta que el periódico más que para estudiantes, está pensado para personas adultas (maestros y padres de familia), por lo que adquiere un carácter institucional, más que escolar, porque el mismo no está orientado, ni producido por estudiantes, sino por profesionales (comunicadora y maestros) quienes son los que deciden temas que van a trabajar, ellos seleccionan quiénes o escriben o que trabajos se publican (algunos son enviados por maestros).

En el caso del Colegio 1 y los textos analizados de los adultos se observa la utilización de un lenguaje religioso en el caso de las editoriales y normativo como en el caso del texto referido a 
los servicios de la biblioteca (Anexo 9). Es con estas evidencias que vale la pena preguntarse si son estas personas, estos temas y la forma de comunicarlos los apropiados para un periódico dirigido a los estudiantes, además porque predomina una mirada "adulta" de los temas publicados.

Ahora, la participación de los estudiantes en el periódico si es evidente y son varios textos de ellos los que se publican de lo que sucede al interior de la institución: celebraciones culturales, deportivas, religiosas son los temas reiterativos y que se publican. Ahora falta una mayor visibilización de los temas y las opiniones de parte de ellos. Es extraño porque en los textos no se evidencia un testimonio o una opinión de algunos estudiantes que "valide la voz de los jóvenes"; contrario a ello se da la voz o el testimonio o la opinión es de una persona adulta (sacerdote, maestro, rector), como las válidas, las importantes. Ahí también predomina la mirada de los últimos y, por tanto, es el reflejo de una cultura educativa tradicional que se traslada a este tipo de experiencias comunicativas.

¿Qué temas se publican? Predominan los acontecimientos institucionales. Los artículos dan cuenta de lo que sucede adentro del colegio y ahí se centra su producción. Aunque se analizó un texto propio de una celebración cultural, en las páginas predominan los temas religiosos: celebraciones de primeras comuniones y retiros espirituales. También aparecen fiestas tradicionales como el Día de la Antioqueñidad o de índole comercial como el Día del Amor y la Amistad o de eventos realizados como Ferias universitarias. Los temas publicados evidencian que la fuerza temática está en lo institucional, en los eventos que suceden "dentro" del colegio, por tanto, se enfocan desde una Comunicación institucional y divulgativa de los eventos: dar cuenta 
de aquello que sucedió y de lo cual los estudiantes ya tienen conocimiento, porque ellos participan de todos estos sucesos.

¿Cómo lo cuentan? Prevalece un esquema divulgativo, porque el interés es dar cuenta de aquellos eventos que se realizan en el colegio. El lenguaje divulgativo tiende a ser neutro, relata de una manera sintética y concreta algo que pasó, presenta solo algunos personajes, de manera especial los directivos de quien se hace referencia en diferentes textos, y si a ello se le suma el uso de palabras triviales utilizadas en algunos textos (sobre todo de los adultos) que en definitiva no dicen nada concreto, se pierde la carga semántica, es decir, no se logra comunicar el sentido y el valor del mensaje.

De acuerdo con los anteriores parámetros se puede deducir que el periódico tiene una orientación instrumental y divulgativa, desde el punto de vista de la comunicación. Es neutra porque se centra en el medio y en la manera de contar o relatar los temas que trabajan basada en informar, pero no se permite preguntar o problematizar la realidad, incluso la institucional. También es el resultado de un modelo tradicional de la educación, en el que prevalece la mirada del adulto (rector y maestros) en los temas y en la manera de relatar los mismos. Si bien los estudiantes participan en esta experiencia, ellos están atados a las decisiones y visiones que tienen los adultos sobre los temas, los cuales se restringen a asuntos institucionales internos. El mundo de los estudiantes, las experiencias de vida, los conocimientos previos no son visibles en los contenidos publicados, por tanto, la misma se limita a las paredes del colegio, de ahí que solo tenga valor aquello que suceda dentro del mismo y lo que pasa afuera no tienen cabida en las páginas de este periódico. 
Es así que los temas se vuelven reiterativos: celebraciones tradicionales (culturales, deportivas, patrióticas) y eventos religiosos, como parte de una programación establecida para el colegio.

Esta experiencia permite señalar que la misma se hace bajo el esquema de producir para (en este caso) los estudiantes, sin embargo, los estudiantes mismos ven que el periódico no está dirigido a ellos, sino que es más para padres de familia y maestros, por los contenidos y la manera de relatarlos.

\section{Colegio 2 (público)}

¿Quién escribe? El protagonismo de los estudiantes es más evidente en las publicaciones del colegio público. Ellos tienen la posibilidad de expresar sus ideas acerca de celebraciones "oficiales" o contar la historia de la institución, como las analizadas en este informe. El ejercicio de darle voz al estudiante es más evidente en estos periódicos. Es desde su punto de vista que se habla acerca de la celebración del Bicentenario de la Independencia de Colombia, en el que prevalece un tono crítico y autónomo para expresar las propias reflexiones sobre el acontecimiento. Y de igual manera, es una estudiante quien reconstruye la historia de la institución, la cual se constituye en un documento de valor, porque requirió investigar diferentes fuentes para consolidar un texto completo y bien estructurado, desde los parámetros establecidos por el periodismo escrito (Anexo 11, análisis de texto producido por estudiante).

Por su parte, la participación de la Rectora en la editorial, muestra un discurso que invita a reflexionar sobre el valor y el compromiso que adquiere una institución educativa con su entorno social inmediato, en este caso, unos barrios que tienen una variedad de problemas que van desde 
la carencia de sistemas de acueducto para sus pobladores, hasta el desempleo que viven la mayoría de las personas. La voz de la rectora, en este caso, es la presentación de una institución que busca aportar a la transformación social de una comunidad.

¿Qué temas se publican? Combinan lo institucional y asuntos relacionados con el contexto social. El colegio tiene estructurado una serie de proyectos y en el periódico tratan de dar cuenta de ellos; también se presta para publicar asuntos cotidianos, festividades (Bicentenario, la Antioqueñidad en lo que concuerdan con la experiencia del otro colegio), asuntos relacionados con las normatividades que rigen la educación en Colombia, entre otros. También sus páginas se prestan para escribir sobre la historia del barrio y de sus primeros pobladores, como una manera de reconocer las raíces históricas y culturales de la institución. En este sentido, el ejercicio de publicar en unos periódicos trata de combinar las actividades internas del colegio y los asuntos históricos y cotidianos que suceden en el contexto social circundante de la institución; esta circunstancia hace que la producción de los contenidos y su publicación tengan otra perspectiva o, por lo menos, otra intención: establecer una comunicación con la vida social que también influye o afecta el desarrollo de las actividades académicas del colegio y hacerlas visibles; es también la posibilidad de tener un contacto permanente con ella, por el hecho de quedar publicado, a manera de documento histórico y de conocimiento social que se conserva en una publicación.

¿Cómo lo cuentan? Según la muestra estudiada, el texto de la rectora es formal y estructurado, dado que utiliza una tipología expositiva para expresar los compromisos que tiene la institución educativa con los estudiantes, los padres de familia, los maestros y el contexto social; para dar 
cuenta de los proyectos y planes que se desarrollan a interior de la institución; para reconocer el esfuerzo de otras entidades (colegios, universidades y empresas) que apoyaron a la institución en sus inicios y para señalar el reto de aportar a la transformación social de la comunidad en general, a través de la educación.

También se destaca en el segundo artículo elaborado por la estudiante, la libertad con la que escribe el texto, caracterizado por la crítica a una celebración con un tinte comercial, la ironía manifestada en la expresión de sus ideas y la autonomía para expresarlas. Así, la estudiante encontró la posibilidad de expresar sus puntos de vista en un periódico publicado en su colegio.

Y el otro texto, tiene forma y contenido: se observa un manejo cuidadoso de los datos presentados (históricos de la fundación del colegio) y el orden de presentar la información sigue los parámetros establecidos por el periodismo de calidad. Se puede concluir que la combinación de ambos posibilita tener una visión completa de la historia institucional.

Basados en los tres textos, también se puede evidenciar lo que en su momento planteó la maestra que coordina este trabajo de medios de comunicación en el colegio público: exploraban sobre cuál era el medio adecuado, pero también la manera de relatar, de contar; se observa una experimentación que va de lo formal, lo estructurado y lo "libre", es lo que hace ver la esencia de los medios de este colegio: la búsqueda de una identidad comunicativa. 


\section{Análisis Productos audiovisuales}

\section{Colegio 1 (Privado)}

La Muestra: para este análisis se tuvieron en cuenta dos programas de televisión que tienen una duración de 20 minutos cada uno, en el colegio 1 (privado). Los programas elegidos para el programa fueron el 98 y el 100. Para el análisis se seleccionaron dos notas de cada programa, en los que se evidencia la presencia y participación de los estudiantes, como criterio evaluativo.

Contextualización: "la Extracurricular", que se lleva a cabo en el colegio privado, se ocupa de la producción de un programa de televisión mensual. En este espacio programado dos veces por semana, asisten estudiantes interesados en participar en el proyecto; el grupo de los viernes (integrado por preadolescentes) es el que hace las "presentaciones" de las secciones del programa. En un promedio participaban 15 estudiantes entre hombres y mujeres.

En el momento del trabajo de campo, segundo semestre de 2012, el programa de televisión se emitió sin interrupciones cada mes y llegó en el mes de noviembre a su número 100. Esto demuestra un apoyo incondicional de los directivos del colegio con este proyecto. La actividad es coordinada por una profesional en Comunicación Audiovisual, quien contaba con el apoyo de un practicante en Comunicaciones Audiovisual quien grababa y editaba las notas que serían montadas en el programa. Al igual que con el periódico, la Comunicadora y un Comité integrado por los maestros, son los responsables de proponer los temas que se publicaran en el programa de televisión. 
Las características de este programa son las siguientes:

\begin{tabular}{|c|c|c|c|}
\hline $\begin{array}{l}\text { Carácter de la } \\
\text { institución }\end{array}$ & $\begin{array}{l}\text { Medio } \\
\text { seleccionado }\end{array}$ & Características & $\begin{array}{l}\text { Criterios de } \\
\text { publicación }\end{array}$ \\
\hline Privada & $\begin{array}{l}\text { Programa de } \\
\text { televisión }\end{array}$ & $\begin{array}{l}\text { - Se publica cada } \\
\text { mes. } \\
\text { - Los temas los } \\
\text { deciden maestros } \\
\text { - Divulga eventos del } \\
\text { colegio, personajes } \\
\text { destacados. } \\
\text { - Las grabaciones se } \\
\text { hacen en las } \\
\text { instalaciones del } \\
\text { colegio. } \\
\text { - Cuenta con los } \\
\text { recursos } \\
\text { económicos que } \\
\text { garantizan su } \\
\text { publicación } \\
\text { - Dura } 20 \text { minutos } \\
\text { - Llegó a su edición } \\
\text { número } 100 \text { en } \\
\text { noviembre de } 2012 . \\
\text { - Se emite por un } \\
\text { canal interno de } \\
\text { televisión. }\end{array}$ & $\begin{array}{l}\text { - Los mismos del } \\
\text { periódico } \\
\text { - Filosofía } \\
\text { institucional } \\
\text { - Los valores que } \\
\text { promueve el colegio } \\
\text { - No hablar de } \\
\text { reggaeton }\end{array}$ \\
\hline
\end{tabular}

Cuadro 12. Características programas tv colegio privado, elaborado por el autor

\section{Colegio 2. Público}

La Muestra: entrevistas de cinco minutos producidas de manera intermitente por la maestra y un grupo de alumnos. Los entrevistados eran estudiantes, profesores, personal administrativo y personas de la comunidad. Las entrevistas se difundían en el Facebook del colegio. En este caso se analizarán dos de estas pequeñas entrevistas, correspondientes al segundo semestre de 2012.

Contextualización: El trabajo de realización era muy sencillo: con una pequeña cámara fotográfica grababan las notas y luego las editaba la profesora. Como se apreció en las 
observaciones realizadas, las reuniones del Semillero de Periodismo fueron muy intermitentes y por ello se complicó la producción de las entrevistas. Las entrevistas se publican en el Facebook del colegio y la profesora envía un mensaje para informar e invitar a la comunidad educativa entrara a mirarlas. Las características de este proyecto son las siguientes:

\begin{tabular}{|c|c|c|c|}
\hline $\begin{array}{l}\text { Carácter de la } \\
\text { institución }\end{array}$ & $\begin{array}{l}\text { Medio } \\
\text { seleccionado }\end{array}$ & Características & $\begin{array}{l}\text { Criterios de } \\
\text { publicación }\end{array}$ \\
\hline Pública & $\begin{array}{l}\text { Programa de } \\
\text { televisión } \\
\text { (entrevistas de } \\
\text { cinco minutos) } \\
\text { emitido por } \\
\text { Facebook }\end{array}$ & $\begin{array}{l}\text { - En el segundo } \\
\text { semestre de } 2012 \text { se } \\
\text { produjeron tres } \\
\text { entrevistas } \\
\text { - Las entrevistas se } \\
\text { publican en } \\
\text { Facebook, porque } \\
\text { los estudiantes } \\
\text { tienen cuenta en esa } \\
\text { red social. } \\
\text { - Los personajes } \\
\text { entrevistados van } \\
\text { desde el Personero, } \\
\text { la estudiante con un } \\
\text { proyecto de huerta } \\
\text { escolar, un } \\
\text { vigilante, una } \\
\text { bibliotecaria, entre } \\
\text { otros. } \\
\text { - La profesora es } \\
\text { quien hace la } \\
\text { cámara y la edición. } \\
\text { - Los estudiantes del } \\
\text { Semillero de } \\
\text { periodismo hacen } \\
\text { un guión de } \\
\text { preguntas. } \\
\text { - Las grabaciones se } \\
\text { hacen en las } \\
\text { instalaciones del } \\
\text { colegio. } \\
\text { - Toca temas de la } \\
\text { institución y de la } \\
\text { comunidad } \\
\text { circundante. } \\
\text { ciliono }\end{array}$ & $\begin{array}{l}\text { No existen criterios } \\
\text { de publicación } \\
\text { establecidos }\end{array}$ \\
\hline
\end{tabular}

Cuadro 13. Características programas tv colegio público, elaborado por el autor 


\section{Matriz de análisis}

En la literatura no se encuentra un prototipo de análisis de programas audiovisuales producidos en instituciones educativas. Por eso, se construye uno propio basado en los análisis textuales de audiovisuales propuestos por Vilches (2011), quien indica que un programa de televisión es un texto audiovisual, que se realiza en un contexto mediático en el que participan un autor y un destinatario; en el mismo intervienen unas categorías semióticas: de qué se habla (un programa, un formato); cómo se habla (formas de la enunciación que adoptan los interlocutores) y dónde se habla (contexto social y cultural), (Vilches, 2011, p. 268).

Con base en estos elementos se estructura la siguiente matriz para interpretar estos productos audiovisuales:

\section{Análisis del texto audiovisual}

\begin{tabular}{|l|l|l|}
\hline Categorías & Análisis & Comentarios \\
\hline Estructura de la nota & & \\
\hline Tema & & \\
\hline Duración & & \\
\hline Presentación & & \\
\hline Contenido & & \\
\hline Cierre & & \\
\hline Imágenes utilizadas & & \\
\hline Planos & & \\
\hline Movimiento de cámara & & \\
\hline Cortinas & & \\
\hline $\begin{array}{l}\text { Participación estudiantes } \\
\text { y maestros }\end{array}$ & & \\
\hline Presentaciones & & \\
\hline $\begin{array}{l}\text { Forma de presentar } \\
\text { (rápida, lenta, pausada) }\end{array}$ & & \\
\hline Vestuario & & \\
\hline Duración presentación & & \\
\hline
\end{tabular}




\begin{tabular}{|l|l|l|}
\hline Planos & & \\
\hline Personajes del informe & & \\
\hline $\begin{array}{l}\text { Relato de la presentación } \\
\text { y la nota }\end{array}$ & & \\
\hline Texto presentación & & \\
\hline Relato de la nota & & \\
\hline Personajes del informe & & \\
\hline Espacios & & \\
\hline $\begin{array}{l}\text { Escenarios (set, } \\
\text { instalaciones, fuera del } \\
\text { colegio) }\end{array}$ & & \\
\hline Tipos de informes & & \\
\hline Informativo & & \\
\hline Entretenimiento & & \\
\hline Opinión & & \\
\hline Otro & & \\
\hline
\end{tabular}

Matriz 7 para análisis de productos audiovisuales, elaborada por el autor

A partir de esta matriz se procede ahora a analizar los productos seleccionados. Como se indicó en este aparte audiovisual se procederá a aplicar la misma a unos fragmentos de cinco minutos (tres notas) en el programa de televisión que se produce en el colegio, dado que la duración oscila entre 20 y 25 minutos. Los fragmentos seleccionados son aquellos en los que es más evidente la participación de los estudiantes.

\subsubsection{Análisis productos audiovisuales. Colegio Privado}

\section{Programa 98}

Medio: MCP

Fecha: Septiembre 2012

Número: 98

Disponible en: https://www.youtube.com/watch?v=1HtDV7OwNuc

Este programa tiene una duración de 18:21 y contiene 13 notas de diferentes actividades que se realizan en el colegio y una campaña: Semana de la Antioqueñidad, Emergencias, Vox Populli (número de libros leídos), Curso de Verano en EEUU, Exposición de talento literario, Personaje 
destacado, Obras en el colegio, Celebración de la familia, Homenaje a los abuelos, Encuentro de puertas abiertas, Olimpiadas del conocimiento, Feria de la ciencia, Personaje administrativo; además de la presentación y la despedida.

Para los fines de análisis se escogieron las siguientes notas, porque son en las que tienen más presencia los estudiantes: Semana de la antioqueñidad (centrado en los niños); Vox populli (encuesta estudiantes).

\section{Primera nota: Semana de la antioqueñidad}

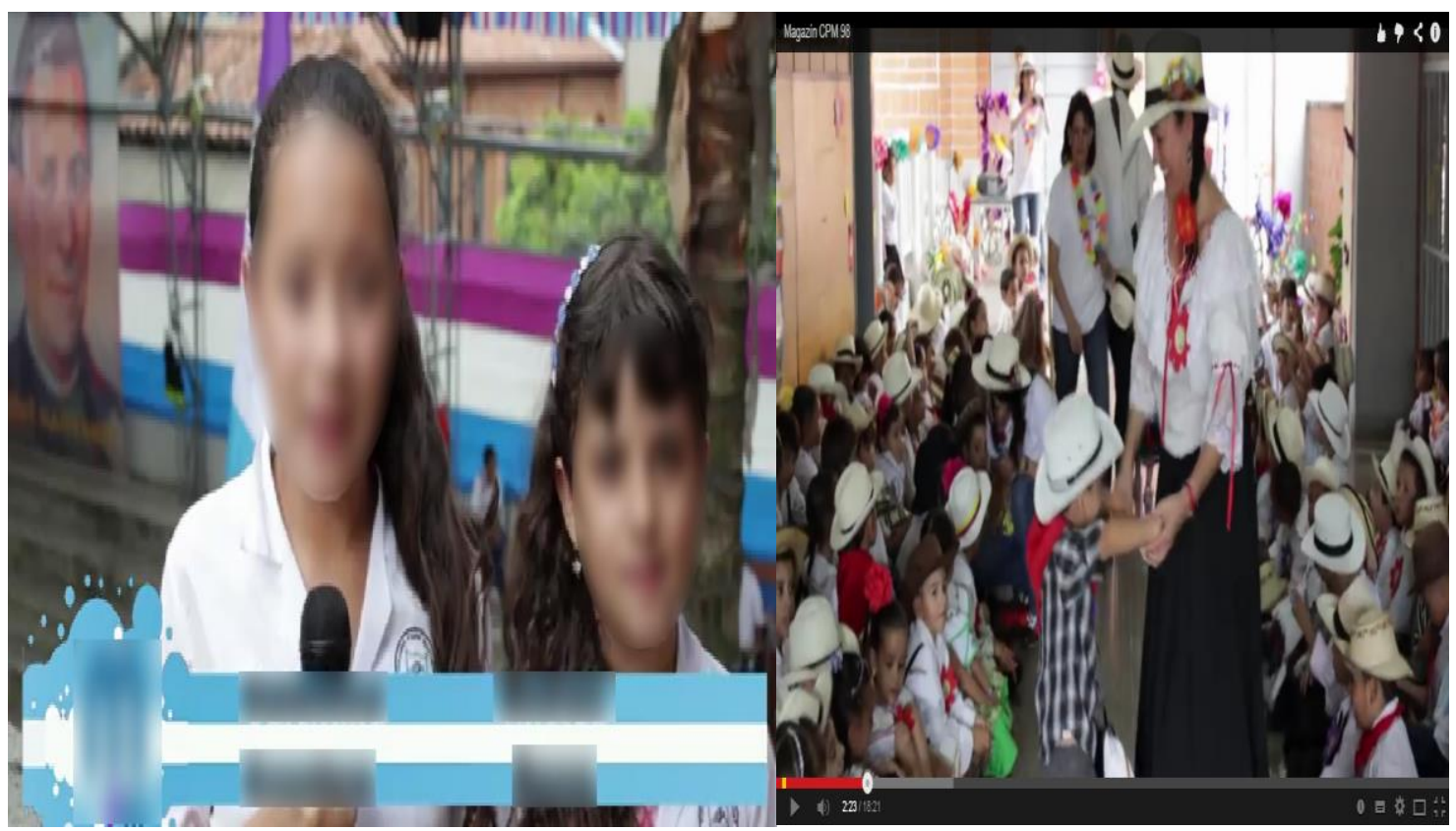

\begin{tabular}{|c|l|l|}
\hline Categorías & Análisis & Comentarios \\
\hline \multicolumn{1}{|c|}{$\begin{array}{l}\text { Estructura de la } \\
\text { nota }\end{array}$} & & \\
\hline Tema & Semana de la Antioqueñidad & $\begin{array}{l}\text { Es una celebración } \\
\text { tradicional que se lleva a } \\
\text { cabo, para conmemorar la } \\
\text { Independencia del } \\
\text { Departamento de }\end{array}$ \\
\hline
\end{tabular}




\begin{tabular}{|c|c|c|}
\hline & & $\begin{array}{l}\text { Antioquia, pero que sirve } \\
\text { para afianzar en los } \\
\text { estudiantes ciertos valores y } \\
\text { creencias sobre el ser } \\
\text { "paisas": ser los mejores } \\
\text { del país. }\end{array}$ \\
\hline Duración & $\begin{array}{l}\text { Presentación 1:17- 1:28 } \\
\text { Cortina Sección: } 1: 28-1: 37 \\
\text { Contenido: } 1: 38-2: 41 \\
\text { Total: } 1: 24\end{array}$ & \\
\hline Presentación & $\begin{array}{l}\text { Presentación de la nota por parte } \\
\text { de dos estudiantes (niños) y una } \\
\text { cortina que indica que se trata de } \\
\text { una sección centrada en los } \\
\text { niños del preescolar }\end{array}$ & $\begin{array}{l}\text { Las presentaciones son } \\
\text { preparadas en el espacio de } \\
\text { la Extracurricular, que } \\
\text { fueron objeto de la } \\
\text { observación durante un } \\
\text { semestre. }\end{array}$ \\
\hline Contenido & $\begin{array}{l}\text { Semana de alegría, tradición y } \\
\text { celebraciones. } \\
\text { Los niños disfrutaron de música } \\
\text { y viaje en bus, cabalgatas y } \\
\text { comidas típicas. } \\
\text { Agradecimiento a los aportes de } \\
\text { los padres de familia. } \\
\text { Se recalca que se celebró el Día } \\
\text { de la Antioqueñidad y el orgullo } \\
\text { paisa. } \\
\text { Habla de sentirse orgullosos y } \\
\text { felices de ser hijos de esta } \\
\text { "tierra antioqueña". }\end{array}$ & $\begin{array}{l}\text { El contenido se estructura } \\
\text { con un texto alusivo a una } \\
\text { festividad tradicional: Día } \\
\text { de la Antioqueñidad. Al } \\
\text { final se refuerza la idea de } \\
\text { felicidad, por ser } \\
\text { "antioqueños". El } \\
\text { contenido se soporta en las } \\
\text { imágenes utilizadas para } \\
\text { ilustrar la actividad en la } \\
\text { que participaron los niños }\end{array}$ \\
\hline Cierre & $\begin{array}{l}\text { El cierre se da por el corte y el } \\
\text { negro para separar la nota }\end{array}$ & $\begin{array}{l}\text { La nota no tiene un cierre } \\
\text { por parte del narrador. }\end{array}$ \\
\hline Imágenes utilizadas & $\begin{array}{l}\text { La nota inicia con un collage de } \\
12 \text { fotos alusivas a comida, } \\
\text { paseo en bus, trajes típicos. } \\
\text { Aparece luego un texto que se } \\
\text { desplaza y que dice "Semana de } \\
\text { la antioqueñidad" en su fondo } \\
\text { pasan las imágenes antes } \\
\text { descritas. } \\
\text { Después salen diferentes } \\
\text { actividades: baile, canto, viaje } \\
\text { en bus, niños con disfraces } \\
\text { caballitos de palo, salones en } \\
\text { donde se ofrecieron platos } \\
\text { típicos. } \\
\text { Imágenes de padres de familia } \\
\text { en la celebración. } \\
\text { Imágenes de niñas disfrazadas }\end{array}$ & $\begin{array}{l}\text { Las imágenes se producen } \\
\text { al interior del colegio, a } \\
\text { excepción de unas pocas } \\
\text { imágenes en el bus. } \\
\text { Las imágenes son coloridas } \\
\text { y muestran el ambiente de } \\
\text { fiesta que se vivió en la } \\
\text { celebración. }\end{array}$ \\
\hline
\end{tabular}




\begin{tabular}{|c|c|c|}
\hline & $\begin{array}{l}\text { con trajes típicos. } \\
\text { Imágenes de niños con banderas } \\
\text { de Antioquia en sus manos. } \\
\text { Imágenes de silleteros (tradición } \\
\text { típica de la región). }\end{array}$ & \\
\hline Planos & $\begin{array}{l}\text { Predominan los planos medios y } \\
\text { cerrados. }\end{array}$ & $\begin{array}{l}\text { Las tomas las hace un } \\
\text { practicante comunicación } \\
\text { audiovisual. La } \\
\text { construcción del texto } \\
\text { visual se hace bajo los } \\
\text { parámetros de un } \\
\text { cubrimiento informativo, } \\
\text { propio de los medios } \\
\text { tradicionales. }\end{array}$ \\
\hline Movimiento de cámara & $\begin{array}{l}\text { A momentos es estática y en } \\
\text { otros hace paneos de los lugares } \\
\text { y las actividades realizadas. }\end{array}$ & $\begin{array}{l}\text { En este sentido sigue lo } \\
\text { establecido en los medios } \\
\text { tradicionales }\end{array}$ \\
\hline Cortinas & $\begin{array}{l}\text { Música tropical alusiva a la } \\
\text { Feria de las flores, festividad } \\
\text { tradicional en la ciudad. }\end{array}$ & $\begin{array}{l}\text { La cortina musical } \\
\text { acompaña la nota de } \\
\text { principio a fin. }\end{array}$ \\
\hline $\begin{array}{ll}\text { 2. } & \text { Participación } \\
\text { estudiantes } \mathbf{y} \\
\text { maestros }\end{array}$ & & \\
\hline Presentaciones & & \\
\hline $\begin{array}{l}\text { Forma de presentar } \\
\text { (rápida, lenta, pausada) }\end{array}$ & $\begin{array}{l}\text { La presentación la hacen dos } \\
\text { niños de manera pausada. Las } \\
\text { presentadoras están de frente a } \\
\text { la cámara; empieza una y } \\
\text { cuando termina su intervención } \\
\text { le pasa el micrófono a la otra } \\
\text { para que termine la } \\
\text { presentación. }\end{array}$ & $\begin{array}{l}\text { Aunque presentan } \\
\text { problemas en la } \\
\text { vocalización, la misma } \\
\text { alcanza a comprenderse. } \\
\text { Es la propuesta que tiene el } \\
\text { programa durante los años } \\
\text { de existencia del mismo. }\end{array}$ \\
\hline Vestuario & Uniforme del colegio & $\begin{array}{l}\text { Se ve la blusa de color } \\
\text { blanco. }\end{array}$ \\
\hline Duración presentación & $1: 17-1: 24$ & \\
\hline Planos & Medio & $\begin{array}{l}\text { Es el plano establecido para } \\
\text { este tipo de trabajos }\end{array}$ \\
\hline Créditos & $\begin{array}{l}\text { Aparecen los nombres de las } \\
\text { presentadoras en color negro, } \\
\text { sobre un fondo azul, blanco y } \\
\text { azul, los colores institucionales. } \\
\text { Al lado izquierdo aparecen las } \\
\text { iniciales institucionales M (en } \\
\text { azul) y cpm del programa. }\end{array}$ & $\begin{array}{l}\text { Los créditos configuran } \\
\text { parte de la identidad gráfica } \\
\text { del programa. }\end{array}$ \\
\hline \multicolumn{3}{|l|}{$\begin{array}{l}\text { Relato de la } \\
\text { presentación y la nota }\end{array}$} \\
\hline Texto presentación & $\begin{array}{l}\text { Se refiere a la celebración de la } \\
\text { Fiesta de la Antioqueñidad }\end{array}$ & $\begin{array}{l}\text { La presentación es un texto } \\
\text { breve que los estudiantes }\end{array}$ \\
\hline
\end{tabular}




\begin{tabular}{|c|c|c|}
\hline & $\begin{array}{l}\text { (celebración tradicional), basado } \\
\text { en tres conceptos: gastronomía, } \\
\text { cabalgata y tradiciones. }\end{array}$ & $\begin{array}{l}\text { aprenden de memoria y } \\
\text { graban días antes de la } \\
\text { edición. }\end{array}$ \\
\hline Relato de la nota & $\begin{array}{l}\text { Utiliza la voz en off. Se hace de } \\
\text { manera pausada }\end{array}$ & $\begin{array}{l}\text { La voz en off la hace una } \\
\text { estudiante que no participa } \\
\text { en el espacio de la } \\
\text { Extracurricular. Es } \\
\text { seleccionada por el Comité } \\
\text { conformado por maestros. }\end{array}$ \\
\hline Personajes del informe & Los niños del preescolar & $\begin{array}{l}\text { Aparecen como registro, } \\
\text { pero no se incluyen } \\
\text { testimonios de los niños } \\
\text { participantes. }\end{array}$ \\
\hline \multicolumn{3}{|l|}{ 3. $\quad$ Espacios } \\
\hline $\begin{array}{l}\text { Escenarios (set, } \\
\text { instalaciones, fuera del } \\
\text { colegio) }\end{array}$ & $\begin{array}{l}\text { En la presentación se utilizó el } \\
\text { coliseo del colegio al fondo se } \\
\text { ven algunas gradas y la foto del } \\
\text { fundador. } \\
\text { Los escenarios de la nota fueron } \\
\text { un bus escalera, salones de clase } \\
\text { adornados con elementos } \\
\text { propios de la celebración; } \\
\text { auditorios, zonas verdes y } \\
\text { corredores del colegio. }\end{array}$ & $\begin{array}{l}\text { Los diferentes espacios del } \\
\text { colegio sirven de escenarios } \\
\text { para producir las imágenes } \\
\text { requeridas. }\end{array}$ \\
\hline \multicolumn{3}{|l|}{$\begin{array}{l}\text { 4. Tipos de } \\
\text { informes }\end{array}$} \\
\hline $\begin{array}{l}\text { Informativo } \\
\text { Entretenimiento } \\
\text { Opinión } \\
\text { Otro }\end{array}$ & $\begin{array}{l}\text { Es informativo en la medida que } \\
\text { da cuenta de la celebración. } \\
\text { Estuvo centrada en los niños de } \\
\text { preescolar, ellos fueron los } \\
\text { protagonistas y la nota muestra } \\
\text { las diferentes actividades que se } \\
\text { llevaron a cabo en esta fiesta. }\end{array}$ & $\begin{array}{l}\text { Es un relato expositivo en } \\
\text { el que se condensan las } \\
\text { diferentes actividades } \\
\text { llevadas a cabo por los } \\
\text { niños que participaron en la } \\
\text { festividad. Se centró en el } \\
\text { qué pasó y quiénes } \\
\text { participaron. }\end{array}$ \\
\hline
\end{tabular}

Matriz 8. Análisis nota sobre la antioqueñidad, elaborada por el autor 


\section{Segunda nota. Vox pop}

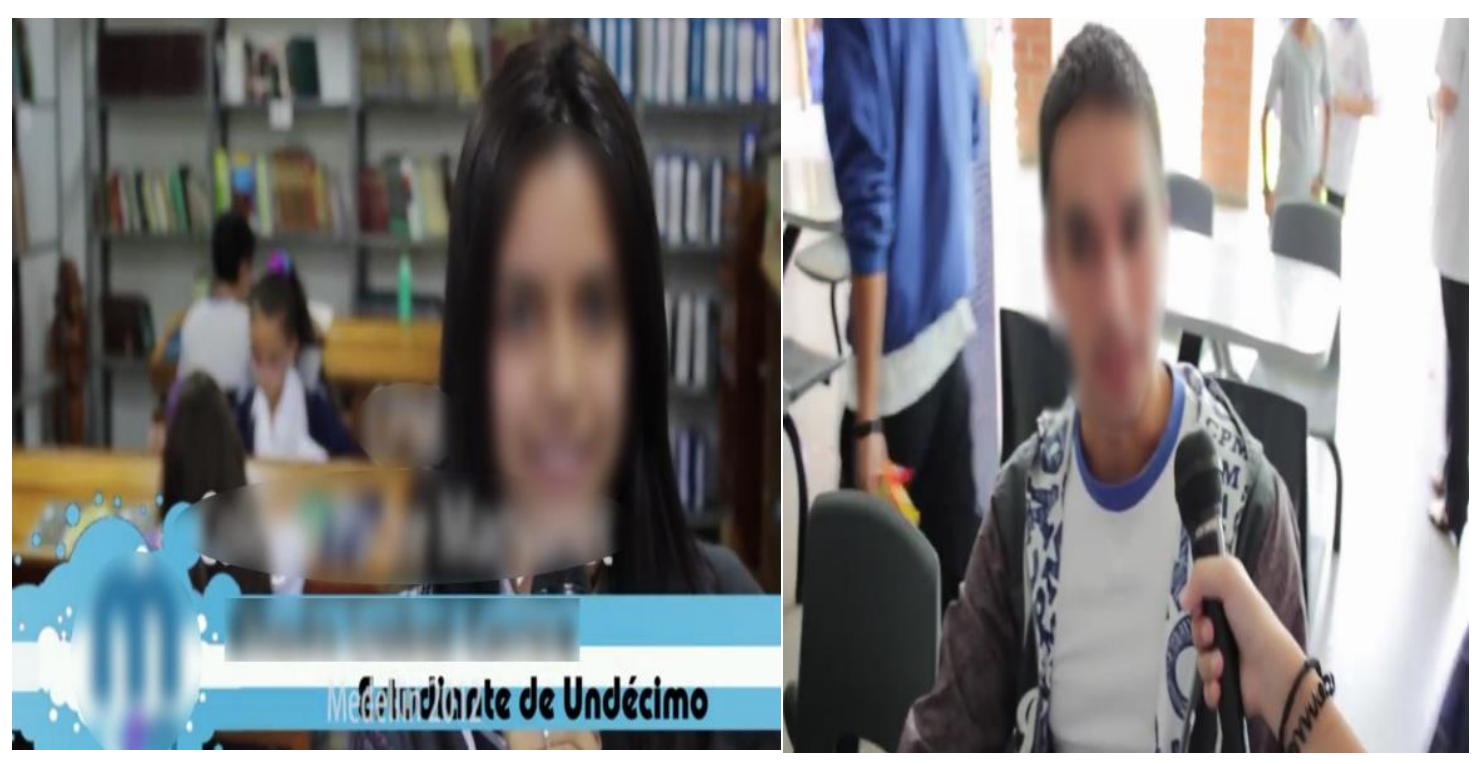

\begin{tabular}{|c|c|c|}
\hline Categorías & Análisis & Comentarios \\
\hline \multicolumn{3}{|l|}{ 1.Estructura de la nota } \\
\hline Tema & Libros leídos (Vox pop) & $\begin{array}{l}\text { Consulta de control basado } \\
\text { en programa académico }\end{array}$ \\
\hline Duración & $\begin{array}{l}\text { 3:37- 4:44 (Consulta) } \\
4: 45-5: 06 \text { (nota de cierre) } \\
\text { Total: 1:39 }\end{array}$ & \\
\hline Presentación & $\begin{array}{l}\text { No tuvo presentación, solo la } \\
\text { imagen Vox Populli }\end{array}$ & $\begin{array}{l}\text { A pesar de no tener, se } \\
\text { genera la sensación que } \\
\text { hizo falta para } \\
\text { contextualizar a los } \\
\text { receptores sobre el } \\
\text { propósito de la nota. }\end{array}$ \\
\hline Contenido & $\begin{array}{l}\text { La nota se estructura en dos } \\
\text { preguntas: ¿Cuántos libros te } \\
\text { has leído y cuál fue el último } \\
\text { que leíste? } \\
\text { Se consultaron tres (3) } \\
\text { estudiantes de primaria y seis } \\
\text { (6) de bachillerato. }\end{array}$ & $\begin{array}{l}\text { Las respuestas ofrecidas } \\
\text { permiten hacerse una } \\
\text { cuenta de lo que sucede en } \\
\text { el colegio en materia de } \\
\text { lecturabilidad. }\end{array}$ \\
\hline Cierre & $\begin{array}{l}\text { La nota termina con una } \\
\text { intervención de una estudiante } \\
\text { que habla sobre el trabajo que se } \\
\text { hace desde el área de español de } \\
\text { proponer a los estudiantes "leer } \\
\text { cierta cantidad de libros por }\end{array}$ & $\begin{array}{l}\text { La nota tiene la } \\
\text { intencionalidad de hacer } \\
\text { ver la estrategia utilizada } \\
\text { por los profesores del área } \\
\text { de español y, según lo } \\
\text { expresado por la }\end{array}$ \\
\hline
\end{tabular}




\begin{tabular}{|c|c|c|}
\hline & $\begin{array}{l}\text { periodo". La invitación es a } \\
\text { descubrir nuevos mundos "que } \\
\text { es lo que se dice de los libros" y } \\
\text { a que "potencialicen su } \\
\text { capacidad lecto-escritora", que } \\
\text { posibilite "analizar textos de una } \\
\text { mejor manera y tener una mejor } \\
\text { expresión oral y escrita". }\end{array}$ & $\begin{array}{l}\text { presentadora, es una } \\
\text { estrategia que apunta más } \\
\text { que a tener un acercamiento } \\
\text { y gusto por la lectura, bajo } \\
\text { un enfoque tradicional de la } \\
\text { educación. }\end{array}$ \\
\hline Imágenes utilizadas & $\begin{array}{l}\text { Estudiantes consultados en la } \\
\text { cafetería del colegio. } \\
\text { Estudiante del cierre en la } \\
\text { biblioteca de la institución }\end{array}$ & $\begin{array}{l}\text { Las imágenes son hechas } \\
\text { al interior de la institución. }\end{array}$ \\
\hline Planos & $\begin{array}{l}\text { Primeros planos, muestran la } \\
\text { cara de los estudiantes. } \\
\text { El cierre es un plano medio de la } \\
\text { presentadora, con un fondo de la } \\
\text { biblioteca en donde se ven } \\
\text { estudiantes y libros } \\
\text { desenfocados }\end{array}$ & $\begin{array}{l}\text { Utilizan los mismos planos } \\
\text { que aplican los medios } \\
\text { cuando hacen este tipo de } \\
\text { consultas con los } \\
\text { ciudadanos. }\end{array}$ \\
\hline Movimiento de cámara & No hay. & \\
\hline Cortinas & $\begin{array}{l}\text { No utilizó. Se trabajó con el } \\
\text { sonido ambiente, propio del } \\
\text { formato utilizado (Vox pop). }\end{array}$ & No era necesaria. \\
\hline \multicolumn{3}{|l|}{$\begin{array}{l}\text { 2. Participación } \\
\text { estudiantes y maestros }\end{array}$} \\
\hline \multicolumn{3}{|l|}{ Presentaciones } \\
\hline $\begin{array}{l}\text { Forma de presentar } \\
\text { (rápida, lenta, pausada) }\end{array}$ & $\begin{array}{l}\text { Dos estudiantes hacen las } \\
\text { preguntas, no aparecen en } \\
\text { cámara. Las preguntas las hacen } \\
\text { de manera rápida. }\end{array}$ & $\begin{array}{l}\text { Más que una presentación } \\
\text { existió una "reportería", } \\
\text { poco común en este } \\
\text { programa. Los chicos } \\
\text { fueron a preguntar a sus } \\
\text { compañeros. Esto lo hace } \\
\text { un ejercicio interesante. }\end{array}$ \\
\hline Vestuario & $\begin{array}{l}\text { Los estudiantes consultados } \\
\text { aparecieron con sus uniformes } \\
\text { institucionales }\end{array}$ & $\begin{array}{l}\text { El uniforme es el vestuario } \\
\text { por naturaleza que aparece } \\
\text { en las notas. }\end{array}$ \\
\hline Duración presentación & $\begin{array}{l}\text { En este caso no hubo } \\
\text { presentación, pero si un cierre } \\
\text { con una estudiante. La duración } \\
\text { de esta nota fue de } 21 \text { segundos. }\end{array}$ & $\begin{array}{l}\text { El hecho de ofrecer un } \\
\text { cierre cambió la estructura } \\
\text { de la nota; en lugar de } \\
\text { presentación hubo un cierre } \\
\text { a manera de colofón. }\end{array}$ \\
\hline Planos & $\begin{array}{l}\text { Un plano medio de la } \\
\text { presentadora y la biblioteca. }\end{array}$ & \\
\hline Créditos & $\begin{array}{l}\text { Se repite el formato de } \\
\text { presentar los créditos: nombre } \\
\text { de la estudiante en negro, sobre } \\
\text { un fondo azul, blanco, azul. }\end{array}$ & $\begin{array}{l}\text { El programa tiene una } \\
\text { identidad en este sentido. El } \\
\text { formato de los créditos se } \\
\text { repite en las diferentes } \\
\text { notas. }\end{array}$ \\
\hline
\end{tabular}




\begin{tabular}{|c|c|c|}
\hline $\begin{array}{l}\text { Relato de la } \\
\text { presentación y la nota }\end{array}$ & & \\
\hline Texto presentación & $\begin{array}{l}\text { No hubo presentación de los } \\
\text { estudiantes }\end{array}$ & \\
\hline Relato de la nota & $\begin{array}{l}\text { Se basa en las preguntas y las } \\
\text { respuestas de los estudiantes. La } \\
\text { única variable fue el relato al } \\
\text { final de la estudiante que se } \\
\text { centró en la estrategia del área } \\
\text { de español para proponer "una } \\
\text { cantidad" de libros para que los } \\
\text { lean y la posibilidad de } \\
\text { "potencializar" las capacidades } \\
\text { lecto-escritura, con miras a } \\
\text { mejorar la expresión oral y } \\
\text { escrita. }\end{array}$ & $\begin{array}{l}\text { La técnica le dio } \\
\text { dinamismo al programa. De } \\
\text { alguna manera rompió con } \\
\text { la estructura de las notas: } \\
\text { presentación, relato de voz } \\
\text { en off y cierre en negro. }\end{array}$ \\
\hline Personajes del informe & $\begin{array}{l}\text { Estudiantes de la institución } \\
\text { consultados para el Vox pop. }\end{array}$ & $\begin{array}{l}\text { Prevalece la voz del } \\
\text { estudiante. }\end{array}$ \\
\hline \multicolumn{3}{|l|}{ 3. Espacios } \\
\hline $\begin{array}{l}\text { Escenarios (set, } \\
\text { instalaciones, fuera del } \\
\text { colegio) }\end{array}$ & $\begin{array}{l}\text { Fueron los espacios de } \\
\text { descanso: la cafetería y algunos } \\
\text { pasillos del colegio. }\end{array}$ & $\begin{array}{l}\text { El colegio es el escenario } \\
\text { por excelencia para las } \\
\text { notas. }\end{array}$ \\
\hline \multicolumn{3}{|l|}{ 4.Tipos de informes } \\
\hline $\begin{array}{l}\text { Informativo } \\
\text { Entretenimiento } \\
\text { Opinión } \\
\text { Otro }\end{array}$ & $\begin{array}{l}\text { Vox pop. Es una encuesta para } \\
\text { dar cuenta de la estrategia } \\
\text { aplicada en el colegio para que } \\
\text { los estudiantes lean. Al final se } \\
\text { hace una explicación sobre en } \\
\text { qué consiste la estrategia (desde } \\
\text { el área de español) y cuál es el } \\
\text { propósito de la misma. }\end{array}$ & $\begin{array}{l}\text { Replica el formato de la } \\
\text { educación tradicional: } \\
\text { pregunta-respuesta. No hay } \\
\text { una apreciación u opinión } \\
\text { de los estudiantes frente a si } \\
\text { importa más la cantidad o } \\
\text { el gusto y la relevancia por } \\
\text { acercarse a la lectura de } \\
\text { libros. }\end{array}$ \\
\hline
\end{tabular}

\section{Programa 100}

Matriz 9. Análisis nota sobre Vox pop, elaborada por el autor

Medio: MCPM

Fecha: Noviembre 2012

Número: 100

Disponible en: https://www.youtube.com/watch?v=1o_tx4kAM-g

Este programa fue la emisión 100, resultado de 12 años de trabajo ininterrumpido. La duración del programa fue de 27:29, porque contó con las notas habituales, pero sobre todo se centró en los egresados que hicieron parte del proyecto y también en los maestros que iniciaron la propuesta en el año 2000. Tuvo 17 notas, dos publicidades, la entrada y la salida. Las notas seleccionadas para 
el análisis son las siguientes: Deberes de los estudiantes; El sentido de la experiencia en el programa, por un egresado; Talentos.

Primera nota. Deberes de los estudiantes

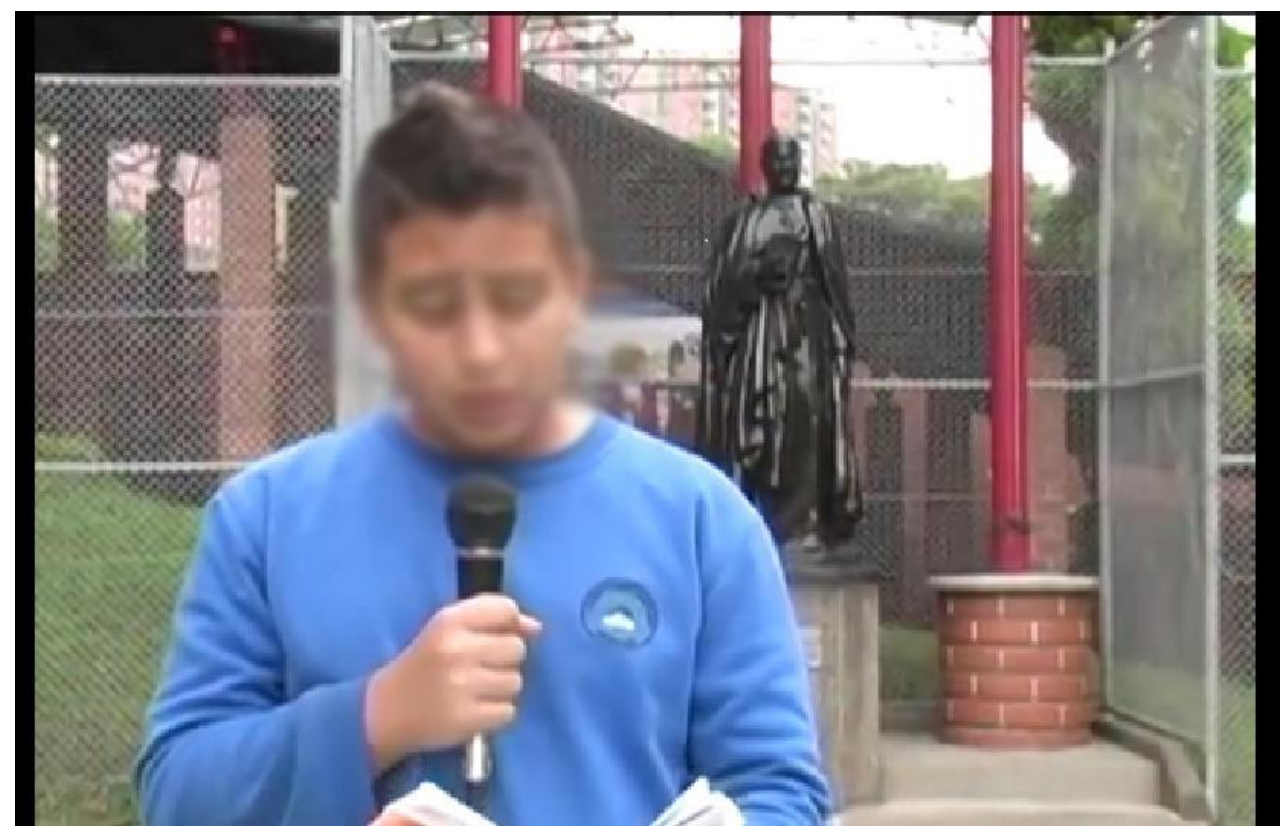

\begin{tabular}{|l|l|l|}
\hline Categorías & Análisis & Comentarios \\
\hline 1.Estructura de la nota & Cumplimiento de los deberes & $\begin{array}{l}\text { El tema entra sin } \\
\text { presentación. No tuvo una } \\
\text { conexión con la anterior, en } \\
\text { la que unos egresados } \\
\text { destacaron la importancia } \\
\text { de la formación recibida en } \\
\text { el colegio }\end{array}$ \\
\hline Demación & $\begin{array}{l}\text { Es la nota más corta de } \\
\text { todas. }\end{array}$ \\
\hline Presentación & Total: 42 seg. & $\begin{array}{l}\text { El estudiante solo hace una } \\
\text { breve referencia al } \\
\text { cumplimiento de los } \\
\text { deberes }\end{array}$ \\
\hline Contenido & $\begin{array}{l}\text { Se basa en la lectura de unos } \\
\text { artículos del Manual de } \\
\text { Convivencia, por parte de un } \\
\text { estudiante: Conocer y aplicar el } \\
\text { Manual de Convivencia, } \\
\text { conocer y aplicar la historia, }\end{array}$ & $\begin{array}{l}\text { Esta nota es una } \\
\text { manifestación de la } \\
\text { educación tradicional: un } \\
\text { estudiante lee de un libro } \\
\text { unos contenidos, pero no } \\
\text { hace una reflexión de la }\end{array}$ \\
\hline
\end{tabular}




\begin{tabular}{|c|c|c|}
\hline & $\begin{array}{l}\text { filosofía y los símbolos del } \\
\text { colegio, respetar los símbolos } \\
\text { patrios y del colegio, los valores } \\
\text { culturales, nacionales y étnicos, } \\
\text { responder por los valores } \\
\text { académicos en las asignaturas, } \\
\text { cuidar el medio ambiente. }\end{array}$ & $\begin{array}{l}\text { misma. Parece una lección } \\
\text { expuesta ante una cámara. } \\
\text { No hay reflexión de parte } \\
\text { del estudiante que lee el } \\
\text { texto. }\end{array}$ \\
\hline Cierre & $\begin{array}{l}\text { Conclusión por parte del } \\
\text { estudiante, quien invita a los } \\
\text { compañeros a cumplir los } \\
\text { deberes para tener mejor } \\
\text { convivencia. }\end{array}$ & $\begin{array}{l}\text { El estudiante no hace una } \\
\text { reflexión propia de los } \\
\text { contenidos leídos. El corte } \\
\text { es frío. }\end{array}$ \\
\hline Imágenes utilizadas & $\begin{array}{l}\text { Se centra en el estudiante } \\
\text { leyendo el Manual de } \\
\text { Convivencia. Al fondo se ve una } \\
\text { estatua del fundador de la } \\
\text { Congregación Religiosa y una } \\
\text { malla. }\end{array}$ & $\begin{array}{l}\text { No se "pintó" la nota, por } \\
\text { tanto la misma quedó } \\
\text { monótona, sin dinámica. }\end{array}$ \\
\hline Planos & Medio & $\begin{array}{l}\text { Es una nota estática, el } \\
\text { plano fue el mismo para } \\
\text { todo. }\end{array}$ \\
\hline Movimiento de cámara & Permanece estática & \\
\hline Cortinas & $\begin{array}{l}\text { La nota tiene una cortina de } \\
\text { fondo. }\end{array}$ & $\begin{array}{l}\text { Ambienta un tanto la } \\
\text { monotonía de la nota. }\end{array}$ \\
\hline \multicolumn{3}{|l|}{$\begin{array}{l}\text { 2. Participación } \\
\text { estudiantes y maestros }\end{array}$} \\
\hline \multicolumn{3}{|l|}{ Presentaciones } \\
\hline $\begin{array}{l}\text { Forma de presentar } \\
\text { (rápida, lenta, pausada) }\end{array}$ & $\begin{array}{l}\text { El estudiante hace una breve } \\
\text { presentación acerca de los } \\
\text { deberes }\end{array}$ & $\begin{array}{l}\text { La carencia de la } \\
\text { presentación da la } \\
\text { sensación que esta nota no } \\
\text { estaba programada. }\end{array}$ \\
\hline Vestuario & Uniforme del colegio & El mismo en todos. \\
\hline Duración presentación & No hubo presentación & \\
\hline Planos & Medio & Se repite el plano \\
\hline Créditos & $\begin{array}{l}\text { Conserva el formato de } \\
\text { presentación de las anteriores } \\
\text { emisiones }\end{array}$ & $\begin{array}{l}\text { El formato genera identidad } \\
\text { del programa }\end{array}$ \\
\hline \multicolumn{3}{|l|}{$\begin{array}{l}\text { Relato de la presentación } \\
\text { y la nota }\end{array}$} \\
\hline Texto presentación & No hubo presentación & \\
\hline Relato de la nota & $\begin{array}{l}\text { Se basa en la lectura de un } \\
\text { fragmento del Manual de } \\
\text { Convivencia }\end{array}$ & $\begin{array}{l}\text { Es apresurada, las pausas } \\
\text { son cortas, muestra afán } \\
\text { para terminar de leer. } \\
\text { La nota no puede } \\
\text { sostenerse sola con la } \\
\text { lectura de un texto, faltaron } \\
\text { ser manejada de otra } \\
\text { manera. }\end{array}$ \\
\hline
\end{tabular}




\begin{tabular}{|l|l|l|}
\hline Personajes del informe & Estudiante & $\begin{array}{l}\text { El estudiante no hace parte } \\
\text { de la Extracurricular, por lo } \\
\text { que resulta extraño que sea } \\
\text { él quien salga ante la } \\
\text { cámara. }\end{array}$ \\
\hline $\begin{array}{l}\text { 3. Espacios } \\
\text { instalaciones, fuera del } \\
\text { colegio) }\end{array}$ & $\begin{array}{l}\text { Instalaciones del colegio, zona } \\
\text { verde, con la estatua del } \\
\text { fundador de la congregación } \\
\text { religiosa. }\end{array}$ & $\begin{array}{l}\text { Tener la imagen del } \\
\text { fundador es un refuerzo a la } \\
\text { moral, si se tiene en cuenta } \\
\text { que el propósito fue la } \\
\text { lectura del Manual de } \\
\text { Convivencia, de manera } \\
\text { específica en el aparte de } \\
\text { los deberes de los } \\
\text { estudiantes. }\end{array}$ \\
\hline $\begin{array}{l}\text { 4.Tipos de informes } \\
\text { Entretenimiento } \\
\text { Opinión } \\
\text { Otro }\end{array}$ & $\begin{array}{l}\text { Es una lección grabada para } \\
\text { televisión, no tiene comentarios } \\
\text { o reflexiones de parte del } \\
\text { estudiante. }\end{array}$ & $\begin{array}{l}\text { Es una demostración de } \\
\text { cómo los modelos } \\
\text { tradicionales de la } \\
\text { educación se ajustan a los } \\
\text { modelos difusionistas de la } \\
\text { comunicación. Leer frente a } \\
\text { una cámara es semejante a } \\
\text { leer frente a un grupo de } \\
\text { estudiantes dentro de un } \\
\text { aula de clase, solo cambia } \\
\text { el escenario y el } \\
\text { instrumento: la cámara. }\end{array}$ \\
\hline
\end{tabular}

Matriz 10. Análisis nota sobre Deberes de los estudiantes, elaborada por el autor

\section{Segunda nota. Talentos}

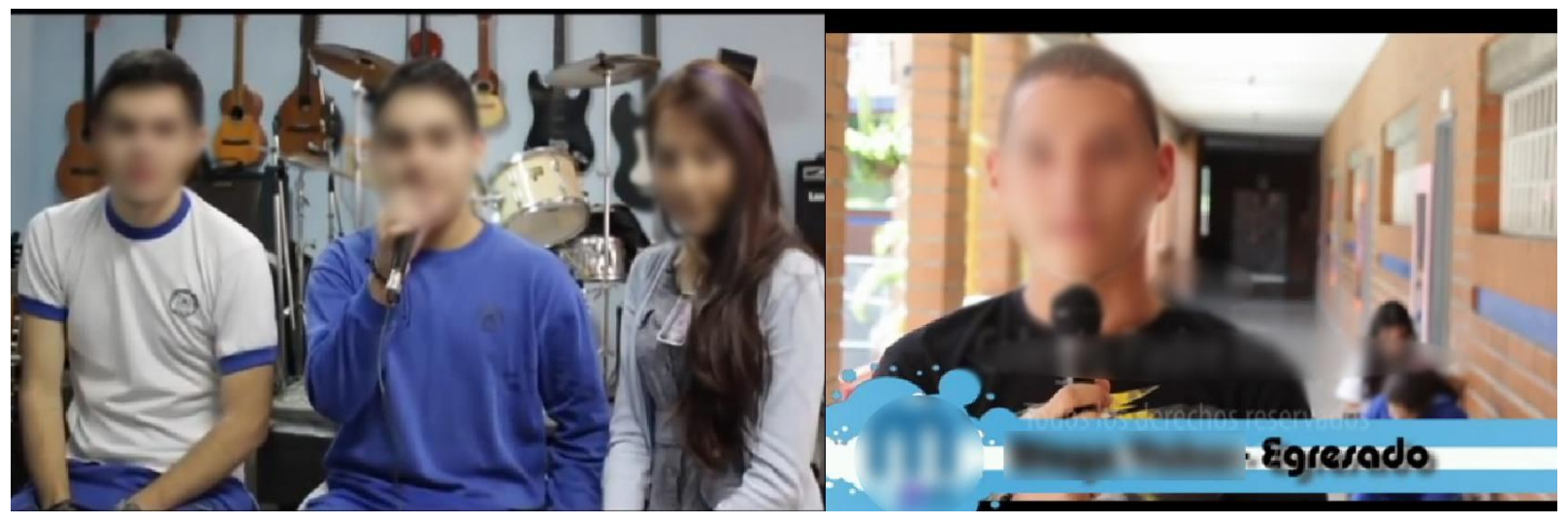




\begin{tabular}{|c|c|c|}
\hline Categorías & Análisis & Comentarios \\
\hline \multicolumn{3}{|l|}{ 1.Estructura de la nota } \\
\hline Tema & Talentos & $\begin{array}{l}\text { Es una nota interesante, } \\
\text { porque tiene a una egresada } \\
\text { y a un estudiante que se } \\
\text { destacan por sus logros } \\
\text { musicales, tienen en común } \\
\text { que esos talentos se } \\
\text { potenciaron en el colegio. }\end{array}$ \\
\hline Duración & $\begin{array}{l}\text { 18:48-18:56. Presentación. } \\
\text { 18:57- } 20: 32 . \text { Nota } \\
\text { Total: } 1.34 .\end{array}$ & \\
\hline Presentación & $\begin{array}{l}\text { Habla de dos talentos que han } \\
\text { crecido y hacen parte del } \\
\text { colegio }\end{array}$ & $\begin{array}{l}\text { En la misma participó una } \\
\text { egresada. A pesar de ello } \\
\text { conserva el formato en que } \\
\text { se hacen las presentaciones. }\end{array}$ \\
\hline Contenido & $\begin{array}{l}\text { Entrevista a egresada y } \\
\text { estudiante que tienen algo en } \\
\text { común: son músicos. } \\
\text { Egresada: aporte del colegio, } \\
\text { facilidad de enfrentarse a un } \\
\text { público, expresarse de mejor } \\
\text { forma. } \\
\text { Estudiante: bien y cómodo por } \\
\text { haber representado bien la banda } \\
\text { y al colegio en el evento en que } \\
\text { participó. Destaca el esfuerzo } \\
\text { que implica preparar } \\
\text { presentaciones en el colegio. La } \\
\text { unión entre todos. }\end{array}$ & $\begin{array}{l}\text { La nota es dinámica, en } \\
\text { cuanto a forma, porque } \\
\text { utilizan a un entrevistador y } \\
\text { participan dos jóvenes que } \\
\text { comparten sus experiencias } \\
\text { y aprendizajes logrados con } \\
\text { la música. } \\
\text { El entrevistador no hace } \\
\text { parte de la Extracurricular. }\end{array}$ \\
\hline Cierre & $\begin{array}{l}\text { Cierran con la interpretación de } \\
\text { una canción en inglés entre los } \\
\text { tres: egresada, estudiante y } \\
\text { entrevistador. E imágenes } \\
\text { informales de los tres antes de } \\
\text { grabar la nota }\end{array}$ & $\begin{array}{l}\text { Es diferente a los demás, } \\
\text { esto lo hizo más fresco, } \\
\text { tranquilo. Demostraron los } \\
\text { participantes sus } \\
\text { conocimientos en la } \\
\text { música. }\end{array}$ \\
\hline Imágenes utilizadas & $\begin{array}{l}\text { Imágenes de apoyo de la } \\
\text { egresada en presentaciones; } \\
\text { también se usaron imágenes de } \\
\text { apoyo de presentación del } \\
\text { estudiante en un evento musical. }\end{array}$ & $\begin{array}{l}\text { Tanto el escenario, como } \\
\text { las imágenes de apoyo } \\
\text { favorecieron la realización } \\
\text { de una nota estética bien } \\
\text { hecha. }\end{array}$ \\
\hline Planos & $\begin{array}{l}\text { Es un plano abierto, para los } \\
\text { tres participantes: periodista y } \\
\text { dos invitados; más los } \\
\text { instrumentos musicales, propios } \\
\text { de una sala de música. También } \\
\text { usa los planos cerrados cuando } \\
\text { intervienen la egresada y el }\end{array}$ & $\begin{array}{l}\text { La nota posibilitó que se } \\
\text { abrieran más los planos, } \\
\text { para mostrar además el } \\
\text { contexto en donde estaban. }\end{array}$ \\
\hline
\end{tabular}




\begin{tabular}{|c|c|c|}
\hline & estudiante. & \\
\hline Movimiento de cámara & No hay movimiento de cámara & La cámara es estática. \\
\hline Cortinas & $\begin{array}{l}\text { Tiene una cortina en toda la } \\
\text { nota, muy dinámica. }\end{array}$ & $\begin{array}{l}\text { Aunque es alta en volumen, } \\
\text { el ritmo de la misma } \\
\text { favoreció el dinamismo de } \\
\text { la nota. }\end{array}$ \\
\hline \multicolumn{3}{|l|}{$\begin{array}{l}\text { 2. Participación } \\
\text { estudiantes y maestros }\end{array}$} \\
\hline \multicolumn{3}{|l|}{ Presentaciones } \\
\hline $\begin{array}{l}\text { Forma de presentar } \\
\text { (rápida, lenta, pausada) }\end{array}$ & Pausada, tranquila, sin guión. & $\begin{array}{l}\text { Fue realizada por un } \\
\text { egresado. }\end{array}$ \\
\hline Vestuario & Informal, camiseta & $\begin{array}{l}\text { Es un egresado del colegio, } \\
\text { por tanto no requería de } \\
\text { uniforme }\end{array}$ \\
\hline Duración presentación & Ocho (8) segundos. & \\
\hline Planos & Medio. & $\begin{array}{l}\text { Es el mismo plano, marca } \\
\text { una identidad }\end{array}$ \\
\hline Créditos & $\begin{array}{l}\text { Conserva el formato de los } \\
\text { créditos }\end{array}$ & $\begin{array}{l}\text { El formato de los créditos } \\
\text { marca una identidad al } \\
\text { programa }\end{array}$ \\
\hline \multicolumn{3}{|l|}{$\begin{array}{l}\text { Relato de la } \\
\text { presentación y la nota }\end{array}$} \\
\hline Texto presentación & $\begin{array}{l}\text { Dos talentos del colegio, } \\
\text { perseverancia. }\end{array}$ & $\begin{array}{l}\text { El texto fue concreto e } \\
\text { indicó sobre qué trataba la } \\
\text { nota. }\end{array}$ \\
\hline Relato de la nota & $\begin{array}{l}\text { Es una entrevista a los dos } \\
\text { invitados. }\end{array}$ & $\begin{array}{l}\text { La entrevista facilitó } \\
\text { conocer los aprendizajes y } \\
\text { enseñanzas que } \\
\text { compartieron los invitados. }\end{array}$ \\
\hline Personajes del informe & $\begin{array}{l}\text { La egresada y el estudiante, } \\
\text { porque se destacan como } \\
\text { músicos. }\end{array}$ & $\begin{array}{l}\text { El sentido de estos espacios } \\
\text { es hacer ver a sus } \\
\text { protagonistas, en este caso } \\
\text { egresados y estudiantes. }\end{array}$ \\
\hline \multicolumn{3}{|l|}{ 3. Espacios } \\
\hline $\begin{array}{l}\text { Escenarios (set, } \\
\text { instalaciones, fuera del } \\
\text { colegio) }\end{array}$ & $\begin{array}{l}\text { Un aula de música, con diversos } \\
\text { instrumentos: guitarras, bajos, } \\
\text { baterías, entre otros. }\end{array}$ & $\begin{array}{l}\text { El salón donde se } \\
\text { desarrolló la entrevista } \\
\text { ambientó perfectamente la } \\
\text { misma, le dio más sentido. }\end{array}$ \\
\hline \multicolumn{3}{|l|}{ 4.Tipos de informes } \\
\hline $\begin{array}{l}\text { Informativo } \\
\text { Entretenimiento } \\
\text { Opinión } \\
\text { Otro }\end{array}$ & $\begin{array}{l}\text { Cultural. Muestra la fortaleza } \\
\text { que tiene la institución en la } \\
\text { formación de sus estudiantes en } \\
\text { el área de música }\end{array}$ & $\begin{array}{l}\text { Fue una nota fresca y } \\
\text { formativa, porque desde las } \\
\text { experiencias de los jóvenes } \\
\text { invitados se percibe el } \\
\text { crecimiento personal que } \\
\text { ellos han tenido desde la } \\
\text { música. }\end{array}$ \\
\hline
\end{tabular}




\subsubsection{Análisis productos audiovisuales. Colegio Público}

\section{Entrevista1}

Medio: P. con...

Fecha: Segundo semestre de 2012

Número: No tiene secuencia

Disponible en:

https://www.youtube.com/watch?v=ZM2gOpcXNrI\&list=UUM75pAm2dprmHdBIIyjgUyQ\&index=1\&feature=plc $\mathrm{p}$

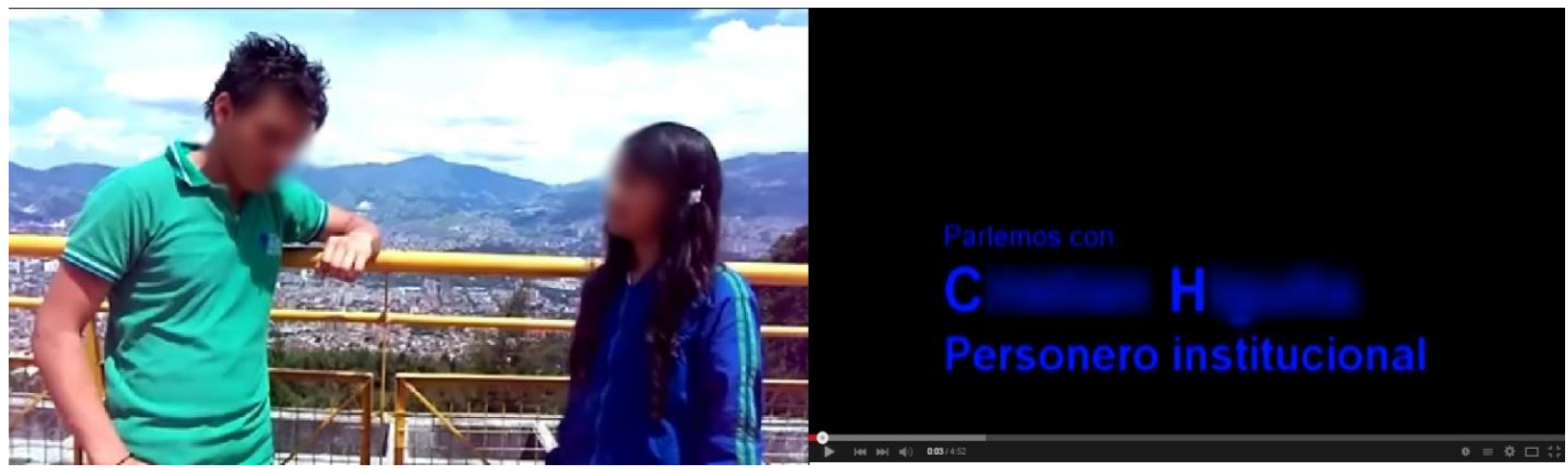

\begin{tabular}{|c|c|c|}
\hline Categorías & Análisis & Comentarios \\
\hline \multicolumn{3}{|c|}{ 1.Estructura de la nota } \\
\hline Tema & Personero estudiantil & $\begin{array}{l}\text { Personaje reconocido en la } \\
\text { institución }\end{array}$ \\
\hline Duración & $4: 52$ & \\
\hline Presentación & $\begin{array}{l}\text { Aparece el nombre del programa } \\
\text { "P. con...", el personaje que van } \\
\text { a entrevistar y el nombre de la } \\
\text { presentadora (una estudiante). } \\
\text { Tiempo: } 10 \text { seg. }\end{array}$ & \\
\hline Contenido & $\begin{array}{l}\text { Preguntas acerca de los } \\
\text { obstáculos para llegar a la } \\
\text { Personería, la confianza para } \\
\text { llegar a ser personero, los } \\
\text { cambios en la vida escolar; } \\
\text { cómo le sirve la experiencia } \\
\text { desde lo personal, las } \\
\text { expectativas frente al proyecto y } \\
\text { por último el mensaje a los } \\
\text { estudiantes. }\end{array}$ & $\begin{array}{l}\text { La presentadora no lleva un } \\
\text { papel donde tenga las } \\
\text { preguntas apuntadas; deja } \\
\text { que el entrevistado hable y } \\
\text { entra con sus preguntas. } \\
\text { Es un acercamiento a la } \\
\text { personalidad del } \\
\text { entrevistado y un ejercicio } \\
\text { de entrevista para la } \\
\text { presentadora. No se ven } \\
\text { cortes. }\end{array}$ \\
\hline Cierre & $\begin{array}{l}\text { Después de un negro, la cámara } \\
\text { entra en otro ángulo y muestra } \\
\text { de nuevo al entrevistado y la } \\
\text { presentadora, quien manifiesta }\end{array}$ & $\begin{array}{l}\text { El mensaje del personaje es } \\
\text { a confiar en él y en su } \\
\text { labor, hace un llamado a } \\
\text { sus compañeros, maestros y }\end{array}$ \\
\hline
\end{tabular}




\begin{tabular}{|c|c|c|}
\hline & $\begin{array}{l}\text { su agradecimiento por la } \\
\text { entrevista. } \\
\text { Al final aparece una frase que } \\
\text { resume la nota, sobre un fondo } \\
\text { negro. }\end{array}$ & $\begin{array}{l}\text { directivas para que trabajen } \\
\text { juntos por la institución. } \\
\text { La frase final es un recurso } \\
\text { para condensar lo esencial } \\
\text { de la nota. }\end{array}$ \\
\hline Imágenes utilizadas & $\begin{array}{l}\text { Se ve al fondo la ciudad. } \\
\text { Utilizan imágenes de apoyo } \\
\text { como carteles de la campaña a la } \\
\text { Personería, estudiantes votando; } \\
\text { foto del personero disfrazado y } \\
\text { participando en obras de teatro; } \\
\text { fotos de estudiantes en una placa } \\
\text { polideportiva rodeada de un } \\
\text { bosque. }\end{array}$ & $\begin{array}{l}\text { Se evidencias problemas } \\
\text { técnicos y de edición, } \\
\text { porque se ponen fotos } \\
\text { (imágenes fijas) sobre la } \\
\text { nota, en algunos casos se ve } \\
\text { partida la imagen de fondo. } \\
\text { Utilizan las fotos para que } \\
\text { la nota no quede muy } \\
\text { plana, es un recurso técnico } \\
\text { conocido como "pintar la } \\
\text { nota". Ante los problemas } \\
\text { técnicos, este es un recurso } \\
\text { creativo, porque muestra } \\
\text { diferentes facetas del } \\
\text { personaje y la institución. }\end{array}$ \\
\hline Planos & $\begin{array}{l}\text { Inicia con un plano medio, luego } \\
\text { de la presentación van a un } \\
\text { negro y abren el plano para } \\
\text { empezar la entrevista. }\end{array}$ & $\begin{array}{l}\text { Los planos son fijos y } \\
\text { permanentes, en este } \\
\text { sentido la nota es estática. }\end{array}$ \\
\hline Movimiento de cámara & $\begin{array}{l}\text { La cámara permanece quieta, en } \\
\text { el plano indicado. } \\
\text { Con la última pregunta de la } \\
\text { presentadora, la cámara se va } \\
\text { hacia el entrevistado y se cierra } \\
\text { el plano en él. Es un pequeño } \\
\text { paneo. }\end{array}$ & $\begin{array}{l}\text { Solo al final hay un leve } \\
\text { movimiento de cámara, } \\
\text { tampoco hay exploración } \\
\text { en este sentido. Se aprecian } \\
\text { unos conocimientos básicos } \\
\text { en este sentido. }\end{array}$ \\
\hline Cortinas & $\begin{array}{l}\text { Tiene una cortina } \\
\text { "institucional" de la nota, sube } \\
\text { al principio y queda de fondo } \\
\text { mientras se hace la entrevista. } \\
\text { La cortina vuelve a subir para } \\
\text { presentar los créditos finales. }\end{array}$ & $\begin{array}{l}\text { La cortina es única y se } \\
\text { utiliza en toda la nota. }\end{array}$ \\
\hline \multicolumn{3}{|l|}{$\begin{array}{l}\text { 2. Participación } \\
\text { estudiantes y maestros }\end{array}$} \\
\hline \multicolumn{3}{|l|}{ Presentaciones } \\
\hline $\begin{array}{l}\text { Forma de presentar } \\
\text { (rápida, lenta, pausada) }\end{array}$ & $\begin{array}{l}\text { La estudiante hace las veces de } \\
\text { presentadora y entrevistadora. } \\
\text { Es pausada, tiene un tono de voz } \\
\text { bajo, por lo que en el momento } \\
\text { de preguntar a veces no se } \\
\text { comprende lo que dice. }\end{array}$ & $\begin{array}{l}\text { La chica no tiene un } \\
\text { manejo corporal, en este } \\
\text { sentido se podría hace un } \\
\text { trabajo, aprender a } \\
\text { relajarse. }\end{array}$ \\
\hline Vestuario & $\begin{array}{l}\text { La presentadora utiliza el } \\
\text { uniforme del colegio, al igual }\end{array}$ & $\begin{array}{l}\text { Se usa el uniforme del } \\
\text { colegio. }\end{array}$ \\
\hline
\end{tabular}




\begin{tabular}{|c|c|c|}
\hline & $\begin{array}{l}\text { que su entrevistado (Personero } \\
\text { del colegio) }\end{array}$ & \\
\hline Duración presentación & 10 segundos & \\
\hline Planos & Son los mismos del contenido & \\
\hline Créditos & $\begin{array}{l}\text { Al principio anuncian a quien } \\
\text { van a entrevistar y quien } \\
\text { presenta; a final aparecen los } \\
\text { créditos de producción. }\end{array}$ & $\begin{array}{l}\text { Se utilizan al principio y al } \\
\text { final de la nota, con fondo } \\
\text { negro. }\end{array}$ \\
\hline \multicolumn{3}{|l|}{$\begin{array}{l}\text { Relato de la } \\
\text { presentación y la nota }\end{array}$} \\
\hline Texto presentación & $\begin{array}{l}\text { Es corto, entra a decir quién es } \\
\text { el personaje y empieza con las } \\
\text { preguntas directas }\end{array}$ & $\begin{array}{l}\text { Es un esquema sencillo, un } \\
\text { texto breve y la pregunta } \\
\text { inicial }\end{array}$ \\
\hline Relato de la nota & $\begin{array}{l}\text { Utilizan la técnica de pregunta } \\
\text { respuesta }\end{array}$ & $\begin{array}{l}\text { Depende mucho del } \\
\text { personaje, en este caso, el } \\
\text { Personero es expresivo y le } \\
\text { da dinamismo a la nota }\end{array}$ \\
\hline Personajes del informe & E1 Personero y la presentadora & $\begin{array}{l}\text { En este caso son dos } \\
\text { estudiantes, el ejercicio } \\
\text { resulta ser interesante en la } \\
\text { medida que un estudiante } \\
\text { pregunta a otro estudiante }\end{array}$ \\
\hline \multicolumn{3}{|l|}{ 3. Espacios } \\
\hline $\begin{array}{l}\text { Escenarios (set, } \\
\text { instalaciones, fuera del } \\
\text { colegio) }\end{array}$ & $\begin{array}{l}\text { La entrevista se desarrolla en } \\
\text { una terraza de la institución, al } \\
\text { fondo se ve la ciudad. }\end{array}$ & $\begin{array}{l}\text { La presentadora no tiene } \\
\text { mucha expresión corporal, } \\
\text { está más pendiente de la } \\
\text { cámara que del } \\
\text { entrevistado. Este por su } \\
\text { lado si la tiene. }\end{array}$ \\
\hline \multicolumn{3}{|l|}{ 4.Tipos de informes } \\
\hline $\begin{array}{l}\text { Informativo } \\
\text { Entretenimiento } \\
\text { Opinión } \\
\text { Otro }\end{array}$ & $\begin{array}{l}\text { Perfil. Se muestra en pocos } \\
\text { minutos, una faceta del } \\
\text { personaje (Personero) }\end{array}$ & $\begin{array}{l}\text { El recurso de la pregunta } \\
\text { respuesta permite conocer } \\
\text { algunas facetas del } \\
\text { personaje (Personero). En } \\
\text { ese sentido, las preguntas } \\
\text { fueron planeadas. }\end{array}$ \\
\hline
\end{tabular}




\section{Entrevista 2}

Medio: P con...

Fecha: Segundo semestre de 2012

Número: No tiene secuencia

Disponible en:https://www.youtube.com/watch?v=hXDQ-oIBq-

$0 \&$ list $=$ UUM75pAm2dprmHdBIIyjgUyQ\&index $=11$
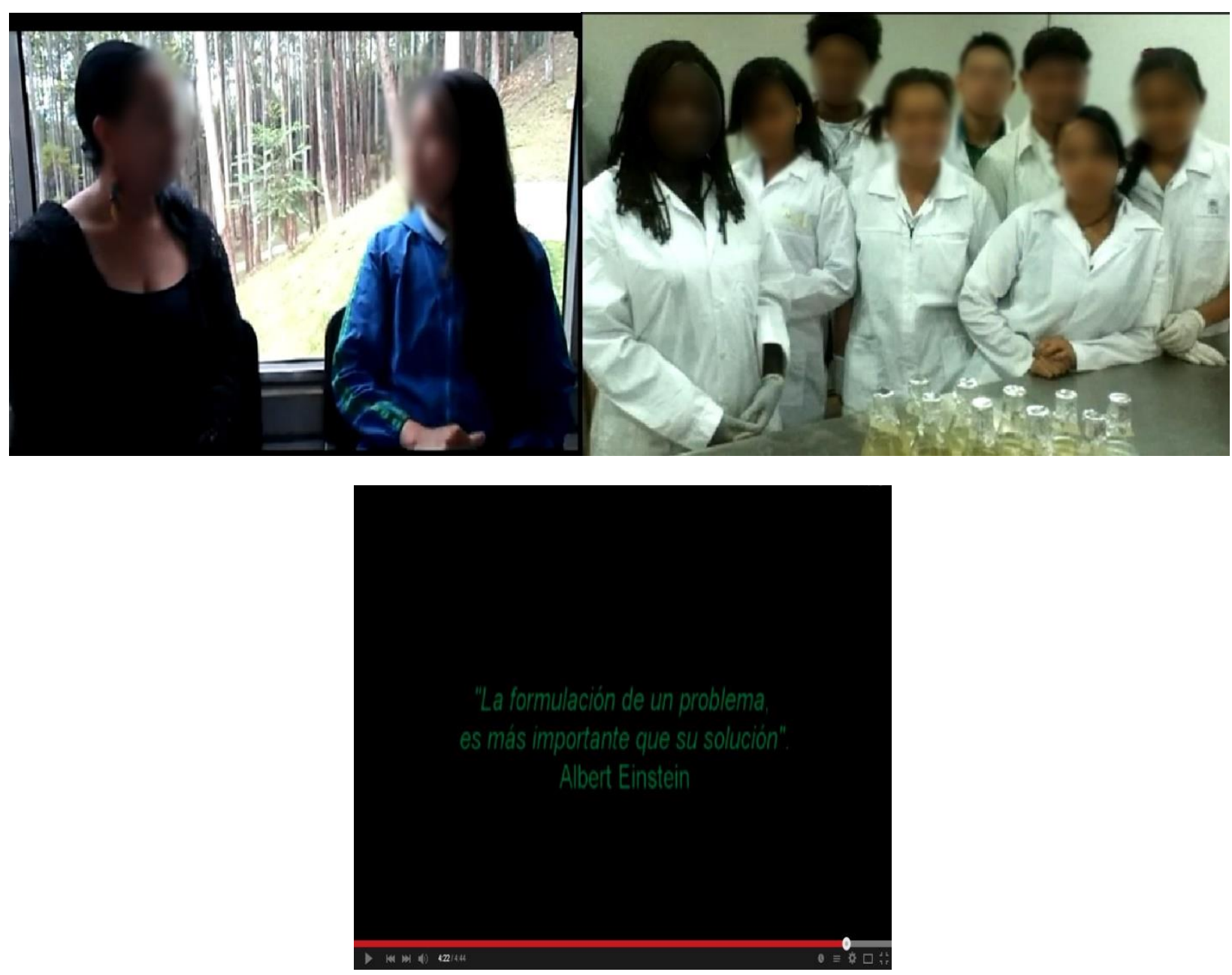

\begin{tabular}{|l|l|l|}
\hline Categorías & Análisis & Comentarios \\
\hline 1.Estructura de la nota & & \\
\hline Tema & Proyectos institucionales & Es una entrevista con la \\
& & Rectora del Colegio, en la \\
& & que una estudiante tiene la \\
& & posibilidad de entrevistar a \\
& & la máxima autoridad y la \\
& & entrevista puede ser \\
& & conocida por toda la \\
& & comunidad educativa. La \\
\hline
\end{tabular}




\begin{tabular}{|c|c|c|}
\hline & & $\begin{array}{l}\text { temática se enfocó en un } \\
\text { proyecto académico. }\end{array}$ \\
\hline Duración & $4: 44$ & \\
\hline Presentación & $\begin{array}{l}\text { Aparece el nombre del programa } \\
\text { "P con...", el personaje que van } \\
\text { a entrevistar y el nombre de la } \\
\text { presentadora (una estudiante). } \\
\text { Tiempo: } 10 \text { seg. } \\
\text { Luego aparece la presentadora } \\
\text { quien dice unas cortas palabras } \\
\text { de la invitada: la rectora }\end{array}$ & $\begin{array}{l}\text { Se repite el esquema de la } \\
\text { presentación de la anterior } \\
\text { nota. } \\
\text { Cambia de presentadora, es } \\
\text { otra estudiante. En este } \\
\text { caso logra una buena } \\
\text { expresión verbal, pero tiene } \\
\text { problemas con la expresión } \\
\text { corporal. }\end{array}$ \\
\hline Contenido & $\begin{array}{l}\text { Los proyectos institucionales, la } \\
\text { responsabilidad que tiene la } \\
\text { rectora frente a los mismos y los } \\
\text { procesos pedagógicos. La } \\
\text { entrevista se centra en primera } \\
\text { instancia en un asunto científico } \\
\text { y es la participación de los } \\
\text { estudiantes y profesores en estas } \\
\text { actividades. Indaga sobre los } \\
\text { proyectos de investigación, } \\
\text { quienes participan en él, por } \\
\text { quienes fueron convocados a } \\
\text { participar y por qué es } \\
\text { importante participar en este } \\
\text { proyecto. }\end{array}$ & $\begin{array}{l}\text { Es la misma presentadora } \\
\text { de la primera nota con el } \\
\text { Personero, en este caso, se } \\
\text { ve y se siente más } \\
\text { tranquila, con más dominio } \\
\text { en las preguntas, lleva bien } \\
\text { la entrevista. }\end{array}$ \\
\hline Cierre & $\begin{array}{l}\text { La presentadora invita a la } \\
\text { rectora a expresar sus ideas } \\
\text { frente al tema de la ciencia en la } \\
\text { institución educativa. Cierra la } \\
\text { nota con un agradecimiento por } \\
\text { el tiempo dedicado a la } \\
\text { entrevista. } \\
\text { El cierre definitivo se hace con } \\
\text { una frase alusiva a la } \\
\text { investigación de Einstein. }\end{array}$ & $\begin{array}{l}\text { El resumen al final es } \\
\text { muestra de la estructura } \\
\text { establecida (el texto) que } \\
\text { tiene este espacio de } \\
\text { microentrevistas. } \\
\text { El texto queda mucho } \\
\text { tiempo en la pantalla. }\end{array}$ \\
\hline Imágenes utilizadas & $\begin{array}{l}\text { Fotos de un experimento } \\
\text { científico, estudiantes } \\
\text { participantes en un laboratorio. }\end{array}$ & \\
\hline Planos & Medio & $\begin{array}{l}\text { Es el mismo plano que se } \\
\text { utiliza en los otros trabajos }\end{array}$ \\
\hline Movimiento de cámara & Está quieta & $\begin{array}{l}\text { Hay un leve temblor en las } \\
\text { imágenes. }\end{array}$ \\
\hline Cortinas & $\begin{array}{l}\text { Utiliza la misma cortina de las } \\
\text { notas anteriores. }\end{array}$ & $\begin{array}{l}\text { Es el mismo esquema: sube } \\
\text { al principio y queda de } \\
\text { fondo mientras se hace la } \\
\text { entrevista. }\end{array}$ \\
\hline
\end{tabular}




\begin{tabular}{|c|c|c|}
\hline & & $\begin{array}{l}\text { La cortina vuelve a subir } \\
\text { para presentar los créditos } \\
\text { finales. }\end{array}$ \\
\hline \multicolumn{3}{|l|}{$\begin{array}{l}\text { 2. Participación } \\
\text { estudiantes y maestros }\end{array}$} \\
\hline \multicolumn{3}{|l|}{ Presentaciones } \\
\hline $\begin{array}{l}\text { Forma de presentar } \\
\text { (rápida, lenta, pausada) }\end{array}$ & $\begin{array}{l}\text { En esta ocasión la estudiante } \\
\text { supo llevar la entrevista, se } \\
\text { mostró serena y tranquila }\end{array}$ & $\begin{array}{l}\text { Prestó mucha atención a la } \\
\text { rectora, más que a la } \\
\text { cámara. }\end{array}$ \\
\hline Vestuario & $\begin{array}{l}\text { Uniforme del colegio en la } \\
\text { presentadora y vestido formal de } \\
\text { la rectora de color negro. }\end{array}$ & $\begin{array}{l}\text { El uso del uniforme genera } \\
\text { la sensación de reforzar la } \\
\text { identidad institucional }\end{array}$ \\
\hline Duración presentación & 10 segundos & \\
\hline Planos & Medio. & $\begin{array}{l}\text { Es el mismo plano utilizado } \\
\text { a lo largo de la nota. }\end{array}$ \\
\hline Créditos & $\begin{array}{l}\text { Es el mismo esquema de la nota } \\
\text { anterior, solo cambia el nombre } \\
\text { de la presentadora }\end{array}$ & $\begin{array}{l}\text { Es algo preestablecido, no } \\
\text { hay necesidad de hacer } \\
\text { cambios en ese sentido, } \\
\text { aunque si debe mejorar la } \\
\text { ortografía. }\end{array}$ \\
\hline \multicolumn{3}{|l|}{$\begin{array}{l}\text { Relato de la } \\
\text { presentación y la nota }\end{array}$} \\
\hline Texto presentación & $\begin{array}{l}\text { Es una presentación básica: un } \\
\text { saludo y decir quién es la } \\
\text { invitada y qué hace }\end{array}$ & $\begin{array}{l}\text { En este caso enfatizó en el } \\
\text { proyecto de investigación. }\end{array}$ \\
\hline Relato de la nota & Son preguntas respuestas & $\begin{array}{l}\text { Conserva el formato de } \\
\text { entrevista. En este caso era } \\
\text { importante ver y escuchar } \\
\text { la voz de la rectora, porque } \\
\text { el tema se centró en un } \\
\text { proyecto educativo, } \\
\text { específicamente en un } \\
\text { trabajo científico }\end{array}$ \\
\hline Personajes del informe & $\begin{array}{l}\text { Estudiante: presentadora. } \\
\text { Rectora de la institución }\end{array}$ & $\begin{array}{l}\text { La rectora valida una } \\
\text { información sobre la } \\
\text { investigación en la } \\
\text { institución y la relevancia } \\
\text { que tiene la misma en la } \\
\text { formación de los } \\
\text { estudiantes y maestros que } \\
\text { participan en el mismo. }\end{array}$ \\
\hline \multicolumn{3}{|l|}{ 3. Espacios } \\
\hline $\begin{array}{l}\text { Escenarios (set, } \\
\text { instalaciones, fuera del } \\
\text { colegio) }\end{array}$ & $\begin{array}{l}\text { Oficina de la rectora, se } \\
\text { aprovecha además la ventana } \\
\text { para lograr la luz natural y el } \\
\text { fondo de los árboles, que le dan } \\
\text { un aire especial a la nota }\end{array}$ & $\begin{array}{l}\text { En este caso se aprovechó } \\
\text { el espacio de la invitada: la } \\
\text { rectoría y, por ello se dio } \\
\text { mayor relevancia a la } \\
\text { entrevista }\end{array}$ \\
\hline 4.Tipos de informes & & \\
\hline
\end{tabular}




\begin{tabular}{|l|l|l|}
\hline $\begin{array}{l}\text { Informativo } \\
\text { Entretenimiento }\end{array}$ & Informativo & La entrevista estuvo bien \\
Opinión & conducida, la estudiante se \\
Otro & mostró serena y apropiada \\
& & de las preguntas; las \\
& & respuestas de la rectora \\
& aportaron un mayor \\
& & conocimiento acerca del \\
& trabajo que se hace en la \\
& institución con proyectos \\
& científicos. \\
\hline
\end{tabular}

Matriz 13. Análisis entrevista con rectora, elaborada por el autor

\section{La construcción del texto audiovisual}

\section{Colegio 1. Privado}

Según lo expuesto por la Comunicadora (Ver Fase de Producción de contenidos) el propósito del programa de televisión en el Colegiol es informar y dar cuenta de los diferentes acontecimientos y eventos que suceden al interior de la institución; la producción del mismo se hace bajo una lógica de registrar los principales acontecimientos sociales, culturales y deportivos sucedidos en el último mes. Los fragmentos analizados dan cuenta de una narrativa propia, una estructura para organizar la información que permita divulgar lo que sucede en el Colegio. Esta narrativa a su vez podría clasificarse en tradicional y no tradicional.

Tradicional. Tiene tres momentos: una presentación en la que aparecen los estudiantes que participan en la Extracurricular de los miércoles y los viernes. El interés de ellos es "presentar" (rol playing), por tanto, aparecer ante cámaras. Por eso, el formato ya está establecido: aparecen dos chicos, uno inicia la presentación con una frase corta y luego pasa la palabra a otro quien también expone la idea de manera corta. El tiempo de duración no pasa de 10 segundos. Luego viene un relato con una voz en off que da cuenta del tema que se presenta. Esto va acompañado 
de imágenes que registran el acontecimiento, donde aparecen estudiantes y en algunos casos padres de familia y maestros. Cuando se usa la voz en off no aparecen testimonios de los participantes involucrados en el informe. En este tipo de notas tradicionales no hay cierres, solo utilizan un elemento técnico (fundir a negro) para indicar que ya terminó.

No tradicional. Se usan en secciones como Vox pop en la que participan los estudiantes vinculados con la Extracurricular. Esta nota no tiene una presentación, entran a preguntar a los estudiantes sobre un tema específico y al final se hace un cierre, en el que enmarcan las respuestas con una estrategia educativa de proponer una cantidad de libros por leer. En este sentido, se da cuenta más de una propuesta académica desde el área de español, que de las reflexiones u opiniones de los estudiantes, quienes se limitaron a responder de manera puntual a dos preguntas planteadas por los "reporteros". Se enfoca más el interés desde la idea del maestro que del estudiante.

También, en el marco de la celebración de la emisión 100 aparecieron los egresados quienes en su momento participaron en el programa de televisión o se destacaron por sus cualidades musicales, por lo que fue algo diferente y llevó a estructurar los informes de otra manera. De igual manera, se destaca en la otra nota no tradicional con los estudiantes y egresados que tienen cualidades y capacidades para la música. Es así como en una especie de diálogo intercambian sus experiencias y de cómo el colegio posibilitó ese espacio formativo. Es otra manera de hacer ver las fortalezas institucionales y cómo los estudiantes pueden hacer parte de ellos, además de representar al colegio en concursos con otras instituciones educativas. 
Pero este espacio de televisión, también se presta para mostrar y hacer visible su enfoque tradicional de la educación, cuando un estudiante aparece frente a las cámaras leyendo el Manual de Convivencia. Es una nota que establece una ruptura con las otras, porque expone a un chico frente a toda la comunidad educativa leyendo unos apartes de la normatividad que rige al colegio. En este caso:

- No hay un texto visual: el estudiante está parado frente a una cámara y lee un texto; para ello utilizan un plano medio. La imagen es la misma durante los 42 segundos que dura la misma.

- Cambia el sentido del hecho: exponer a un estudiante frente a una cámara a leer una normatividad es hacerlo público; cuando se emite el programa la comunidad educativa ve al estudiante leyendo un Manual de convivencia y si el chico no hace parte de un equipo de trabajo (Extracurricular), ¿qué lectura se hace del acontecimiento?

- En este caso, la cámara no registra un hecho, la cámara no da cuenta de un evento o de resaltar la labor de alguien, la cámara sirve de instrumento para mostrar una sanción a la que es sometido el estudiante.

- Es una muestra de cómo la educación tradicional lleva y traslada lo privado (una sanción) a lo público a través de un instrumento (la cámara). Este tipo de prácticas pone en evidencia que bajo esquemas tradicionales de educación, la comunicación es un asunto instrumental y puede cumplir funciones sancionatorias.

Este tipo de prácticas contraría el valor formativo y educativo que pueda tener la comunicación, como posibilidad de reflexión y expresión de la voz de los estudiantes. 
Hacer ver los estudiantes. Aparte de lo anterior y en ese marco divulgativo que caracteriza a los medios de este colegio, vale la pena indicar que cuando aparecen los estudiantes como protagonistas de las notas y tienen la posibilidad de expresar sus ideas ante las cámaras, así sea en un marco tradicional de la educación, las notas adquieren otro sentido.

En general, los estudiantes aparecen en las notas emitidas. En las que sirvieron de muestra para el análisis salen a manera de registro en la mayoría de los casos, acompañadas de un relato en off y en ellas no publican sus testimonios o sus voces. Este esquema varía cuando en algunas de ellas los estudiantes hablan, se escucha lo que dicen y se conoce la manera de expresar las ideas. En estos casos se dice algo del colegio y de las posibilidades académicas que les ofrece. Así, los estudiantes expresan sus ideas sobre su colegio y de una educación que los "prepara para la vida". En este marco, los medios y de manera específica su programa de televisión estructuran sus textos audiovisuales con unos propósitos informativos, además para reforzar la filosofía de la institución: dar a conocer, resaltar y promover una idea de la educación basada en los valores.

Desde un punto de vista crítico, esta experiencia es exógena (Kaplún, 1998) centrada en los contenidos, en este caso, lo que sucede al interior del colegio y de ahí su carácter divulgativo. Cae en el reduccionismo y en la repetición (algunos de los temas del programa de televisión también se publican en el periódico, ver caso de la nota sobre el Día de la Antioqueñidad), porque los temas se repiten cada año. Los medios en esta perspectiva no tienen un contacto y una conexión con el contexto social que rodea a la institución educativa o las vivencias de los estudiantes, no posibilitan el ejercicio de la lectura de las realidades sociales y, por tanto, niega la 
oportunidad de formar a los estudiantes en la apropiación de la palabra, para expresar el propio mundo.

De ahí que los estudiantes tengan un rol de "emisores repetidores", es decir, que replican lo que el maestro escribe para que ellos digan frente a la cámara (caso de las presentaciones) o para que lean frente a la cámara un texto (caso analizado en la muestra). Es un rol además que no implica una reportería, esto es investigar sobre un tema para ser comunicado a toda la comunidad educativa. Por tanto, es un rol pasivo el que asumen los estudiantes en esta experiencia.

Esa perspectiva divulgativa impide que los medios en este colegio adquiera una dimensión comunicacional, es decir, que no sean solo trasmisores de datos, sino espacios en los que circulan otros relatos que contienen los conocimientos propios de los estudiantes, en definitiva en su experiencia de vida. Si los espacios de los medios de comunicación en los colegios posibilitan este tipo de expresiones, se tendrá la posibilidad de validar la voz de los estudiantes, esto es, generar el sentido comunicacional de los medios (Huergo, 2001).

\section{Colegio 2. Público}

En el caso del Colegio 2, después de varias exploraciones por diferentes medios y acorde a sus limitados recursos económicos y tecnológicos, llegaron a la experiencia de las microentrevistas. Los productos permiten leer varios aspectos concretos:

Estructura narrativa. Esta consiste en una entrada con el nombre del espacio: "P con...", luego el nombre del invitado y de la presentadora. Después de ello, se procede a la entrevista como tal, 
entre cinco y seis preguntas, una despedida por parte de la presentadora; luego se pasa a una frase que queda registrada por unos 20 segundos y termina con los créditos de producción. Esta estructura se da en los dos programas analizados, sin ninguna variante.

Protagonismo de los estudiantes. Ellos son quienes entrevistan a otros estudiantes, maestros o directivos. Los entrevistados, en el caso de los alumnos, tienen la posibilidad de hablar de sus vidas y de sus proyectos (Personería y huerta escolar), en este sentido se hacen públicas sus ideas y sus propuestas. Por su parte, los entrevistadores adquieren un reconocimiento ante la comunidad educativa, como los periodistas que preguntan a otros acerca de proyectos que se llevan a cabo en la institución.

Hablan de sí mismos y de sus proyectos. Los temas están relacionados con asuntos que pasan al interior de la institución y tienen una intencionalidad de hacerlos públicos para que toda la comunidad educativa tenga un mayor conocimiento de lo que pasa en la institución. Es así que el Personero habla de los compromisos adquiridos con los estudiantes y maestros; la rectora manifiesta su respaldo a un proyecto de investigación que puede servir para fomentar y fortalecer la formación científica de los estudiantes y maestros.

La producción de estas microentrevistas es más sencilla, busca dar a conocer o resaltar la labor que cumplen estudiantes, maestros e incluso directivas de la institución. Los estudiantes que participan en el Semillero tienen la responsabilidad de preparar las preguntas que harán a sus entrevistados, para ello deben hacer una pequeña investigación y antes de realizar la entrevista ante cámaras, comparten los cuestionarios con la maestra. De ahí que al momento de hacer la producción se muestren tranquilos y tratan de mostrarse tal como son. 
Así, los textos construidos en esta comunidad educativa dan cuenta de sus proyectos. El propósito de los mismos es dar a conocer, para que otros se enteren de lo que sucede en la institución y qué beneficios puede tener como la idea de la huerta escolar e incluso con temas como la apuesta por unos proyectos científicos; también es conocer el pensamiento y el compromiso de uno de los líderes estudiantiles, como lo fue en su momento el Personero. Según los trabajos analizados en estos aspectos se concreta el sentido de estas microentrevistas.

Para la maestra este tipo de experiencias debe servir para educar mejor a los estudiantes, sobre todo cuando viven en contextos sociales difíciles. Si bien los recursos técnicos con que cuentan son mínimos, en ella existe la idea que estos espacios facilitan la apropiación de la palabra, tanto para quién pregunta, como para quien responde, en la perspectiva que lo digan será conocido por otros cuando la entrevista se publique.

Para los estudiantes, someterse a un ejercicio de entrevista frente a una cámara, sin importar si esta es sofisticada o no, es tener la posibilidad de hablar sobre el propio mundo, en este caso, la escuela y lo que sucede en ella. Esta es la manera que ellos tienen de mostrar lo que sucede en su colegio. En este caso, no buscan replicar lo que la maestra quiere que digan, sino que ellos mismos tienen la responsabilidad (aunque no se tenga la disciplina para ello) de buscar la información que necesitan para preparar las preguntas que harán a sus entrevistados.

De acuerdo con la muestra analizada, en las entrevistas no existe un interés por buscar el dato o la reseña de un evento, sino de dar a conocer proyectos o personas que hacen parte de la institución. Por eso, en el esquema estructurado se trabaja con preguntas abiertas, para que los entrevistados tengan la posibilidad de contar y relatar sus ideas de manera amplia. 
De esta manera, se hace visible la idea que tiene la maestra acerca de la comunicación como la posibilidad de conectar a las personas entre sí, en este caso, entre los directivos, maestros y estudiantes. El propósito es despertar el interés de estudiantes y maestros por este tipo de trabajo y genere entre ellos interés por el tema. Sin embargo, el colegio no había asumido la comunicación como un elemento fundamental para la formación de sus estudiantes, sino que era una actividad en manos de una maestra y, por ello, se reducía la misma al interés y entusiasmo de ella.

\section{Aspectos comunes}

Son varios aspectos en los que estas experiencias coinciden. Veamos cuáles.

Intramuros: se habla de actividades que suceden al interior de las instituciones educativas, ya sea cultural, deportiva, académica o religiosa. En el privado tiene un carácter más informativo, en el oficial de dar cuenta de proyectos. En este sentido ambas experiencias hablan de sí mismos, las notas no hacen referencia explícita a temáticas o situaciones que se vivan afuera de los colegios y que de alguna manera incidan en ellos.

Escenarios: las locaciones de las instituciones educativas son las que sirven de escenario para la presentación o producción de las notas. Así, salones, corredores, patios y zonas verdes son los escenarios utilizados para la producción de las notas.

Los planos y el movimiento de la cámara: prevalece el plano medio y la cámara estática, propios para la reseña, para mostrar, para registrar, pero no para relatar, para contar una historia. 
Propósito informativo: el trabajo se basa en dar a conocer, si bien en el primero tiene una intención más divulgativa de los eventos, más institucional que el segundo, ambos buscan que la comunidad educativa esté enterada de lo que sucede en su colegio.

Según estos aspectos reseñados, la experiencia de los medios de comunicación en estas instituciones educativas puede ser más significativa si:

Traspasa los muros. Buscar la conexión con el contexto social en donde está inscrita la institución educativa. En este sentido los estudiantes van a sus barrios, a interpretar lo que sucede en ellos y luego relatarlos en los medios de comunicación. Es una manera de establecer comunicación con la realidad circundante y de ser posible mostrarla a la misma, como una resultado de la lectura social que hace la institución educativa de las comunidades locales.

Explorar otras maneras de narrar. La comunicación ofrece diversas posibilidades de relatar la realidad. Si la experiencia se concentra dentro de los muros, bajo una perspectiva divulgativa e institucional, tiene el riesgo de quedarse en la reseña divulgativa. De ahí que sea necesario tener otros retos, otros asuntos que contar que impliquen compromiso y creatividad para relatar, esto tiene que ver con la exploración y apropiación de los lenguajes audiovisuales para dar cuenta de otros temas.

Trascender el esquema informativo. La escuela no es un espacio solo donde se producen noticias, también tiene historias para contar y para ello deben explorar sus propias maneras de relatar y de contar, sobre todo, si toman la decisión de buscar otros temas por fuera de la institución. Así las entrevistas, las crónicas y las opiniones pueden ser formatos que aporten a la 
búsqueda de esas otras formas de narrar, con un propósito: facilitar la apropiación de la palabra, para contar el mundo. 


\subsection{Etapa 5. Fase de recepción. Recepción de contenidos.}

Este aparte da cuenta de los resultados de las encuestas aplicadas a estudiantes y maestros de las dos instituciones educativas como destinatarios de los contenidos publicados en los medios de comunicación. El objetivo planteado para esta etapa fue "comprender la importancia que le otorga la comunidad educativa (estudiantes, maestros, directivos y padres de familia) a los medios de comunicación escolar que se producen en las instituciones educativas, teniendo en cuenta la pertinencia y la relevancia de los informes que se publican en ellos". Por su parte, la pregunta planteada fue la siguiente: ¿Qué valoración de los contenidos publicados en los medios escolares hace la comunidad educativa y en qué medida influye en ello los enfoques aportados por los maestros, el modelo pedagógico de la institución y la idea comunicacional que prevalece en la institución educativa?

Las encuestas estaban dirigidas a estudiantes de $5^{\circ}, 6^{\circ}, 7^{\circ}, 8^{\circ}, 9^{\circ}, 10^{\circ}$ y $11^{\circ}$, porque si bien los medios de comunicación que se publican en estas instituciones educativas tratan de orientar sus contenidos a toda la comunidad educativa, la mayoría de ellos está dirigida a los alumnos que están entre los 10 y 17 años, debido a que tienen un mejor desarrollo de sus capacidades de lectura y escritura, además son más exigentes y críticos con los contenidos que reciben.

Esto obedece, a su etapa de adolescencia entendida como "el momento evolutivo de la búsqueda y de la consecución de la identidad del individuo" (Fierro, 1991 p.110). El autor señala que esta etapa lleva a que el adolescente agudice la conciencia de sí mismo, genere autoconceptos y desarrolle razonamientos morales, lo que se asocia a la apropiación de valores. Sostiene Fierro: 
“es pues, la edad que define la orientación duradera que, por lo general, el adulto mantendrá respecto a metas, fines y proyectos social o personalmente valiosos" (1991, p.129).

Al final la encuesta se aplicó a: 195 en el privado (la muestra establecida fue de 264) y 188 en el público (la muestra establecida fue de 220). Hubo varias dificultades para no cubrir la totalidad de la muestra:

- En el colegio privado se aplicaron dos encuestas al mismo tiempo: una del colegio y otra del investigador. Esto confundió a los estudiantes y la jornada se extendió más de lo previsto, por lo que no se pudo cubrir a los grupos programados, por ello se dejaron de lado varios de ellos.

- El tiempo destinado para la actividad se prolongó y el grupo de estudiantes de $10^{\circ}$ no aplicó la encuesta, porque finalizaron las clases y se fueron para la casa.

- La comunicadora se comprometió a aplicar la encuesta con los estudiantes que faltaron, pero se enfermó y luego cuando retornó ya los alumnos habían salido a vacaciones.

- En el colegio público las dificultades fueron del orden cultural (poca capacidad lectora de los estudiantes, sobre todo del grado $5^{\circ}$ ).

- Con la profesora responsable del medio de comunicación se acordó aplicar la encuesta una fecha, sin embargo, ella no informó que el día acordado para aplicar la encuesta era el último de clases. Además se anticipó la salida y el día acordado solo estaban los estudiantes de refuerzo. Como en el otro colegio, a los estudiantes de $10^{\circ}$ no se les pudo aplicar la encuesta, porque ya no se encontraban en el colegio.

Por su parte, la encuesta con los maestros también tuvo sus dificultades. En primera instancia, algunos de ellos no colaboraron, porque expresaron que con frecuencia eran sometidos a 
diferentes cuestionarios; en segundo lugar, porque estaban al final del periodo académico y ello hacía difícil sacar un tiempo para responder el cuestionario.

Dado que el grupo de maestros no era tan numeroso se decidió que la muestra para el colegio privado serían los 37 docentes de básica secundaria y media académica; por su parte, la muestra en el colegio público fue de 32 , correspondiente a los profesores asignados para los cursos de $5^{\circ}$ hasta $11^{\circ}$, para un total de la muestra de 69. Entre ambas instituciones, el cuestionario fue respondido por 29 profesores en total.

Hay que considerar que el enfoque analítico del estudio se basa en lo cualitativo, en el que se concentró el análisis de este trabajo, la encuesta sirvió para elaborar una lectura descriptiva de las percepciones que tenían algunos estudiantes y maestros sobre los contenidos y en general de los medios de comunicación de sus colegios. Para el análisis solo se considerarán las preguntas relacionadas con la pertinencia del medio escolar, porque son las que dan cuenta, de manera concreta, el objetivo de esta actividad.

\section{Respuestas de los estudiantes (Anexo 12)}

Sobre la pregunta: ¿Considera que los informes publicados en el medio de comunicación escolar de su colegio le sirven a ud. para? (pregunta con posibilidad de responder varias opciones), los estudiantes de ambas instituciones contestaron así:

$295(44.2 \%)$ señalaron que sirven para informarse sobre lo que sucede en el colegio, lo cual ratifica los enfoques divulgativos de estos medios (eventos y actividades en general); 122 
$(18.3 \%)$ indicaron que para conocer a otras personas de la institución (estudiantes, maestros, empleados), otro aspecto en que enfatizan las publicaciones; y aparece en tercer lugar, con 80 respuestas (12\%) que sirven para "hacer tareas", otra de las estrategias que se utilizan para que los estudiantes consulten los contenidos (en el caso de los periódicos) o estén atentos a lo que ven en los programas de televisión. Otros aspectos como posibilitar "hablar de los temas publicados" (55 respuestas, 8.2\%) o “conocer la situación social del barrio donde está ubicado el colegio" (52 respuestas, $7.8 \%$ ) son bajas comparando con las primeras.

Sobre la pregunta: Como estudiante y receptor de los contenidos ¿se identifica ud. con los temas que se publican en los medios de comunicación escolar de su colegio? 213 respondieron que sí (62.1\%) y 118 que no (34.4\%). Los que respondieron que sí señalan que les permite "estar al tanto de lo que sucede en el colegio", conocer "los días especiales", "como tarea", "es información importante para nosotros", lo cual ratifica el carácter informativo y divulgativo que prevalece en estos medios. Por su parte, entre las razones por las que no se identifican con los temas están: "hay temas que no son interesantes", "los temas son monótonos ", "lo que comentan no tienen nada que ver con lo que se ve en clases", "los temas son ajenos a mi desarrollo personal y académico", "los temas no tienen nada que ver conmigo", "los temas son escogidos por los profesores y se vuelven aburridos e infantiles", "es más que todo comunicativo para los padres", "los contenidos se repiten y no hay necesidad de repetirlos", "terminamos distrayéndonos sin importar lo que están trasmitiendo", "hay poco contenido interesante para los estudiantes", "los temas prácticamente son los mismos". En estas respuestas también sale a relucir que los temas publicados no son acordes a los intereses de los estudiantes y algunos expresan que los mismos son escogidos por los "profesores” y que son más útiles para los padres de familia. 
En general, si bien se ratifica el carácter informativo de los medios, reconocido y valorado por los estudiantes, también es importante ver el alto porcentaje que no se identifica con los contenidos, ahí es necesario concentrar la atención: indagar sobre cuál o cuáles son los temas de "interés” y que convocan a los estudiantes, de manera que este tipo de proyectos tenga real incidencia entre los niños y jóvenes a quienes dirigen los contenidos. Además que sean los propios estudiantes quienes se empoderen de los medios, de manera que los maestros comprendan que los temas de ellos son más importantes que los propuestos por los profesores (adultos), en este tipo de experiencias. Es un cambio de perspectiva que debe ser considerada.

Sobre la pregunta: Ud. cree que los temas que se publican en los medios de comunicación escolar son propuestos por, (respuesta con múltiples opciones): 248 (32.8\%) respondió que el Rector de la institución y 215 (28.5\%) dijo que los maestros. Esto ratifica la idea que los contenidos de los medios de comunicación en las instituciones educativas son pensados, propuestos, dirigidos, controlados y producidos por los adultos, en este caso maestros. Sin embargo, otros 178 (23.6\%) reconoce que los temas son propuestos por los estudiantes, a pesar de ello, si suman los porcentajes del Rector y los maestros será muy superior frente al porcentaje de los estudiantes. Teniendo en cuenta esto, la incidencia de los estudiantes en los temas aún es baja y es un factor en el que se debe trabajar más, para darle esa identidad "escolar" a los medios de comunicación.

Sobre la pregunta: Ud. considera que los temas que se publican en los medios de comunicación escolar de su colegio están dirigidos principalmente a, las respuestas dan a entender lo siguiente: 273 (47\%) indicó que a los estudiantes. Quienes producen los medios en las instituciones educativas consultadas creen que los contenidos y temas están dirigidos a los estudiantes; sin 
embargo, también es importante considerar que 163 de ellos (28.1\%) señalaron que los temas estaban dirigidos a los padres de familia, o sea, que están pensados para los papás, así se enteran de los asuntos que suceden en la institución, como parte de ese enfoque divulgativo de estas experiencias; y de igual manera, otros 113 (19.4\%) señala que los temas están dirigidos a los maestros. Ahora, sumando tanto los padres de familia, como los maestros, los porcentajes igualan a los estudiantes, así los temas no están dirigidos a los estudiantes de manera exclusiva, porque el porcentaje de los adultos (maestros y padres de familia) es similar. En conjunto también se observa, con base en estos resultados, que los contenidos son propios del acontecer institucional y se dirigen a quienes están "dentro" de la institución, no "afuera", porque solo 22 (3.8\%) considera que los temas están destinados a los habitantes del barrio o del sector donde está ubicado el colegio. Esto muestra la "desconexión” que existe entre el colegio y el barrio o la falta de diálogo entre ambos, porque un medio de comunicación en un colegio también debe establecer lazos comunicativos con las comunidades locales y permitir que los temas de "afuera" sean conocidos al interior de las instituciones, para tener una mejor comprensión del contexto social donde está inscrita la institución educativa.

Sobre la pregunta: ¿Ud. está de acuerdo con que los contenidos de los medios escolares deben ser leídos o vistos de manera obligatoria? 226 (65.9\%) respondieron que No y 109 (31.8\%) dijeron que Sí. Esta es una de las estrategias utilizadas en las instituciones educativas para garantizar que los estudiantes tengan en cuenta los contenidos que se publican en los medios de comunicación de las instituciones educativas, dado que los estudiantes rechazan los contenidos que se publican. Sin embargo, es una estrategia inadecuada si se tienen en cuenta algunas de las respuestas anteriores, en el sentido que los estudiantes no se sienten identificados con los temas, 
porque no están relacionados con sus experiencias de vida y por el enfoque de adulto que prevalece.

Entre las razones que indican los estudiantes para que esto no sea obligatoria están: “a veces dicen que hay anotación si no lo hacemos" (castigo); "como no son interesantes hay que verlos obligatoriamente", "hay estudiantes que no están interesados en los temas que se presentan en los medios", "en este colegio lo que no es obligatorio nadie lo hace"; en general, quienes dicen que si deben ser obligatorio argumentan que para "estar informado" o "porque ayudan a entender cosas que no entendíamos", "porque a veces nos ponen talleres y nos dicen que tenemos que hacer", “es una herramienta de estudio". Basados en estas respuestas hay que indicar que un medio de comunicación en una institución educativa debe ser, ante todo, un punto de encuentro de las ideas, los temas y los contenidos de interés de los estudiantes.

Sobre la pregunta: ¿Ud. considera que desde los medios escolares se debe favorecerla divulgación de las ideas, reflexiones y opiniones propias que tengan estudiantes y maestros? 210 (81. 9\%) de las respuestas respondieron que sí, frente a 39 (15. 1\%) que no. Entre las razones que exponen figuran: "podemos conocer nuevas ideas", "ayudamos al desarrollo de cada quien", “ayuda a una mejor comprensión entre maestros y alumnos", "cada uno tiene libre expresión”, "facilitar la comunicación en el colegio", "ayudar a formar la personalidad de cada individuo", “necesitamos propuestas de los maestros para analizar y pensar", "para que los estudiantes compartan las ideas", "para que nos escuchemos mutuamente", "para reflexionar", "porque podríamos convivir con los profesores". Estas respuestas son el argumento en el que se pueden fundamentar quienes dirigen los medios de comunicación de las instituciones educativas, para 
que abran las páginas a las "ideas propias" de los estudiantes, no las que imponen desde sus visiones de "adultos".

\section{Respuestas de los profesores (Anexo 13)}

Sobre la pregunta: ¿Considera que los informes publicados en el medio de comunicación escolar de su colegio le sirven a ud. para? (Posibilidad de respuestas múltiples). 26 profesores (31,3\%) indicaron que para informarse sobre lo que sucede en el colegio; 20 maestros $(24,1 \%)$ respondieron que para conocer sobre otras personas: estudiantes, profesores, empleados; de igual manera, otros 20 docentes $(24,1 \%)$ señalaron que para conversar sobre los temas que se publican en ellos con otras personas y en un porcentaje menor, 9 correspondiente a $(10,8 \%)$ contestó que para programar tareas para los estudiantes, y solo $4(4,8 \%)$ consideró que el medio de comunicación del colegio sirve para conocer la situación social del barrio o del sector donde está ubicado el colegio. Estas respuestas indican: primero, el carácter interno y divulgativo de los medios en las instituciones educativas, centradas en dar a conocer lo qué sucede en el colegio o para saber más de otras personas. Segundo, como agenda de conversación, es decir, sirven para hablar entre los maestros sobre los temas publicados; tercero, aunque en un porcentaje menor (10.8\%) señala que los medios sirven para "programar tareas", es decir, asumen las dinámicas de la educación tradicional: los contenidos sirven para ser evaluados, en este caso, los informes que se publican en los medios. Además de lo anterior, y como un asunto pendiente de los medios en los colegios, los maestros en un porcentaje muy bajo 4 (4.8\%) indicaron que los informes publicados servían para conocer la situación social del barrio o del sector donde está ubicado el colegio. Desde este punto de vista, es importante convocar a la escuela en general y a los 
maestros y estudiantes para que conecten la realidad del contexto social con la institución educativa, los medios de comunicación de los colegios son una alternativa para ello.

Sobre la pregunta: Como maestro y receptor de los contenidos ¿se identifica ud. con los temas que se publican en los medios de comunicación escolar de su colegio? 27 de los maestros (93.1\%) responden que sí, 2 de ellos $(6.9 \%)$ dijeron que no. Entre las razones por las que justifican las respuestas están: “conocer el entorno social y la forma cómo participan en él como institución", "presentan noticias y personas destacadas de la institución”, "resaltar valores y que los estudiantes conozcan lo que se hace en la institución", "sirve para que se presente una buena comunicación en el colegio y toda su comunidad", "nos informan sobre aspectos de la comunidad, estudiantes, profesores, actualidades y novedades", "son de interés general, actuales y hay diversidad de temáticas", "ayuda al manejo racional de los estudiantes". Hay una identificación con los temas planteados desde las perspectivas de los adultos (maestros que planean los contenidos), además destacan algunos elementos propios de la información y el papel que cumple en las instituciones educativas: conocer, presentar, resaltar valores, interés general, diversidad temática y divulgación, como elementos articuladores de este tipo de proyectos.

Sobre la pregunta: Ud. cree que los temas que se publican en los medios de comunicación escolar son propuestos por: 28 de los profesores (30.4\%) cree que son los maestros; 26 , correspondientes al (28.3\%) dice que los estudiantes; 22 (23.9\%) considera que es el Rector. Si bien los estudiantes aparecen en un segundo lugar, la sumatoria entre los profesores y el Rector supera al anterior $(54.3 \%)$ muestra que un asunto central, como es la proposición de los temas, tenga una alta incidencia de los adultos y marcan de manera significa la forma cómo se enfocan y se producen 
los contenidos que se publican, de ahí que buena parte de estos textos tengan un carácter informativo-divulgativo. Esto concuerda con los análisis realizados en las entrevistas y los materiales (páginas y videos) que muestran el papel protagónico que tienen los maestros sobre los estudiantes, en la producción de estos medios y en los enfoques de los temas que se publican.

Sobre la pregunta: Ud. considera que los temas que se publican en los medios de comunicación escolar de su colegio están dirigidos principalmente a: 28 de los maestros $(96.6 \%)$ consideran que a los estudiantes y $17(58.6 \%)$ dice que a los maestros; por su parte, 20 (69\%) indica que a los padres de familia. En porcentajes más bajos cinco (5) correspondiente al $17.2 \%$ señala que a los habitantes del barrio. Frente a estos resultados, si bien en primera instancia los maestros creen que los temas están dirigidos a los estudiantes, los altos porcentajes de los maestros (58.6\%) y de los padres de familia (69\%) también muestran que los docentes reconocen que los temas están dirigidos al grupo de los adultos, se corrobora así que buena parte de los contenidos tienen un carácter institucional más que de escolar, entendido que son dirigidos a los estudiantes. Por su parte, el bajo porcentaje dado por los maestros a los temas orientados a los habitantes del barrio 17.2\% muestra que los medios de comunicación en las instituciones educativas dan más prioridad a los asuntos internos que a los acontecimientos propios de la vida cotidiana de las comunidades locales, donde está inscrita la institución educativa.

Sobre la pregunta: ¿Ud. está de acuerdo con que los contenidos de los medios escolares deben ser leídos o vistos de manera obligatoria por los estudiantes? 18 maestros (62.1\%) dicen que sí; $11(37.9 \%)$ respondieron que no. Entre las respuestas que indican que sí, están: “es una forma de estar actualizados con los eventos del colegio, porque conocen más a las personas del colegio, a 
los de oficios varios, a sus compañeros, a los docentes, al rector"; "porque de tal manera se garantiza que la información sea para todos, además es muestra de respeto al trabajo realizado"; otros indican que es una manera de favorecer la institucionalidad y el trabajo académico: "ayuda a la socialización de ejercicios escritos y garantiza que se dé mejor uso; para adquirir el hábito de la lectura"; "para generar conciencia y compromiso hacia la comunidad educativa"; y otra razón se fundamenta en que posibilita conocer sobre el contexto social: "porque a través de ellos conocen más de su entorno, adquieren valores, porque se hace para ellos y contienen mucho saber, se reflexiona a partir de ellos". En cuanto a quienes indican que no debe ser obligatoria argumentan: "la democracia nos hace libres"; "la imposición no fomenta el amor a la lectura, porque no se debe obligar a estas cosas, la información o contenido debe ser del agrado para que ellos lo vean cuando deseen". Prevalece la idea que el medio de comunicación cumple una función similar al texto escolar y aunque los contenidos sean diferentes la estrategia para ser conocida es "obligar" a los estudiantes a leer e incluso evaluar sus contenidos. Queda el reto, como lo indican algunos profesores, de producir contenidos que sean de interés de los estudiantes, más relacionados con la experiencia de vida, las reflexiones a partir de las vivencias de los estudiantes y con otras narrativas que generen procesos de reflexión y diálogo entre los integrantes de la comunidad educativa en general.

Sobre la pregunta: ¿Ud. considera que desde los medios de comunicación escolar se debe favorecer la divulgación de las ideas, reflexiones y opiniones propias de estudiantes y maestros? Los maestros consultados indicaron que si 27 (93.1\%). Algunas de las respuestas que apoyan esta respuesta están orientadas a favorecer la libertad de expresión: "hacer manejo respetuoso de la libertad de expresión”; “es un medio de expresión, siempre y cuando se haga con prudencia y 
pertinente"; "la libre expresión es un derecho y quien quiera hacerlo a través de este medio que lo haga sin temor"; "permite leer puntos de vista diferentes, hace que las personas puedan hacer públicos sus gustos, sus sueños, sus conocimientos, sus quejas y reclamos". Otros condicionan la libertad de expresión a la institucionalidad: "por la razón de que se denominan medios de comunicación se debe expresar todo, siempre y cuando sea apropiado y no esté en contra de los valores institucionales" y otro señala la importancia de tener en cuenta la diversidad de opiniones: "se habla de una comunidad educativa, donde es importantísimo conocer los diferentes puntos de vista y hacia donde apunta".

Estas respuestas dan pie para señalar que los medios de comunicación producidos en las instituciones educativas centran su quehacer en lo informativo-divulgativo, los contenidos son direccionados por los adultos (directivos y maestros); la participación de los estudiantes aún es limitada, falta más empoderamiento de parte de ellos para apropiarse de los medios. Estos deben servir como espacios de formación para que los estudiantes aprendan a expresar sus ideas con fundamentos, con responsabilidad y creatividad. En este sentido, la escuela tiene una oportunidad para formar ciudadanos desde la apropiación de la palabra para hablar del mundo que viven y comprometerse a transformarlo de acuerdo con sus posibilidades. Favorecer la palabra y la expresión de las ideas es también la posibilidad de empezar a participar en la sociedad, si se tiene en cuenta que la escuela es una esfera pública, donde los estudiantes aprendan y comprendan los valores de la diversidad y el respeto por la misma.

\section{Coincidencias}

De acuerdo con los resultados arrojados por estudiantes y maestros se puede apreciar lo siguiente: 
- El mayor porcentaje de los estudiantes (44.2\%) y los maestros (31. 3\%) señalaron que los informes que se publican en los medios de comunicación del colegio sirven básicamente para informarse acerca de lo que sucede en el colegio; en segunda instancia, los estudiantes (18.1\%) indicaron que para conocer o saber algo sobre las personas del colegio y lo maestros (24.1\%). Esto ratifica el carácter informativo-divulgativo en el que se enfocan los contenidos de los medios producidos en las instituciones educativas.

- De igual manera, en un mayor porcentaje los estudiantes con un $62.1 \%$ y los maestros con un $93.1 \%$ indicaron que se sienten identificados con los temas que se publican en este tipo de medios; sin embargo, se debe prestar atención al 34.4\% de los estudiantes que señalaron no estar identificados con los temas, esto es una respuesta a las decisiones sobre los temas y los enfoques en los que prevalece la visión de los maestros.

- Sobre quien propone los temas que se publica en los medios de los colegios, predomina la idea que los mismos salen de los maestros y los rectores. Así lo cree el 32.8\% de los estudiantes quienes indican que es el Rector del colegio y en un $28.5 \%$ que son los maestros; por su parte, los maestros señalan que son ellos mismos en un $30.4 \%$ los que proponen los temas y el Rector con un 23.9\%. Si bien los estudiantes también son reconocidos como quienes los que aportan los temas en un 23.6\% según los mismos estudiantes y en un $28.3 \%$ según los maestros, los resultados indican que los temas están pensados en una perspectiva de adultos.

- En cuanto a quien están dirigidos los temas que se publican en los medios de comunicación escolar los estudiantes señalaron que en un $47 \%$ a ellos y los maestros, en un $96 \%$, indicaron también que para los estudiantes. Por su parte, mientras el $19.4 \%$ de los estudiantes responde que los temas se dirigen a los maestros, el 58.6\% de los docentes dice que para ellos; de igual manera, $28.1 \%$ de los estudiantes dice que los temas se dirigen a los padres de familia al igual que el 69\% de los maestros. Se muestra así que tanto estudiantes como maestros reconocen que buena parte de los temas se dirigen a los adultos. Y una coincidencia final está en que el 3.8\% de los estudiantes y el 17.2\% de los 
maestros creen que los temas se dirigen a los habitantes del barrio donde está la institución educativa, fue la más baja de todas. De esta manera se muestra que los temas son más de corte institucional (adentro) que relacionados con el entorno social (afuera).

- Una de las estrategias en los colegios es obligar a los estudiantes a leer o ver los medios de comunicación producidos en ellos, la consulta sobre si los medios deben ser o no visto bajo esa perspectiva indicó lo siguiente: el $65.9 \%$ de los estudiantes y el $62.1 \%$ de los maestros considera que sí; por su parte, el 31.8\% de los estudiantes y el $37.9 \%$ de los maestros considera que no. Es así que la obligatoriedad es el resultado de las características impositivas de los contenidos propio de la educación tradicional y de una comunicación vertical (de arriba hacia abajo). Son asuntos que tienen como propósito inculcar datos y contenidos, pero no generar procesos de reflexión, diálogo o problematización de los temas.

- En contraposición a lo anterior y en perspectiva del deber ser, a la pregunta si estos medios deben promover la divulgación de las ideas, reflexiones y opiniones propias que tengan estudiantes y maestros, el $81.9 \%$ de los estudiantes y el $93.1 \%$ de los maestros están de acuerdo con esta propuesta. Los proyectos de medios de comunicación social producidos en las instituciones educativas deben servir de espacios para promulgar el derecho a la libertad de comunicación, en los que sea posible la expresión de las propias ideas de los estudiantes y de los maestros, producto de sus propias reflexiones, de las lecturas que hagan del contexto social y del mismo colegio, en una perspectiva de formar a los estudiantes en la participación y en la ciudadanía activa, con el fin de promover en ellos el compromiso de transformar la sociedad en la que viven. 


\section{Etapa 6. Reflexiones y conclusiones analíticas a las que llega este estudio.}

A manera de cierre se presentan a continuación las conclusiones derivadas del análisis de las siguientes fases: producción de contenidos, conceptos, productos y recepción. De igual manera se planteará al final un cierre que propicie otros campos y reflexiones en torno a este tema.

\subsection{Fase Producción de contenidos}

El objetivo planteado para el mismo fue el siguiente: Indagar cómo y desde quiénes la escuela construye los procesos de producción de los medios de comunicación, que hacen circular informaciones y contenidos a estudiantes, maestros, directivos, padres de familia y comunidad aledaña a la IE.

Las conclusiones producto de este objetivo son las siguientes:

\section{Una fuerte tendencia de la mirada de los adultos y la educación tradicional en los contenidos}

Una vez realizado el análisis de la información recopilada en este capítulo, basada en las observaciones, las entrevistas y los grupos focales se concluye que esto sucede por las siguientes razones:

- El proceso de producción de los contenidos (Discursos) está centrado en los adultos, sobre todo en los maestros, entendido esto, como la fase donde se deciden los temas, investigan lo que se publicará, se escriben los textos, se obtienen las imágenes y se diseña los 
periódicos o montan los programas de televisión. Es así como son los maestros y otros profesionales (comunicadores) quienes deciden los temas, orientan los contenidos, autorizan lo que se publicará y llegan incluso a escribir los textos o los informes. Esa mirada del adulto privilegia lo institucional, de ahí que los contenidos estén enfocados en los eventos o asuntos que suceden al interior de los colegios, en los fundamentos filosóficos de los colegios. Por tanto, los relatos tienden a ser pesados y esquemáticos en el lenguaje y poco interesante para los estudiantes, quienes no ven reflejados en ellos los temas y contenidos que pueden ser de su interés. En términos de Hull (1996) no existe una "simetría” entre quien produce los códigos (adultos) y quién los decodifican (estudiantes), como tampoco hay una identidad con los códigos (lenguaje, temas) que se trasmiten. Hull plantea que las "distorsiones" o "malentendidos" surgen por la falta de equivalencia entre los actores del acto comunicativo, en este caso maestros y estudiantes.

- Resulta particular que estas experiencias estén más centradas en los adultos (maestros y profesionales de la comunicación) que en los estudiantes. Mientras los primeros tienen un papel activo: proponen y enfocan temas, escriben textos, graban las notas periodísticas, editan y delegan funciones; los segundos tienen un papel más pasivo: esperan las órdenes de los adultos, acatan sus indicaciones, escriben lo que los adultos les indican, por eso, asumen la figura de "emisores/repetidores" expuesta en el aparte del Discurso. Esto difiere a la propuesta de Freinet (1977) basada en la espontaneidad y en la libertad de escribir lo que el estudiante quieren expresar, con el pensamiento puesto en sus compañeros, en las personas de su comunidad o de su entorno social (p.20), en este sentido, los contenidos deben ser los resultados de la cultura experiencial de los estudiantes (Pérez, 1998). Lo que se podría denominar el método Freinet, no está centrado en el adulto, sino en "los verdaderos intereses de los niños" (p.40).Y esto es algo que no se evidencia en las experiencias de producción de los medios en los colegios. Por eso, un primer paso que se propone a las instituciones educativas que tienen este tipo de experiencias es dar un vuelco y permitir que los estudiantes sean quienes se empoderen de los medios de comunicación de sus colegios, para que estos se conviertan en escenarios 
formativos en la expresión libre de sus ideas, en la discusión acerca de los temas que a ellos los convocan, en la producción de contenidos con sentido.

- Además de lo anterior, otro aspecto es el marco educativo tradicional en el que se desarrollan estas experiencias de producción de medios de comunicación. Características propias de este modelo educativo son la figura del maestro quien es el que sabe y que trasmite algo al estudiante quien debe aprender de memoria los contenidos seleccionados por el docente; esto se evidenció en estas experiencias al ver que los estudiantes se aprendían de memoria dos líneas que un profesional de la comunicación les entregaba, para que luego las repitiera ante una cámara o escribir ensayos con temas propuestos por los maestros, con el propósito de obtener una buena calificación y ser premiado con la publicación de su texto en el periódico. Estas manifestaciones son las que Kaplún (1998) incluye en su modelo educativo que llama exógeno basado en los contenidos (p.18). Es el mismo modelo que Freire (1985, p. 72) calificó como educación bancaria y es bajo ellos que se orientan, en gran medida, la producción de los medios de comunicación de las instituciones educativas estudiadas.

- De ahí que, como sostiene Freire, para romper con esos esquemas establecidos en la producción de los medios en las instituciones educativas sea necesario que las mismas se abran a otras perspectivas pedagógicas, para potenciar este tipo de experiencias y lograr que tengan un mayor sentido para los estudiantes. La educación problematizadora es una de ellas (Freire, 1985, p. 88) entendida como un acto reflexivo permanente de la realidad que viven los alumnos; es una apuesta por la pregunta y la lectura del texto social que lo rodea, en esa medida se sale de los muros de la escuela y se conecta con la comunidad local donde está presente. Relatar esas realidades en un medio de comunicación es posibilitar que la escuela también conozca el contexto del que hace parte, entre en diálogo con el mismo y comprenda mejor el mundo de la vida de sus estudiantes. Y es la posibilidad, desde otras perspectivas educativas, de formar sujetos autónomos, críticos y creativos, para llegar a lo que Kaplún propone que más que formar "locutores" se potencien "interlocutores" (1998, p. 220) para contar "esas otras historias" que no están 
en los textos de estudio o en los temas institucionales promovidos por los adultos (maestros y profesionales). Así sea en contextos educativos tradicionales, valdría la pena tener en cuenta estas perspectivas, para que la experiencia de producción de medios de comunicación trascienda el dato, el registro de eventos y se conecte con la experiencia de vida de los estudiantes y con las realidades de las comunidades locales que rodean a la escuela.

\section{El medio como instrumento o como espacio para circulación de saberes}

Analizar la producción de contenidos está atravesado por la idea que tienen maestros y estudiantes -sobre todo los primeros- acerca de los medios de comunicación. La reflexión por los medios y por la comunicación es poca, porque se privilegia el "hacer", la producción. En esa medida, se considera que estos tienen valor, porque sirven de complemento a la actividad docente y a los contenidos académicos que se ofrecen en las aulas de clase. No existe una lectura crítica a los mismos y falta apropiación de su gramática y sus lenguajes, por tanto, es un aprender intuitivo basado en los modelos impuestos por los medios masivos a los que tienen como referencia, de manera especial para producir periódicos y noticieros.

Dentro de estas experiencias es necesario establecer que el alcance en contenidos y en incidencia son las comunidades educativas constituida por estudiantes, maestros, directivos y padres de familia; y en casos más puntuales, los habitantes del barrio, líderes comunitarios y egresados. Desde este punto de vista, hay que considerarlos como Micromedios, porque llegan a comunidades con unas características particulares y por los contenidos que publican. Este punto debe ser considerado por las instituciones educativas, en la medida que si conocen su alcance, 
también pueden identificar cuáles son los temas, los relatos, los formatos o géneros, la circulación y el alcance de los contenidos que se publicarán y que sean más adecuados para sus destinatarios.

Ahora, el paradigma que sigue la escuela para producir contenidos que se publican en sus medios de comunicación es el informativo, cuya pretensión es divulgar la mayor cantidad de informes, datos y productos a una gran masa de la población. Igual sucede en la escuela cuando el interés está centrado en la trasmisión y divulgación de sus propios eventos. La dinámica es registrar el acontecimiento y luego publicarlos unas semanas o meses después o que los estudiantes escriban sus reflexiones bajo los parámetros evaluativos de los maestros. Por su parte, una práctica que prevalece con los destinatarios es obligar y evaluar los contenidos para garantizar su lectura y esto, en últimas, incide en la manera de recibirlos por parte de los estudiantes. El solo registro de los hechos, más su obligatoriedad y su evaluación no motiva a generar otros procesos de reflexión o de motivación por conocer más sobre un tema o establecer dinámicas de discusión y diálogo entre estudiantes, maestros, directivos, padres de familia y menos con los habitantes de las comunidades locales, quienes no se sienten incluidos en los mismos.

Así, la producción de medios (periódicos, programas de televisión, blogs) basados en la divulgación de eventos y como apoyo a la filosofía institucional, fundamentada en datos o en los intereses de maestros y directivos (adultos), llevan a que estas experiencias tengan un enfoque instrumentalista (Huergo y Fernández, 2000), centrado en el medio y en esa racionalidad instrumentalista existe un interés específico: el control y el dominio de los otros (p. 128), en este caso la comunidad educativa. Y en este sentido coincide con Rodríguez (2004) quien plantea que la entrada de los medios en la escuela está condicionada a una labor de esparcimiento o de 
transmisión de informaciones, por lo que se reduce a los medios a un asunto técnico para divulgar informaciones y, por ello, lo considera como una función meramente instrumental (p. 211). También concuerda con Valderrama (2007) al referirse que la incorporación de los medios en la escuela no sobrepasa el uso instrumental, ya sea para trasmitir de manera eficaz y eficiente cierta información y hacer más dinámicas las clases e incluso para acercar a los estudiantes a la realidad externa de la escuela (p. 81) cuando se trabaja con periódicos para acercarse a la información y los contenidos relacionados con el mundo político, social, económico, cultural, que en ellos se publican.

Esa mirada instrumental limita la función formadora de los medios, de manera especial en la reflexión y crítica a los estudiantes, por el contrario, su orientación está en los asuntos prácticos como recoger la información para luego divulgarla a la comunidad educativa o aprenderse un texto de memoria para repetirlo ante una cámara y para evaluar los contenidos publicados; todo lo anterior, fomenta el dogmatismo sobre la reflexión crítica, el individualismo y la competencia sobre la solidaridad y la construcción colectiva (Kaplún, 1998, p.24). Este tipo de prácticas comunicativas centradas en lo instrumental niega la posibilidad de preguntar y cuestionar lo qué pasa tanto en las instituciones educativas y en las experiencias de vida de los estudiantes. Por ello, el acercamiento al estudio de las realidades propias de los niños y jóvenes se hace desde las lógicas del medio (informar), perdiéndose la posibilidad de involucrarse en el estudio de esas realidades que viven los estudiantes (Rodríguez, 2004, p. 213), lo que daría otro sentido y dinámica de trabajo en este tipo de experiencias. 
Por eso, cuando se presentan experiencias en que los medios producidos en la escuela, van más allá de divulgar eventos o asuntos institucionales y buscan dar cuenta de lo que sucede en el barrio o en el entorno natural del estudiante, el medio como tal adquiere otro sentido, porque deja de ser un canal divulgador, para convertirse en un espacio de encuentro, aprendizaje y reflexión; como indica Rodríguez, es posibilitar que los estudiantes, como productores de contenidos, muestren su realidad social y escolar, para generar de esa manera relaciones de participación y conocimiento entre la escuela y el entorno social (p. 216). Es posibilitar que estos medios producidos en la escuela sean vistos como "medios de expresión del ser", tal como propone Valderrama (2007), es decir, que brinden la posibilidad de expresar cómo ven su propio mundo y, sobre todo, propiciar que los saberes de la escuela entren en diálogo con los saberes cotidianos (p. 190), como sucedía en la experiencia del Colegio 2 al permitir que los estudiantes relataran lo que se vivía en el barrio.

Es por esto que el medio de comunicación debe ser concebido y producido como un espacio que contiene la memoria colectiva de los estudiantes. Como lo plantea Kaplún, más que una sumatoria de individualidades que publican para ser reconocidos, un medio de comunicación en la escuela debe ser producto social (1998, p. 205) porque debe ser el resultado de una construcción colectiva de los estudiantes y maestros, que buscan compartir una información transformada en conocimiento a la comunidad educativa.

A partir de ello, esos medios en la escuela deben adquirir otra significación, cuando se atrevan a dejar esa idea instrumental y asumir que los mismos sean espacios de construcción colectiva, por donde circulan "otros" contenidos producidos por los estudiantes y maestros; así los medios en la 
escuela tienen un horizonte por lograr: en ellos deben aglutinarse nuevas significaciones sociales que trasciendan la institucionalidad, como plantea Kaplún (2010) que los medios sean "cajas de resonancia" que transforme a los estudiantes en comunicadores de sus aprendizajes y en esa medida, posibilite celebrar la "proyección social de su propia palabra" (p. 51). Este es el sentido por el cual los medios en la escuela, más que una herramienta, deben ser dispositivos que contienen otros conocimientos alternativos y que son compartidos con la comunidad educativa y con las personas del entorno socio/cultural en la que está inscrita la institución educativa, con el fin de favorecer procesos de discusión y diálogo entre las personas que accedan a este tipo de información contenida en los medios de la escuela.

Así, es necesario plantear esta reflexión a las instituciones educativas que tienen las experiencias de medios - Micromedios-, si lo conveniente es continuar bajo esa perspectiva instrumental, alejada de los intereses de los estudiantes y de las posibilidades de conocimiento y comprensión de sus propias realidades o permitirse revisar el sentido de los medios en la escuela, como los escenarios que sirvan para la expresión de las ideas de los estudiantes; el estudio, la crítica, la reflexión y la circulación de saberes propios de los estudiantes y maestros, en definitiva, el espacio que se construye desde los intereses y conocimientos de los alumnos.

\section{Pronunciar el propio mundo}

La experiencia de producir medios de comunicación en las instituciones educativas es algo más complejo y denso de lo que aparenta ser. En ellas se tejen intereses, tensiones, esfuerzos, frustraciones y deseos para que estos medios y sus contenidos tengan un valor y significado 
relevante en las comunidades educativas. Estas prácticas muestran aciertos y desaciertos que es necesario ver desde las teorías de la comunicación/educación.

En primera instancia debe ponerse a consideración la idea que comunicar es igual a trasmitir información o dar cuenta de los hechos institucionales que es la práctica habitual de los medios producidos en los colegios. La escuela, como espacio de socialización, debe comprender que la comunicación además de propiciar encuentros también genera tensiones, discusiones y promueve otras ideas, por tanto, es más densa, sobre todo cuando da cabida a los conocimientos, saberes y vivencias que llevan consigo los estudiantes de sus entornos sociales y familiares a la institución educativa y que pueden ser relatados a manera de historias en crónicas, reportajes, entrevistas y opiniones, para que sean publicados en los medios de las instituciones educativas y circulen de manera paralela con los conocimientos contenidos en los planes de estudio. En esta perspectiva la comunicación adquiere otro sentido.

Esto implica un cambio de roles en los estudiantes, sobre todo, porque no se tratan que sean "emisores" bajo un esquema lineal de la comunicación, sino que se asuman como "productores de significaciones"(Martín Barbero, 1998, p. 291) entendido como productores de otros conocimientos -algo que va más allá de la reseña o del dato que prevalece en el paradigma informacional- que se construyen a partir de sus propias preguntas, reflexiones, interpelaciones, deliberaciones e investigaciones y su mundo cultural: el barrio, la unidad residencial, la ciudad.

El sentido es compartirlos y ponerlos a circular entre la comunidad educativa, con el propósito de generar nuevas sensibilidades desde la pronunciación del mundo propio con sus propias palabras (Freire, 1985, p. 100). Si el estudiante siente que ese conocimiento tiene valor y significado 
buscará compartirlo y comunicarlo, para que otros lo conozcan (Kaplún, 2010, p. 53); es darle un nuevo sentido a la idea de "escribir para ser leídos", esto es, construir relatos a partir de la lectura de las complejas situaciones sociales que viven los niños y los jóvenes; implica expresar las propias opiniones, ser creativos para comunicar y atraer la atención de sus pares, de manera que se vean reflejados e identificados en esas historias, para que se motiven a hablar, a dialogar, a compartir con otros (maestros, padres de familia, vecinos) a partir de lo que leen, escuchan o ven en los medios de comunicación de su colegio.

Así, la comunicación que se ejerce en estos medios, deja el carácter académico (la tarea, el informe para el profesor, la evaluación) y divulgativo (dar a conocer eventos institucionales) para transformarlo en conocimiento como producto social (Kaplún, 2010, p. 56). Es un conocimiento producido por los propios estudiantes que se construye con diferentes fuentes y perspectivas, con la idea que sea compartido con otros, para que a su vez lo socialicen con nuevos interlocutores ( $p$. 57).

Romper con una estructura requiere asumir también una perspectiva crítica, desde la educación, en la medida que se cambian los paradigmas de elaborar unos contenidos a partir de los intereses y visiones de los maestros (adultos) para producir otros discursos desde el descubrimiento de la propia realidad de los estudiantes (Freire, 1985, p. 88) y en esa medida hacer de su propia realidad (social y familiar) un acto de conocimiento (McLaren, 1994, p. 47). De ahí que se considere como propuesta fundamental para este cambio de mirada, los planteamientos de la pedagogía crítica (Giroux, 2003), porque toma como punto de partida las necesidades e intereses de los estudiantes, sus experiencias y valora como legítimo esos conocimientos y experiencias 
que le dan sentido a la vida de los estudiantes (p. 250). Así preguntarle a su propio mundo, hablar de su propio mundo, opinar de su propio mundo y proponerle a su propio mundo debe ser el acto que se promueva en la experiencia de publicar en un medio de comunicación escolar.

Y como lo plantea la mirada crítica de la educación, se hace necesaria plantear otra perspectiva de la comunicación que supere la mirada instrumental. Implica dejar esa posición "neutra" (Saintout, 2003) con la que se busca darle una utilidad a una tecnología instalada aprovechada para la divulgación de informes, y asumir en su lugar la idea que la comunicación es algo más que un asunto de "aparatos", es una cuestión de sujetos (de seres humanos) que tienen capacidad de narrar sus experiencia de vida.

Por eso, se trata de un producir, más que de reproducir, desde el cual sea posible potenciar en ese sujeto (estudiante) su capacidad de creación (Saintout, 2003, p.82).Con esto se sustenta, tanto desde la educación, como desde la comunicación, que es posible otra experiencia de producir contenidos para los medios de comunicación en la escuela, a partir de los intereses de los estudiantes. Ya no son los "meros receptores", ni los "emisores repetidores", sino los productores de significaciones (Martín Barbero, 1998) que ponen a circular otros contenidos y conocimientos que surgen de la vida cotidiana.

Desde la comunicación/educación es posible reconfigurar los medios en la escuela, viéndolos como otros escenarios desde los que sea posible compartir con las publicaciones otros conocimientos y contenidos, otros papeles y roles para los estudiantes y para los maestros; otras maneras de "producir significaciones" y otras alternativas para "atraer" el interés de los pares por 
lo que se produce, se comunica y se comparte en estos espacios de comunicación construidos en la escuela.

\section{La palabra y la ciudadanía}

Desde sus inicios Freinet (1977) propuso que la experiencia del Diario escolar era una preparación en la actividad cívica de los futuros ciudadanos (p. 125) idea que comparte Bacher (2009) cuando reflexiona que la escuela debe adoptar nuevos paradigmas -como los medios de comunicación- para que emerjan otros espacios de pensamiento crítico que estimulen la capacidad de preguntar, interpelar, analizar, producir, conectar, comprender e incidir en la transformación de sujetos autónomos (P. 29-30). Esto lleva a pensar que uno de los aspectos fundamentales para iniciarse en la formación de la ciudadanía es la apropiación de la palabra, elemento esencial para el trabajo con los medios de comunicación en la escuela.

Por eso, la insistencia de convertir estos escenarios en los espacios de la apropiación de la palabra, que parten de los propios intereses de los estudiantes, para que con sus propias voces narren los conocimientos y las experiencias de vida. La palabra es la matriz de la política, porque es un sistema de intercambio entre las personas para excluir la violencia, es el elemento esencial de la comunicación para convencer al otro (Arendt, 1993, p. 40). En ese sentido la palabra tiene "poder" y el mismo se adquiere al reconocer el valor de la propia voz, de ahí que sea importante que la escuela estimule, desde sus medios de comunicación, la expresión de la voz de los estudiantes para que narren con sus propias palabras lo que vive en la cotidianidad. Este es un sencillo acto que lleva al estudiante a integrarse desde su propia historia a la vida pública. En términos de McLaren (1994) es posibilitar que los estudiantes asuman el papel de "ciudadanos 
creativos", en la medida que desde los relatos visibilizan su particular manera de participar en la sociedad.

De ahí que resulte preocupante el hecho que la escuela niegue la expresión de la propia voz de los estudiantes, cuando les impone los temas o les niegue el derecho de expresar sus ideas y relatar sus historias (censura). Álvarez (2003) indica que en estos casos las prácticas de apropiación de la palabra se constituye en una actividad puntual que tiene como meta la elaboración de un texto (p. 86). Por eso, propone alternativas como la alfabetización crítica que relaciona el "leer y el mundo" como asuntos intencionados, críticos y emancipatorios y sus planteamientos concuerdan con los pedagogos críticos en la medida que afirma que "quien lee la palabra está leyendo el mundo para problematizarlo" (p.87). Ahí la palabra adquiere otro sentido: posibilita la lectura del contexto que rodea la escuela y en la medida que el maestro y estudiante se concienticen de esto, hacen que la responsabilidad para relatar sea no un acto de registro, sino de lectura $\mathrm{y}$ conocimiento de lo que pasa en sus vidas y en sus comunidades locales.

Sostiene Bacher (2009) negar o anular la expresión es un riesgo que se corre, porque abre fisuras para que la violencia se haga presente ante la imposibilidad de la comunicación. Por el contrario, "poner palabras a los conflictos permite desarticular esa violencia y superarlos" (p. 114). En consecuencia, es necesario que la escuela otorgue el sentido y el valor de tiene la experiencia de producir medios de comunicación en ella, más allá de una función divulgativa y controladora, es propio que sirva de escenario para que "descubran el inagotable valor de la palabra" y que “ejercer el derecho a la comunicación es una oportunidad para establecer vías de participación ciudadana, de reflexión y creatividad" (Bacher, 2009, p. 117). Es en esta perspectiva-como 
alternativa válida, aunque no única- en que las experiencias de medios de comunicación en la escuela pueden resignificarse y adquirir otro sentido a partir de la apropiación de la palabra como alternativa para la formación ciudadana.

\subsection{Fase de los conceptos}

El objetivo planteado para este capítulo es "examinar los modelos y conceptos de comunicación (medios de comunicación escolares), educación, información y ciudadanía que tienen los maestros y estudiantes que participan en los proyectos de medios de comunicación escolar". La pregunta planteada es la siguiente: ¿Qué visión (idea) de la comunicación y de la información prevalece en los maestros y estudiantes como productores de contenidos y cómo incide ello en las experiencias de producción de los medios de comunicación escolar? Luego del análisis realizado, las conclusiones son las siguientes:

Se requiere establecer un diálogo entre las ideas que tienen de la comunicación los adultos (maestros y profesionales de la comunicación) con las de los estudiantes, sobre todo, tratar de romper las estructuras verticales y hacerlas más horizontales, en donde las ideas y visiones de los estudiantes permeen e influyan en los paradigmas tradicionales de la comunicación que tienen los adultos. El concepto que se tenga de la comunicación incide en la producción de medios. En este sentido se recomienda que los medios de comunicación de las instituciones educativas sean escenarios en los que se formen los estudiantes en la expresión de las ideas y en la responsabilidad de contar y dar a conocer a los temas que sean de interés general y que lleven a quienes accedan a esos contenidos a compartirlos con otros (comunidad educativa, habitantes de los barrios o sectores circundantes), por el valor y el aporte que encuentren en ellos. 
Esa discusión entre una Comunicación basada en la trasmisión y una comunicación que permite la expresión de ideas, conectarse con los otros para generar procesos de diálogo y de encuentro con los "otros" es lo que propone Schmucler (1997) al reivindicarla como algo constitutivo del ser humano, "de comunión con el otro" (p.113) y que además va más allá de la visión instrumental -prácticas propias de la escuela que se evidencia en la producción de medios de comunicación-y señala que la "comunicación es un hecho ético, es decir político, no instrumental" (p. 150). Esto permite señalar que es necesario que la escuela asuma la comunicación como la posibilidad de generar un espacio de encuentro, discusión, expresión y conexión entre maestros y estudiantes, escuela y comunidad, comunidad y escuela, estudiantes y maestros.

Es necesario asumir la idea de la comunicación como un "vivir con el otro" (p.199). De esta idea resulta la relación de comunicación/cultura, que sería lo ideal para que los estudiantes puedan encontrar en los medios de sus colegios, el espacio para expresar su mundo (el individual) y el mundo que los rodea (sus comunidades locales). Por eso, cuando el estudiante tiene la posibilidad de interpretar el mundo que vive y lo relata en los medios de comunicación de su colegio, tiene la oportunidad de hacer evidente la comunicación como lo que plantea Saintout (2003): construcción social de conocimientos, puesta en común, los modos de socialidad, estar juntos (p.84). En definitiva, es algo cercano a lo que Wolton (2010) señala como la "emancipación del individuo" (la comunicación). "El derecho a pensar, expresarse, buscar al otro, establecer relaciones, volver a empezar" (p.124). 
En cuanto a la información, estos temas que surgen del análisis sirven de base para establecer unos parámetros o políticas que orienten el manejo de la información que se produce y publica en los medios de comunicación de las instituciones educativas. Información: elemento esencial del ser humano que se construye desde las inquietudes y preguntas que surgen de su relación con el mundo social que lo circunda. Es la base para que los estudiantes elaboren relatos que contengan conocimientos (Kaplún, 2010, p. 52) y que al publicarlas posibilite una mejor comprensión de situaciones que debe afrontar en la cotidianidad. De esta manera, la información no se queda como un acto mecánico, basado en el registro de unos acontecimientos o en la publicación de unos datos, sino como el insumo esencial que contiene el conocimiento, las experiencias, las reflexiones que se comparten con otros, para que comprendan el mundo local que circunda a las instituciones educativas.

De igual manera, es necesario tener una perspectiva de educación que encaje con la relación comunicación/cultura e información/conocimiento. Las opiniones de maestros y estudiantes que surgen en el tema de la educación llevan a insistir en la necesidad que la escuela tenga un diálogo permanente con el contexto social en la que está inscrita la institución educativa, porque tal como lo plantea Pérez con su concepto de "cultura experiencial", los estudiantes ya tienen unos significados y comportamientos aprendidos en sus contextos familiares y sociales, indica además que la cultura del estudiante es el resultado de la cultura social de su comunidad (1998, p. 199) y que coincide con McLaren cuando señala que la institución educativa debe tener en cuenta el contexto cultural de los estudiantes, porque así puede leer sus vidas, sus privaciones, expectativas y propuestas (1994, p. 32). Por esto, es importante tener en cuenta que los estudiantes también se 
“educan" en los contextos donde viven: el barrio, las calles y ahora con la exposición permanente a redes sociales.

Esa "otra" educación que encaja con los otros conceptos abordados es la pedagogía crítica expuesta por Giroux (2008), porque la misma otorga una responsabilidad diferente al estudiantes: pensar de manera crítica y ello implica que aquella debe brindar las condiciones para que el estudiante hable "con sus propias voces para autenticar sus propias experiencias" (p. 256). Es una educación que problematiza, pregunta, reflexiona, muestra las realidades que viven los estudiantes en sus comunidades locales y en las instituciones educativas. De ahí que unos medios de comunicación en la escuela que favorezcan esto, permiten que se valide la voz de los estudiantes, es una ruptura de aquella figura de "emisor/replicador" o "emisor/trasmisor" que se vive en la experiencia de los medios en los colegios investigados.

En cuanto el concepto de medios de comunicación escolar la discusión se enriquece con las ideas y reflexiones de los actores (estudiantes y maestros). Si bien aún aparece la concepción instrumental y divulgativa, entre la maestra y los estudiantes, emerge otra idea diferente: un medio escolar es un espacio para el encuentro, la discusión, la problematización, la reflexión y la concertación. En este sentido, se busca que los medios escolares dejen la perspectiva "neutra" de trasmisión de datos planteada por Saintout (2003) y entren en esa dinámica cultural y formativa en la que se posibilite la expresión de la palabra de los actores, los estudiantes y en esa medida el medio adquiere otro significado: se convierte en memoria colectiva, porque conserva los contenidos investigados y publicados por los estudiantes; es una construcción colectiva, cuando deja de ser resultado de unos esfuerzos individuales y se convierte en producto de decisiones 
colectivas en cuanto los temas, los enfoques y las maneras cómo serán relatados los mismos. Así se constituye en un producto social, como lo planteó Kaplún (1998, p. 205).

Como indica Huergo (2001), hay que darle un carácter "comunicacional" a los medios que se producen en la escuela, en la medida que se vean como espacios en los que se articulen prácticas y procesos sociales y desde los cuales los integrantes de la comunidad educativa se sientan interpelados y se reconozcan (o no), y a la vez (los medios) sean asumidos como espacios con los cuales es posible educar y formar (2001, p. 31) a quienes accedan a los contenidos y conocimientos que se ponen a circular desde ellos.

Por su parte, Bacher (2009) señala que en la escuela es necesario que existan "escenarios comunicativos", en este caso los medios escolares, porque es la posibilidad que tienen los niños y jóvenes para "expresar sus ideas, inquietudes y anhelos", que no se quedarán en un aula de clase, sino que "trascenderán para llegar a oídos desconocidos, da al mensaje un sentido especial" (p. 134) y ese sentido está relacionado con la responsabilidad que tienen los estudiantes de asumir esa labor de producir los discursos con los que interpelaran a sus pares y con los que producirán otros conocimientos a partir de sus experiencias de vida, con un valor diferente a los contenidos académicos ofrecidos en la escuela.

La reflexión que surge sobre el concepto de "producción de sentidos" permite plantear el reto que tienen las instituciones educativas y los maestros de "darle la voz" a los estudiantes (Giroux, 2008). Hay que pasar la hoja de la trasmisión de datos, repetición de textos o elaboración de informes bajo la perspectiva y la autorización de los maestros (adultos), a la de generar un espacio (los medios de comunicación) donde los estudiantes se formen como "productores de 
sentido" (objeto de la comunicación), porque aportan algo significativo (conocimientos) en los relatos que comparten con quienes reciben sus mensajes y, en esa medida, influyan en otros estudiantes, maestros y padres de familia con lo que expresan; faciliten la comprensión de los temas que trabajan, en la medida que profundizan en los mismos.

Así, formar "productores de sentido" es asumir ese rol que propone Martín Barbero (1998) de no servir de instrumentos para poner a circular información, sino productores de mensajes con significado, esto es que lo que se comunique tenga valor y poder de compartirlo con los otros, porque encontrará en esos relatos algo importante para comprender lo que sucede en el mundo escolar o en el mundo social en el que se desenvuelven. Por eso, formar en la escuela productores de sentido, desde sus proyectos de medios de comunicación, es educar en el valor y sentido de la palabra que compromete, en la palabra que pronuncia el mundo, con el propósito de transformarlo, como lo señaló Freire (1985). Y es aquí donde se conecta con el concepto de la ciudadanía que sigue a continuación.

De acuerdo con lo compartido por los estudiantes quienes entienden que la ciudadanía está relacionada con "los otros", con el respeto por la diferencia, con la aceptación que se hace parte de una sociedad concreta que posee unas costumbres, unas expresiones culturales; si los medios de comunicación en la escuela permiten que los estudiantes compartan en sus páginas o secciones de programas de televisión la vida del contexto social en que viven, si permiten que analicen las situaciones sociales de lo que pasa en las calles de sus barrios, con sus amigos y vecinos; si permiten que hablen de las expresiones musicales de su interés, que reflexionen sobre las injusticias que ven y hagan propuestas para contribuir que la pequeña sociedad en la que viven 
sea más justa y equitativa, en este marco, los medios de comunicación podrán llegar a ser espacios de formación ciudadana, porque trascienden el paradigma informativo que los caracteriza.

Basados en que estos medios son producidos en contextos académicos, pueden asumir el carácter de Medio Ciudadano, (Rodríguez, 2009). Estos se caracterizan porque se producen en comunidades locales y concuerdan con los de las escuelas en que pueden crear imágenes de sí mismo y de entorno, convertirse en relatores de la propia historia, recobrar la voz propia, reconstruir el autorretrato de la propia comunidad y sus culturas, explorar los propios lenguajes y hacerlos visibles en la esfera pública (p. 17). Estas características serían otra perspectiva interesante para los maestros y estudiantes, porque ofrecen nuevas posibilidades en la producción de sus medios.

Rodríguez indica que un medio es ciudadano cuando permite a la gente expresar el mundo en sus propios términos $(2009$, p.18) y esto es lo que se propone a las instituciones educativas que tienen estas experiencias: darle la voz a los estudiantes, para que pronuncien su palabra y relaten sus mundos en la perspectiva de transformar sus comunidades locales. La autora toma como referente a Martín Barbero, quien señala que "solo quienes estén en capacidad de narrar sus propias identidades y de nombrar el mundo en sus propios términos tendrán una presencia sólida como sujetos políticos" (Martín Barbero, 2002, citado en Rodríguez, 2009). Y en esto concuerda con lo ya expuesto antes por Arendt, en el sentido que la palabra es la matriz de la política. Por eso, la escuela debe tener en cuenta que una de las oportunidades que tiene con este tipo de experiencias con medios de comunicación es formar a los estudiantes en la apropiación de la palabra, base 
para iniciarse en el mundo de la participación política, es decir, de interesarse por lo público, por la justicia, la solidaridad, la equidad.

Los medios "escolares" pueden ser espacios de formación ciudadana si facilitan la transformación de individuos y comunidades en ciudadanos (según Mouffe) y en subjetividades empoderadas con voz propia (según Martín Barbero), según lo expuesto por Rodríguez. Son espacios donde las personas (en este caso maestros y estudiantes) aprenden a manipular sus lenguajes, códigos, signos y símbolos, para nombrar sus mundos en sus propios términos. Estos medios activan procesos a través de los cuales individuos y comunidades re-codifican tanto sus contextos como su propia identidad y los que pueden usar los ciudadanos (en nuestro caso maestros y estudiantes) para activar procesos de comunicación que contribuyen a moldear sus comunidades locales (Rodríguez, 2009, p. 19), de manera concreta en la escuela.

Con estas perspectivas, las instituciones educativas que tienen este tipo de experiencias de medios de comunicación, pueden optar por otras alternativas relacionadas con el diálogo entre la institución educativa y el contexto social de las comunidades locales, que implican lectura de las situaciones sociales, explorar maneras de relatar el mundo, de concientizarse de sus realidades para contarlas en estos medios, acercarse a ese mundo de lo público, asumirse como seres de palabra, es decir, como seres políticos.

\subsection{Fase Análisis de Contenidos}

El objetivo planteado para este capítulo fue "revelar las tendencias y las intencionalidades de los temas publicados en los medios escolares en las instituciones y comunidades educativas desde el 
análisis de los contenidos de las publicaciones impresas y audiovisuales" y la pregunta que orientó el trabajo fue ¿Quiénes son los que publican en los medios de comunicación de los colegios, qué tipos de temas son los que se dan a conocer desde los mismos y cómo se refleja el contexto institucional y social de la institución educativa en las publicaciones?

En las muestras analizadas se evidencia una tendencia de los adultos (Rectores, maestros y colaboradores) a publicar en estos medios, sobre todo la opinión, la editorial y otros informes institucionales. También se refleja en los trabajos publicados por los estudiantes o los que presentan ante las cámaras de televisión, por la orientación y la manera de relatar los contenidos. Estas posturas son contrarias a la propuesta de Freinet (1977) quien promulgó porque estas experiencias de medios estuvieran basadas en los intereses de los estudiantes. Y desde el punto de vista de Kaplún (1998) es una muestra de una educación que pone énfasis en los contenidos (educación tradicional), ocupada en la trasmisión de unos conceptos y valores, donde predomina la verdad del maestro y se relega la experiencia de vida del estudiante. Por su parte, siguiendo con Kaplún, son experiencias desde el punto de vista de la comunicación en las que predomina la trasmisión de datos, informaciones, ideas, y que denominó como "comunicación bancaria”. Es una comunicación unidireccional, porque va de un emisor hacia un receptor. Esto hace que la información pierda interés y la comunicación sentido, porque en los materiales se evidencia que los textos utilizan frases comunes, que relegan el valor de las palabras, a perder su carga semántica, en definitiva a generar una comunicación "neutra" (Saintout) y a trivializar la información (Schmucler), dado que los informes suelen repetirse a lo largo de los años, por estar centrados en lo que sucede al interior de los colegios, donde los eventos son los mismos y se reseñan de manera permanente. 
Por su parte, existe una variación en la participación de los estudiantes. Por un lado es “condicionada" por varias razones:

- Escriben o muestran lo que les imponen sus maestros; existe una actitud pasiva por parte de los alumnos, porque no relatan sus temas, sino los que los docentes les indican: hablan de los acontecimientos o eventos institucionales, celebraciones, en los que predominan los datos, las fechas, los resultados y los aspectos a destacar en la institución.

- Además llama la atención que cuando reseñan algunos acontecimientos las voces que aparecen en los informes, para validar la información, es la de los maestros u otras personas adultas, pero no recurren a la visión, a la reflexión o al análisis que hacen los propios compañeros.

- Los estudiantes quieren aparecer y ser reconocidos, pero no preparan los informes, ni buscan la información que requieren, por tanto, repiten lo que los maestros preparan para ellos.

En este sentido, los materiales muestran que la voz de los estudiantes no es validada, como lo señala Giroux. Sin embargo, en las mismas experiencias se evidencia que cuando los estudiantes asumen la responsabilidad y la libertad para expresar sus ideas, así algunas de ellas estén relacionadas con eventos institucionales (como celebraciones patrias que se programan en la institución educativa) la dinámica de los medios cambia. Existe la posibilidad que relaten el mundo propio: la vida de barrio, la historia del mismo, las experiencias de sus pobladores y ello le da una perspectiva diferente al medio de comunicación. También se dan los casos en que pueden mostrar la vida de las personas que integran una institución educativa (compañeros, maestros, directivos, personal administrativo) por medio de exploraciones con géneros periodísticos como las entrevistas, donde el estudiante no solo es quien pregunta, sino que 
prepara el cuestionario, contacta al personaje y se enfrenta a una cámara, para que la comunidad educativa conozca algo más de ese personaje cuando se publica.

De esta manera, los estudiantes pueden explorar otras maneras de contar sus historias, más relacionadas con una comunicación que se ocupa por mostrar la vida cotidiana, la cultura propia, lo cual brinda más carga significativa a los contenidos, basados en los relatos propios de sus mundos, de manera que los saberes de la escuela entren en diálogo con los saberes de entorno social (Valderrama, 2007, p.190); y esto lleva a preguntar por qué es importante que sean los estudiantes quienes se asuman como productores de sentido, porque como lo indica Huergo (2000) cuando tienen la posibilidad de relatar su realidad, hablar de su mundo, esto es, pronunciar la palabra, implica decir algo más allá de lo dicho hasta el momento (p.130), con lo que se rompe con las miradas de una educación tradicional, enfocada en la información y en los valores. Y otra razón fundamental, darle sentido a este tipo de experiencias, bajo el protagonismo de los estudiantes, como lo indica López De la Roche (2000) al señalar que la escuela puede formar a sus estudiantes como "participantes sociales", cuando puedan explorar y debatir temas y sucesos que los afecten en la cotidianidad, tanto en lo personal o como integrantes de una familia, un barrio, una unidad residencial o una comunidad donde habiten (p. 391) y la participación en este tipo de experiencias de producción de medios, puede ser un espacio propicio para ello, de empoderamiento por parte de los estudiantes, como una preparación para su participación activa en la sociedad o en las comunidades locales a las que pertenecen.

Para concluir, y a manera de recomendación para los maestros y en general a los adultos (directivos, maestros, padres de familia) que tienen a cargo este tipo de proyectos, existe la 
necesidad de cambiar la perspectiva de este tipo de experiencias. En primera instancia hay que dejar de verlas en su carácter instrumental, divulgativo y "neutro"; en segundo lugar, se debe involucrar de manera más comprometida a los estudiantes y centrar este tipo de experiencias en los intereses de los alumnos; un tercer aspecto, tener presente que la experiencia de los medios requiere una postura pedagógica que forme en el pensamiento crítico, facilite la pregunta y promueva el diálogo para que los estudiantes hablen de su mundo, sus experiencias de vida, investiguen acerca de sus realidades para contarlas a la comunidad educativa y entornos sociales y, un cuarto aspecto, asumir que la comunicación no es solo trasmisión, ni garantiza el orden, sino que la comunicación es la posibilidad de vivir juntos en medio de las diferencias, la comunicación ofrece otros lenguajes para expresar ideas y conocimientos, por eso, como indica Bacher (2009) existen nuevos paradigmas que proponen la comunicación y las tecnologías, y las mismas pueden actuar como incubadoras de pensamiento crítico, desde las que se promueven la pregunta, el análisis, la producción, el relato o la narración creativa utilizando los diferentes lenguajes de la comunicación, la conexión con los otros y el entorno social, en definitiva promueve la formación de sujetos autónomos, con un propósito: permitir “a los más jóvenes imaginar sociedades más justas" (p. 29-30). Pensar la experiencia de producción de medios en las instituciones educativas en esta perspectiva debe llevar a considerar que tiene más posibilidades formativas de las que se les otorga de manera real, basada más que todo en el manejo del lenguaje, que las mismas se pueden constituir en espacios para la formación de una ciudadanía activa como lo propone Ruíz (2007); una comunicación que lee, interpreta, relata y compromete para transformar el mundo. 
De ahí la importancia de cambiar la perspectiva informacional de estos medios producidos en las instituciones educativas, por la de comunicación/cultura que abra la puerta a otras posibilidades, desde donde tendrán otras alternativas para darle sentido a este tipo de experiencias.

\subsection{Fase de recepción}

El objetivo trazado para este capítulo es el siguiente: “comprender la importancia que le otorga la comunidad educativa (estudiantes, maestros, directivos y padres de familia) a los medios de comunicación escolar que se producen en las instituciones educativas, teniendo en cuenta la pertinencia y la relevancia de los informes que se publican en ellos". La pregunta que se planteó para el mismo fue la siguiente: ¿Qué valoración de los contenidos publicados en los medios escolares hace la comunidad educativa y en qué medida influye en ello los enfoques aportados por los maestros, el modelo pedagógico de la institución y la idea comunicacional que prevalece en la institución educativa?

Si bien el foco de esta investigación estuvo en la producción, resultó importante consultar a los estudiantes y maestros como destinatarios de los contenidos por medio de encuestas, para confrontar los aspectos que fueron objeto de análisis en este trabajo.

En primera instancia el carácter divulgativo de los medios: algo que es reconocido y aceptado por estudiantes y maestros al indicar que los mismos les sirven para estar enterados de lo que pasa en los colegios. Se resaltan los datos, las reseñas de los acontecimientos y eventos, como también las decisiones y las reflexiones que comparten los directivos en las diferentes páginas o espacios de televisión. Es una muestra del modelo informacional señalado por Huergo (2001) con el que se 
pretende incrementar la información bajo una lógica de la trasmisión. En segundo lugar, a pesar que los estudiantes encuestados señalan que se identifican con los temas publicados (62. 1\%) existe un 34.4\% de ellos que no, por considerarlos monótonos, sin interés, ajenos al desarrollo personal o académico, los temas son escogidos por los profesores, algunos se repiten o terminan distrayéndose cuando los proyectan por los sistemas cerrados de televisión. Este tipo de comentarios es necesario escucharlos, porque el hecho que la base de la comunicación y la información sea lo que sucede al interior del colegio agota los temas y las posibilidades de tratar otros temas, por tanto, es necesario que este tipo de experiencias tenga alternativas de contenidos, sobre todo en lo que se insiste desde Freinet: centrar la producción en los intereses de los estudiantes.

Un tercer aspecto, relacionado con lo anterior, es la identificación que hacen los estudiantes sobre quien propone y decide los temas que se publican: los adultos (rector y maestros); esto desde el punto de vista de los destinatarios, es un reconocimiento a los modelos tradicionales de la educación que prevalecen y que se replican en este tipo de experiencias, lo cual incide en los enfoques temáticos y la producción de los medios de comunicación en las instituciones educativas. De igual manera se ratifica la falta de empoderamiento por parte de los estudiantes al interior de estos proyectos. Por eso, si los medios de comunicación siguen orientados bajos los intereses de los adultos, los mismos no trascenderán el carácter institucional y neutro que los caracteriza, por tanto, es necesario abrir la posibilidad de generar otras experiencias más comprometidas, como el modelo pedagógico crítico propuesta por Huergo (2001) y que busca generar procesos dialógicos, basadas en las propuestas, relatos y reflexiones que surjan de los estudiantes, lo cual implica una apuesta pedagógica y comunicativa que promueva la validación 
de la voz de los estudiantes y la apropiación de su palabra, que les permita relatar su mundo y conectarlo con el contexto académico de la escuela.

En cuarto lugar, existe un reconocimiento que los contenidos publicados están dirigidos a los estudiantes, aunque también se indica por parte de los encuestados que los mismos son de interés para los padres de familia, para que estén enterados de lo qué pasa en los colegios. De ahí que si bien este tipo de experiencias están pensadas y dirigidas a los estudiantes, terminan dirigidas a un público de adultos, con un propósito informativo e institucional; así mismo, se muestra que no existe un interés muy marcado por ofrecer contenidos que sean dirigidos a las comunidades locales (barrios, unidades residenciales), con lo que se recalca aún más el carácter interno con el que se producen estos medios. Desde Huergo (2000) se comprende que este tipo de experiencias se da más en la perspectiva de unos maestros, dirigido para los otros (estudiantes, maestros y padres de familia) que con los otros, (los estudiantes que participan en este tipo de proyectos), recalca que estos últimos cuentan en la medida que relatan su realidad, hablan de su mundo, pronuncian su palabra, constituyéndose en un acto dialógico más comprometido, porque busca transformar el mundo, en este caso las comunidades locales y las instituciones educativas a las que pertenecen.

$\mathrm{Y}$ un quinto aspecto, producir medios en la escuela, bajo el paradigma informativo/divulgativo, encajan con los modelos tradicionales de la educación que propugnan, entre otros aspectos, por la memorización, la obligatoriedad de consultar los contenidos, la imposición de los temas por parte de los maestros y directivos es algo que necesita ser revaluado. Por eso, basados en la importancia que tiene la propuesta de Freinet "escribir para ser leídos", es algo que debe tenerse 
en cuenta en los tiempos contemporáneos. Esta invitación implica motivar a la sustentación de las propias ideas, investigar sobre el tema, hacerse preguntas sobre el mismo, recopilar la información desde diferentes fuentes: documentos, observación, entrevistas; para los estudiantes es un reto pensar que si su trabajo va a ser leído o visto o escuchado por otros (compañeros, maestros, padres de familia, habitantes de las comunidades locales), ello debe motivar a la escritura creativa y, sobre todo, la consciencia que aquello que se publique tiene mucho valor, porque aporta más que información, es conocimiento acerca de lo que los otros no ven, no conocen y no piensan. Es un gran reto, porque debe generar una lectura sin presiones de ningún tipo "academicista", sino de querer aprender algo más a partir de lo que los estudiantes comunican o cuentan en sus relatos.

Y esto tiene que ver con la apropiación de la palabra, porque la misma no se impone, por el contrario, obedece a un proceso de concientización cultural de que el ser humano es un ser de palabra y que ella le pemite "hablar" de sus mundos, en diferentes momentos de la historia de la humanidad. Por eso, los medios de comunicación de la escuela deben servir de escenarios para que el estudiante descubra el valor de la palabra, se apropie de ella y con ella pueda hablar de su mundo. Ese debe ser uno de los grandes propósitos de los medios de comunicación que se producen en las instituciones educativas.

\subsection{Por qué apostarle a las mediaciones en las experiencias de medios en la escuela. Reflexión final.}

Estudios anteriores a esta tesis dieron cuenta que las experiencias de medios de comunicación la escuela se desarrollaban bajo un paradigma instrumental y divulgativo, de ahí que era necesario 
buscar alternativas desde lo teórico que permitiera abrir las perspectivas de investigación para estos proyectos y que posibiliten ofrecer algunas recomendaciones para hacer de las mismas experiencias de comunicación/educación más relevantes. Desde el inicio se optó por asumir la propuesta de las mediaciones comunicacionales (Martín Barbero) como el fundamento teórico que orienta la interpretación de los hallazgos logrados en el trascurso de la investigación y es la base para generar una reflexión en torno la relación comunicación/cultura que también adquiere relevancia en este estudio. De igual manera, era necesario apostar por otra perspectiva educativa que entrará en diálogo con esta posición comunicacional y ella fue la pedagogía crítica (McLaren, Giroux) o la educación problematizadora (Freire), porque desde las mismas es posible argumentar los cambios de paradigma tradicionales de la educación, necesarios para desarrollar experiencias educativas más deliberativas, dialogantes y, sobre todo, empoderadas por parte de los estudiantes, quienes deben ser el centro y protagonistas en la producción de medios de comunicación en la escuela.

De ahí que sea importante retomar el objetivo general y la pregunta que orientaron esta investigación, para ofrecer algunas respuestas a los mismos, no definitivas y en perspectiva de abrir la discusión. Así el objetivo planteado fue: "Analizar la producción de los medios de comunicación escolar desde la perspectiva de las Mediaciones comunicacionales que posibilite una explicación sobre la relevancia que tienen estos proyectos en la escuela, la incidencia en la cultura escolar y las posibilidades de convertirse en espacios de formación ciudadana y de proyección social, tomando como base las experiencias de una institución educativa pública y una institución educativa privada de Medellín (2009-2012)”. 
De igual manera, la pregunta expuesta fue: ¿Por qué es necesario que los medios de comunicación escolar transformen la perspectiva instrumental/divulgativa que prevalece en ellos por un enfoque de comunicación/cultura que promueva la apropiación del lenguaje y la palabra, el análisis social, la producción de significados y la construcción colectiva de sentidos para generar en la escuela escenarios de discusiones, deliberaciones y diálogos en ambientes democráticos propicios para la formación de una ciudadanía activa en la comunidad educativa?

Basados en que la experiencia de los medios estudiados dan cuenta que los mismos son experiencias extra curriculares, es decir, son asumidos como actividades por fuera de las clases, ello hace que las mismas se concentren en actividades relacionadas con el registro de los acontecimientos que suceden al interior de las instituciones educativas, adquieren una perspectiva institucional -aspecto más evidente en el colegio privado, pero que también tiene manifestaciones en el público-, fundamentada en el registro y en el fomento de unas prácticas ligadas al querer “aparecer" y "ser reconocidos" por sus compañeros, porque salen frente a una cámara o publican en un periódico.

En este marco se generan tensiones entre maestros y estudiantes relacionadas más con lo operativo (aparecí o no aparecí), la falta de compromiso de los estudiantes (no pueden faltar a clases o la falta de tiempo para dedicarse a la producción del medio), la imposición de los temas por parte de los adultos (maestros) y la falta de empoderamiento de las experiencias por parte de los estudiantes, impiden en buena medida que se reflexione sobre la comunicación más allá de lo institucional, de lo instrumental (apoyo a la labor docente, hacer más agradables las clases) y verla como una alternativa educativa, en la medida que experiencias con medios de comunicación 
favorecen que se piense acerca de la apropiación de la palabra, por parte de los estudiantes y también de los maestros; de construir una comunicación como resultado de la pregunta (a un contexto social, a unas realidades, a unas experiencias de vida que los estudiantes llevan a la escuela) y la lectura de los "textos sociales". Esto requiere una mirada más amplia de la comunicación que trascienda el esquema básico de Emisor-mensaje-receptor.

Por eso, cuando la experiencia de producir los medios en la escuela no se queda solo en el registro, sino que se busca relatar lo que sucede en el barrio, las problemáticas cotidianas que viven los estudiantes y que llevan a las páginas o informes de sus medios de comunicación, cuando cuentan la historia de los habitantes de un sector o plantean preguntas a las autoridades de la institución educativa, como sucedió en el colegio público, se generan otros procesos comunicativos tanto al interior de la institución educativa, como una relación de intercambio entre la misma y las comunidades locales. Ese hecho de leer, interpretar y contar genera otras maneras de preguntar y relatar más creativas y profundas, por tanto, exigen narraciones más comprometidas de manera que generen procesos de reflexión de las realidades que narran, tanto en quienes los producen, como en sus destinatarios, para tratar de transformarlos.

Desde la perspectiva de las Mediaciones es posible pensar en aquella alternativa, porque invita a la escuela a ver la comunicación más allá de modelos básicos y unos medios -lo divulgativo y lo instrumental- y ocuparse de lo que está afuera: el contexto, lo que se vive en él, las costumbres de sus habitantes, las problemáticas sociales, las sonoridades propias, los relatos, las experiencias de vida, es decir, la cultura. Leer esto escapa a toda pretensión de empaquetarlo en un evento, en un dato o en una reseña, esto requiere otra lectura y otra manera de contarlo, esto hace ver que la 
comunicación no es un asunto de aparatos, sino de reflexión, relaciones y diversidad de puntos de vista, de ahí la relación comunicación/cultura.

De esta manera, hay que comprender que la comunicación es algo más complejo y denso, porque se construye en la relación con el otro o los otros, desde la experiencia de vida, también desde la pregunta que cuestiona, que pide respuestas, hace ver lo que no se quiere ver (hacerse consciente), compromete, por tanto, no es un asunto tan trasparente, sino que está lleno de matices y ofrece desde esa perspectiva diversas posibilidades de interpretación y de lecturas, porque cada quien lee desde su propia situación de vida, desde su propio capital cultural, social y económico, además reta a explorar las maneras de contar y relatar, de manera que provoque en los destinatarios o en quienes accedan a estos contenidos a leerlos con interés; y también reta a comprometerse con lo que se publica, en la medida que no escribe con el interés que le guste al maestro u obtener una buena calificación o ser reconocido por sus pares, por el contrario, hay que “escribir para ser leído”, para comprender el propio mundo y para motivar a cambiarlo, para hacerlo más justo, solidario y equitativo.

Y en este sentido, desde las Mediaciones, Martín Barbero propone un cambio de rol entre el emisor tradicional y el receptor tradicional para transformarse en un productor de significaciones. En el caso de las experiencias de medios en la escuela prevalece la figura del emisor tradicional (el maestro) quien propone y produce contenidos, organiza, dirige, aprueba o desaprueba lo que los estudiantes deben "repetir" o escribir; de ahí que su función sea controlar y que mejor manera de hacerlo que reducir la comunicación al dato, a la reseña o al registro de los eventos que suceden al interior de la institución educativa; ahora, si la escuela tiene un propósito formativo 
con los estudiantes, en el marco de la relación comunicación/cultura, debe centrar la experiencia en los estudiantes, darles el poder de la palabra para validar sus voces desde las que puedan relatar su mundo, sus visiones de la vida, sus opiniones, sus interpretaciones. Por eso, se trata es de narrar y relatar temas con sentido que cuenten el propio mundo (incluso el de la escuela), de manera que lleven a reflexionar, a comprender y a actuar; por eso, en términos de Martin Barbero, más que unos emisores son unos productores de significaciones.

Comprender la comunicación en esta perspectiva debe llevar a la escuela a darle otro sentido y razón de las experiencias de medios de comunicación que trascienda lo institucional y divulgativo, para darle el carácter de escolar, en la medida que es pensado y producido por los estudiantes, a entenderlo como un espacio de encuentro, diálogo, pero también lugar que provoca discusiones y preguntas; más que un instrumento diseñada desde la tarea y los esquemas tradicionales de escritura, es una construcción colectiva de ideas y de exploraciones narrativas; más que dirigirse a unos "receptores" pasivos o desinteresados, los productores de significaciones o de sentido tienen el reto de generar conexión con los destinatarios, para que estos a su vez interpreten estos contenidos y los compartan con otros destinatarios más cercanos: compañeros, familiares, amigos, vecinos, maestros, directivos y estos a su vez, lo compartan con otros, para generar así redes temáticas provocadas desde la escuela.

En perspectiva de las Mediaciones, la información también cambia de significado, ya no es solo el dato, el informe que se reseña, con el propósito de mantener informado a un grupo de personas; la información se constituye en conocimiento, porque se construye desde la pregunta, la experiencia de vida, da cuenta del contexto social y se convierte en relato que se comparte con 
los otros para generar procesos de diálogo, discusión, debate; para conocer más acerca de lo que se narra, para posibilitar un "encontrarnos", un "reconocernos", para generar procesos de identificación.

¿Y por qué la escuela debe asumir esta responsabilidad? Para darle sentido a la experiencia y para reconocerse como un espacio vigente de formación en la apropiación de la palabra, del reconocimiento de la diversidad, de socialización y, sobre todo, un lugar cultural que produce conocimiento. Una manera de compartir esto puede ser la experiencia de producción de medios de comunicación que se dan al interior de las instituciones educativas. La escuela, desde el punto de vista de las Mediaciones, debe abrir sus puertas y traspasar los muros que la cierran para permitir que los otros textos de la vida cultural la permeen y, a su vez, retorne a ese contexto social comprensión, interpretación y conocimientos que contribuyan a transformar esas realidades que viven los estudiantes y que llevan a la escuela para encontrar las respuestas.

El siguiente cuadro condensa las reflexiones entre el paradigma instrumental/divulgativo y el paradigma de las Mediaciones, como una alternativa para trabajar los medios de comunicación en la escuela.

\begin{tabular}{|l|c|l|}
\hline $\begin{array}{l}\text { Paradigma } \\
\text { instrumental/Divulgativo }\end{array}$ & Paradigma Mediaciones & Recomendaciones \\
\hline - La comunicación es un asunto & - La comunicación está & Aunque se den en contextos \\
instrumental. & relacionada con la cultura. & tradicionales de la educación, \\
- El medio sirve para trasmitir & - El medio es un espacio que & es necesario que la experiencia \\
y divulgar eventos, apoyo a la & se construye con las ideas y & de medios de comunicación en \\
labor docente. & contenidos aportados por la & la escuela parta de una \\
- El propósito es mantener & comunidad educativa. & reflexión más profunda y \\
informada a la comunidad & - El propósito es comprender & amplia del concepto de \\
educativa de lo que sucede al & que la comunicación es la & comunicación, porque ellos \\
interior de la institución. & posibilidad de vivir juntos. & darían otra perspectiva \\
\hline
\end{tabular}




\begin{tabular}{|c|c|c|}
\hline - No se abre al contexto social. & $\begin{array}{l}\text { - Se privilegia el contexto } \\
\text { social. }\end{array}$ & $\begin{array}{l}\text { diferente a este tipo de } \\
\text { proyectos. La } \\
\text { comunicación/cultura es una } \\
\text { posibilidad que abre otras } \\
\text { posibilidades de formación con } \\
\text { los medios, diferente a las } \\
\text { tradicionales. }\end{array}$ \\
\hline $\begin{array}{l}\text { - El maestro es el centro del } \\
\text { proceso. } \\
\text { - Propone temas, marca } \\
\text { orientaciones en los mismos, } \\
\text { produce contenidos, } \\
\text { condiciona los mensajes. }\end{array}$ & $\begin{array}{l}\text { - El maestro conecta a los } \\
\text { estudiantes con el contexto } \\
\text { social. } \\
\text { - Motiva a los estudiantes a } \\
\text { relatar lo que sucede en las } \\
\text { comunidades locales. }\end{array}$ & $\begin{array}{l}\text { El maestro y en general los } \\
\text { adultos, deben comprender que } \\
\text { el centro de estos proyectos son } \\
\text { los estudiantes y los mismos } \\
\text { deben girar en torno a los } \\
\text { intereses de ellos, no de los } \\
\text { adultos. El rol del maestro debe } \\
\text { ser formar a sus estudiantes en } \\
\text { la libertad de comunicar. }\end{array}$ \\
\hline $\begin{array}{l}\text { - Los temas se enfocan en lo } \\
\text { que sucede adentro de la } \\
\text { institución educativa, } \\
\text { adquiere una dimensión de } \\
\text { comunicación institucional. } \\
\text { - Tienden a repetirse de manera } \\
\text { permanente. }\end{array}$ & $\begin{array}{l}\text { - Se privilegia lo que sucede } \\
\text { afuera de la institución, para } \\
\text { conocer más sobre el } \\
\text { contexto social, para } \\
\text { comprender mejor la } \\
\text { experiencia de vida de los } \\
\text { estudiantes. } \\
\text { - Abre las perspectivas } \\
\text { temáticas. }\end{array}$ & $\begin{array}{l}\text { Los medios son la posibilidad } \\
\text { que tienen los estudiantes para } \\
\text { hablar del mundo, expresar sus } \\
\text { ideas, llevar sus preguntas a la } \\
\text { escuela. Deben entenderse } \\
\text { como espacios donde es } \\
\text { posible validar la voz del } \\
\text { estudiante y hacerlo sentir que } \\
\text { hace parte de una sociedad. }\end{array}$ \\
\hline $\begin{array}{l}\text { - El estudiante es un } \\
\text { emisor/repetidor de lo que el } \\
\text { maestro prepara, para que } \\
\text { diga. } \\
\text { - Genera actitudes pasivas en } \\
\text { los estudiantes. }\end{array}$ & $\begin{array}{l}\text { - El estudiante es un } \\
\text { productor de significaciones. } \\
\text { - Interpreta sus realidades } \\
\text { sociales, las relata para que } \\
\text { los otros las conozcan. } \\
\text { - Genera opiniones, cuestiona } \\
\text { el mundo que vive, plantea } \\
\text { soluciones. }\end{array}$ & $\begin{array}{l}\text { Es necesario que el estudiante } \\
\text { se asuma como un ser de } \\
\text { palabra y comprenda que sus } \\
\text { relatos pueden tener mucha } \\
\text { importancia, porque hablan de } \\
\text { su mundo y ello debe llevar a } \\
\text { comprenderlo, para actuar en él } \\
\text { y comprometerse a } \\
\text { transformarlo. }\end{array}$ \\
\hline $\begin{array}{l}\text { - El estudiante escribe para el } \\
\text { maestro. } \\
\text { - Busca una calificación y el } \\
\text { reconocimiento de sus } \\
\text { compañeros. }\end{array}$ & $\begin{array}{l}\text { - El estudiante escribe para } \\
\text { ser leído. } \\
\text { - Si es consciente que los } \\
\text { otros lo leerán se } \\
\text { compromete a comunicar } \\
\text { algo con sentido y } \\
\text { significado. }\end{array}$ & $\begin{array}{l}\text { El destinatario de los } \\
\text { contenidos no debe ser el } \\
\text { maestro que califica unos } \\
\text { contenidos, sino que hay que } \\
\text { generar consciencia en los } \\
\text { estudiantes que sus relatos son } \\
\text { importantes para otros, siempre } \\
\text { y cuando aporten temas de } \\
\text { interés, sobre todo a los } \\
\text { estudiantes. }\end{array}$ \\
\hline $\begin{array}{l}\text { - Limita los temas que } \\
\text { proponen los estudiantes, } \\
\text { antepone la institucionalidad. }\end{array}$ & $\begin{array}{l}\text { Promueve que los } \\
\text { estudiantes hablen de su } \\
\text { experiencia de vida y la } \\
\text { relacionen con el mundo }\end{array}$ & $\begin{array}{l}\text { La escuela debe ser un espacio } \\
\text { de formación en la apropiación } \\
\text { de la palabra, no un lugar de } \\
\text { negación de la expresión de las }\end{array}$ \\
\hline
\end{tabular}




\begin{tabular}{|c|c|c|}
\hline & social que viven. & $\begin{array}{l}\text { ideas. En esa medida los } \\
\text { medios de comunicación } \\
\text { pueden ser lugares de } \\
\text { formación en la } \\
\text { responsabilidad de comunicar, } \\
\text { no en la negación de la palabra. }\end{array}$ \\
\hline $\begin{array}{l}\text { - Ofrece herramientas para que } \\
\text { los estudiantes aprendan a } \\
\text { trabajar con los lenguajes } \\
\text { comunicativos, en perspectiva } \\
\text { de competencias, para } \\
\text { desempeñarse en algo en la } \\
\text { vida. }\end{array}$ & $\begin{array}{l}\text { - Es necesario apropiarse de la } \\
\text { palabra, para relatar el } \\
\text { mundo que lo rodea, en } \\
\text { perspectiva de comprenderlo } \\
\text { y comprometerse a } \\
\text { cambiarlo. }\end{array}$ & $\begin{array}{l}\text { - La palabra es una herencia } \\
\text { cultural del ser humano, que le } \\
\text { permite expresar, decir, } \\
\text { comunicar su mundo. Por eso, } \\
\text { los medios de comunicación en } \\
\text { la escuela pueden ser uno de } \\
\text { los escenarios que favorece el } \\
\text { aprendizaje de la cultura del } \\
\text { lenguaje. }\end{array}$ \\
\hline $\begin{array}{l}\text { - En algunos casos, los } \\
\text { contenidos son materia de } \\
\text { evaluación en las clases. } \\
\text { - Los destinatarios no } \\
\text { encuentran interesantes los } \\
\text { contenidos que se publican. } \\
\text { - No se generan nuevos } \\
\text { procesos comunicativos. }\end{array}$ & $\begin{array}{l}\text { - La información se convierte } \\
\text { en conocimiento que se } \\
\text { comparte con la comunidad } \\
\text { educativa. } \\
\text { - Provoca nuevos procesos de } \\
\text { comunicación en los } \\
\text { destinatarios a quienes } \\
\text { lleguen los contenidos. }\end{array}$ & $\begin{array}{l}\text { - Cuando la información se } \\
\text { construye desde la experiencia } \\
\text { de la vida y con preguntas } \\
\text { problematizadora se busca } \\
\text { comprender la realidad; la } \\
\text { misma supone investigar, } \\
\text { documentar y relatar con } \\
\text { creatividad para que otros se } \\
\text { interesen por esta información, } \\
\text { que de esta manera, más que un } \\
\text { dato, es conocimiento } \\
\text { producido con el interés de } \\
\text { aportarle al destinario } \\
\text { reflexiones, inquietudes, } \\
\text { necesidad de dialogar entre } \\
\text { ellos: maestros, estudiantes, } \\
\text { directivos, habitantes de las } \\
\text { comunidades locales, a quienes } \\
\text { se dirigen estos contenidos. }\end{array}$ \\
\hline
\end{tabular}

Cuadro 14. Comparativo paradigma instrumental/divulgativa y paradigma de las mediaciones. Elaborado por el autor

En definitiva, es necesario darle otra dimensión a la experiencia de los medios de comunicación que se producen en la escuela, para hacerlos espacios de socialización, apropiación de la palabra, lecturas sociales y exploraciones narrativas. De no hacerlo, quedaran como experiencias estancas, repetitivas, controladoras, inexpresivas de la vida de los estudiantes, por eso, es necesario reconfigurar estas experiencias como espacios propicios para la formación de ciudadanos activos 
(sobre todo los estudiantes), desde los que sea posible afrontar el reto de aprender a relatar el mundo, para transformarlo, hacerlo más justo, solidario y equitativo. Tomar la palabra es el primer paso para ello y ese sería el reto para los medios de comunicación que se producen en la escuela. 


\section{Bibliografía}

ÁLVAREZ, A. (2003). Los medios de comunicación y la sociedad educadora. ¿Ya no es necesaria la escuela? Cooperativa Editorial Magisterio, Bogotá.

ÁlVAREZ, D. (2003). Exploración de las relaciones entre lectura, formación ciudadana y cultura política. Una a las propuestas de formación ciudadana de la Escuela de Animación Juvenil (Medellín). (Tesis), Medellín, Universidad de Antioquia.

ALONSO, L. (1998). Sujeto y discurso: el lugar de la entrevista abierta en las prácticas de la sociología cualitativa. En: Delgado, J.; Gutiérrez, J. (ed.): Métodos y técnicas cualitativas de investigación en Ciencias Sociales. 2a . reimpresión. Editorial Síntesis, S.A., Madrid, 225-240.

ANDER-EGG, E. (1997). Diccionario de pedagogía. Editorial Magisterio, Buenos Aires.

ANGROSINO, M. (2012). Etnografía y observación participante en investigación cualitativa. Morata, Madrid.

APARICI, R. (2006). Introducción. La reinvención de la educomunicación. En: Aparici, R. (coord.): Comunicación educativa en la sociedad de la información. $1^{\mathrm{a}}$ ed. Universidad Nacional de Educación a Distancia, Madrid, 23-33.

APARICI, R. (2006). Comunicación. El robo de la palabra comunicación y su proceso de transvetización. En: Aparici, R. (coord.): Comunicación educativa en la sociedad de la información. $1^{\text {a }}$. ed. Universidad Nacional de Educación a Distancia, Madrid, 39-43. 
ARENTH, H. (1993). La condición humana. Paidós, Barcelona.

ATEHORTÚA, A. L. (2012). El Banco Mundial y las políticas educativas en Colombia. En: Simposio Internacional de Pedagogía - Humanidades y Educación. Escuela y Pedagogía Transformadora. Universidad Autónoma de Occidente - Cali Colombia. 20 Recuperado: 03/7/ 2015. file:///C:/Users/USUARIO/Downloads/bancomundial_politicaseducativas_colombia.pdf

BACHER, S. (2009). Tatuados por los medios. Paidós, Buenos Aires.

BALLE, F. (1991). Comunicación y sociedad: evolución y análisis comparativo de los medios. Tercer Mundo, Bogotá.

BALL, S.; YOUDELL, D. (2007). Privatización encubierta de la educación pública. Universidad de Londres, $\quad$ Londres. $\quad$ Recuperado: $\quad 06 / 3 / 2015$ http://www.joanmayans.com/privatizacion_encubierta_de_la_educacion_publica.pdf

BENITO, A. (1991). Diccionario de ciencias y técnicas de la comunicación. Ediciones Paulinas, Madrid.

BOURDIEU, P. (2008). El oficio de sociólogo. Presupuestos epistemológicos. $2^{\mathrm{a}}$ ed. Siglo XXI Editores, México.

CANALES, M.; PEINADO, A. (1998). Grupos de discusión. En: Delgado, J.; Gutiérrez, J. (ed.): Métodos y técnicas cualitativas de investigación en Ciencias Sociales. 2a . reimpresión. Editorial Síntesis, S.A., Madrid, 287-316. 
CERVANTES SAAVEDRA, M. (2005). Don Quijote de la Mancha. Edición del IV Centenario. Alfaguara, Bogotá.

COLOMBIA. (1991). Constitución Política. Recuperado: 9/08/2011 de http://www.banrep.gov.co/regimen/resoluciones/cp91.pdf

COLOMBIA. Congreso Nacional de la República (1994). Ley 115 de 8 de febrero de 1994, por la cual se expide la ley general de educación. Recuperado: 9/08/2011 de http://www.mineducacion.gov.co/1621/articles-85906_archivo_pdf.pdf

COLOMBIA. Ministerio de Educación Nacional (2006). Estándares básicos de competencias en Lenguaje, Matemáticas, Ciencias y Ciudadanas. Recuperado: 22/08/2011 de http://www.mineducacion.gov.co/1621/articles-116042_archivo_pdf.pdf.

COLOMBIA. Ministerio de Educación Nacional (2006). Estándares básicos de competencia de Lenguaje. Recuperado: 27/08/2011 de http://www.mineducacion.gov.co/cvn/1665/articles116042 archivo_pdf1.pdf

COLOMBIA. Ministerio de Educación Nacional (1998). Lengua Castellana: lineamientos curriculares; áreas obligatorias y fundamentales. Magisterio, Bogotá.

COLOMBIA. Ministerio de Educación Nacional (1998). Constitución Política y Democracia. Lineamientos curriculares. Magisterio, Bogotá. 
CORTINA, A. (1995). La educación del hombre y del ciudadano. Revista Iberoamericana de Educación. 7: 41-63.

CULLEN, C. (2007). Ciudadanía urbi et orbi. Desventuras de un concepto histórico y desafíos de un problema contemporáneo. En: Cullen, C. (comp.): El malestar de la ciudadanía. ${ }^{\text {a }}$. ed. Ediciones La Crujía, Editorial Stella, Buenos Aires, 17-42.

DE ALBA, A. (1998). Curriculum: crisis, mito y perspectivas. Miño y Dávila editores S.R.L., $\begin{array}{cccc}\text { Buenos } & \text { Aires, } & 75-88 . & \text { Recuperado: }\end{array}$ http://www.um.edu.ar/catedras/claroline/backends/download.php?url=L0JpYmxpb2dyYWbtYV9 Db21wbGV0YS8xL18wMy1fQ3VycmljdWx1bS1jcmlzaXMsX21pdG9zL19EZV9BbGJhLnBkZ g\%3D\%3D\&cidReset=true\&cidReq=FP001.

D’ELIA, A. (2002). El diario en la educación. Sociedad Interamericana de Prensa, Guadalajara.

EL TIEMPO (2004). Escuela Electrónica El Tiempo. El Tiempo, Medellín.

FIERRO, A. (1991). Desarrollo social y de la personalidad en la adolescencia. En: Marchesi, A; Carretero, M.; Palacio, J. (comp.). Psicología evolutiva, madurez y senectud. Alianza Editorial, Madrid.

FREINET, C. (1977). El diario escolar. $2^{\mathrm{a}}$ ed. Editorial Laia, Barcelona.

FREINET, E. (1983). Nacimiento de una pedagogía popular. Historia de una escuela moderna. $3^{\mathrm{a}}$. ed. Editorial Laia, Barcelona. 
FREINET, E. (1983). Nacimiento de una pedagogía popular. Historia de una escuela moderna. $3^{\mathrm{a}}$. ed. Editorial Laia, Barcelona.

FREIRE, P. (1992) La educación como práctica de la libertad. 41ª ed. Siglo XXI editores, México.

FREIRE, P. (1985). Pedagogía del oprimido. 33ª . ed. Siglo XXI editores, México.

GALEANO, M. (2004). Estrategias de investigación social cualitativa. El giro en la mirada. La carreta editores, Medellín.

GIROUX, H. (2003). La escuela y la lucha por la ciudadanía. $3^{\text {a }}$ ed. Siglo XXI Editores, México.

GIROUX, H. (2008). Teoría y resistencia en educación. $7^{\mathrm{a}}$ ed. Siglo XXI Editores, México.

GOODY, J. (1992) Alfabetos y escritura. En: Williams, R. (ed.): Historia de la comunicación. Del lenguaje a la escritura, Vol.1 1 ${ }^{\text {a }}$. ed. en español. Bosch Casa Editorial, S.A., Barcelona, 189242.

GUBER, R. (2001). La etnografía. Método, campo y reflexividad. Norma, Bogotá.

HALL, S. (1996). Codificar y decodificar. En: Culture, Media, Language. Working Papers in Cultural Studies, 1972-79. (Alejandra García, trad.). Londres, Routledge \& The CCCS University of Birmingham. Recuperado de: http://comunicacionyteorias1.files.wordpress.com/2009/10/hall_s_codificar_decodificar.pdf 
HUERGO, J. (2001). Comunicación/educación. Ámbitos, prácticas y perspectivas. Ediciones de Periodismo y Comunicación $N^{\circ}$ 2. Facultad de Periodismo y Comunicación Social, Universidad Nacional de La Plata, La Plata.

HUERGO, J. (2004). Hacia una genealogía de Comunicación/Educación. Rastreo de algunos anclajes político-culturales. Universidad Nacional de La Plata, La Plata.

HUERGO, J. (2010). Una guía de comunicación/educación, por las diagonales de la cultura y la política. En: Aparici, R (coord.): Educomunicación: más allá del 2.0. 1ª ed. Barcelona, Gedisa, 65-104.

HUERGO, J.; FERNÁNDEZ, M.B. (2000). Cultura escolar, cultura mediática/intersecciones. Universidad Pedagógica Nacional, Bogotá.

IREGUI, A.; MELO, L.; RAMOS, J. (2006). La educación en Colombia: análisis en el marco normativo y de los indicadores sectoriales. Revista de Economía del Rosario. 9 (2): 175-238.

KAIRUZ MARQUÉZ, V. (2010). Plan Nacional de Tic 2008-2010. Ibagué, León Gráficas Ltda.

KAPLÚN, M. (1998). Una pedagogía de la comunicación. Ediciones de La Torre, Madrid.

KAPLÚN, M. (2010). Una pedagogía de la comunicación. En: Aparici, R (coord.): Educomunicación: más allá del 2.0. $1^{\text {a }}$. ed. Barcelona, Gedisa, 41-61. 
KATZ, Ch; DORIA, F; COSTA LIMA, L. (1980). Diccionario básico de comunicación. Editorial Nueva Imagen, México.

LÓPEZ DE LA ROCHE, M.; MARTÍN BARBERO, J.; RUEDA, A.; VALENCIA, S. (2000). Los niños como audiencias. Instituto Colombiano de Bienestar Familiar, Bogotá.

MARIN O. B.; VELASQUEZ, C. (1997). Prensa Escuela. Comunicación para la educación. El Colombiano, Medellín.

MARTÍN BARBERO, J. (1996-1997). Heredando el futuro. Pensar la educación desde la comunicación. Nómadas, 5: 10-21.

MARTÍN BARBERO, J. (1998). De los medios a las mediaciones. Comunicación, cultura, hegemonía. Convenio Andrés Bello, Bogotá.

MARTÍN BARBERO, J. (2002). La educación desde la comunicación. Norma, Bogotá.

MARTÍN BARBERO, J. (2008). Reconfiguraciones de la comunicación entre escuela y sociedad. En: Tenti Fanfani. E. (Comp.): Nuevos temas en la agenda de política educativa. Siglo XXI Editores, Buenos Aires, 65-99.

MARTÍN BARBERO, J. (2004). Oficio de cartógrafo. Fondo de Cultura Económica, Buenos Aires. 
MARTIN, H.J. (1992) La imprenta. En: Williams, R. (ed.): Historia de la comunicación. De la imprenta a nuestros días, Vol.2 1 19. ed. en español. Bosch Casa Editorial, S.A., Barcelona, 9-62.

MARTÍNEZ BOOM, A. (2003). La educación en América Latina: de políticas expansivas estrategias competitivas. Revista Colombiana de Educación. Universidad Pedagógica Nacional. 44: $12-37$.

MCLAREN, P. (1994). Pedagogía crítica, resistencia cultural y la producción del deseo. Aique, Buenos Aires.

MEJÍA, J.I.; MONTOYA, A.C. (2011). Los procesos de certificación de la calidad en el sector educativo: un dispositivo de control (tesis), Medellín, Universidad Pontificia Bolivariana.

MORABES, P. (2001). Comunicación/Educación: trayectorias y representaciones en los docentes y sus propuestas escolares. En: Crovi, D. (coord.): Comunicación y educación, la perspectiva latinoamericana. Instituto latinoamericano de la Comunicación Educativa, México, 207-239.

MORABES, P. (2006). La investigación en comunicación/educación: problemas epistemológicos y teóricos en la (in)definición del campo. Oficios Terrestres. Facultad de Periodismo y Comunicación Social, Universidad Nacional de La Plata. 21: 68-79.

MORABES, P.; ROTHSTEIN, M. (2012). Comunicación y educación: las transformaciones que nos interpelan. TICs y prácticas socioeducativas emergentes a partir de la restitución de lo público. Oficios Terrestres, Facultad de Periodismo y Comunicación Social, Universidad 
Nacional de La Plata. 28: 1-28. Recuperado el 23/03/2015 http://perio.unlp.edu.ar/ojs/index.php/oficiosterrestres/article/view/1595/1427

NAKACHE, D. (S.D.) La producción de medios en la escuela. Una posición en el debate actual. En: Ministerio de Educación. Dirección general de Educación. Programa Medios en la escuela, 122. Recuperado el $21 / 04 / 11$ de: http://estatico.buenosaires.gov.ar/areas/educacion/niveles/primaria/programas/medios_en_la esc $\underline{\text { uela/produccion.pdf }}$

NOVACAIXAGALICIA (2011). Programa Prensa-Escuela curso 2010-2011. Recuperado de: http://obrasocial.novacaixagalicia.es/portal/site/WINS002/menuitem.fa94be90447f368fdc5aa845 51d001ca/?vgnextoid=8513da7a148e4210VgnVCM100000140d10acRCRD

OROZCO, G; GONZÁLEZ, R. (2012). Una coartada metodológica. Abordajes cualitativos en la investigación en comunicación, medios y audiencias. Productora de contenidos culturales, México.

PAOLI, J. A. (2004). Comunicación e información. Perspectivas teóricas. Trillas, México

PARRA SANDOVAL, R. (1997). El tiempo mestizo. Escuela y modernidad en Colombia. En: Fundación Fes, Colciencias: La cultura fracturada, ensayos sobre la adolescencia colombiana. Proyecto Atlántida: estudio sobre el adolescente escolar en Colombia. 1ª reimp. Tercer Mundo Editores, Bogotá, 129-158. 
PÉREZ GÓMEZ, A. (1998). La cultura escolar en la sociedad neoliberal. Ediciones Morata, Madrid.

PRESIDENCIA DE LA REPÚBLICA-COLCIENCIAS. (1998). Colombia: al filo de la oportunidad. $3^{\mathrm{a}}$. ed. Tercer Mundo Editores, Bogotá.

REAL ACADEMIA DE LA LENGUA (RAE) (2006). Diccionario esencial de la lengua española. Espasa Calpe, Madrid.

REGUILlO, R. (1999). De la pasión metodológica o de la (paradójica) posibilidad de la investigación. En: Mejía, R.; Sandoval, S. (coord.). Tras las vetas de la investigación cualitativa. Perspectivas y acercamientos desde las prácticas. 1ª reimpresión. Iteso, Jalisco, México. 17-38.

REGUILLO, R (2008). Instituciones desafiadas. Subjetividades juveniles: territorios en reconfiguración. En: Tenti Fanfani. E. (Comp.): Nuevos temas en la agenda de política educativa. Siglo XXI Editores, Buenos Aires, 125-143.

REYNAGA OBREGÓN, S. (1999). Perspectivas cualitativas de investigación en el ámbito educativo. La etnografía y la historia de vida. En: Mejía, R.; Sandoval, S. (coord.). Tras las vetas de la investigación cualitativa. Perspectivas y acercamientos desde las prácticas. $1^{\mathrm{a}}$. reimpresión. Iteso, Jalisco, México. 123-154.

RODRÍGUEZ, C. (2009). De medios alternativos a medios ciudadanos: trayectoria teórica de un término. Folios, 21-22: 13-25. 
RODRÍGUEZ, J. (2004). Medios y tecnologías de la información y la comunicación: una caracterización de las prácticas en instituciones escolares de Bogotá. Revista Colombiana de Educación. Universidad Pedagógica Nacional. 46: 186-218.

RUÍZ, A. (2007) ¿Ciudadanía por defecto? Relatos de la civilidad en América Latina. En: Schujman, G. y Siede I. (Comp.): Ciudadanía para armar: aportes para la formación ética y política . 1ª ed. Aique, Buenos Aires, 89-110.

RUÍZ, A. (2008) El diálogo que somos. Ética discursiva y educación. Civitas Magisterio, Bogotá.

RUÍZ, A., y CHAUX, E. (2005). La formación de competencias ciudadanas. Ascofade, Bogotá.

RUÍZ, L.; TORO, A.; MORANTE, E.; MONSALVE, B.; GIRALDO, P. (2006). El pacto como campo de posibilidad para la formación política en la escuela. En: Prada M. et.al. (Comp.): Subjetividad (es) política (s). Apuestas en investigación pedagógica y educativa. Universidad Pedagógica Nacional, Bogotá, 123-158.

SAINTOUT, F. (2003). La ruptura. Un campo en movimiento. En: Saintout, F. ed.: Abrir la comunicación. Tradición y movimiento en el campo académico. Facultad de Periodismo y Comunicación Social, Universidad Nacional de La Plata, La Plata, 75-85. 
SAINTOUT, F. (2006). Jóvenes: el futuro llegó hace rato. Comunicación y estudios culturales latinoamericanos. Facultad de Periodismo y Comunicación Social, Universidad Nacional de La Plata, La Plata.

SCHMUCLER, H. (1997) Memoria de la comunicación. Biblos, Buenos Aires.

SOLER, P. (2011). La investigación cualitativa. Un enfoque integrador. En: Vilches, L. (coord.). La investigación en comunicación. Métodos y técnicas en la era digital. $1^{\mathrm{a}}$. ed. Gedisa, Barcelona, 189- 235.

TABARES, L. X. (2009). Políticas públicas en Tecnologías de Información y Comunicación en la Alcaldía de Medellín: período 2001-2007. Revista Q (Educación, Comunicación, Tecnología). 7: 1-26 Recuperado el 04/09/2012 de: http://revistaq.upb.edu.co/articulos/ver/297

TENTI FANFANI, E. (2008). Mirar la escuela desde afuera. En: Tenti Fanfani. E. (Comp.): Nuevos temas en la agenda de política educativa. Siglo XXI Editores, Buenos Aires, 11-26.

TORO, I.; PARRA, R. (2010). Fundamentos epistemológicos de la investigación y la metodología de investigación cualitativa/cuantitativa. Fondo editorial Eafit, Bogotá.

TORRICO, E.R. (2004). Abordajes y períodos de la teoría de la comunicación. Grupo editorial Norma, Bogotá. 
UNIVERSIDAD PONTIFICIA BOLIVARIANA y EL COLOMBIANO (2009). Convenio de Cooperación celebrado entre la Universidad Pontificia Bolivariana y El Colombiano S.A. y CIA S.C.A.. Medellín.

VALDERRAMA, C. (2007). Ciudadanía y comunicación. Saberes, opiniones y haceres escolares. Siglo del Hombre Editores. Universidad Central -Ieco, Bogotá.

VALDERRAMA, C. (2010). Ciudadanía y formación ciudadana en la sociedad de la información. Una aproximación desde la comunicación-educación. En: Aparici, R (coord.): Educomunicación: más allá del 2.0. 1ª ed. Barcelona, Gedisa, 281-305.

VALERIO, C.; LÓPEZ, L.; OSPINA, H.; ALVARADO, S. (2006). La democracia y la participación: una mirada desde las y los jóvenes. En: Prada, M. et.al. (Comp.): Subjetividad (es) política (s). Apuestas en investigación pedagógica y educativa. Universidad Pedagógica Nacional, Bogotá, 67-121.

VILCHES, L. (2011). Análisis textual del audiovisual. En: Vilches, L. (coord.): La investigación en comunicación. Métodos y técnicas en la era digital. 1ª ed. Gedisa, Barcelona. 266-288.

WAN. (n.d.). A Brief History of a Global Effort. Recuperado de http://www.wanifra.org/articles/2012/04/17/united-states-a-brief-history-of-nie.

WILLIAMS, R. (1992). Tecnologías de la comunicación y e instituciones sociales. En: Williams, R. (ed.): Historia de la comunicación. De la imprenta a nuestros días, $1^{\mathrm{a}}$. ed. Bosch Casa Editorial, Barcelona, 181-209. 
WOLTON, D. (2006). Salvemos la comunicación. Gedisa, Barcelona.

WOLTON, P. (2010). Informar no es comunicar. Contra la ideología tecnológica. Gedisa, Barcelona.

WOODS, P. (1987). La escuela por dentro. Paidós, (Barcelona) Centro de publicaciones del Ministerio de Educación y Ciencia (Madrid). 
Tesista: CEBALLOS SEPÚLVEDA, Juan Carlos

DIRECTORA: MARÍN OCHOA, Beatriz Elena. Doctora en Comunicación y Periodismo, Universidad Autónoma de Barcelona. Directora GICU, UPB.

CO-DIRECTORA: MORABES, Paula. Directora COMEDI, UNLP. 